\title{
Ageing in place safely
}

Citation for published version (APA):

Thilo, F. J. S. (2020). Ageing in place safely: Lessons learnt from a multi-perspective immersion into the use and non-use of Personal Safety Alerting Devices. [Doctoral Thesis, Maastricht University]. Ridderprint BV. https://doi.org/10.26481/dis.20200117ft

Document status and date:

Published: 01/01/2020

DOI:

10.26481/dis.20200117ft

Document Version:

Publisher's PDF, also known as Version of record

\section{Please check the document version of this publication:}

- A submitted manuscript is the version of the article upon submission and before peer-review. There can be important differences between the submitted version and the official published version of record.

People interested in the research are advised to contact the author for the final version of the publication, or visit the DOI to the publisher's website.

- The final author version and the galley proof are versions of the publication after peer review.

- The final published version features the final layout of the paper including the volume, issue and page numbers.

Link to publication

\footnotetext{
General rights rights.

- You may freely distribute the URL identifying the publication in the public portal. please follow below link for the End User Agreement:

www.umlib.nl/taverne-license

Take down policy

If you believe that this document breaches copyright please contact us at:

repository@maastrichtuniversity.nl

providing details and we will investigate your claim.
}

Copyright and moral rights for the publications made accessible in the public portal are retained by the authors and/or other copyright owners and it is a condition of accessing publications that users recognise and abide by the legal requirements associated with these

- Users may download and print one copy of any publication from the public portal for the purpose of private study or research.

- You may not further distribute the material or use it for any profit-making activity or commercial gain

If the publication is distributed under the terms of Article $25 \mathrm{fa}$ of the Dutch Copyright Act, indicated by the "Taverne" license above, 


\section{Ageing in place safely}

Lessons learned from a multi-perspective immersion into the use and non-use of Personal Safety Alerting Devices

Friederike Johanna Schirin Thilo 
The research presented in this thesis was conducted at Care and Public Health Research Institute (CAPHRI), Department of Health Services Research (HSR) of Maastricht University in collaboration with Bern University of Applied Sciences (BFH): Department of Health Professions, Applied Research and Development in Nursing, Bern, Switzerland. CAPHRI participates in the Netherlands School of Primary Care Research (CaRe).

The studies presented in chapters 3 to 6 of this thesis were financially supported by Bern University of Applied Sciences. The studies reported in the chapters 3 and 4 were additionally financially supported by the Symphasis Foundation and in the chapters 5 and 6 by the Nursing Science Foundation Switzerland.

Copyright ๑ Friederike J.S. Thilo, Maastricht, 2020

All rights reserved. No part of this thesis may be reproduced or transmitted in any form or by any means, electronic or mechanical, including photocopying, recoding on any information storage or retrieval system without permission from the author, or when appropriate, from the publisher of the publications.

ISBN: 978-94-6375-708-9

Lay-out and Printing: Ridderprint BV, www.ridderprint.nl

Cover image: Adobe Stock 


\title{
Ageing in place safely
}

\author{
Lessons learned from a multi-perspective \\ immersion into the use and non-use \\ of Personal Safety Alerting Devices
}

\author{
DISSERTATION
}

to obtain the degree of Doctor at Maastricht University, on the authority of the Rector Magnificus, Prof. Dr. Rianne M. Letschert, in accordance with the decision of the Board of Deans, to be defended in public on Friday, 17 January 2020, at 14.45 hours

by

Friederike Johanna Schirin Thilo 


\section{Supervisors}

Prof. Dr. J.M.G.A. Schols

Prof. Dr. S. Hahn (Bern University of Applied Sciences, Switzerland)

\section{Co-Supervisor}

Dr. R.J.G. Halfens

\section{Assessment committee}

Prof. Dr. G.I.J.M. Kempen (chair)

Prof. Dr. R.A. de Bie

Prof. Dr. A.-M. Brady (Trinity College Dublin, The University of Dublin, Ireland)

Prof. Dr. K.G. Luijkx (Tilburg University, Tilburg School of Social and Behavioural Sciences)

Prof. Dr. S.M.G. Zwakhalen 


\section{Table of contents}

$\begin{array}{lll}\text { Chapter } 1 & \text { General Introduction } & 7\end{array}$

Chapter 2 Study 1: Involvement of older people in the development 35 of fall detection systems: a scoping review

Chapter 3 Study 2: Involvement of the end user: exploration of older 71 people's needs and preferences for a wearable fall detection device - a qualitative descriptive study

Chapter 4 Study 3: Usability of a wearable fall detection prototype from the perspective of older people - A real field testing approach

Chapter 5 Study 4: How older persons consider using a Personal Safety Alerting Device: a qualitative study

Chapter 6 Study 5: Advancing Personal Safety Alerting Device Use in

Older Persons - the Views of Relatives and Health Care Professionals

Chapter 7 General Discussion

Chapter 8 Summary

Samenvatting

Valorisation

Acknowledgements

About the author

List of publications 


\section{Chapter 1}

\section{General Introduction}

"Individual phenomena must never be torn out of context. Stay with the phenomena, think within them, accede with your intentionality to their patterns, which will gradually open your thinking to an intuition of their structure." (Johann W. von Goethe) 



\section{Mathilde - a brief history of becoming}

Mathilde is an elegant lady in her mid-eighties. Proud twinkles beam from her green eyes. Mathilde's gait is slow but advancing and her posture slightly bent. For more than thirty-five years she worked as a primary school teacher in a provincial town. Once her children left home, she moved with her husband to the countryside, where she still lives in her cosy apartment.

It is autumn, which she has already experienced many times. Autumn is Mathilde's favourite season, even though its meaning has changed throughout her life. During her childhood, autumn was the time of Thanksgiving and rustling heaps of leaves thrown to the blue sky and for playing hide and seek. As an adolescent, autumn was the time in which Mathilde, as the eldest daughter, helped her parents to carry out the last preparations for winter. As a young adult she left the safe family haven. Mathilde explored the beautiful mountain world on her own, which is at its most colourful during autumn. Her passion for the mountains was planted in her by her father, in brief moments of leisure time during her youth. She conquered summits and discovered foreign countries. Soon, she met her future husband. Having her own family, brought her back to the autumns of her own childhood, but from a different perspective. As soon as her own children grew older, Mathilde took them with her in those bewitching autumnal mountains. Long walking-tours with her husband followed, which became longer and more frequent once the children left.

However, those beautiful autumn memories have already become part of the past. Two years ago, her husband passed away. It was a sorrowful time and still saddens her secretly. Although Mathilde is surrounded by her beloved children and grand-children, the desire remains for her special autumns with her husband. She wanted to believe that those autumns would never come to an end. It is not only this loss which touches her innermost being; Mathilde realises that the strength of her legs and the sparkling energy of her body are steadily retreating. Since her frightening fall on wet brown leaves, her favourite autumnal season has taken on a strong aftertaste: feelings of uncertainty, perceptions of physical decline and losing control as well as the need for assistance have emerged. She, a woman who bravely managed her life and the life of her family, who used to attack summits and travel far and wide, must acknowledge that she is becoming an older person, with an unreliable body, someone who's losing stamina, muscle strength and perceptual abilities. But her mind is still lucid and living in those memories.

This mind-body gap confuses her a great deal. Mathilde perceives herself as an independent woman, able to deal with her daily life on her own. In addition, recently, her children have started to talk about a so-called "Personal Safety Alerting Device". But she has no idea what it is, nor has she ever seen - not to mention touched - such a device. She is wondering why this "thing” should be helpful for her, what does it means to use it in daily life? Will she know how to manipulate it? Will it be necessary to wear it all the time? She wants to be on the go and not to be tied to her apartment, will this still be possible? Who will come to her apartment? Does she need a community nurse now? What does her physician think about it? And what 
about the opinion of her "old" friend Joy, she always said that dying healthy was the best thing in life. But above all, and for heaven's sake, when and why should she use this device? Just because she fell once, there is no need to be worried! Although she has to concede that her ageing body surprises her more often in a negative way than she would like to admit, Mathilde is still bewildered, and the matter is constantly on her mind: she never felt insecure, she has always managed her life on her own, she is used to living independently and to deciding for herself... 


\section{Introduction}

The ageing of society is currently in the spotlight all over the globe. A majority of older persons worldwide reside in urban, suburban or rural communities and age in place. ${ }^{1}$ Older persons emphasise that they want to live as long as possible in their accustomed environment, ${ }^{2,3}$ however, emergency situations without rapid assistance, as well as increasing gait and balance disorders, have negative impacts on the health and psychological wellbeing of older persons. ${ }^{4-6}$ Thus, institutionalization or an assisted living facility might become necessary.

To facilitate older persons' ability to call for help in an emergency, various Personal Safety Alerting Devices (PSAD) are available on the market. They can increase the safety of the older person living at home in the community by enabling them to get rapid assistance in case of an emergency situation, e.g. a fall. ${ }^{7}$ The home is known as a prevalent locus for falls and falls represent a considerable risk for the wellbeing of older persons..$^{8,9}$ Despite this, PSADs are still hardly used by older persons in daily life..$^{10-14}$ Therefore, a comprehensive understanding of the phenomenon of PSAD use and nonuse by community-dwelling older persons is needed.

After this brief thematical sketch of the problems that led to this doctoral thesis, for further understanding, a detailed theoretical background is required to address the followings topics: ageing in place, social embedding, meaning of home, assistive technology, safety, personal safety alerting device, use and non-use, user involvement, technology acceptance and adoption.

\section{Ageing in place}

Ageing in place is embraced by health care and political agendas worldwide, ${ }^{15}$ being considered as an "attainable and worthwhile goal"16 and as a desideratum of older persons. ${ }^{2,3,17-19}$ Ageing in place is estimated to be cost-effective compared to longterm institutionalised living. ${ }^{20}$ Ageing in place aims to support older persons while they age independently, safely and socially integrated in the community despite illness or disabilities ${ }^{16,21}$ and "regardless of age, income, or ability level".22 In other words, notwithstanding declining health or functional abilities, increasing support should allow older persons to age in their current residence. ${ }^{23}$

Scharlach and Diaze Moore ${ }^{21}$ suggested an integrated model entailing six attributes to describe a current understanding of ageing in place: continuity, compensation, control, connection, contribution and challenge/comfort. Those attributes summarize that ageing in place should enhance the maintenance of one's sense of self when ageing, the possibility to compensate for age-related changes, to maintain control over the social and physical environment as well as over one's own life, to maintain social 
relationships (connection), to engage in meaningful activities (contribution) in daily life and to find the right balance of manageable activities (comfort) versus stressful challenges that positively or negatively influence dependency in daily life.

Whereas early conceptualizations of ageing in place considered it as a goal, recent developments suggest ageing in place as an adaptive process. ${ }^{21}$ The adaptive process relates to the idea that different living environments should be included in the understanding of ageing in place, for instance joining an assisted living facility or senior residences.

This change of understanding promotes the idea that ageing in place is not "only" the accustomed home environment which was the centre of the family life. Weil and $S_{\text {Smith }}{ }^{24}$ argue that ageing in place should include different places along the continuum of care. Thus, they suggest broadening the definition in order to avoid that any place being considered a "failure". In other words, ageing in place has the potential to become an undesirable place to be "stuck in". Depending on available health care or public services and social support, community and shopping infrastructures or depending on physical and cognitive functioning, ageing in place might even jeopardize older persons' well-being and quality of life. ${ }^{24,25}$ As a consequence, community-dwelling older persons might dislike their home environment and be motivated to move. ${ }^{26}$

\section{Social embedding}

While ageing in place, the availability and maintenance of meaningful relationships are particularly pivotal to older persons while ageing in place. ${ }^{27,28}$ Being socially connected impacts their health positively. ${ }^{29,30}$ Older persons prioritize, among other things, relationships with the family and the support of health professionals in their own living environment; for instance, general practitioners and especially community nurses. ${ }^{31}$ Relatives often care for their parents and thus facilitate ageing in place. ${ }^{32}$ The parentchild relationship is supportive and positively influences the health of older persons. ${ }^{33}$

Community care is frequently a precondition for ageing in place..$^{16}$ Community nurses often support and facilitate it. ${ }^{34}$ Their involvement in the care of older persons has increased in the last decade..$^{32}$ Community nurses assist in activities of daily living and in the medication management; they enable safe living ${ }^{35}$ and are responsible for early identification of symptoms change. ${ }^{36}$ Community nurses focus on the prevention of illness and injury, on the promotion and maintenance of health as well as on the optimization of older persons' abilities to deal with daily life. ${ }^{37,38}$ General practitioners (GPs) in the community often maintain a long lasting relationship with the older person, characterized by emotional support and mutual trust. ${ }^{39}$ GPs are typically the point of first medical contact. They promote patient empowerment, focus on the provision of care continuity to the individual and deal, of course, with health problems. ${ }^{40}$ 
Overall, relatives and health care professionals, particularly community nurses and general practitioners, can be considered as decisive persons supporting and enabling the ageing in place of community-dwelling older persons.

\section{Meaning of home}

Another prominent theme in the ageing in place literature is the strong whish of many older persons to age in their current residence persists. ${ }^{2,3}$ This might be rooted in the particularly meaning that older persons attach to their home: It is a familiar place, linked to the feeling of being safe, a place of independent living and social connectivity to family, neighbourhood, community or cultural groups. ${ }^{41}$ Moreover, the home is a place that allows environmental mastery, personal control and preservation of a sense of self. 2, 42,43 In contrast, admission to a nursing home is often experienced as a threat to the independence and self-determination, with an association of depersonalization. ${ }^{42}$ Furthermore, the meaning of one's home increases crucially throughout life, with very old persons spending about $80 \%$ of their time at home. ${ }^{44}$

\section{Assistive technology}

Besides, another significant and seminal component related to ageing in place is the ongoing progress in so-called assistive technologies. Technologies can support health and independence, enhance everyday safety and increase social participation. 5, 45-47 Assistive technologies are increasingly regarded as a pillar and facilitator of safe and independent living when people age in place. ${ }^{16,48,49}$ They may comprise aids for mobility, hearing and vision or daily living aids ${ }^{50}$ as well as information- and communication technology (ICT), robotics, telemedicine, sensor technology, video games, and medication-dispensing devices. ${ }^{51}$ They aim to promote and facilitate social connectedness with the family and health professionals, to monitor for health and safety, to enable communication in case of an emergency, to remind for daily life activities or enhancement of mobility. ${ }^{46,47,49,52} \mathrm{~A}$ recent literature review shows that current assistive technologies mainly target the following areas: chronic disease, dementia, depression, fall risk, dependent living, poor medication management, social isolation and poor health. ${ }^{51}$

When focusing on older persons, the term gerontechnology is often used instead of assistive technology, combining gerontology and technology. ${ }^{53,54}$ Gerontechnology is aimed at the prevention of injuries or illnesses, care in chronic conditions, compensation for declining capabilities and help with gaining new capabilities, and experiences or information to overcome functional limitations., 53,55 Gerontechnology likewise aims to positively influence the quality of life of older persons. ${ }^{56}$ Thus, the two terms can be considered as similar. However, the word "geron" from "gerontology" connotates "aged". 
Depending on the intended use, the technology often assists the community dwelling older person and her/his next of kin as well as the health professionals involved, i.e. the technology is not solely used by the older person. Throughout this doctoral thesis the term assistive technology or technology is used, due to the assumption that a technology should assist different users, i.e. the older person and her/his social network.

Overall, the use of technology for ageing in place is a priority of many countries due to the growing challenge of reduced human resources. ${ }^{57}$ Additionally, a recent trend in the United States shows why the need for assistive technology might increase. One fourth of the population over 65 is at risk of a phenomenon called "elder orphans", i.e. they have nobody for help or support, because, amongst other things, they are ageing as singles. ${ }^{58} \mathrm{~A}$ European study revealed that approximately $35 \%$ of older persons living alone are at risk of "restricted" networks, defined as lacking social relationships including kin and non-kin, and thus may be without sufficient access to support in daily life. ${ }^{59}$ Therefore, older persons living in Europe will also increasingly need technological support when ageing in place.

\section{Safety}

With regard to ageing in place, the safety of older persons at home has been identified as a pivotal component. ${ }^{60}$ There is evidence that older persons' sense of safety is significantly related to their well-being and quality of life. ${ }^{61,62}$ Additionally, older persons attach importance to their personal and physical safety. ${ }^{31}$ However, due to the frailty syndrome, a multidimensional dynamic state whereby older persons experience losses in physiological, psychological, social and environmental aspects, or the risk of adverse outcomes related to safety increases with ageing ${ }^{63,64}$ Frail persons present with, amongst other things, loss of muscle strength and mass, visual deficits as well as gait and balance disorders ${ }^{6}$ are significantly associated with an increased risk of falling ${ }^{6,65-67}$ Thus, as is well-known, falls represent a considerable safety risk for older persons.

In terms of location, the home environment is widely documented as a common place for falls. ${ }^{8} 9$ Twenty-five percent to $35 \%$ of persons aged 65 and older experience at least one fall per year ${ }^{68-70}$ and fall rates are up to twice as high in older persons 75 years and older.66,71,72 A fall is "an unexpected event in which the participants come to rest on the ground, floor or lower level".73 Falls threaten the independence, well-being and the health of older persons. $8,74,75$ They may lead to hospital and long-term care admission ${ }^{70,74,76}$ and negatively impact the costs of the health care system. ${ }^{77}$ In addition, psychological consequences are just as important as physical ones. Falls negatively influence the psychological well-being of the older person in the form of: fear of falling, loss of confidence, physical activity avoidance and decreased self-efficacy. ${ }^{78-81}$ Furthermore, it is a vicious circle, since fear of falling increases the risk of falling ${ }^{82}$ and 
could thus be considered a threat to independence. Bloch ${ }^{76}$ points out that falls without injuries or bone fractures should not be underestimated and should be taken seriously because of the psychological fall consequences. This is in line with previous research recommending also focusing on psychological fall consequences. ${ }^{73}$

Although the prevention of falls in community-dwelling older persons is regarded as crucial, to date, multifactorial and multiple component interventions can moderate the fall rate and risk of falling, but evidence for their efficacy is still of low quality. ${ }^{83}$ Therefore, beyond fall prevention, it is pivotal that the older person should obtain rapid assistance when a fall has occurred. Fleming and Brayne ${ }^{7}$ found that most older persons were unable to get up without assistance which can result in a so-called "long-lie". Furthermore, long-lies are defined as lying on the ground for one hour or more. ${ }^{84} \mathrm{Long}$-lies are associated with negative consequences for the older persons such as: dehydration, hypothermia, pressure ulcers or pneumonia, injuries and a higher risk of mortality during the six months after a long-lie due to a fall.7,85,86 Several studies have investigated the prevalence of long-lies, with heterogenous findings. Simpson et al. ${ }^{84}$ found that $13 \%$ of their participants who called an emergency ambulance reported having experienced a (self-assessed) long-lie. In another study, more than half of the study participants were still on the ground when the ambulance arrived, however, without knowing exactly the length of time they had spent on the ground prior to contacting the emergency service. ${ }^{87}$ A further study revealed that $30 \%$ of the fallers experienced a long-lie. ${ }^{?}$

\section{Personal Safety Alerting Device (PSAD)}

Therefore, to prevent long-lies as well as negative consequences of falls, PSADs may provide crucial help. A PSAD allows its user to receive rapid assistance in case of an emergency situation, such as a fall, but also in other situations, e.g. COPD, dysrhythmias, septicaemia or pneumonia., ${ }^{4}$ Furthermore, a considerable number of studies found that particularly PSADs can enhance the perceived safety of older persons..$^{88-92}$

Regarding PSADs themselves, a variety of systems have been developed and are on the market. The main distinguishing characteristics of those systems are being wearable or non-wearable (embedded) ${ }^{14}$ as well as having automatic and or manual alerting mechanisms. ${ }^{93}$ Embedded systems comprise motion sensors, floor sensors, microphones or cameras; ${ }^{14,93-95}$ wearable systems include mobile phones, devices worn as an accessory, or sensors embedded in the user's outfit. ${ }^{95-97}$ According to Chaudhuri et al. ${ }^{14}$ most of the published research has focused on wearable systems.

\section{Use and non-use}

Unfortunately, the use of PSADs in older persons is still problematic. That is, even though, PSADs may be accepted, in terms of having a PSAD at home, they are hardly 
used in daily life. ${ }^{10-13} \mathrm{~A}$ majority of older persons might be favourably disposed towards a PSAD, but only a minority would or is actually using one. ${ }^{10,12,14,98}$ Usability issues, faulty and infrequent PSAD use, have been reported. 7, 10, 12, 87, 99, 100 A recent literature review draws the attention to possible reasons, such as wearing discomfort, fear of false alarms, being uncertain about the alert range, not being waterproofed, or lacking a Global Positioning System (GPS). ${ }^{89}$ Non-use of PSADs might also be due to aesthetical objections, for instance in terms of the colour or seize of the device ${ }^{96}$ or poor design. ${ }^{101}$ Furthermore, ageing persons are affected by increasing frailty in terms of changes of perceptual abilities and cognition ${ }^{55}$ which might impact the ability to use a PSAD. Research suggests that the following factors might result in non-use: difficulties in remembering how to use it, fear of damaging the technology, not perceiving a need for it, difficulty in accepting a younger person to teach an older one in its use, not having a person who can assist in learning to use the PSAD as well as perceived excessive costs related to its use. ${ }^{102} \mathrm{~A}$ further factor might also negatively influence its use in daily life: Nyman and Victor ${ }^{10}$ and Chaudhuri et al. ${ }^{101}$ discuss a possible link between the PSAD and the self-identity of the older person, in the sense that it can be a symbol for being dependent and frail.

\section{User involvement}

With respect to PSAD use and non-use, the literature indicates mainly usability issues as pivotal reasons. To solve usability issues, involving users in technology development is recommended. ${ }^{103}$ User involvement promotes a "needs-driven" instead a "technologydriven" approach, ${ }^{103}$ leading to more user-friendly products. Preferences, needs and the context of use as well as the interactions between the technology and its users can be investigated and considered from the beginning of device development, ${ }^{104-109}$ and thus facilitate technology use in daily life. However, up to now, older persons seem not yet sufficiently involved in the development or in real-world tests of PSADs. ${ }^{14,94}$ For instance, automatic fall detection technologies are criticised for using algorithms which are often developed with simulated falls of healthy adults and not with the target group of the technology. ${ }^{14,94,110}$ Consequently, to resolve PSADs usability issues, user involvement should be considered as essential and necessary.

\section{Technology acceptance and adoption}

Beyond the lack of user involvement, it is still unclear what the "bigger picture" of PSAD use and non-use is. As was pointed out by Nyman and Victor ${ }^{10}$ and Chaudhuri et al. ${ }^{101}$ it seems that factors beyond usability might play a role. They suggested that older persons might attribute a negative meaning to a PSAD, which in turn might significantly influence its use and non-use. In other words, what other factors than usability issues 
can influence the acceptance and decision of older persons to use or not to use a PSAD in daily life?

Research has revealed that the general technology acceptance of older persons can be influenced by relatives and health professionals. ${ }^{89,91,99,111-114}$ For instance, community nurses' perceptions of its usefulness and appropriateness for patient care was shown to determine assistive technology usage in older persons. ${ }^{115}$ Health care professionals can positively encourage and facilitate technology acceptance. ${ }^{11,114,116}$ So far, little attention has been given to the perspectives of informal and formal caregivers..$^{90,93,97,117}$ Several experts argue that the perspectives of carers and or caregivers should be investigated to understand how technologies are used in daily life. ${ }^{116,118,119}$

Over the past decades, research has aimed to understand the technology use and non-use of older persons, by drawing on technology acceptance models from the field of information systems. ${ }^{120-122}$ Those models were originally developed to explain an individual's technology acceptance while working in organizations. In the following, the most important theories are presented in more detail.

The Technology Acceptance Model (TAM) is frequently cited and predominantly used in research. ${ }^{123}$ It was developed "to provide an explanation of the determinants of computer acceptance that is generally capable of explaining user behaviour across a broad range of end-user computing technologies and user populations, while at the same time being both parsimonious and theoretically justified"(p. 985). ${ }^{124}$ The model assumes that technology acceptance is determined by two main variables which are "perceived usefulness" and "perceived ease of use" (Figure 1). Perceived usefulness is defined "as the prospective user's subjective probability that using a specific application system will increase his or her job performance within an organizational context"(p. 985) and perceived ease of use "refers to the degree to which the prospective user expects the target system to be free of effort."124 A number of researchers have reported that both variables explain 40 percent of an individual's intention to use a technology. ${ }^{125,126}$

The TAM was built on the Theory of Reasoned Action ${ }^{127}$ stemming from the field

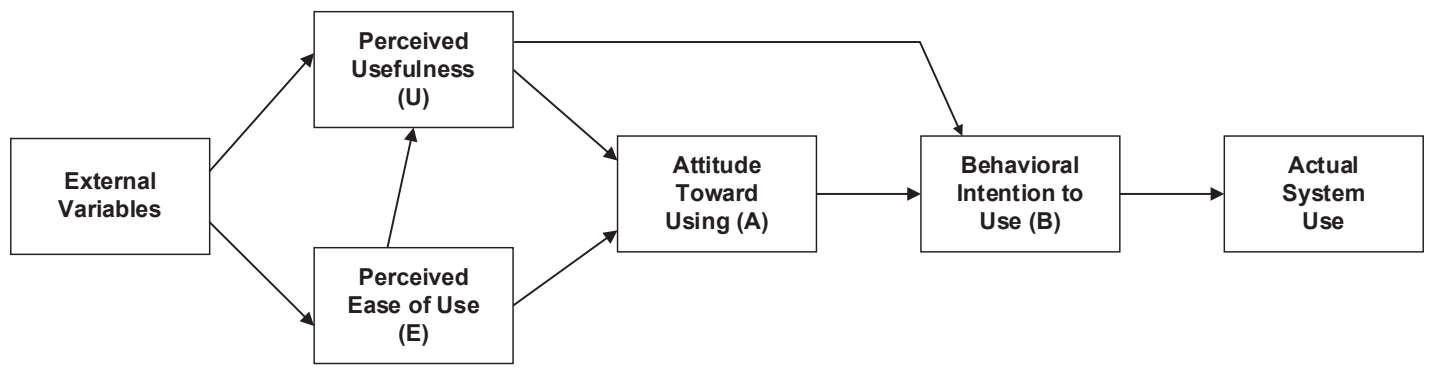

Figure 1. Technology Acceptance Model (TAM) ${ }^{124}$ 
of Social Psychology. The Theory of Reasoned Action provides a theory to understand and predict human behaviour. Further developments and extensions were published in 1991, with the Theory of Planned Behaviour, ${ }^{128}$ and the latest version in 2010, the Reasoned Action Approach. ${ }^{129}$ The underlying premise of this theory is that human behaviour is determined by a sequential process of "beliefs about the behaviour" which influence the "attitude" and "subjective norm" towards the behaviour which in turn informs the "intention to perform the behaviour" before the behaviour itself occurs (Figure 2). The stronger the behavioural intention is the likelier the person will perform the behaviour. The definitions of the determinants are:

- Belief - "the subjective probability of a relation between the object of the belief and some other object, value, concept, or attribute"(p.131); ${ }^{127}$

- Attitude - "a person's location on a bipolar evaluative or affective dimension with respect to some object, action, or event. An attitude represents a person's general feeling of favourableness or unfavourableness toward some stimulus object"(p.216); ${ }^{127}$

- Subjective norm - "the person's perception that most people who are important to him think he should or should not perform the behaviour in question"( $p$. $302) i^{127}$

- Intention - "person's location on a subjective probability dimension involving a relation between himself and some action. A behavioural intention, therefore, refers to a person's subjective probability that he will perform some behaviour"( $p$. 288); ${ }^{127}$

- Behaviour - "observable acts that are studied in their own right. (...) A person's behaviour is determined by his intention to perform that behaviour"(p. 335). ${ }^{127}$

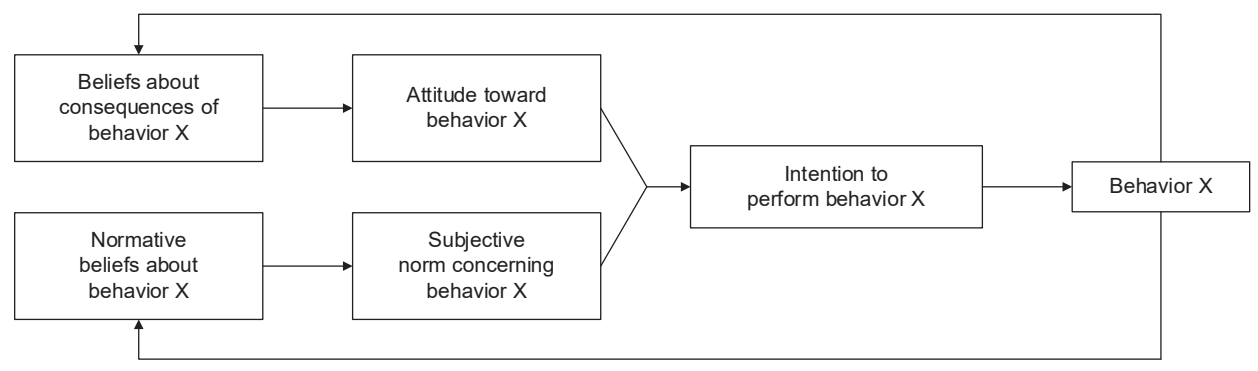

Figure 2. Schematic presentation of the Theory of Reasoned Action ${ }^{127}$ 
The Theory of Planned Behaviour and the Reasoned Action Approach added to the model the determinants of "behaviour control", defined as "people's perception of the degree to which they are capable of, or have control over, performing a given behaviour"(p.64) 129 and "background factors", such as dispositions (self-esteem or personality traits), demographics (age or education) and Information (experience or knowledge).

Since the introduction of the first TAM published in $1989^{124}$ it was extended to TAM $2^{130}$ and TAM $3^{131}$ in the following years, in order to better understand relationships of variables and factors influencing technology acceptance. ${ }^{132}$ Four main categories of TAM modifications were identified: 1) external predictors (e.g. technology anxiety, prior usage, technology experience, self-efficiency, confidence in technology); 2) factors from other theories (e.g. subjective norm, expectations, risk, trust); 3 ) contextual factors (gender, cultural diversity, technology characteristics) and 4) usage measures (e.g. attitude toward technology, usage perception, actual usage of technology). ${ }^{123,125}$ In sum, a meta-analysis of the TAM showed that over time more than 70 external variables were proposed for perceived usefulness and perceived ease of use. ${ }^{133}$

To enable a more exhaustive understanding of technology acceptance, the Unified Theory of Acceptance and Use of Technology (UTAUT) was developed and validated. ${ }^{134}$ The UTAUT draw on a synthesis of eight models: Theory of Reasoned Action; Theory of Planned Behaviour; TAM; Combined TAM and Theory of Planned Behaviour Model, Model of Personal Computer Utilization; Diffusion of Innovation Theory; Motivational Model and Social Cognitive Theory. The explanatory power of the UTAUT regarding usage behaviour of a technology increased up to 70 percent compared with the TAM. ${ }^{135}$ The model comprises four independent variables ("performance expectancy", "effort expectancy", etc.) respective moderating variables (gender, age, etc.) as depicted in Figure 3. The independent and moderating variables are supposed to influence "behavioural intention" and "use behaviour" respectively.

Despite extensive TAM research and the satisfactory explanatory power of the UTAUT, they have hardly been applied and further developed for the group of older persons. ${ }^{102,120}$ One adaption to older persons is the Senior Technology Acceptance and Adoption Model (STAM). ${ }^{136}$ The STAM draws on the TAM and further theoretical considerations which were enriched by empirical qualitative findings. The focus of the STAM is on adoption by suggesting that actual use is an antecedent of acceptance in daily life. Renaud and van Biljon ${ }^{136}$ developed a multiphase model, describing how the intention to use a mobile phone is influenced by social and contextual factors, by experiences of its use as well as its perceived usefulness. They concluded that ease of use of the technology is crucial for the conversion, meaning the adoption into daily life. However, there is a major concern with the validity of this model: When developed, 


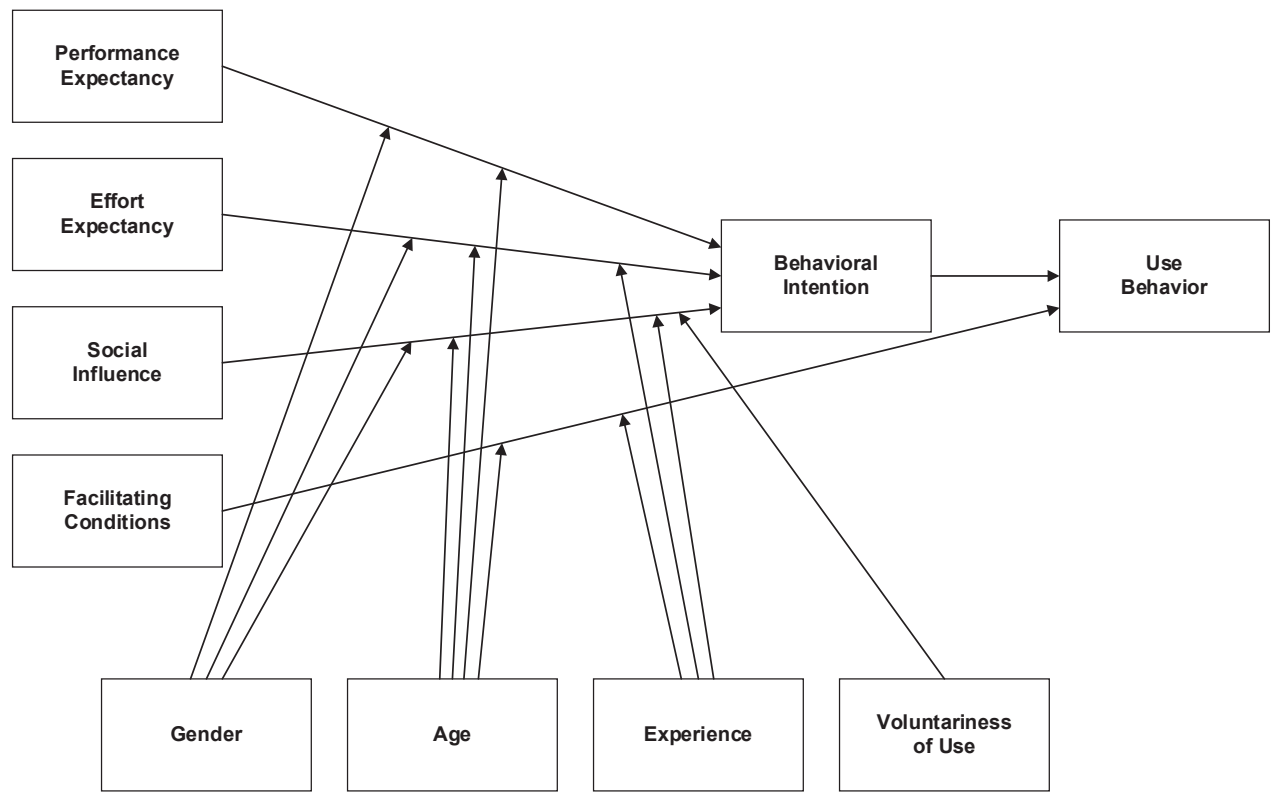

Figure 3. Unified Theory of Acceptance and Use of Technology (UTAUT) $)^{134}$

the authors included thirty-four South African older mobile phone users (age range 60 to 92 years) in their study. This means that the participants already owned a mobile phone, implying pre-existing intention to use and in addition, they already showed the behaviour (phone usage). The STAM was further validated by Reneau, ${ }^{122}$ investigating smartphone acceptance, adoption and diffusion in senior citizens in the USA. He criticized (1) that the STAM fails to consider how a technology is acquired as well as (2) that it simplifies the motivation to use a device by giving great importance to the device's ease of use as the strongest motivation.

Almost concurrently, another Senior Technology Acceptance Model (STAM), as depicted in Figure 4, was developed and tested, this time in older people in Hong Kong, aged between 55 and $85 \pm$, living in the community or in a nursing home, in the context of gerontechnology acceptance. ${ }^{102}$ This STAM drew on the TAM, but also the UTAUT and added ageing-related variables, for instance gerontechnology self-efficacy or health and ability characteristics. The validation study applied the model to a wide range of gerontechnology used in daily life: housing and daily living technology (e.g. credit cards or remote-control devices), communication technology (e.g. mobile phones or e-mail), health/assistive technology (e.g. telecare or emergency alert products/services) and education and recreation technology (e.g. digital cameras or DVD/VCD players). ${ }^{102}$ The researchers found that use of gerontechnology correlated strongly with age, education, 


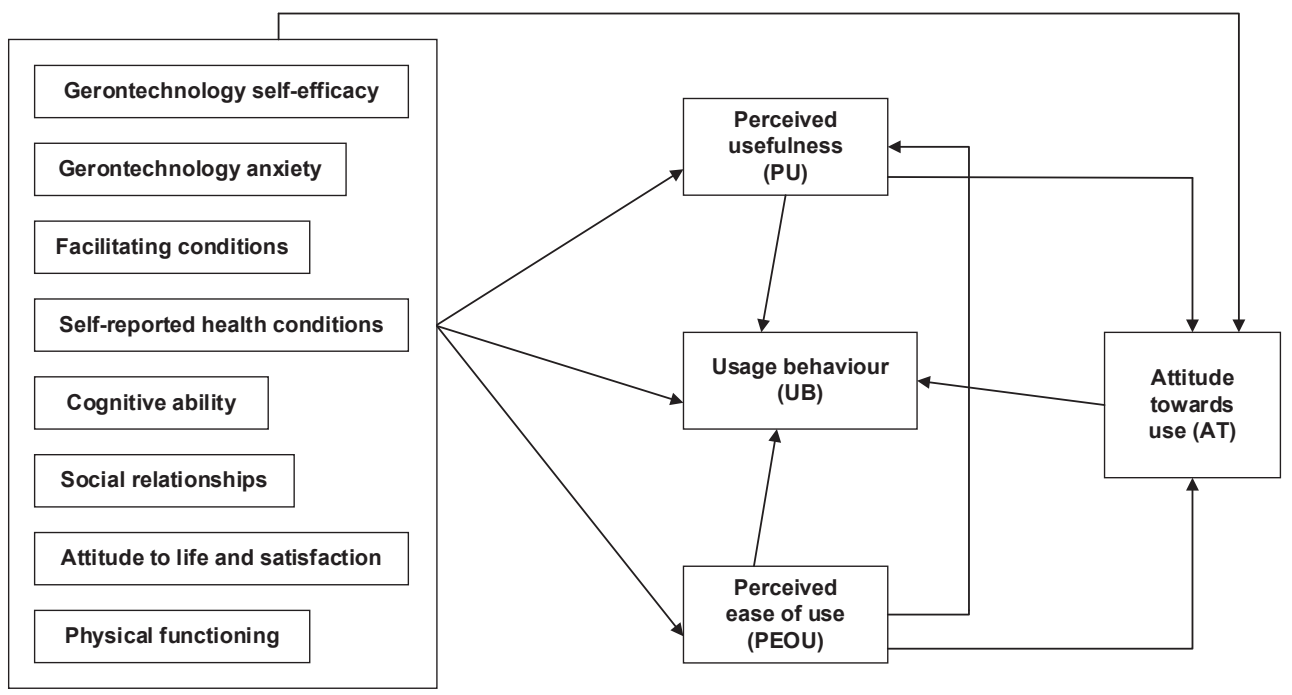

Figure 4. Senior Technology Acceptance Model (STAM) ${ }^{102}$

gender, economic status, gerontechnology self-efficacy and anxiety, health and ability characteristics, e.g. cognitive abilities, life satisfaction or physical functioning and facilitating conditions, such as available help or financial resources. In contrast to other studies, they reported that the direct effects of attitudinal factors on gerontechnology usage were non-significant in their sample. ${ }^{102}$

Overall, despite of this important previous work, there are limits to how transferable the proposed technology acceptance models are to the context of PSAD use and nonuse. Technology acceptance may fluctuate over time, which is not taken into account in the TAM. ${ }^{137}$ Another major concern is that most of this research disregards the possibility of rejection. ${ }^{138}$ Moreover, despite its captivating parsimony for research, ${ }^{132,139}$ the TAM and its further developments have been criticized for describing a deterministic process and thus omitting the human complexity, for instance, neglecting social influence, emotion, personal values and motives or cultural influences. ${ }^{139,140}$

Therefore, an approach from the discipline of Sociology seems interesting for the underlying research context, as it describes amongst others a process leading to both adoption and rejection of an innovation and includes social and cultural influences. The Diffusion of Innovations Theory of Rogers ${ }^{141}$ maps the process of an innovation diffusing into the daily life of an individual or an organisation. The diffusion is "the process by which an innovation is communicated through certain channels over time among the members of a social system"; and the innovation is "an idea, practice, or object that is perceived as new by an individual or another unit of adoption" (p.11). ${ }^{141}$ This process is 
described as a decision process, which is dynamic, iterative and occurring over time, and based on five stages as depicted in Figure 5. Briefly and simply summarized, in the Knowledge stage the individual is exposed to the innovation and gains understanding about the function of the innovation. In the Persuasion stage, the person's attitude towards the innovation is formed. Afterwards, the individual takes the decision to adopt or reject an innovation. In the fourth stage, the Implementation, the person uses the innovation and gathers experiences with it. Only in the last stage, the Confirmation, will the individual will either reinforce the decision and continue with use or reverse the decision.

Although, taken all together, there is considerable research in trying to explain and predicting technology acceptance, researchers have not dealt with PSAD use and nonuse in the daily life of community-dwelling older persons (beyond usability issues) in much detail. Technology acceptance research itself is criticized as relying too heavily on TAM and UTAUT and thus missing important determinants. ${ }^{137,139}$ This is exemplified in the work undertaken by Künemund and Tanschus ${ }^{98}$ who uncovered that technology use of older persons might vary due to age-related changes. Also Chen and Chan ${ }^{142}$ emphasize that the biophysical (e.g. functional loss) and psychosocial characteristics (e.g. loneliness) of older persons are overlooked. A major criticism of TAM and UTAUT is their primary focus on the organizational usage of information systems in the workplace. ${ }^{122}$ Thus, they would benefit from an adaption to the health care context. ${ }^{126}$

Overall, no theory yet explains and predicts the use and non-use of technology in community-dwelling older persons. ${ }^{143}$ The suggested models aim to explain and predict human behaviour in the context of technology acceptance. The TAM and the UTAUT were developed for empirical research endeavours, which is essential for conducting studies, but on the other hand they hardly seem transferable to the context of ageing in place, which can be regarded as dynamic and complex. The UTAUT, for instance, does not include the step of adoption, ${ }^{144}$ which is according to Rogers ${ }^{141}$ a step following the acceptance of an innovation. Even when a person has decided to accept a device, this decision might be discontinued. ${ }^{141}$ The adoption step seems to be crucial, because the literature points out that older persons might possess a PSAD, but never or almost never use it in daily life. ${ }^{10-13}$

Even though, as shown in the technology acceptance literature, ${ }^{125}$ the variables of perceived usefulness and perceived ease of use are significantly determine the intention to use and thus the usage behaviour of an individual, the UTAUT is omits attitude towards a technology. ${ }^{136}$ However, a person's attitude towards an innovation or a behaviour has been shown to critically influence the adoption of an innovation ${ }^{141}$ or changing of a behaviour. ${ }^{129}$ As highlighted earlier, many older persons might be favourable towards a PSAD, but only a minority would or do use it. ${ }^{10,12,14,98}$ Therefore, it would be interesting 


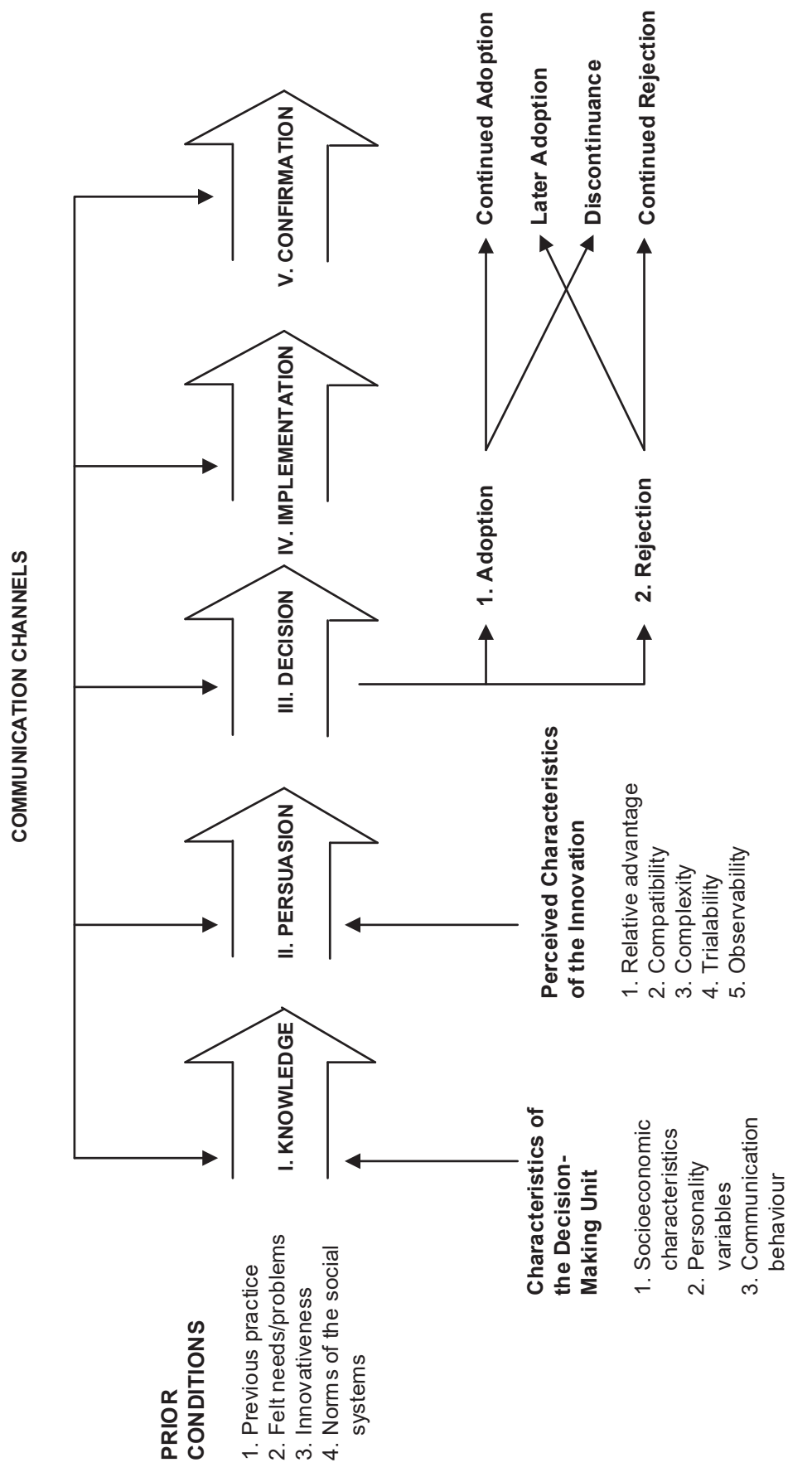


to understand, what a person's attitude towards a PSAD might signify. In addition, the TAM and UTAUT represent a one-way process to technology acceptance, excluding for instance iterative decision cycles, which seems plausible in older persons due to agerelated changes or social influence, e.g. relatives or health professionals.

Most of the criticism mentioned above also applies also to the STAMs since they draw on the TAM and the UTAUT, but additionally, only little research was identified using a STAM. Furthermore, the STAM from South Africa implied pre-existing intention to use, which is hardly useful for investigating factors influencing PSAD use and nonuse. The STAM with the Hong-Kong sample was validated in older persons also living in long-term care settings, as well as by using a very broad variety of technologies. This highly heterogeneity in terms of sample, settings and technology was considered as too uncertain regarding its validity for the specific context of PSAD use and non-use in community-dwelling older persons.

According to the Diffusion of Innovations Theory, it is pivotal to identify attitudes/ beliefs and social norms prior to use, in the context of PSAD use and non-use by older persons. The theory indicates that norms of the social system and attitudes/beliefs toward an innovation are highly influential for decision making. ${ }^{141}$

When available theories provide limited descriptions or explanations of a phenomenon, further observations and or experiments are required. ${ }^{145}$ Research suggests that understanding technology acceptance requires knowledge about the actors involved in its use. ${ }^{89,98,146,147}$ It is crucial to investigate how they are influence its use and how they use the technology in their everyday context. ${ }^{118,148}$ In addition, understanding technology use requires an answer to the "when, why and how" of technology use. ${ }^{139,143,146,149}$ Technologies should not be considered as black boxes which can be integrated into daily life without modifying caring practice. ${ }^{89}$ In addition, non-use should be investigated,$^{53}$ because" (...) something else likely exists in place of use, and it is that something we should be studying"(p.54). ${ }^{150}$ Non-use should not be pathologized, as it is "often, active, meaningful, motivated, considered, structured, specific, nuanced, directed, and productive"(p.7). ${ }^{151}$

So far, much uncertainty exists about the "bigger picture" of what goes on prior to PSAD use and what leads to its use and non-use in community-dwelling older persons. And this, not only from the perspective of older persons themselves, but also from the stakeholders involved in PSAD use, i.e. relatives, community nurses and GPs. 


\section{Problem statements}

The state of the scientific literature outlined above indicates an important research need. Firstly, despite efforts to address assistive technology acceptance in general and the PSAD acceptance of older persons specifically, a major focus was mostly on usability issues. Older persons remain reluctant regarding PSAD use. Secondly, older persons hardly seem to be involved in the design and testing of these devices, which might be a reason for their problematic PSAD use. Thirdly, suggested technology acceptance models comprise several limitations and are not yet sufficiently empirically adapted to the context of community-dwelling older persons. Thus, research focusing on PSAD use and non-use would benefit from an inductive approach to enable new insights into determinants and related processes. Additionally, little is known about the perspective of relatives, community nurses and general practitioners, who are both pivotal for ageing in place and PSAD use and non-use in daily life. Lastly, to date, it is unclear how PSAD use and non-use is viewed and affected by community-dwelling older persons, relatives, community nurses and general practitioners.

\section{Aim and research questions}

The overall objective of this doctoral thesis is to investigate PSAD use and non-use of community-dwelling older persons from a multiperspective approach. This thesis aims to extend current knowledge by providing a deeper understanding and insight into user involvement during PSAD development as well as reasons, thoughts, motives and influencing factors of PSAD use and non-use from the perspectives of older persons, relatives, community nurses and general practitioners. Therefore, the following research questions are addressed:

1. What is the nature and extent of user involvement of people 65 years of age and older, in the development, testing and/or evaluation of fall detection systems? (Chapter 2)

2. What are the needs and preferences of community-dwelling older people regarding a wearable fall detection sensor and its smartphone application during the design and mock-up stage? (Chapter 3)

3. What is the usability of a wearable, waterproof, automatically alerting, fall detection prototype, according to the community-dwelling older persons involved? (Chapter 4) 
4. What are the reasons, thoughts, motives and influencing factors regarding the use and non-use of a PSAD in daily life from the perspective of communitydwelling older persons? (Chapter 5)

5. What are the reasons for the PSAD use and non-use among community-dwelling older persons according to relatives, nurses and GPs? In what situations are PSADs used or not used by community-dwelling older persons according to relatives, nurses and GPs? What is the involvement of relatives, nurses and GPs in the use and non-use of PSADs? (Chapter 6)

\section{Outline of this thesis}

This thesis comprises seven chapters which are briefly outlined below:

Chapter 2 describes the results of a scoping review that identified the state of research involving older persons in the development of fall detection systems. The research question was: What is the nature and extent of user involvement of people 65 years of age and older, in the development, testing and/or evaluation of fall detection systems?

Chapter 3 focuses on the involvement of community-dwelling older person in the device design of a fall detection sensor, including its smartphone application. By investigating the mock-up of the device, the prototype can be developed according to needs, preferences, feasibility and practical aspects related to its daily use. The research question of this qualitative descriptive study was: what are the needs and preferences of community-dwelling older people regarding a wearable fall detection sensor and its smartphone application during the design and mock-up stage?

Chapter 4 reports on the usability of a wearable, waterproof, automatically alerting, fall detection prototype, through the involvement of community-dwelling older people in a qualitative study using a real field testing approach. For the purposes of this study, usability was understood as the prototype's practical aspects, its ease of use, and the users' satisfaction with its handling and manipulation in everyday life.

Chapter $\mathbf{5}$ explores the following research question: What are reasons, thoughts, motives and influencing factors regarding the use and non-use of a PSAD in daily life from the perspective of community-dwelling older persons? Chapter 6 studies the perspectives of relatives, nurses and GPs regarding their experiences, perceptions and involvement in PSAD use or non-use in community-dwelling older persons. The following research questions were explored: What are the reasons for the PSAD use and non-use of community-dwelling older persons according to relatives, nurses and GPs? In what situations are PSADs used or not used by community-dwelling older persons 
according to relatives, nurses and GPs? What is the involvement of relatives, nurses and GPs in the use and non-use of PSADs?

Chapter 7 discusses the main findings of the studies presented in the thesis and reflects on methodological and theoretical issues that should be taken into consideration when interpreting the findings; it also addresses implications for practice and research.

Chapter $\mathbf{8}$ provides the following content: summary, samenvatting, valorisation acknowledgements, about the author and the author's list of publications. 


\section{References}

1. Kagan, S.H., Editorial: Ageing in place, older people and community nursing: gerontological nursing in place. International Journal of Older People Nursing, 2015. 10(3): p. 159-159.

2. Ahn, M., H.J. Kwon, and J. Kang, Supporting Aging-in-Place Well: Findings From a Cluster Analysis of the Reasons for Aging-in-Place and Perceptions of Well-Being. Journal of Applied Gerontology, 2017.

3. Gitlin, L.N., Conducting research on home environments: lessons learned and new directions. The Gerontologist, 2003. 43(5): p. 628-37.

4. Agboola, S., et al., Healthcare utilization in older patients using personal emergency response systems: an analysis of electronic health records and medical alert data Brief Description: A Longitudinal Retrospective Analyses of healthcare utilization rates in older patients using Personal Emergency Response Systems from 2011 to 2015. BMC Health Services Research, 2017. 17(1).

5. Parra, C., et al., Information Technology for Active Aging A Review of Theory and Practice. Vol. 7. 2013, Foundationas and Trends in Human-Computer Interaction: now.

6. Clegg, A., et al., Frailty in elderly people. The Lancet, 2013. 381(9868): p. 752-762.

7. Fleming, J. and C. Brayne, Inability to get up after falling, subsequent time on floor, and summoning help: prospective cohort study in people over 90. BMJ, 2008. 337: p. a2227.

8. Hefny, A.F., A.K. Abbas, and F.M. Abu-Zidan, Geriatric fall-related injuries. African health sciences, 2016. 16(2): p. 554-559.

9. National Council for Aging Care. Fact Sheet: Falls - The Biggest Threat to Senior Health and Safety. 2018 [cited 2019 April 12]; Available from: https://www.aging.com/falls-fact-sheet/.

10. Nyman, S.R. and C.R. Victor, Use of personal call alarms among community-dwelling older people. Ageing \& Society, 2014. 34(1): p. 67-89.

11. Lai, C.K., et al., A survey of older Hong Kong people's perceptions of telecommunication technologies and telecare devices. Journal of Telemedicine and Telecare, 2010. 16(8): p. 441-446.

12. Heinbüchner, B., et al., Satisfaction and use of personal emergency response systems. Z Gerontol Geriatr, 2010. 43.

13. McLean, P.A., Exploring older Adults' Persceptions of the Utility and Ease of Use of Personal Emergency Response Systems, in Faculty in Nursing. 2016, CNUY Academic Works: New York.

14. Chaudhuri, S., H. Thompson, and G. Demiris, Fall Detection Devices and Their Use With Older Adults: A Systematic Review. J Geriatr Phys Ther, 2014.

15. International Federation on Ageing Global Ageing Issues \& Action, Ageing in place. International Federation on Ageing, 2011. 7, 1-60.

16. Vasunilashorn, S., et al., Aging in Place: Evolution of a Research Topic Whose Time Has Come. Journal of Aging Research, 2012. 52: p. 306-16.

17. AARP Home and community preferences of the 45+ population. 2010.

18. Boldy, D., et al., Older people's decisions regarding 'ageing in place': A Western Australian case study. Australasian Journal on Ageing, 2011. 30(3): p. 136-142.

19. Eckert, J.K., L. Morgan, and N. Swamy, Preferences for Receipt of Care Among Community-Dwelling Adults. Journal of Aging \& Social Policy, 2004. 16(2): p. 49-65.

20. European Network on Independent Living Comparing the Costs of Independent Living and Residential Care. 2014. 29.

21. Scharlach, A.E. and K. Diaze Moore, Aging in place, in Handbook of theories of aging, V.L. Bengtson and R.A Settersten, Editors. 2016, Springer: New York. p. 407-25.

22. Center for Disease Control and Prevention. Healthy places terminology: Aging in place. 2013 [cited 2019 5/4]; Available from: https://www.cdc.gov/healthyplaces/terminology.htm.

23. Greenfield, E.A., Using Ecological Frameworks to Advance a Field of Research, Practice, and Policy on Aging in-Place Initiatives. The Gerontologist, 2011. 52(1): p. 1-12.

24. Weil, J. and E. Smith, Revaluating aging in place: from traditional definitions to the continuum of care. Working with Older People, 2016. 20(4): p. 223-230. 
25. Vitman Schorr, A. and R. Khalaila, Aging in place and quality of life among the elderly in Europe: A moderated mediation model. Archives of Gerontology and Geriatrics, 2018. 77: p. 196-204.

26. Hillcoat-Nallétamby, S. and J.I.M. Ogg, Moving beyond 'ageing in place': older people's dislikes about their home and neighbourhood environments as a motive for wishing to move. Ageing and Society, 2013. 34(10): p. 1771-1796.

27. Boyle, A., J.L. Wiles, and R.A. Kearns, Rethinking ageing in place: the 'people' and 'place' nexus. PROGRESS IN GEOGRAPHY, 2015. 34(12): p. 1495-1511.

28. Jopp, D.S., et al., How could lay perspectives on successful aging complement scientific theory? Findings from a u.s. And a German life-span sample. Gerontologist, 2015. 55(1): p. 91-106.

29. Sirven, N. and T. Debrand, Social capital and health of older Europeans: Causal pathways and health inequalities. Social Science \& Medicine, 2012. 75(7): p. 1288-1295.

30. Holt-Lunstad, J., T.B. Smith, and J.B. Layton, Social relationships and mortality risk: a meta-analytic review. PLoS Med, 2010. 7(7): p. e1000316.

31. Grimmer, K., et al., Consumer views about aging-in-place. Clinical interventions in aging, 2015. 10: p. 18031811.

32. BASS Statistische Auswertungen zur Anzahl Angehöriger, die Betreuungs- und Pflegeleistungen erbringen. 2016.

33. Hank, K., Proximity and Contacts Between Older Parents and Their Children: A European Comparison. Journal of Marriage and Family, 2007. 69(1): p. 157-173.

34. Greenfield, E.A., et al., Community Gerontology: A Framework for Research, Policy, and Practice on Communities and Aging. The Gerontologist, 2018: p. gny089-gny089.

35. Young, Y., et al., Is Aging in Place Delaying Nursing Home Admission? Journal of the American Medical Directors Association, 2015. 16(10): p. 900.e1-900.e6.

36. Smolowitz, J., et al., Role of the registered nurse in primary health care: meeting health care needs in the $21 \mathrm{st}$ century. Nurs Outlook, 2015.63(2): p. 130-6.

37. Spichiger, E., et al., Professionelle Pflege - Entwicklung und Inahlte einer Definition. Pflege: Die wissenschaftliche Zeitschrift für Pflegeberufe, 2006. 19: p. 45-51.

38. ANA, Nursing's social policy statement. 2003, Washington, DC: American Nurses Association.

39. Glanz, K., B.K. Rimer, and K. Viswanath, Health Behavior - Theory, Research, and Practice. 5 ed. 2015, San Francisco: Jossey-Bass.

40. WONCA EUROPE The European Definition of General Praactice / Family Medicine. 2011.

41. Wiles, J.L., et al., The Meaning of "Aging in Place" to Older People. The Gerontologist, 2012. 52(3): p. $357-366$.

42. Stones, D. and J. Gullifer, 'At home it's just so much easier to be yourself': older adults' perceptions of ageing in place. Ageing \& Society, 2016. 36(3): p. 449-481.

43. Roy, N., et al., Choosing between staying at home or moving: A systematic review of factors influencing housing decisions among frail older adults. PLoS ONE, 2018. 13(1).

44. Baltes, M.M., et al., Everyday competence in old and very old age: Theoretical considerations and empirical findings, in The Berlin Aging Study, P.B. Baltes and K.U. Mayer, Editors. 1999, Cambridge University Press: Cambridge, England. p. 384-402.

45. Ghosh, R., et al. The new era of connected aging: a framework for understanding technologies that support older adults in aging in place. 2014.

46. Fischer, S.H., et al., Acceptance and use of health information technology by community-dwelling elders. Int J Med Inform, 2014. 83(9): p. 624-35.

47. Kim, K.-I., S.S. Gollamudi, and S. Steinhubl, Digital technology to enable aging in place. Experimental Gerontology, 2017. 88: p. 25-31.

48. Carnemolla, P., Ageing in place and the internet of things - how smart home technologies, the built environment and caregiving intersect. Visualization in Engineering, 2018. 6(1).

49. Rantz, M.J., et al., Sensor technology to support Aging in Place. Journal of the American Medical Directors Association, 2013. 14(6): p. 386-91.

50. McCreadie, C. and A. Tinker, The acceptability of assistive technology to older people. Ageing and Society, 2005. 25(1): p. 91-110. 
51. Khosravi, P. and A.H. Ghapanchi, Investigating the effectiveness of technologies applied to assist seniors: $A$ systematic literature review. International Journal of Medical Informatics, 2016. 85(1): p. 17-26.

52. Soar, J. and Y. Seo, Health and Aged Care Enabled by Information Technology. Annals of the New York Academy of Sciences, 2007. 1114(01): p. 154-161.

53. Schulz, R., et al., Advancing the Aging and Technology Agenda in Gerontology. Gerontologist, 2015. 55(5): p. 724-734.

54. Bouma, H., Foundations and goals of gerontechnology. Gerontechnology, 2012. 11(1): p. 1-4.

55. Kwon, S., Gerontechnology: Research, Practice, and Principles in the Field of Technology and Aging. 2017, Springer Publishing Company: New York, NY.

56. Bronswijk, J.E.M.H.V., et al., Defining gerontechnology for R\&D purposes. Gerontechnology, 2009. 8(1).

57. Pruchno, R., International Aging: Spotlighting the Spotlights. The Gerontologist, 2017. 57(3): p. $392-395$.

58. Lapook, J. More American seniors at risk of becoming "elder orphans". 2015 [cited 2019 April 10]; Available from: https://www.cbsnews.com/news/more-american-seniors-at-risk-of-becoming-elder-orphans/.

59. Dykstra, P.A., M. Djundeva, and T. Fokkema, Is Living Alone "Aging Alone"? Solitary Living, Network Types, and Well-Being. 2018.

60. Carpenter, D., et al. Patient Safety in the Home. 2017.

61. De Donder, L., et al., Individual risk factors of feelings of unsafety in later life. European Journal of Ageing, 2012. 9(3): p. 233-242.

62. De Donder, L., et al., Social Capital and Feelings of Unsafety in Later Life: A Study on the Influence of Social Networks, Place Attachment, and Civic Participation on Perceived Safety in Belgium. Research on Aging, 2012. 34(4): p. 425-448.

63. Gobbens, R.J., et al., In search of an integral conceptual definition of frailty: opinions of experts. J Am Med Dir Assoc, 2010. 11(5): p. 338-43.

64. Tocchi, C., Frailty in Older Adults: An Evolutionary Concept Analysis. Res Theory Nurs Pract, 2015(1): p. 66-84.

65. British Geriatrics Society 10. CGA in Primary Care Settings: Patients presenting with mobility and balance issues. 2019.

66. Aihie Sayer, A., C. Cooper, and C.R. Gale, Prevalence and risk factors for falls in older men and women: The English Longitudinal Study of Ageing. Age and Ageing, 2016. 45(6): p. 789-794.

67. Kojima, G., Frailty as a Predictor of Future Falls Among Community-Dwelling Older People: A Systematic Review and Meta-Analysis. Journal of the American Medical Directors Association, 2015. 16(12): p. 1027 1033.

68. Gillespie, L.D., et al., Interventions for preventing falls in older people living in the community. Cochrane Database Syst Rev, 2012. 9: p. CD007146.

69. Centers for Disease Control and Prevention. Falls Among Older Adults: An Overview. 201220.09 .201209 Dec 2016]; Available from: http://www.cdc.gov/homeandrecreationalsafety/falls/adultfalls.html.

70. Hester, A.L. and F. Wei, Falls in the community: state of the science. Clin Interv Aging, 2013. 8: p. 675-9.

71. Rubenstein, L.Z., Falls in older people: epidemiology, risk factors and strategies for prevention. Age Ageing, 2006. 35 Suppl 2: p. ii37-ii41.

72. Fuller, G.F., Falls in the elderly. AMerican FAmily Physician, 2000. 61(7): p. 2159-68.

73. Lamb, S.E., et al., Development of a common outcome data set for fall injury prevention trials: the Prevention of Falls Network Europe consensus. J Am Geriatr Soc, 2005. 53(9): p. 1618-22.

74. Gill, T.M., et al., Association of injurious falls with disability outcomes and nursing home admissions in community-living older persons. Am J Epidemiol, 2013. 178(3): p. 418-25.

75. Spaniolas, K., et al., Ground level falls are associated with significant mortality in elderly patients. J Trauma, 2010. 69(4): p. 821-5.

76. Bloch, F., Les complications non traumatiques des chutes : des conséquences trop souvent négligées chez la personne âgée. NPG Neurologie - Psychiatrie - Gériatrie, 2015. 15(88): p. 188-190.

77. Turner, S., R. Kisser, and W. Rogm Falls among older adults in the EU-28: Key facts from the available statistics. 2015.

78. Zijlstra, G.A., et al., Prevalence and correlates of fear of falling, and associated avoidance of activity in the general population of community-living older people. Age Ageing, 2007. 36(3): p. 304-9. 
79. WHO What are the main risk factors for falls amongst older people and what are the most effective interventions to prevent these falls?. Health Evidence Network, 2004.

80. Denkinger, M.D., et al., Factors Associated with Fear of Falling and Associated Activity Restriction in Community-Dwelling Older Adults: A Systematic Review. The American Journal of Geriatric Psychiatry, 2015. 23(1): p. 72-86.

81. Md Sazedur, R., Prevalence and Risk Factors of Fear of Falling among Elderly: A Review. Medical Journal of Clinical Trials \& Case Studies, 2018. 2(11): p. 000185

82. Liu, J.Y.W., Fear of falling in robust community-dwelling older people: Results of a cross-sectional study. Journal of Clinical Nursing, 2015. 24: p. 393-405.

83. Hopewell, S., et al., Multifactorial and multiple component interventions for preventing falls in older people living in the community. Cochrane Database of Systematic Reviews, 2018. 7.

84. Simpson, P.M., et al., Epidemiology of emergency medical service responses to older people who have fallen: a prospective cohort study. Prehosp Emerg Care, 2014. 18(2): p. 185-94.

85. Lord, S.R., C. Sherrington, and H.B. Menz, Falls in oder people. Risk, factors and strategies for prevention. 2001, Cambridge: Cambridge University Press.

86. Ryynanen, O.P., et al., Falls and lying helpless in the elderly. Z Gerontol, 1992. 25(4): p. 278-82.

87. Johnston, K., et al., Personal alarm use to call the ambulance after a fall in older people: characteristics of clients and falls. Journal of Emergency Primary Health Care (JEPHC), 2010. 8(4): p. 1-9.

88. Stokke, R., Older People Negotiating Independence and Safety in Everyday Life Using Technology: Qualitative Study. J Med Internet Res, 2018. 20(10): p. e10054.

89. Stokke, R., The Personal Emergency Response System as a Technology Innovation in Primary Health Care Services: An Integrative Review. J Med Internet Res, 2016. 18(7): p. e187.

90. Lapierre, N., et al., The state of knowledge on technologies and their use for fall detection: A scoping review. International Journal of Medical Informatics, 2018. 111: p. 58-71.

91. Peek, S.T.M., et al., Older Adults' Reasons for Using Technology while Aging in Place. Gerontology, 2016. 62(2): p. 226-237.

92. Sixsmith, A. and N. Johnson, A smart sensor to detect the falls of the elderly. leee Pervasive Computing, 2004. 3(2): p. 42-47.

93. Ward, G., et al., Fall detectors: a review of literature. Journal of Assistive Technologies, 2012. 6(3): p. 202215.

94. Igual, R., C. Medrano, and I. Plaza, Challenges, issues and trends in fall detection systems. Biomed Eng Online, 2013. 12: p. 66.

95. Mubashir, M., L. Shao, and L. Seed, A survey on fall detection: Principles and approaches. Neurocomputing, 2013. 100: p. 144-152.

96. Doughty, K., R. Lewis, and A. McIntosh, The design of a practical and reliable fall detector for community and institutional telecare. Journal of Telemedicine and Telecare, 2000. 6: p. 150-154.

97. Chan, M., et al., Smart wearable systems: current status and future challenges. Artif Intell Med, 2012. 56(3): p. 137-56.

98. Künemund, H. and N.M. Tanschus, The technology acceptance puzzle. Results of a representative survey in Lower Saxony. Z Gerontol Geriatr, 2014. 47(8): p. 641-7.

99. Johnston, K., K. Grimmer-Somers, and M. Sutherland, Perspectives on use of personal alarms by older fallers. Int J Gen Med, 2010. 3: p. 231-7.

100. Mann, W.C., et al., Use of personal emergency response systems by older individuals with disabilities. Assist Technol, 2005. 17(1): p. 82-8.

101. Chaudhuri, S., et al., Older Adluts' Perceptions of Fall Detection Devices. Journal of Applied Gerontology, 2015. 36(8): p. 915-930.

102. Chen, K. and A.H. Chan, Gerontechnology acceptance by elderly Hong Kong Chinese: a senior technology acceptance model (STAM). Ergonomics, 2014. 57(5): p. 635-52.

103. Bridgelal Ram, M., P. Grocott, and H. Weir, Issues and challenges of involving users in medical device development. Health Expect, 2007. 11: p. 63-71. 
104. Shah, S.G.S., I. Robinson, and S. AIShawi, Developing medical device technologies from users' perspectives: $A$ theoretical framework for involving users in the development process. International Journal of Technology Assessment in Health Care, 2009. 25(4): p. 514-521.

105. Rodeschini, G., Gerotechnology: a new kind of care for aging? An analysis of the relationship between older people and technology. Nurs Health Sci, 2011. 13(4): p. 521-8.

106. Gulliksen, J., et al., Key principles for user-centred systems design. Behaviour and Information Technology, 2003. 22(6): p. 397-409.

107. De Vito Dabbs, A., et al., User-centered design and interactive health technologies for patients. Comput Inform Nurs, 2009. 27(3): p. 175-83.

108. Shah, S.G.S. and I. Robinson, Benefits of and barriers to involving users in medical device technology development and evaluation. Int J Technol Assess Health Care, 2007. 23(1): p. 131-7.

109. Kujala, S., User involvement: a review of the benefits and challenges. Behaviour \& Information Technology, 2003. 22(1): p. 1-16.

110. Schwickert, L., et al., Fall detection with body-worn sensors A systematic review. Zeitschrift fuer Gerontologie und Geriatrie, 2013. 46(8): p. 706-719.

111. Peek, S.T.M., et al., Origins and consequences of technology acquirement by independent-living seniors: towards an integrative model. Bmc Geriatrics, 2017. 17.

112. Dahms, R. and M. Haesner, Akzeptanz von Informations- und Kommunikationstechnologien bei Senioren Prävention und Gesundheitsförderung, 2018. 13(1): p. 46-52.

113. Luijkx, K., S. Peek, and E. Wouters, "Grandma, You Should Do It-It's Cool" Older Adults and the Role of Family Members in Their Acceptance of Technology. International Journal of Environmental Research and Public Health, 2015. 12(12): p. 15470-15485.

114. Peek, S.T.M., et al., Factors influencing acceptance of technology for aging in place: a systematic review. Int J Med Inform, 2014. 83(4): p. 235-48

115. Piscotty, R.J., Jr., B. Kalisch, and A. Gracey-Thomas, Impact of Healthcare Information Technology on Nursing Practice. Journal of nursing scholarship : an official publication of Sigma Theta Tau International Honor Society of Nursing, 2015. 47(4): p. 287-93.

116. Saborowski, M. and I. Kollak, "How do you care for technology?" - Care professionals' experiences with assistive technology in care of the elderly. Technological Forecasting and Social Change, 2015. 93: p. 133140

117. Satariano, W.A., A.E. Scharlach, and D. Lindemann, Aging, place, and Technology: Toward Improving Access and Wellness in Older Populations. Journal of Aging and Health, 2014. 26(8): p. 1373-89.

118. Lupton, D., Cirtical Perspectives on Digital Health Technologies. Sociology Compass, 2014. 8(12): p. $1344-59$.

119. de Veer, A.J., et al., Successful implementation of new technologies in nursing care: a questionnaire survey of nurse-users. BMC Medical Informatics and Decision Making, 2011. 11(1): p. 67.

120. Claßen, K.,Zur Psychologie von Technikakzeptanz im höheren Lebensalter:Die Rolle von Technikgenerationen, in Fakultät für Verhaltens- und Empirische Kulturwissenschaften. 2012, Ruprechts-Karls-Universität Heidelberg: Heidelberg.

121. Peek, S.T.M., Understanding technology acceptance by older adults who are aging in place: a dynamic perspective. 2017, Ipskamp: Enschede.

122. Reneau, J.M., An examination of the acceptance, adoption, and diffusion of smartphone devices with senior citizens, in Graduate School of Computer and Information Sciences. 2013, Nova Southeastern University: Davie.

123. Marangunić, N. and A. Granić, Technology acceptance model: a literature review from 1986 to 2013. Universal Access in the Information Society, 2015. 14(1): p. 81-95.

124. Davis, F.D., R.P. Bagozzi, and P.R. Warshaw, User Acceptance of Computer Technology: A Comparison of Two Theoretical Models. Management Science, 1989. 35: p. 982-1003.

125. King, W.R. and J. He, A meta-analysis of the technology acceptance model. Information \& Management, 2006. 43(6): p. 740-755.

126. Holden, R.J. and B.-T. Karsh, The Technology Acceptance Model: Its past and its future in health care. Journal of Biomedical Informatics, 2010. 43(1): p. 159-172. 
127. Fishbein, M. and I. Ajzen, Belief, attitude, intention and behavior: An introduction to theory and research, ed. D. Mills. 1975, New York: Addison Wesley.

128. Ajzen, I., The Theory of Planned Behavior. Organizational Behavior and Human Decision Processes, 1991. 50(2): p. 179-211.

129. Fishbein, M. and I. Ajzen, Predicting and Changing Behavior: The Research Action Approach. 2010, New York, USA: Taylor \& Francis.

130. Venkatesh, V. and F.D. Davis, A theoretical extension of the Technology Acceptance Model: Four longitudinal field studies. Management Science, 2000. 46(2): p. 186-204.

131. Venkatesh, V. and H. Bala, Technology Acceptance Model 3 and a Research Agenda on Interventions. Decision Sciences, 2008. 39(2): p. 273-315.

132. Lee, Y., K. Kozar, and K. Larsen, The Technology Acceptance Model: Past, Present, and Future. Communications of the Association for Information System, 2003. 12: p. 752-80.

133. Yousafzai, S.Y., G.R. Foxall, and J.G. Pallister, Technology acceptance: a meta-analysis of the TAM: Part 1. Journal of Modelling in Management, 2007a. 2(3): p. 251-280.

134. Venkatesh, V., et al., User acceptance of information technology: Toward a unified view. Mis Quarterly, 2003. 27(3): p. 425-478.

135. Khechine, H., S. Lakhal, and P. Ndjambou, A meta-analysis of the UTAUT model: Eleven years later. Canadian Journal of Administrative Sciences / Revue Canadienne des Sciences de I'Administration, 2016. 33(2): p. 138-152.

136. Renaud, K. and J. van Biljon. Predicting technology acceptance and adoption by the elderly: a qualitative study. in Annual research conference of the South African Institute of Computer Scientists and Information Technologists on IT research in developing countries: riding the wave of technology. 2008. New York: ACM.

137. Yousafzai, S.Y., G.R. Foxall, and J.G. Pallister, Technology acceptance: a meta-analysis of the TAM: Part 2. Journal of Modelling in Management, 2007b. 2(3): p. 281-304.

138. Vishwanath, A. and G.A. Barnett, The Diffusion of Innovations A Communication Science Perspective, ed. A. Vishwanath and G.A. Barnett. 2011, New York: Peter Lang.

139. Bagozzi, R.P., The Legacy of the Technology Acceptance Model and a Proposal for a Paradigm Shift. Journal of the Association for Information Systems, 2007. 8(4).

140. Ding, Y., K. Chai, and G. Ng. Continued Use of Information Technology: A Synthesis and Future Directions. in 2012 International Joint Conference on Service Sciences. 2012.

141. Rogers, E.M., Diffusion of Innovations. 5th ed. ed. 2003, New York, USA: The Free Press.

142. Chen, K. and A. Chan, A review of technology acceptance by older adults. Gerontechnology, 2011. 10(1).

143. Lorenzen Huber, L., et al., Aging in intra-and intergenerational contexts: the family technologist, in Gerontechnology: Research, Practice, and Principles in the Field of Technology and Aging S. Kwon, Editor. 2017.

144. Kiwanuka, A., Accpetance Process: The Missing Link between UTAUT and Diffusion of Innovation Theory. American Journal of Information Systems, 2015. 3(2): p. 40-4.

145. Chalmers, A.F., Wege der Wissenschaft - Einführung in die Wissenschaftstheorie, ed. N. Bergemann and C. Altstötter-Gleich. 2007, Berlin Heidelberg New York: Springer.

146. Connelly, K., et al., Approaches to Understanding the Impact of Technologies for Aging in Place: A MiniReview. Gerontology, 2014. 60(3): p. 282-288.

147. Nieboer, M.E., et al., Professional values, technology and future health care: The view of health care professionals in The Netherlands. Technology in Society, 2014. 39: p. 10-17.

148. Stokke, R., "Maybe we should talk about it anyway": a qualitative study of understanding expectations and use of an established technology innovation in caring practices. BMC Health Services Research, 2017. 17(1): p. 657.

149. Mostaghel, R., Innovation and technology for the elderly: Systematic literature review. Journal of Business Research, 2016. 69(11): p. 4896-4900.

150. Baumer, E.P.S., et al., On the Improtance and Implications of Studying Technology Non-Use. INTERACTIONS, 2015. 22(March + April): p. 52-6.

151. Satchell, C. and P. Dourish, Beyond The User: Use and Non-Use in HCl, in OZCHI. 2009: Melbourne. 


\section{Chapter 2}

\section{Involvement of older people in the development of fall detection systems: a scoping review}

This chapter was published as: Thilo, F.J.S., Hürlimann, B., Hahn, S., Bilger, S., Schols, J.M.G.A., \& Halfens, R.J.G. (2016). Involvement of older people in the development of fall detection systems: a scoping review. BMC Geriatrics, 16(42). doi:10.1186/s12877-0160216-3 


\section{Abstract}

Background: The involvement of users is recommended in the development of health related technologies, in order to address their needs and preferences and to improve the daily usage of these technologies. The objective of this literature review was to identify the nature and extent of research involving older people in the development of fall detection systems.

Methods: A scoping review according to the framework of Arksey and O'Malley was carried out. A key term search was employed in eight relevant databases. Included articles were summarized using a predetermined charting form and subsequently thematically analysed.

Results: A total of 53 articles was included. In 49 of the 53 articles, older people were involved in the design and/or testing stages, and in 4 of 53 articles, they were involved in the conceptual or market deployment stages. In 38 of the 53 articles, the main focus of the involvement of older people was technical aspects. In 15 of the 53 articles, the perspectives of the elderly related to the fall detection system under development were determined using focus groups, single interviews or questionnaires.

Conclusions: Until presently, involvement of older people in the development of fall detection systems has focused mainly on technical aspects. Little attention has been given to the specific needs and views of older people in the context of fall detection system development and usage. 


\section{Background}

People aged 65 years and older are the age group mostly affected by falls and their subsequent negative health consequences. ${ }^{1-3}$ Approximately 25 to $35 \%$ of them have had one or more falls per year. ${ }^{2,4} \mathrm{~A}$ fall is defined as "an unexpected event in which the participants come to rest on the ground, floor, or lower level"(p. 1619). ${ }^{5}$ Falls significantly affect mortality, morbidity and quality of life as well as health care costs among the ageing population.-12 Falls are also one of the main causes of physical injuries ${ }^{4,13,14}$, are a frequent causal factor for hospital admissions ${ }^{15}$ and are additionally a precipitator for institutional long-term care admissions. ${ }^{16,17}$ The rates of falls and the outlined associated negative consequences are twice as high for persons over 75 years of age. ${ }^{18}$

One determining factor influencing the severity of fall consequences in older people is the amount of time spent lying on the floor or ground. ${ }^{19,20}$ This is particularly critical when a person cannot call for help, for instance when she/he has lost consciousness or is alone when the fall occurred. Even when uninjured, $47 \%$ of people who have experienced a fall were unable to get up after without help. ${ }^{21}$ Lying on the floor due to a fall event for one hour or more is defined as a "long-lie".22 Experiencing a "long-lie" event is associated with serious injuries, higher mortality rates and hospital admissions, as well as consequent care home admissions. ${ }^{19,20,23}$ Thirteen $^{22}$ to $20 \%{ }^{24}$ of older people admitted to a hospital due to a fall have experienced a "long-lie" event. In order to avoid this and ensure prompt assistance, early fall detection is vital among community dwelling older people. A fall detection system could be defined as a system which detects falls and alerts a designated person or emergency services, in order to facilitate rapid assistance. ${ }^{25,26} \mathrm{~A}$ fall detection system could prevent or limit impairment and subsequently allow preservation of activities of daily living. Although the literature outlines a variety of fall detection systems, ${ }^{26,27}$ minimal and faulty use of fall detection systems in community-dwelling older people has been reported. ${ }^{19,28-32}$ Hence, it seems that the target users, older people, struggle with the usability of available fall detection systems in their daily lives. ${ }^{19,} 28,32$

In order to provide fall detection systems which meet the needs and expectations of older people, user involvement should be applied to the different stages of development of the system, as is described with other health-related technologies. ${ }^{33}$ The process of user involvement is relevant because it facilitates the development of technology that is "needs-driven" and "not technology-driven". ${ }^{34}$ It enables a better understanding of the process of the interaction and the surrounding context between technology and its users. $^{35,36}$ User involvement may help to ensure that preferences are considered from the beginning of the development process, ${ }^{33,37,38}$ and may therefore improve the level of acceptance of the users. ${ }^{39}$ It might facilitate short- and long-term usage and hence 
decrease costs and the need for redesign at a later time. ${ }^{38}$ Additionally, it might increase sales, decrease training costs and decrease user support. ${ }^{39}$

Currently, an overview of the nature and extent of published research regarding the involvement of older people in the development, testing and/or evaluation of fall detection systems is lacking. Recent literature reviews have focused on the technical aspects of available fall detection systems or on the views of older people, carers and health professionals regarding benefits or challenges of fall detection systems and aspects related to their implementation. $25-27,40,41$

Therefore, the aim of this scoping review is to identify the state of research involving older people in the development of fall detection systems. The research question is: What is the nature and extent of user involvement of people 65 years of age and older, in the development, testing and/or evaluation of fall detection systems?

\section{Methods}

To answer the research question a scoping review was undertaken. A scoping review is a particularly suitable type of literature review for gaining a comprehensive overview of the research field of interest. ${ }^{42,43} \mathrm{~A}$ scoping review differs from a systematic review in that a scoping review does not aim to assess the effectiveness of an intervention; instead it aims to assess the feasibility of a systematic review and to guide for future research. A scoping review also aims to map the nature and extent of research activities and provides a rigorous and transparent methodology. ${ }^{43}$ It provides a descriptive overview of the analysed articles without critically appraising the quality of the included studies. ${ }^{44}$ Five stages are characteristic for a scoping review. ${ }^{42,43}$ Stage one refers to the identification of the research question (see above). Stages two to five comprise the process of the literature search and conclude with the reporting of the results. They were carried out as follows:

\section{Stage 2: Identifying relevant studies}

A systematic literature search was conducted between May and July 2014 across nursing, medicine and engineering disciplines in the following eight databases: IEEE Xplore@ Digital Library, Inspec, Scopus, Compendex, BIOSIS Previews, Cochrane Library, CINAHL / EBESCO and PubMed. A key word strategy was applied, which was developed progressively by two members of the research team (FJST and SB) and was approved by a third member of the research team $(\mathrm{SH})$. The following terms were used: fall detection, fall, aged, old, senior, elder*, monitoring, device, system, sensor, fall risk assessment, fall prevention, gait assessment. These terms were combined with the Boolean operators 
AND, OR, or NOT. An additional search of reference lists of articles fulfilling the inclusion criteria was carried out.

\section{Stage 3: Study selection}

Literature published in English, French or German within the last ten years (2004-2014) was retrieved in order to reflect the recent research trends. The time limit was chosen due to the visible evolvement of technology during this period. Moreover, according to the literature, there is an evolving body of knowledge regarding user involvement in the development of health-related technologies in the last ten years. Articles were eligible for inclusion if they: 1) focused on either development, testing and/or evaluation regarding a fall detection system; 2 ) included in their study at least one older person who was involved in the development or who was a target person to test or to evaluate the system; 3 ) the older person was 65 years of age and older, or was defined as older. Records were identified, duplicates removed, titles screened, abstracts examined, and the remaining full-texts assessed for eligibility. The assessment of titles and abstracts was carried out independently by two reviewers (FJST, BH). There were few discrepancies. The first reviewer assessed all full-text articles for eligibility and $20 \%$ of the retained full-text articles were assessed by the second reviewer independently. The first reviewer (FJST) randomly selected the full-text articles for the second reviewer $(\mathrm{BH})$. Differences in the article screening and selection process were solved by consensus. Only one article was discussed with a third reviewer (SB) due to a lack of consensus concerning eligibility.

Currently, reporting guidelines for scoping reviews do not exist. ${ }^{44}$ Therefore, in accordance to the recommendation of Pham et al. ${ }^{44}$, the Preferred Reporting Items for Systematic Reviews and Meta-Analysis ${ }^{45}$ was used to report the flow of articles from identification to final inclusion.

\section{Stage 4: Charting the data}

A data charting form was iteratively developed focusing on themes relevant to the research question and was based on the following: author(s), year, title, country, publication type, design, aim, type of fall detection system, fall detection alert, placement of system, methodology (narrative description of user involvement in the development/testing/ evaluation), sample size, sample characteristics and setting. The first draft of the data charting form was tested independently on $20 \%$ of a second random reselection of articles by two researchers (FJST, BH). After critical comparison of these results, discrepancies were resolved through discussion. Subsequently, the revised data charting form was critically discussed and jointly approved by the research team. The charting form was then applied to all included articles in order to narratively extract the data. In studies containing a mixed population (participants under 65 years 
as well as 65 years and older), only data related to older people was extracted, and only with those who involved a target person in the development, testing and/or evaluation of a fall detection system.

\section{Stage 5: Collating, summarizing and reporting the results}

The charted findings were numerically and thematically ${ }^{46}$ analysed and then summarized from a descriptive perspective. Absolute frequencies were calculated for the numerical description of the nature and extend of literature. The following themes were identified, describing the nature (A.-B.) and extend (C.) of the literature:

A. General aspects of literature involving older people: Author(s) year, country, design, type of fall detection system (wearable system - e.g. body-worn sensors; or environmental systems - e.g. infrared sensors or camera) fall detection alert, sample size, mean age in years, gender of involved older people and length of test time.

B. Descriptive characteristics of the involved older people: age gender, height and/ or weight and/or BMI, state of health, fall risk (no risk, at risk, at high risk), fear of falling and fall history (with, without).

C. Focus involvement and stage(s) of involvement of older people:

Focus of involvement:

i. Involvement of older people for technical aspects such as simulation or performance of either scripted activities of daily living (ADL), which signifies that study participants had to perform a series of ADL (sitting down or walking), or of everyday life activities, which signifies that study participants had to perform as usual their activities of daily living during the testing stage of a fall detection system.

ii. Involvement of older people to investigate their views on fall detection systems.

Stage(s) of involvement:

The framework of user involvement in the development of medical device technology according to Shah et al. ${ }^{33}$ was used to define the stages of user involvement in each article:

I. Idea generation and concept development

II. Device (re-)design and prototype development

III. Prototype testing involving in-house and trials in the real field

IV. Device deployment in the market and user feedback

In order to test the process of stage five, $20 \%$ of the articles from a third random selection were analysed and summarized independently by the first and second reviewer (FJST, BH). After critical comparison of these results, 
discrepancies were resolved through discussion. Afterwards, all included articles were analysed and summarized by the first reviewer. This result was subsequently critically discussed and jointly approved by the research team. This scoping review is part of a research project, which was approved by the Ethical Committee of the Canton of Bern (Z020/2014).

\section{Results}

After the selection process, as displayed in Figure 1, a total of 53 studies was included from the original 1633 potentially relevant records. ${ }^{47-99}$

The findings relevant to the research question are summarized in the following three tables: nature of literature - Additional file 1: Table S1 and Additional file 2: Table S2 and extent of literature - Additional file 3: Table S3.

A. General aspects of the literature Additional file 1: Table $S 1$ presents the general aspects of the analysed literature involving older people in the development, testing and/or evaluation of fall detection systems. Researchers from four continents have carried out studies involving older people in the development, testing and/or evaluation of fall detection systems, although most of this research has been conducted in Europe (see Additional file 1:Table S1). 37 studies focused on wearable systems, ten on environmental systems, four on both and two on fall detection systems amongst other technologies (e.g. general event reminder or monitoring of physiological parameters) (see Additional file 1: Table S1). The sample size in the included studies varied. In more than three-fourths $(n=47)$ of the studies, the sample size ranged from one to 35 older people. In five studies the sample size was not clearly stated and in one study it included a sample of 97 older people. The length of test time in which older people were involved in the respective studies was reported in 20 articles, and it ranged from 40 minutes to several hours, days, weeks until 1.5 years (see Additional file 1:Table S1). In nearly half of the studies ( $n=25)$, it was not stated and in eight studies this criterion was not applicable due to the study design.

B. Descriptive characteristics of the involved older people Information regarding the age of the involved older people was reported in 45 studies (see Additional file 2: Table S2). Eight studies characterised their sample by describing them as old or elderly people. 27 articles displayed information about the gender of the study participants (see Additional file 2: Table S2). In nine studies the involved older people were described as healthy. In 14 studies fall risk, fear of falling and/ or fall history was assessed (see Additional file 2: Table S2). 
C. Focus and stage(s) of involvement Additional file 3: Table S3 shows the findings regarding the focus of involvement, distinguishing between the technical aspects and the views of the older people as well as defining the stage (s) of involvement of the older people.

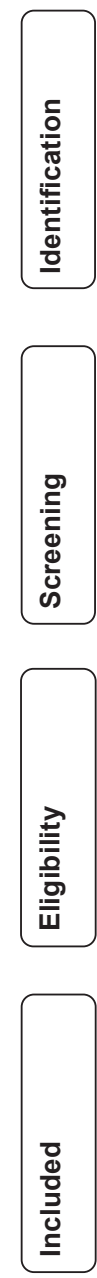

Records identified through database searching $(n=1620)$

IEEE ( $n=785)$; Inspec $(n=375)$; Scopus $(n=302)$; Compendex $(n=58)$;

BIOSIS Previews $(n=26)$; Cinahl $(n=24)$; PubMed $(n=49)$; Cochrane

Library $(n=1)$

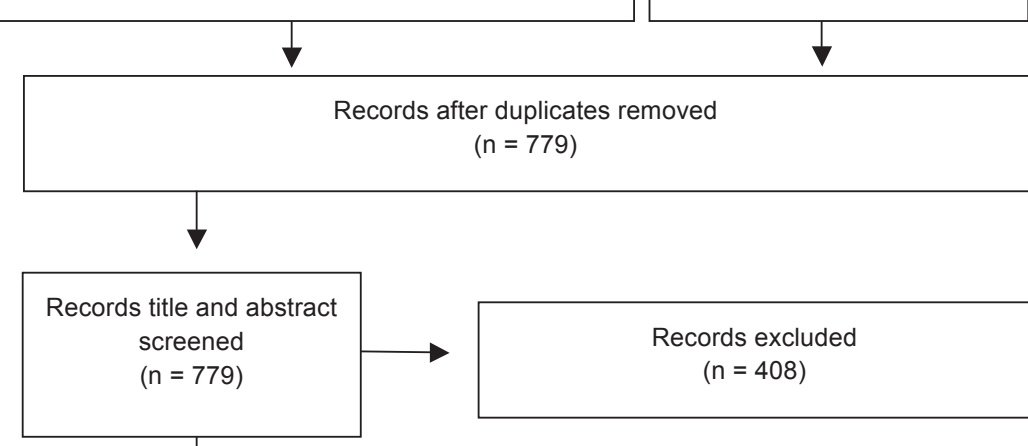

Additional records identified through reference lists $(n=13)$

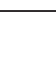

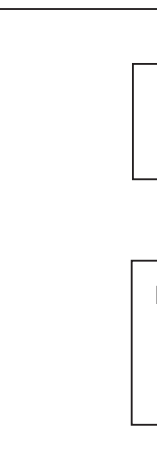

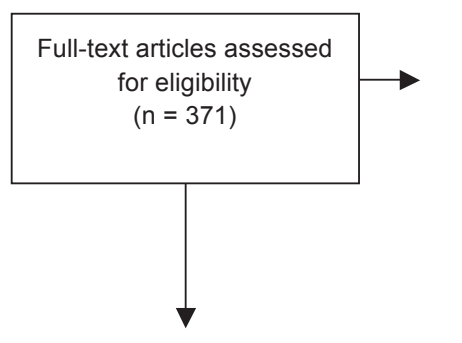

Full-text articles excluded, with reason $(n=318)$

$\mathrm{n}=14$ (actor, stuntman)

$\mathrm{n}=229$ (age $<65$ years or no age indicated)

$\mathrm{n}=3$ (dummy)

$\mathrm{n}=1$ (caregivers, manager)

$\mathrm{n}=67$ (without subjects)

$\mathrm{n}=4$ (not English, German or French)

Studies included

in scoping study

$(\mathrm{N}=53)$

Figure 1. Flow chart of study selection ${ }^{45}$ 


\section{Focus of involvement}

\section{i. Technical aspects}

Nearly three-fourths $(n=38)$ of the included studies solely examined the technical aspects of fall detection systems, without involving the views of older persons (see Additional file 3: Table S3). Five studies investigated both the technical aspects and the views of the older people in the context of fall detection systems. Regarding the settings of involvement of older people, most studies were $(n=12)$ carried out in the home environment, followed by the nursing home and the hospital setting (see Additional file 3: Table S3). Five studies reported the laboratory environment as the setting of involvement for older people. In three studies, older people were involved in more than one setting and eleven studies did not clearly state the setting of involvement (see Additional file 3: Table S3). During their involvement, in order to develop a valid and reliable fall detection algorithm, older people were invited to simulate scripted ADL and/or to perform everyday life activities (see method section). Most frequently ( $n=22)$ they simulated scripted ADL and in six studies older people simulated both scripted ADL and performed everyday life activities (see Additional file 3: Table S3).

\section{ii. Views of older people}

Ten studies focused solely on the views of older persons related to the fall detection system under development. Aspects of their examinations were, for example, usability, perceptions of usefulness, concerns associated with usage, attractiveness or wearing comfort. Their views were investigated in 15 studies utilizing focus group interviews, single interviews and/or questionnaires. The focus group interviews were carried out both with and without a fall detection system prototype and both with and without visual material showing fall detection systems or fall scenarios (see Additional file 3: Table S3).

\section{Stage(s) of involvement}

Older people were involved in all four of the following stages of development and testing of a fall detection system: In three studies - stage I, in 18 studies - stage II, in 28 studies - stage III and in one study - stage IV. In three studies, older people were involved in two stages; stages II and III (see Additional file 3: Table S3). According to the analysed literature, there was no study reporting on the development of a fall detection system which involved older people in three of the four stages, nor in all four stages. A comparison of the included studies showed that six research groups ${ }^{51-58,72,73,75,76,}$ 93,94, 96, 97 published several articles referring to results either from stage II or stage III of development without reporting on the examination of the view of involved older people regarding the fall detection system under development (see Additional file 3: 
Table S3). Quagliarella et al. ${ }^{85,86}$ published two articles referring to results from the same fall detection system; once from stage II and once from stage III, however without reporting on the examination of the view of the involved older people.

\section{Discussion}

This scoping review shows that older people are predominantly involved in the design and testing stages of fall detection systems under development, with a strong focus on the technical aspects. Most of this research was carried out in Europe with the majority of the studies targeting the development of wearable fall detection systems. Information regarding the older people involved was in general limited to age and gender.

This scant description of the study participants is noteworthy, given that older people are a heterogeneous age group. ${ }^{100}$ In regard to fall detection systems, characteristics of the target users, such as risk of falling, history of falls or fear of falling, might influence the needs and expectations of older people. ${ }^{101}$ Moreover, the functional and cognitive status of older people might affect their handling and, therefore, their acceptance of the technology. Ageing is linked to a change of cognitive abilities and cognitive impairment may hinder the use of a fall detection system. ${ }^{102}$ Considering the cognitive abilities of the target group might enhance the development of a fall detection system which is also easy for people with an impaired cognitive status to learn and to use. On the other hand, it might be considered that carers of cognitively impaired people should also be involved in the development of a fall detection system.

However, it seems that the scant description is in accordance with the predominant involvement of older people in the technical aspects of the design and testing stages. It might be argued that for the technical aspects of a fall detection system under development, study participants' information such as age, gender or BMI is sufficient. Nevertheless, Shah and Robinson ${ }^{103}$ indicated that specific information concerning the targeted users is relevant, because different users employ the same technology in different settings and contexts. This argument is confirmed by Kaufman et al. ${ }^{104}$ in their evaluation of a telemedicine system. They reported that even if users are a part of the same setting or age group, they differ considerably in terms of knowledge, competencies, need for social help, health status or self-efficacy.

This scoping review also revealed that if older people were involved, it occurred mostly in their home setting, which is congruent with the idea that the development and validation of fall detection systems should be carried out with the target group in their "real-world", and not only in laboratory settings. ${ }^{26,40}$ Reliable and valid fall detection and alert systems are a very important aspect. Several researchers stressed that developing 
a fall detection system based on falls from the real-world might minimize the rate of false positive and false negative alarms. ${ }^{105,}{ }^{106}$ Consequently, the involvement of older people in stages two and/or three, as well as in their real-world setting, seems to be very important in ensuring valid and reliable fall detection systems.

Nevertheless, user involvement primarily aims to investigate needs and requirements promoting the daily use of fall detection systems. ${ }^{26,35}$ This scoping review also revealed that older people's views regarding fall detection systems were scarcely used. The reasons for this could be the higher costs or difficulties in accessing the targeted users. ${ }^{39}$ Shah et al. ${ }^{38}$ specified that minimal user involvement might originate from issues in confidentiality, (e.g. patent application) in terms of bringing technology into the market or due to limited experience of user involvement in the research group. Moreover, knowing the views (e.g., needs or preferences) of users might be challenging for a research team. According to the view of users, the design of a product or a system should then be adapted. ${ }^{39}$ However, there could be gap between the users' views and the technical, product or design solutions. ${ }^{34}$ The disaccord is that user involvement might be challenging and depends upon research resources. Hence, it seems important to carry out user involvement if there are "real" possibilities for users in influencing design or solutions of a fall detection system. If not, it is conceivable that user involvement might generate legitimate cost concerns, as well create frustration with the involved users due to their views not being considered in the further development of the fall detection system.

Older people were involved in all four stages of fall detection system development. However, their involvement was mostly limited to the design and testing stages. As discussed, the older target users were hardly involved in the beginning and end stages of the development process. Additionally, older people were minimally involved in several other stages of development and no article described involvement exceeding two stages of development. Hence, due to the predominant involvement in the prototype design and testing stages, it is logical that technical aspects of the fall detection system under development are at the forefront. However, the involvement of the target users in all stages of development is associated with several advantages. ${ }^{38,39}$ Involvement of target users beginning in the first stage fosters their influence in the concept development of the fall detection system and thus avoids additional cost in later stages due to redesign issues. User involvement from the first stage onward may improve the level of acceptance of fall detection systems by older people due to the early focus on their views (e.g., needs, preferences or requirements) including the practical aspects of daily living. Furthermore, it could be considered that user feedback also in the last stage is important in order to identify any aspects that are lacking. These aspects may not be completely related to technical issues and it is conceivable that 
support or coaching services, e.g. from health care providers, would help to enable older people in long-term usage of fall detection systems in daily life. Moreover, the fourth stage may provide ideas, due to recurrent needs of target users, for the further development of fall detection systems such as combining them with additional features (e.g. capturing mobility patterns or physiological parameters). This would signify that the involved older people would «truly» have the possibility to enhance the meaningful use of fall detection system in daily life.

The literature scrutinized in this scoping review illustrated that there is not yet widespread involvement of older people from the beginning until the last stage of development. It also revealed that it is not yet common practice to investigate older peoples' views regarding fall detection systems under development. User involvement can be interpreted in different ways. According to Kujala ${ }^{107}$ and Damodoran ${ }^{108}$, the user may be involved for providing information (informative), for comments about a predefined matter (consultative) or for influencing decision making regarding a system under development (participative). It seems that apart from the stages and methods of involvement, it should also be considered whether users be involved in an informative, consultative or a participative way. In the context of fall detection systems, the participative way would best facilitate older people to influence the decision-making process as it necessitates capturing their views, needs, preferences, requirements or issues of the practical usage of fall detection systems in daily life.

\section{Strengths and limitations}

This scoping review applied a rigorous and transparent methodology throughout the five recommended steps of the framework from Arksey and O'Malley. ${ }^{43}$ In order to ensure that the research question was explored in breadth, literature was searched in eight data bases across different disciplines. Although relevant published articles may have been omitted, for instance, due to the limitation of articles written in English, German and French, references from the selected articles did not indicate any other important studies.

Scoping reviews have been criticised for lacking methodological details during stage five, with collating, summarizing and reporting the results of the framework. ${ }^{109}$ Therefore, this scoping review transparently described, utilizing the thematical analysis approach, ${ }^{46}$ how stage five was conducted. The validation of the applied framework of Shah et al. ${ }^{33}$, describing the four stages of health-related technology development is still missing, according to the authors. However, due to the health-related context of technologies as well the clear description of each stage, this framework was considered and shown to be suitable for the underlying study. 


\section{Conclusions}

This scoping review reveals that older people were predominantly involved in the design and testing of fall detection systems, which denotes that the focus was on the technical aspects in the development of fall detection algorithms. In the development and use of fall detection systems, little attention has been given to the views, needs, preferences or practical aspects of usefulness in daily life of the older people themselves. This may be an important factor in explaining, in general, the minimal and often faulty use of fall detection systems in the daily lives of older people.

A more "needs-driven" rather than "technology-driven" approach in the development of fall detection systems is necessary. Therefore, future research also needs to involve older people more in idea generation and concept development as well as in device deployment and market and user feedback. Future involvement should consider a more participative way to capture the views, needs, preferences, requirements or issues for the practical use of fall detection systems in the daily lives of older people. This may positively influence the daily usage and acceptance of fall detection systems in community-dwelling older people.

\section{Abbreviations}

ADL: activities of daily living.

\section{Competing interests}

The authors declare that they have no competing interests.

\section{Authors' contributions}

FJST and SH conceived the study. SH, JMGA and RJGH supervised the study. SB, FJST and $\mathrm{SH}$ designed the search strategies. FJST and SB implemented the search strategies and $\mathrm{BH}$ assessed the process and quality of the search. FJST, SB and BH extracted and synthesised the data. SH, JMGA and RJGH assessed the process and quality of data extraction and synthesis. FJST, BH, SH, JMGA and RJGH were involved in drafting the manuscript. All authors edited the manuscript and have read and approved the final manuscript.

\section{Acknowledgments}

We are grateful to Tannys Helfer, from Bern University of Applied Sciences, Bern, Switzerland, for her linguistical support. 


\section{References}

1. Center for Disease Control and Prevention. Healthy places terminology: Aging in place. 2013 [cited 2019 5/4]; Available from: https://www.cdc.gov/healthyplaces/terminology.htm.

2. BFS. Gehvermögen und Stürze. 201309 Dec 2016]; Available from: http://www.bfs.admin.ch/bfs/portal/ de/index/themen/14/02/01/key/07/05.html.

3. Meyer, K., Gesundheit in der Schweiz - Nationaler Gesundheitsbericht 2008. 2009, Bern: Hans Huber.

4. WHO WHO Global Report on Fall Prevention in Older Age. 2007.

5. Lamb, S.E., et al., Development of a common outcome data set for fall injury prevention trials: the Prevention of Falls Network Europe consensus. J Am Geriatr Soc, 2005. 53(9): p. 1618-22.

6. Centers for Disease Control and Prevention. Falls Among Older Adults: An Overview. 201220.09 .201209 Dec 2016]; Available from: http://www.cdc.gov/homeandrecreationalsafety/falls/adultfalls.html.

7. Hanley, A., C. Silke, and J. Murphy, Community-based health efforts for the prevention of falls in the elderly. Clin Interv Aging, 2011. 6: p. 19-25.

8. Gründler, B.M., Sturzprävention für Senioren und Seniorinnen. Die rolle des Hüftprotektors in der SturzFraktur-Prävention. 2006, Schweizerische Beratungsstelle für Unfallverhützung bfu: Bern.

9. Hester, A.L. and F. Wei, Falls in the community: state of the science. Clin Interv Aging, 2013. 8: p. 675-9.

10. Stenhagen, M., et al., Accidental falls, health-related quality of life and life satisfaction: a prospective study of the general elderly population. Arch Gerontol Geriatr, 2014. 58(1): p. 95-100.

11. Tuunainen, E., et al., Risk factors of falls in community dwelling active elderly. Auris Nasus Larynx, 2014. 41(1): p. 10-6.

12. Sartini, M., et al., The epidemiology of domestic injurious falls in a community dwelling elderly population: an outgrowing economic burden. Eur J Public Health, 2010. 20(5): p. 604-6.

13. Scuffham, P., S. Chaplin, and R. Legood, Incidence and costs of unintentional falls in older people in the United Kingdom. J Epidemiol Community Health, 2003. 57(9): p. 740-4.

14. Maastricht, L., Instruktionsmaterial und Begleitdokumente LPZ, Messzyklus 2011. 2011.

15. Canadian Institute for Health Information National Trauma Registry 2011 Report: Hospitalizations for Major Injury in Canada, 2008-2009 Data. 2011.

16. Department of Health National Service Framework for Older People. 2001.

17. Todd, C. and D. Skelton What are the main risk factors for falls amongst older people and what are the most effective interventions to prevent these falls? 2004.

18. Rubenstein, L.Z., Falls in older people: epidemiology, risk factors and strategies for prevention. Age Ageing, 2006. 35 Suppl 2: p. ii37-ii41.

19. Fleming, J. and C. Brayne, Inability to get up after falling, subsequent time on floor, and summoning help: prospective cohort study in people over 90. BMJ, 2008. 337: p. a2227.

20. Lord, S.R., C. Sherrington, and H.B. Menz, Falls in oder people. Risk, factors and strategies for prevention. 2001, Cambridge: Cambridge University Press.

21. Tinetti, M.E., W.L. Liu, and E.B. Claus, Predictors and prognosis of inability to get up after falls among elderly persons. JAMA, 1993. 269(1): p. 65-70.

22. Simpson, P.M., et al., Epidemiology of emergency medical service responses to older people who have fallen: a prospective cohort study. Prehosp Emerg Care, 2014. 18(2): p. 185-94.

23. Ryynanen, O.P., et al., Falls and lying helpless in the elderly. Z Gerontol, 1992. 25(4): p. $278-82$.

24. Vellas, B., et al., Prospective study of restriction of activity in old people after falls. Age Ageing, 1987. 16(3): p. 189-93.

25. Igual, R., C. Medrano, and I. Plaza, Challenges, issues and trends in fall detection systems. Biomed Eng Online, 2013. 12: p. 66.

26. Chaudhuri, S., H. Thompson, and G. Demiris, Fall Detection Devices and Their Use With Older Adults: A Systematic Review. J Geriatr Phys Ther, 2014. 
27. Ward, G., et al., Fall detectors: a review of literature. Journal of Assistive Technologies, 2012. 6(3): p. 202215.

28. Johnston, K., K. Grimmer-Somers, and M. Sutherland, Perspectives on use of personal alarms by older fallers. Int J Gen Med, 2010. 3: p. 231-7.

29. Johnston, K., et al., Personal alarm use to call the ambulance after a fall in older people: characteristics of clients and falls. Journal of Emergency Primary Health Care (JEPHC), 2010. 8(4): p. 1-9.

30. Heinbuchner, B., et al., Satisfaction and use of personal emergency response systems. Z Gerontol Geriatr, 2010. 43.

31. Nyman, S.R. and C.R. Victor, Use of personal call alarms among community-dwelling older people. Ageing \& Society, 2014. 34(1): p. 67-89.

32. Zingaro, S. Nottelefone teils untauglich und überteuert. 2012.

33. Shah, S., I. Robinson, and S. AIShawi, Developing medical device technologies from users' perspectives: $A$ theoretical framework for involving users in the development process. International Journal of Technology Assessment in Health Care, 2009. 25(4): p. 514-521.

34. Bridgelal Ram, M., P. Grocott, and H. Weir, Issues and challenges of involving users in medical device development. Health Expect, 2007. 11: p. 63-71.

35. Rodeschini, G., Gerotechnology: a new kind of care for aging? An analysis of the relationship between older people and technology. Nurs Health Sci, 2011. 13(4): p. 521-8.

36. Gulliksen, J., et al., Key principles for user-centred systems design. Behaviour and Information Technology, 2003. 22(6): p. 397-409.

37. De Vito Dabbs, A., et al., User-centered design and interactive health technologies for patients. Comput Inform Nurs, 2009. 27(3): p. 175-83.

38. Shah, S.G. and I. Robinson, Benefits of and barriers to involving users in medical device technology development and evaluation. Int J Technol Assess Health Care, 2007. 23(1): p. 131-7.

39. Kujala, S., User involvement: a review of the benefits and challenges. Behaviour \& Information Technology, 2003. 22(1): p. 1-16.

40. Schwickert, L., et al., Fall detection with body-worn sensors A systematic review. Zeitschrift fuer Gerontologie und Geriatrie, 2013. 46(8): p. 706-719.

41. Hawley-Hague, H., et al., Older adults' perceptions of technologies aimed at falls prevention, detection or monitoring: A systematic review. International Journal of Medical Informatics, 2014. 83(6): p. 416-426.

42. Levac, D., H. Colquhoun, and K.K. O'Brien, Scoping studies: advancing the methodology. Implementation Science, 2010. 5.

43. Arksey, H. and L. O'Malley, Scoping studies: towards a methodological framework. International Journal of Social Research Methodology, 2005. 8(1): p. 19-32.

44. Pham, M.T., et al., A scoping review of scoping reviews: advancing the approach and enhancing the consistency. Health Expect, 2014. 5(4): p. 371-385.

45. Moher, D., et al., Preferred reporting items for systematic reviews and meta-analyses: the PRISMA statement. J Clin Epidemiol, 2009. 62(10): p. 1006-12.

46. Dixon-Woods, M., et al., Synthesising qualitative and quantitative evidence: a review of possible methods. J Health Serv Res Policy, 2005. 10(1): p. 45-53.

47. Abbate, S., et al., A smartphone-based fall detection system. Pervasive and Mobile Computing, 2012. 8(6): p. 883-899.

48. Ariani, A., et al., Simulated unobtrusive falls detection with multiple persons. IEEE Transactions on Biomedical Engineering, 2012. 59(12 PART2): p. 3185-3196.

49. Barralon, P., I. Dorronsoro, and E. Hernandez, Automatic fall detection: Complementary devices for a better fall monitoring coverage. 2013 IEEE 15th International Conference on e-Health Networking, Applications and Services (Healthcom 2013), 2013: p. 590-593.

50. Bloch, F., et al., Evaluation under real-life conditions of a stand-alone fall detector for the elderly subjects. Ann Phys Rehabil Med, 2011. 54(6): p. 391-8.

51. Bourke, A.K. and G.M. Lyons, A threshold-based fall-detection algorithm using a bi-axial gyroscope sensor. Medical Engineering and Physics, 2008. 30(1): p. 84-90. 
52. Bourke, A.K., J.V. O'Brien, and G.M. Lyons, Evaluation of a threshold-based tri-axial accelerometer fall detection algorithm. Gait \& Posture, 2007. 26(2): p. 194-199.

53. Bourke, A.K., et al. Embedded fall and activity monitoring for a wearable ambient assisted living solution for older adults. in Engineering in Medicine and Biology Society (EMBC), 2012 Annual International Conference of the IEEE. 2012.

54. Bourke, A.K., et al. Assessment of waist-worn tri-axial accelerometer based fall-detection algorithms using continuous unsupervised activities. in 2010 32nd Annual International Conference of the IEEE Engineering in Medicine and Biology Society, EMBC'10. 2010. Buenos Aires.

55. Bourke, A.K., et al. Design and test of a long-term fall detection system incorporated into a custom vest for the elderly. in IET Irish Signals and Systems Conference, ISSC 2008. 2008. Galway.

56. Bourke, A.K., et al. Testing of a long-term fall detection system incorporated into a custom vest for the elderly. in 30th Annual International Conference of the IEEE Engineering in Medicine and Biology Society, EMBS'08. 2008. Vancouver, BC.

57. Bourke, A.K., et al. Applications of waist segment kinematic measurement using accelerometry for an autonomous fall-detection system during continuous activities. in IET Irish Signals and Systems Conference, ISSC 2010. 2010. Cork.

58. Bourke, A.K., et al., Evaluation of waist-mounted tri-axial accelerometer based fall-detection algorithms during scripted and continuous unscripted activities. J Biomech, 2010. 43(15): p. 3051-7.

59. Boyle, J. and M. Karunanithi. Simulated fall detection via accelerometers. in 30th Annual International Conference of the IEEE Engineering in Medicine and Biology Society, EMBS'08. 2008. Vancouver, BC.

60. Campo, E., et al., Remote tracking patients in retirement home using wireless multisensor system. 2010 12th IEEE International Conference on e-Health Networking, Applications and Services (Healthcom 2010), 2010: p. 226-230.

61. Che-Chang, Y. and H. Yeh-Liang. Algorithm Design for Real-time Physical Activity Identification with Accelerometry Measurement. in Industrial Electronics Society, 2007. IECON 2007. 33rd Annual Conference of the IEEE. 2007.

62. De La Guia Solaz, M., et al. Real-time low-energy fall detection algorithm with a Programmable Truncated $M A C$. in 2010 32nd Annual International Conference of the IEEE Engineering in Medicine and Biology Society, $E M B C^{\prime} 10.2010$. Buenos Aires.

63. Demiris, G., et al., Older adults' attitudes towards and perceptions of 'smart home' technologies: a pilot study. Medical Informatics and the Internet in Medicine, 2004. 29(2): p. 87-94.

64. Fourty, N., et al., Embedded system used for classifying motor activities of elderly and disabled people. Computers and Industrial Engineering, 2009. 57(1): p. 419-432.

65. Gietzelt, M., et al., GAL@Home A feasibility study of sensor-based in-home fall detection. Zeitschrift fuer Gerontologie und Geriatrie, 2012. 45(8): p. 716-721.

66. Goevercin, M., et al., Defining the user requirements for wearable and optical fall prediction and fall detection devices for home use. Informatics for Health \& Social Care, 2010. 35(3-4): p. 177-187.

67. Holzinger, A., et al., Perceived usefulness among elderly people: Experiences and lessons learned during the evaluation of a wrist device. 2010 4th International Conference on Pervasive Computing Technologies for Healthcare (Pervasive Health 2010), 2010: p. 5 pp.-5 pp.

68. Horton, K., Falls in older people: The place of telemonitoring in rehabilitation. Journal of Rehabilitation Research and Development, 2008. 45(8): p. 1183-1194.

69. Huang, C.N., et al., Accelerometry-based motion pattern analysis for reliable fall detection. Advanced Science Letters, 2012. 9: p. 412-416.

70. Jantaraprim, P., et al., A system for improving fall detection performance using critical phase fall signal and a neural network. Songklanakarin Journal of Science and Technology, 2012. 34(6): p. 637-644.

71. John, S.G., et al. Utilisation of telemedicine to assess energy expenditure and stability in older people with chronic kidney disease. in Computers in Cardiology, 2008. 2008.

72. Kangas, M., et al., Comparison of real-life accidental falls in older people with experimental falls in middleaged test subjects. Gait \& Posture, 2012. 35(3): p. 500-505.

73. Kangas, M., et al., Sensitivity and specificity of fall detection in people aged 40 years and over. Gait Posture, 2009. 29(4): p. 571-4. 
74. Kerdegari, H., et al., Evaluation of fall detection classification approaches. Proceedings of the 20124 th International Conference on Intelligent \& Advanced Systems (ICIAS), 2012: p. 131-136.

75. Lai, C.F., et al., Adaptive Body Posture Analysis for Elderly-Falling Detection with Multisensors. leee Intelligent Systems, 2010. 25(2): p. 20-30.

76. Lai, C.-F., et al., Detection of Cognitive Injured Body Region Using Multiple Triaxial Accelerometers for Elderly Falling. Sensors Journal, IEEE, 2011. 11(3): p. 763-770.

77. Lindemann, U., et al., Evaluation of a fall detector based on accelerometers: A pilot study. Medical and Biological Engineering and Computing, 2005. 43(5): p. 548-551.

78. Liu, J. and T.E. Lockhart, Automatic individual calibration in fall detection an integrative ambulatory measurement framework. Computer Methods in Biomechanics and Biomedical Engineering, 2013. 16(5): p. 504-510.

79. Londei, S.T., et al., An intelligent videomonitoring system for fall detection at home: perceptions of elderly people. Journal of Telemedicine and Telecare, 2009. 15(8): p. 383-390.

80. Marquis-Faulkes*, F., et al., Gathering the requirements for a fall monitor using drama and video with older people. Technology and Disability, 2005. 17: p. 227-236.

81. McKenna, S.J., et al., Requirements gathering using drama for computer vision-based monitoring in supportive home environments. Gerontechnology, 2006. 5(1): p. 29-45.

82. Miao, Y., et al., An online one class support vector machine-based person-specific fall detection system for monitoring an elderly individual in a room environment. IEEE Journal of Biomedical and Health Informatics, 2013. 17(6): p. 1002-1014.

83. Narasimhan, R., Skin-contact sensor for automatic fall detection. Conf Proc IEEE Eng Med Biol Soc, 2012. 2012: p. 4038-41.

84. Parker, S., et al., ENABLE - A view on user's needs, in 11th International Conference on Computers Helping People with Special Needs, ICCHP 2008. 2008: Linz. p. 1016-1023.

85. Quagliarella, L., N. Sasanelli, and G. Belgiovine, An interactive fall and loss of consciousness detector system. Gait \& Posture, 2008. 28(4): p. 699-702.

86. Quagliarella, L., N. Sasanelli, and G. Belgiovine, Performances of an accelerometric device for detecting fall and loss of consciousness. Journal of Applied Biomaterials \& Biomechanics, 2008. 6(2): p. 119-126.

87. Rantz, M.J., et al., In-Home Fall Risk Assessment and Detection Sensor System. Journal of Gerontological Nursing, 2013. 39(7): p. 18-22.

88. Sixsmith, A. and N. Johnson, A smart sensor to detect the falls of the elderly. leee Pervasive Computing, 2004. 3(2): p. 42-47.

89. Shinmoto Torres, R.L., et al. Sensor enabled wearable RFID technology for mitigating the risk of falls near beds. in RFID (RFID), 2013 IEEE International Conference on. 2013.

90. Soaz, C., C. Lederer, and M. Daumer. A new method to estimate the real upper limit of the false alarm rate in a 3 accelerometry-based fall detector for the elderly. in 34th Annual International Conference of the IEEE Engineering in Medicine and Biology Society, EMBS 2012. 2012. San Diego, CA.

91. Stone, E. and M. Skubic, Fall Detection in Homes of Older Adults Using the Microsoft Kinect. Biomedical and Health Informatics, IEEE Journal of, 2014. PP(99): p. 1-1.

92. Tamrat, T., et al., Operationalizing a wireless wearable fall detection sensor for older adults. 2012 6th International Conference on Pervasive Computing Technologies for Healthcare, 2012: p. 297-302.

93. van de Ven, P., et al., A wireless platform for fall and mobility monitoring. IET Irish Signals and Systems Conference. ISSC 2008, 2008: p. 319-324.

94. van de Ven, P., et al., An integrated fall and mobility sensor and wireless health signs monitoring system. 2008 IEEE Sensors, 2008: p. 625-628.

95. Wang, J., et al., An enhanced fall detection system for elderly person monitoring using consumer home networks. Consumer Electronics, IEEE Transactions on, 2014. 60(1): p. 23-29.

96. Wu, G. and S. Xue. Automatic fall detection based on kinematic characteristics during the pre-impact phase of falls. in 6th World Congress of Biomechanics, WCB 2010 - In Conjunction with 14th International Conference on Biomedical Engineering, ICBME and 5th Asia Pacific Conference on Biomechanics, APBiomech. 2010. Singapore. 
97. Wu, G. and S.W. Xue, Portable preimpact fall detector with inertial sensors. leee Transactions on Neural Systems and Rehabilitation Engineering, 2008. 16(2): p. 178-183.

98. Zhang, T., et al., Fall detection by wearable sensor and one-class SVM algorithm, in Lecture Notes in Control and Information Sciences, D.S. Huang, K. Li, and G.W. Irwin, Editors. 2006. p. 858-863.

99. Godfrey, A., et al., Activity classification using a single chest mounted tri-axial accelerometer. Medical Engineering \& Physics, 2011. 33(9): p. 1127-1135.

100. Grigsby, J.S., The meaning of heterogeneity: An introduction. Gerontologist, 1996. 36(2): p. 145-146.

101. Kim, J. and H.A. Park, Development of a Health Information Technology Acceptance Model Using Consumers' Health Behavior Intention. Journal of Medical Internet Research, 2012. 14(5).

102. Chen, K. and A. Chan, Use or Non-Use of Gerontechnology-A Qualitative Study. International Journal of Environmental Research and Public Health, 2013. 10(10): p. 4645-4666.

103. Shah, S. and I. Robinson, Medical device technologies: who is the user. Int. J. Healthcare Technology and Management, 2008. 9(2): p. 181-197.

104. Kaufman, D.R., et al., Usability in the real world: assessing medical information technologies in patients' homes. J Biomed Inform, 2003. 36(1-2): p. 45-60.

105. Klenk, J., et al., Comparison of acceleration signals of simulated and real-world backward falls. Medical Engineering and Physics, 2011. 33(3): p. 368-373.

106. Kangas, M., et al., Sensitivity and False Alarm Rate of a Fall Sensor in Long-Term Fall Detection in the Elderly. Gerontology, 2015. 61.

107. Kujala, S., Effective user involvement in product development by improving the analysis of user needs. Behaviour \& Information Technology, 2008. 27(6): p. 457-473.

108. Damodaran, L., User involvement in the systems design process - A practical guide for users. Behaviour \& Information Technology, 1996. 15(6): p. 363-377.

109. Davis, K., N. Drey, and D. Gould, What are scoping studies? A review of the nursing literature. International Journal of Nursing Studies, 2009. 46(10): p. 1386-1400. 


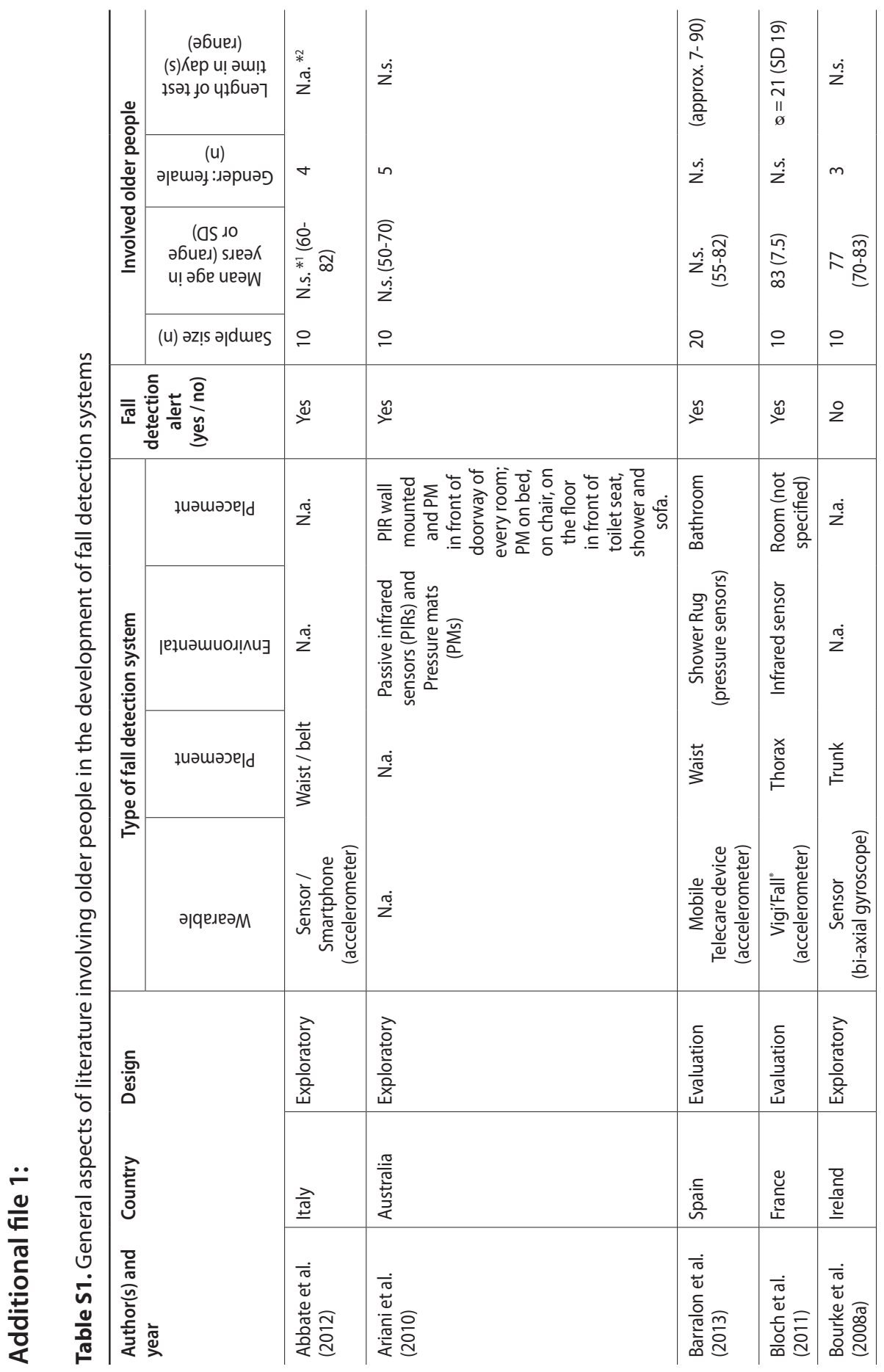




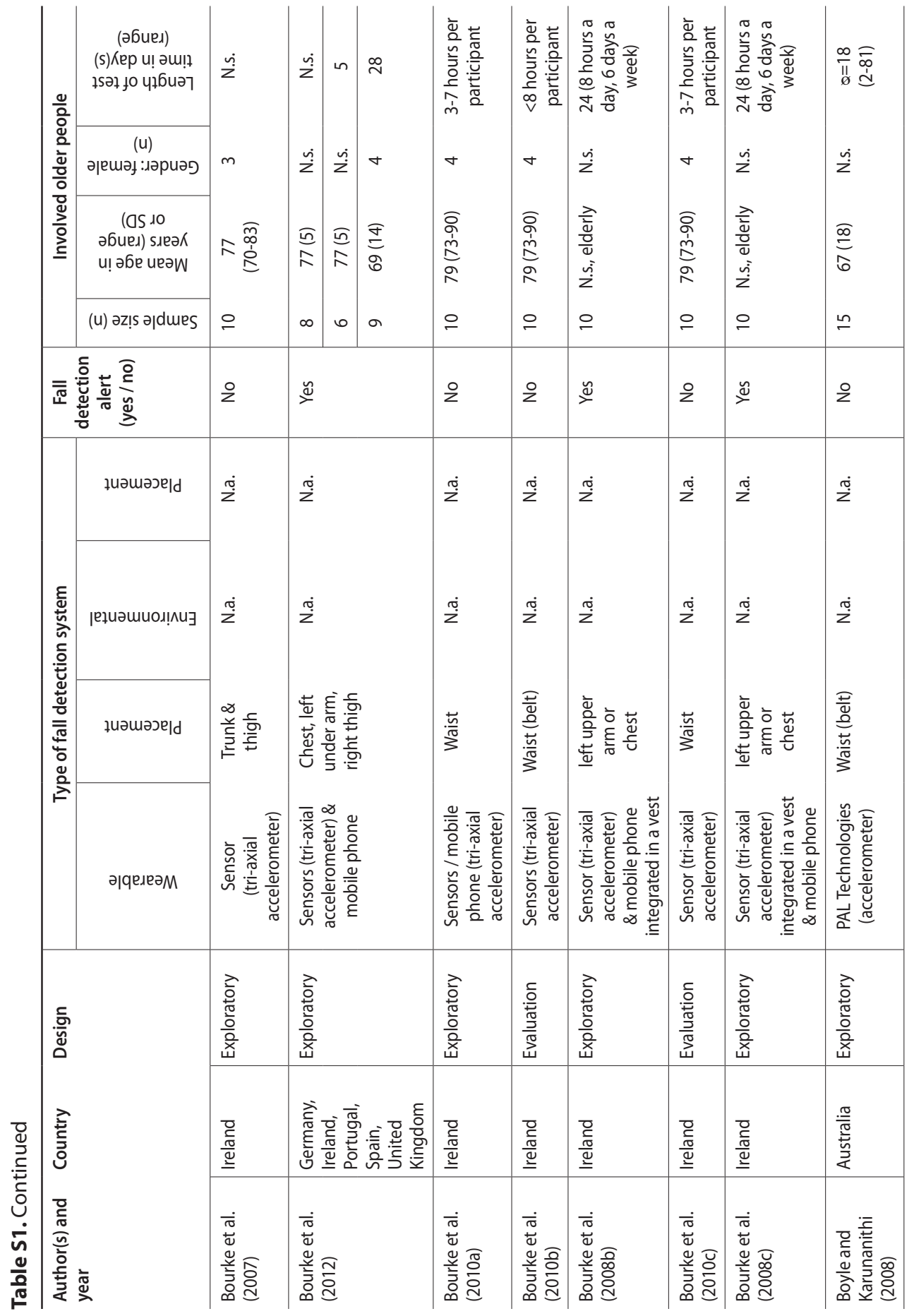




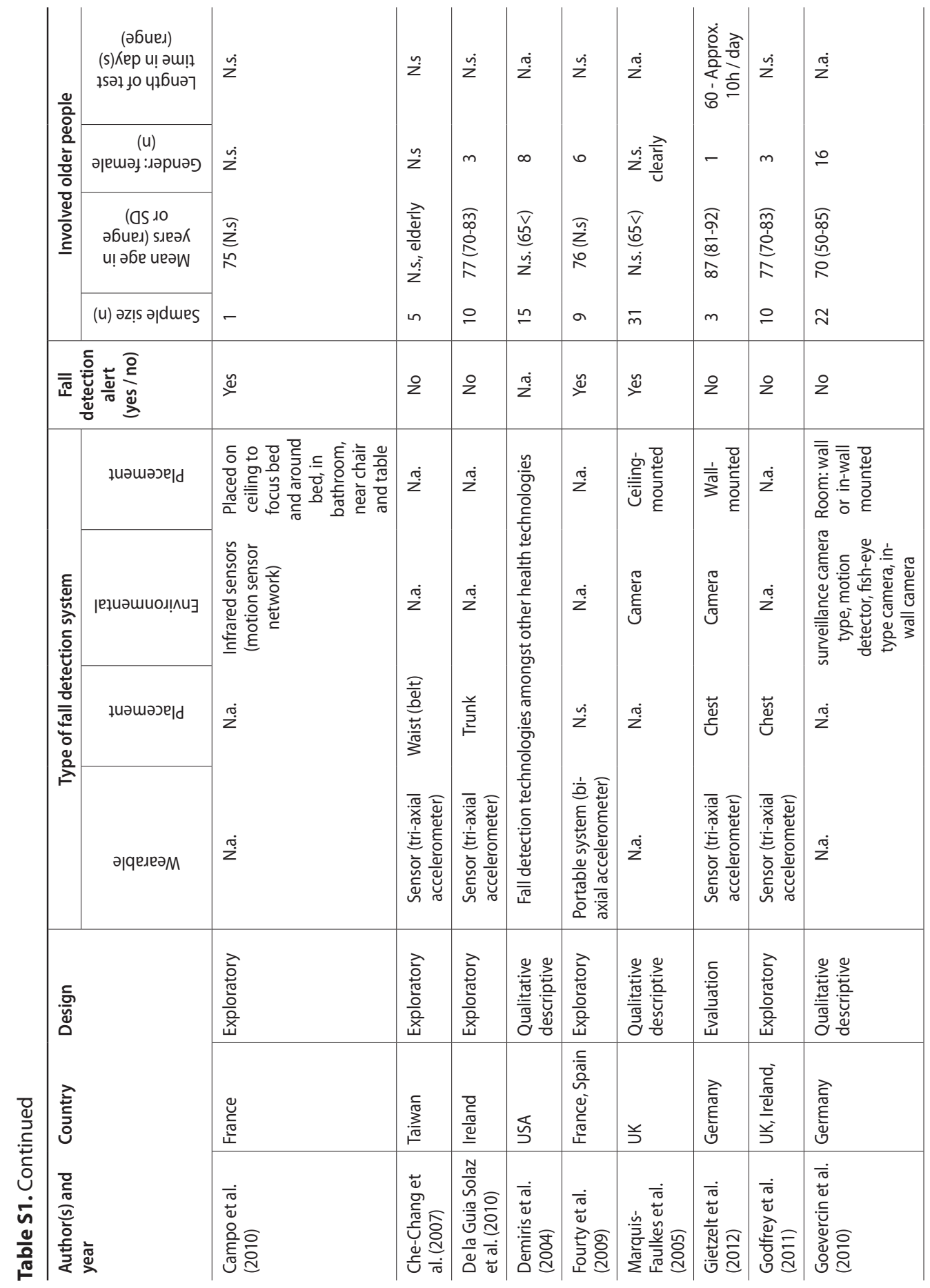




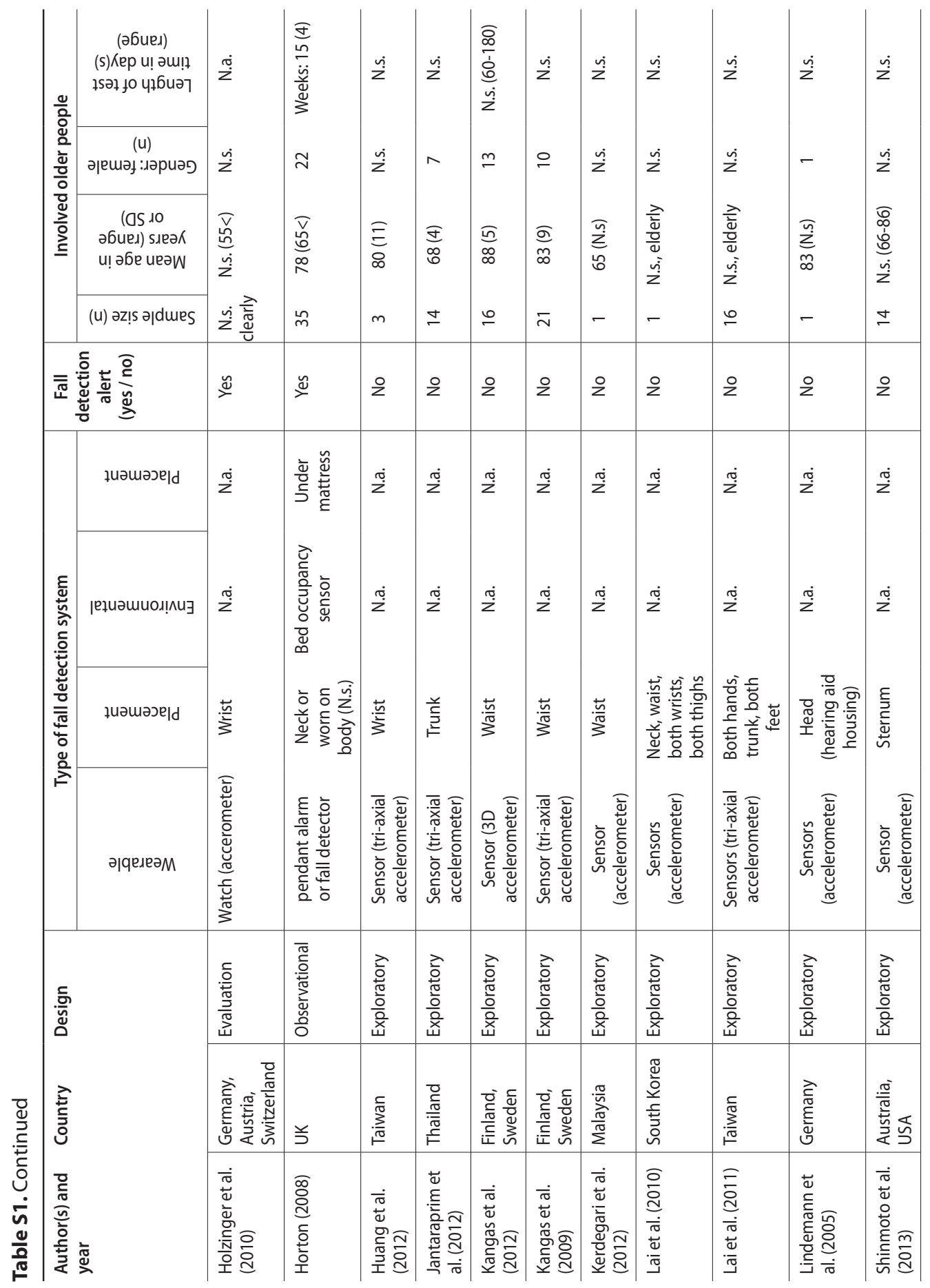




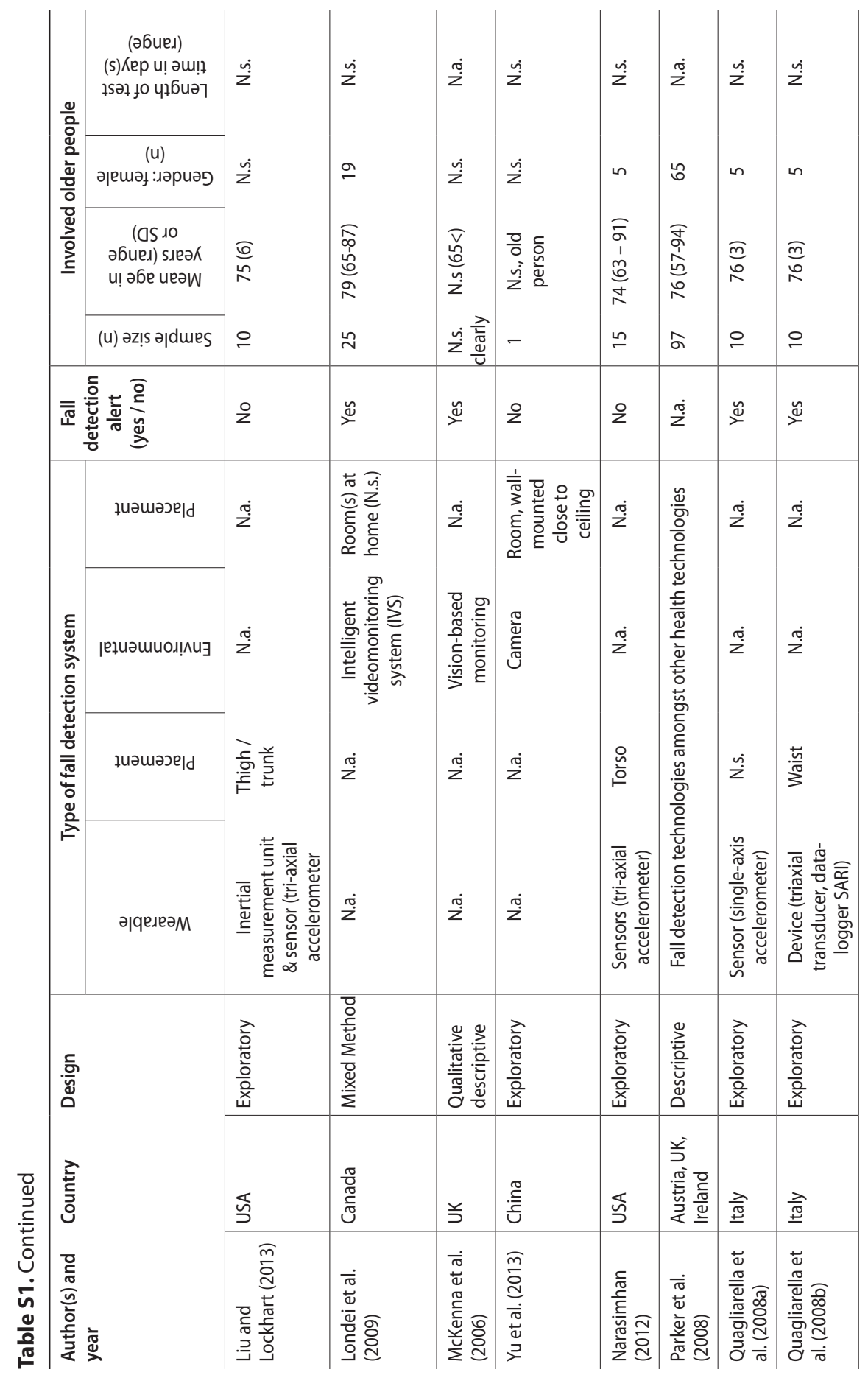




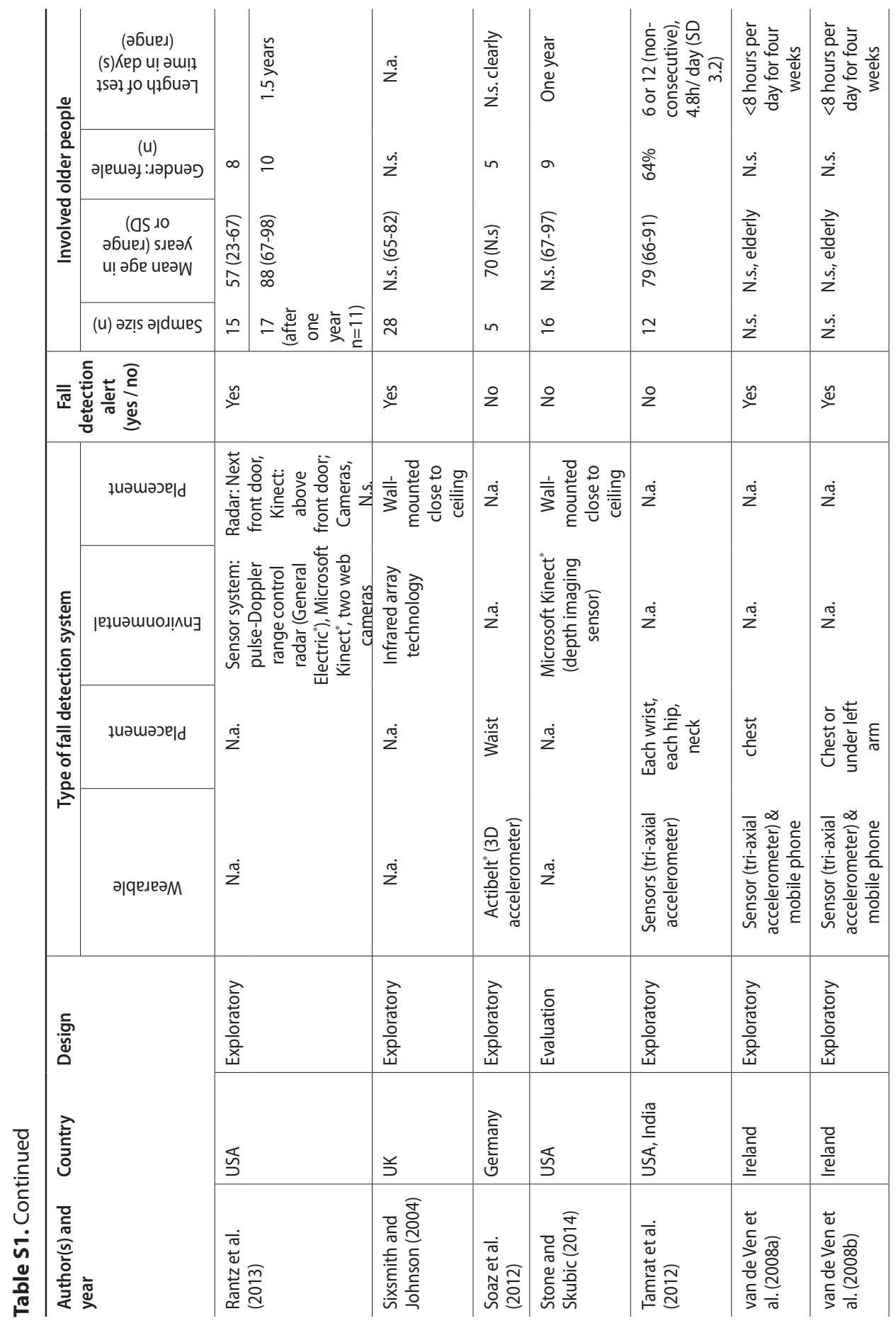




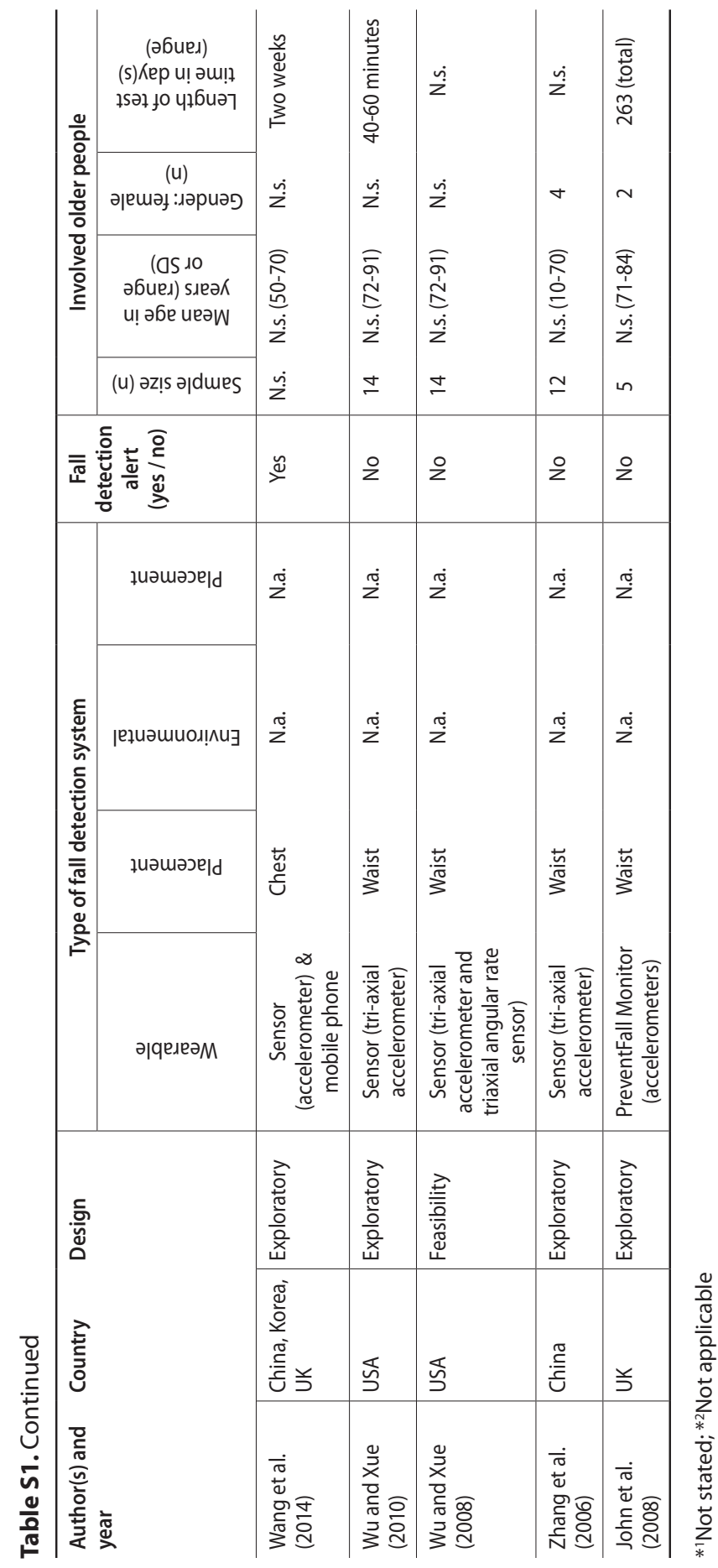




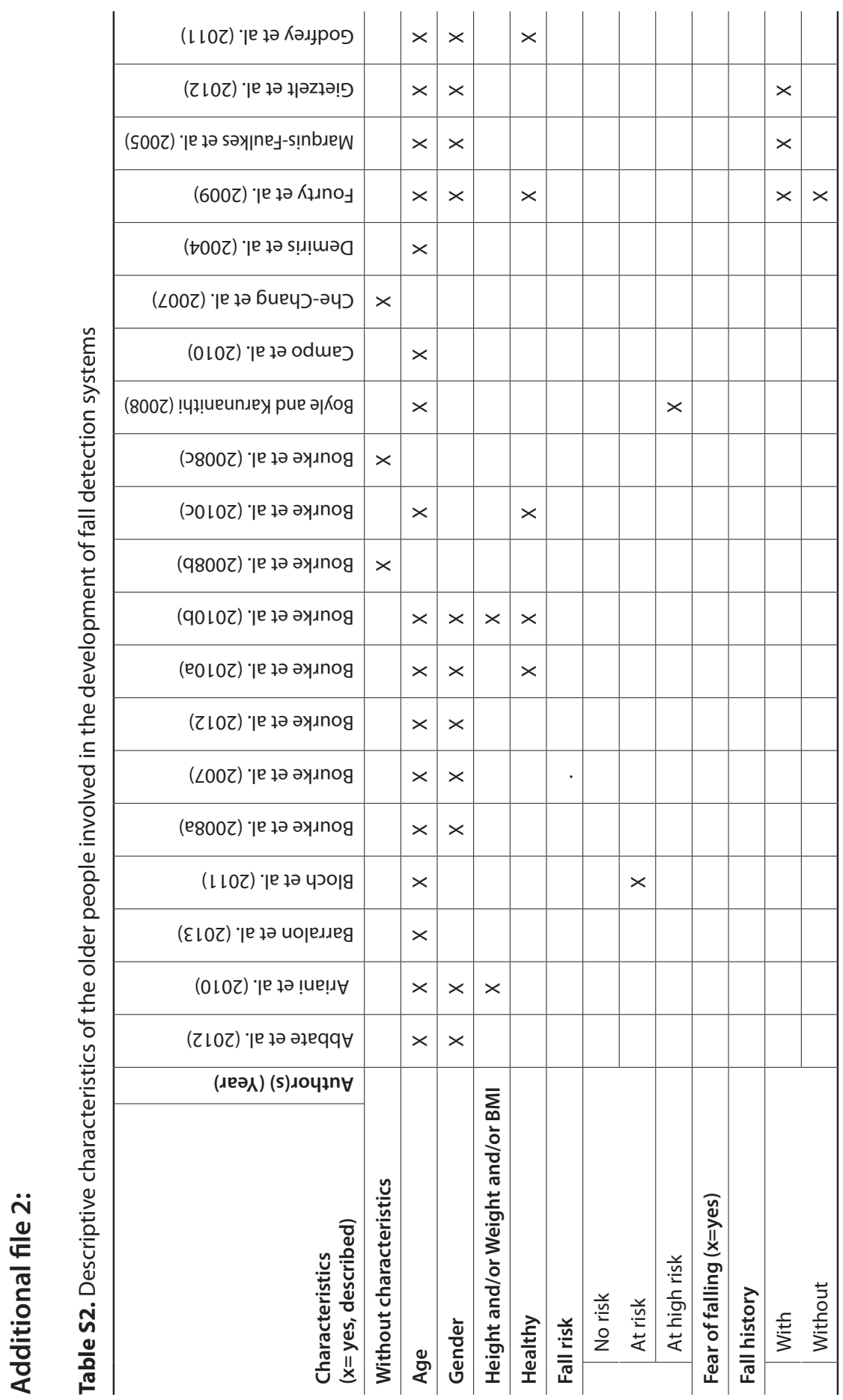




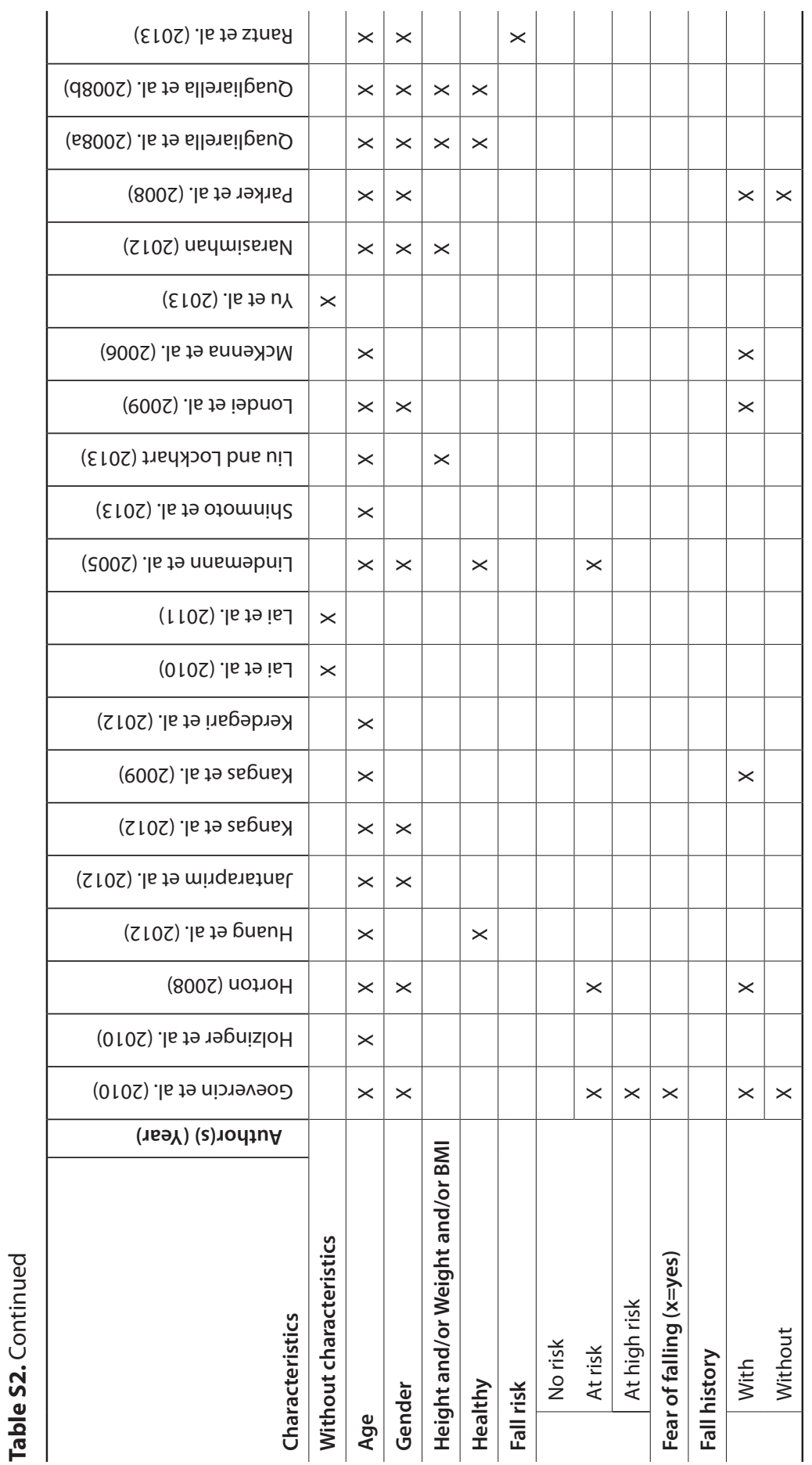




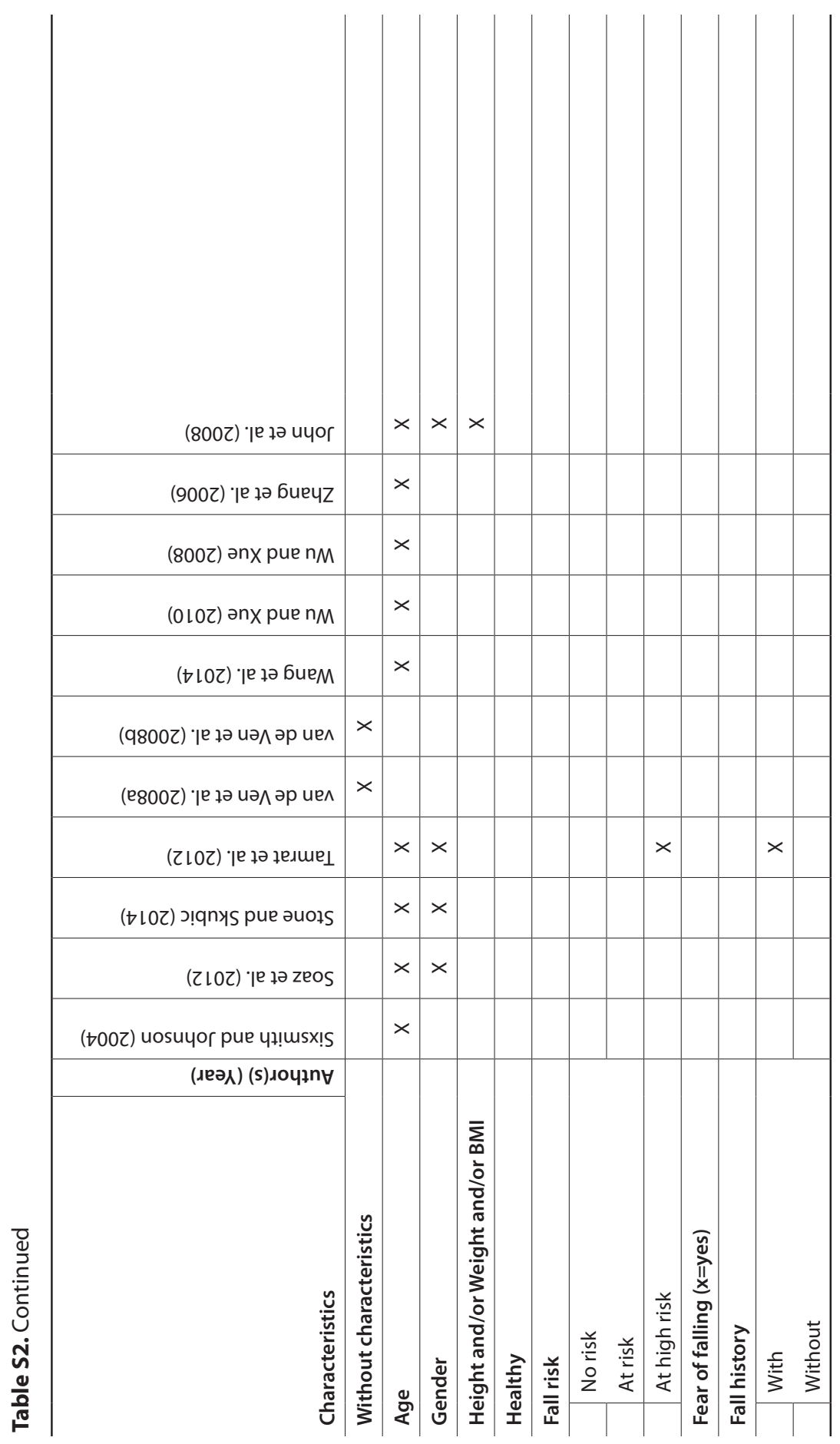




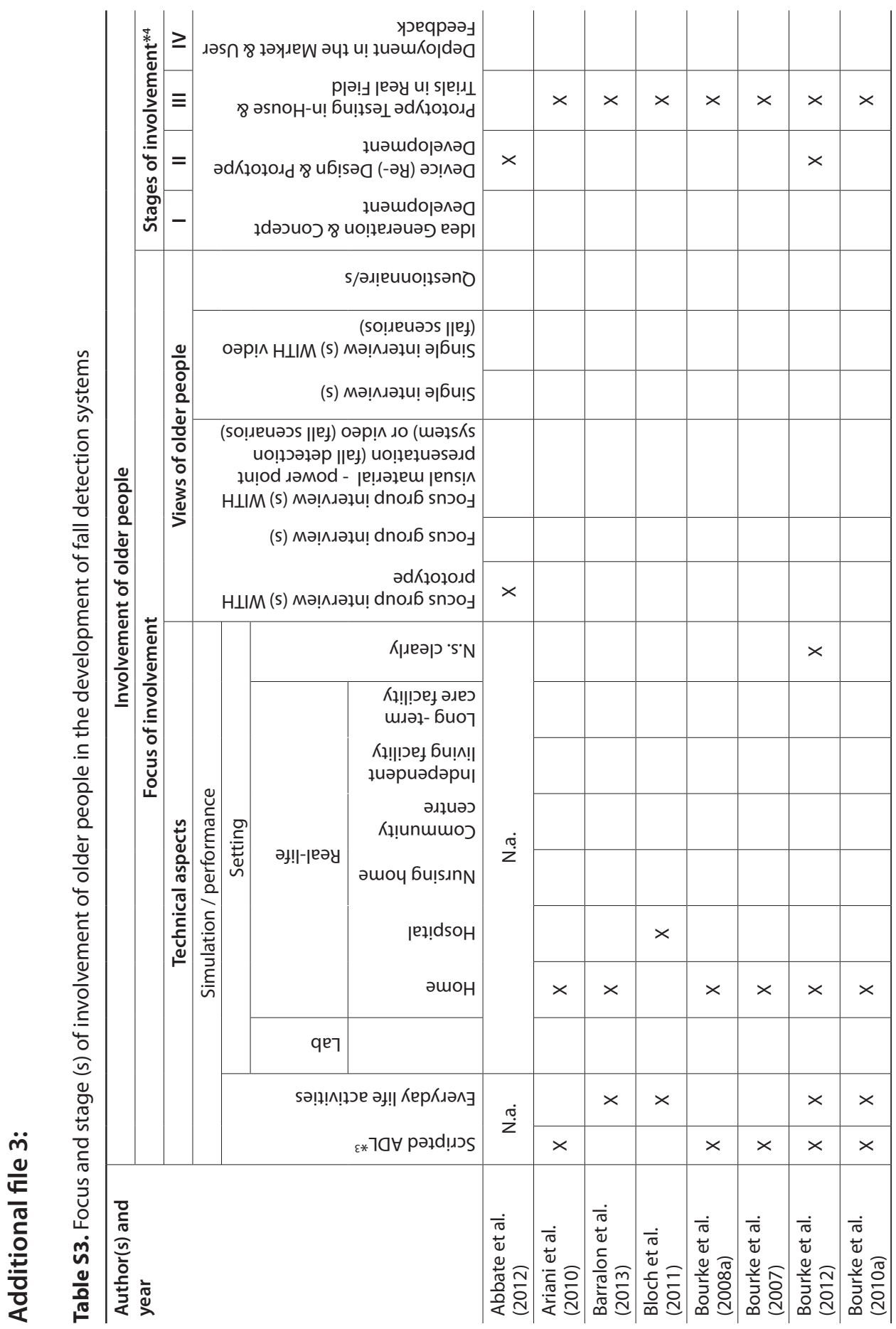




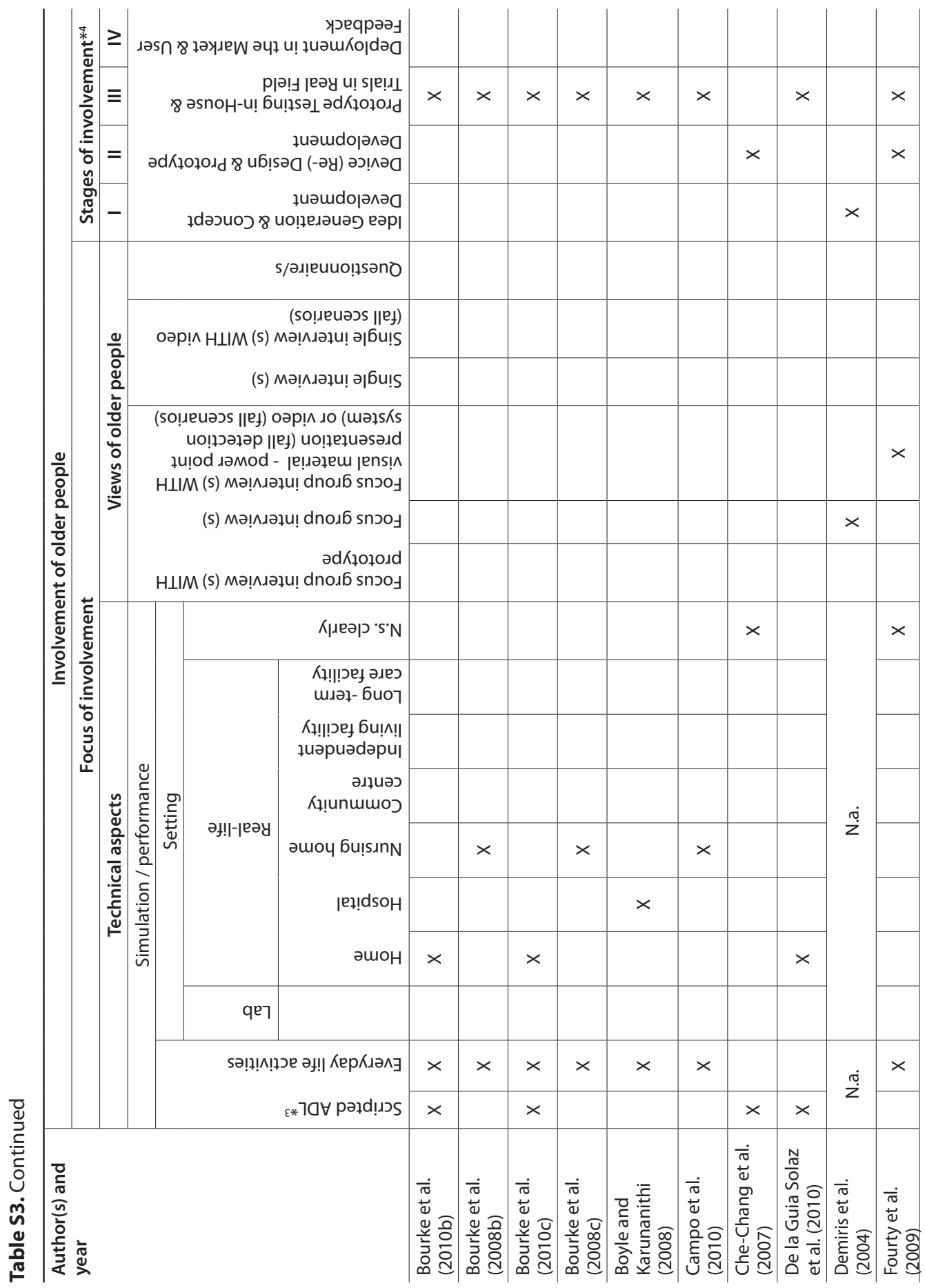




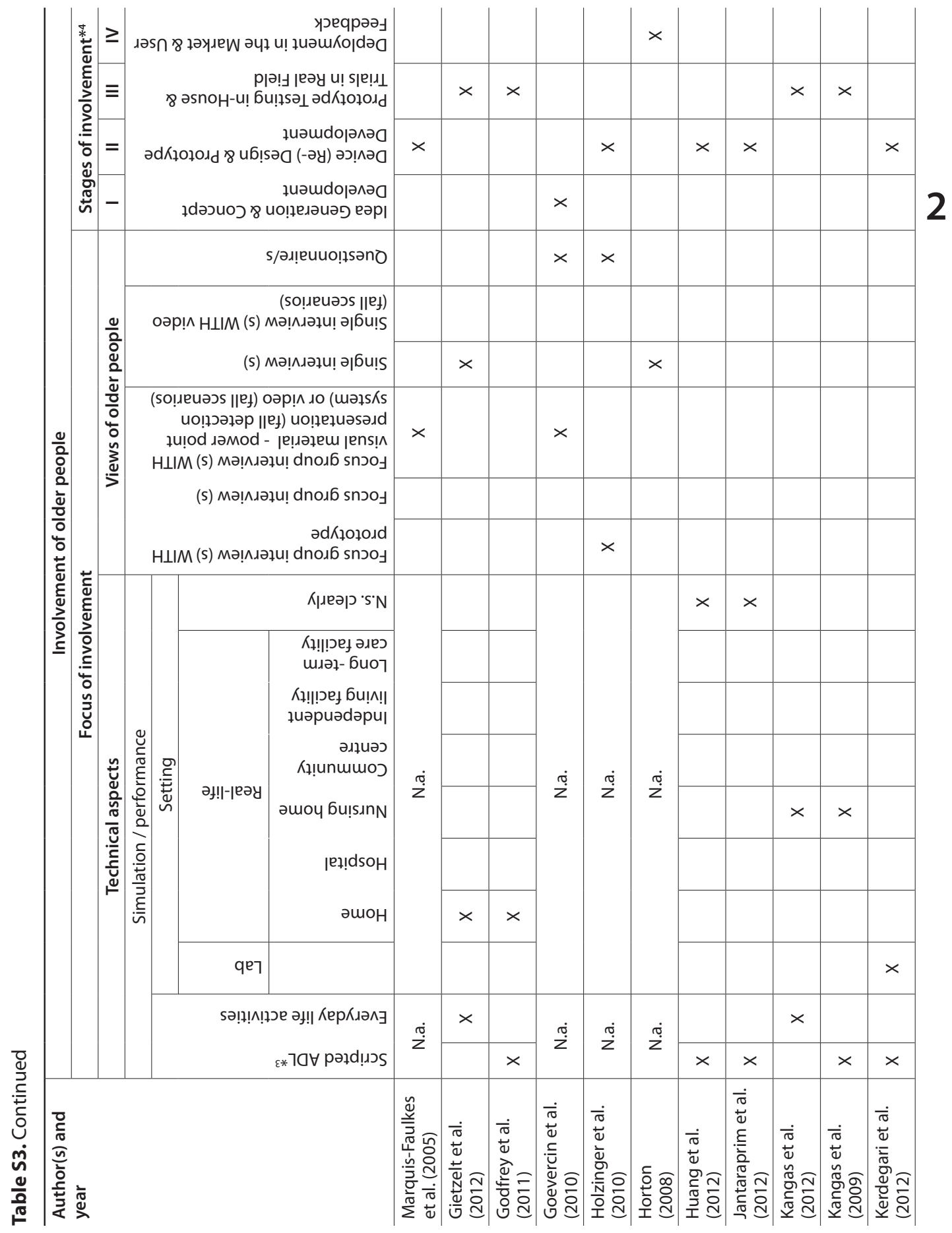


Table S3. Continued

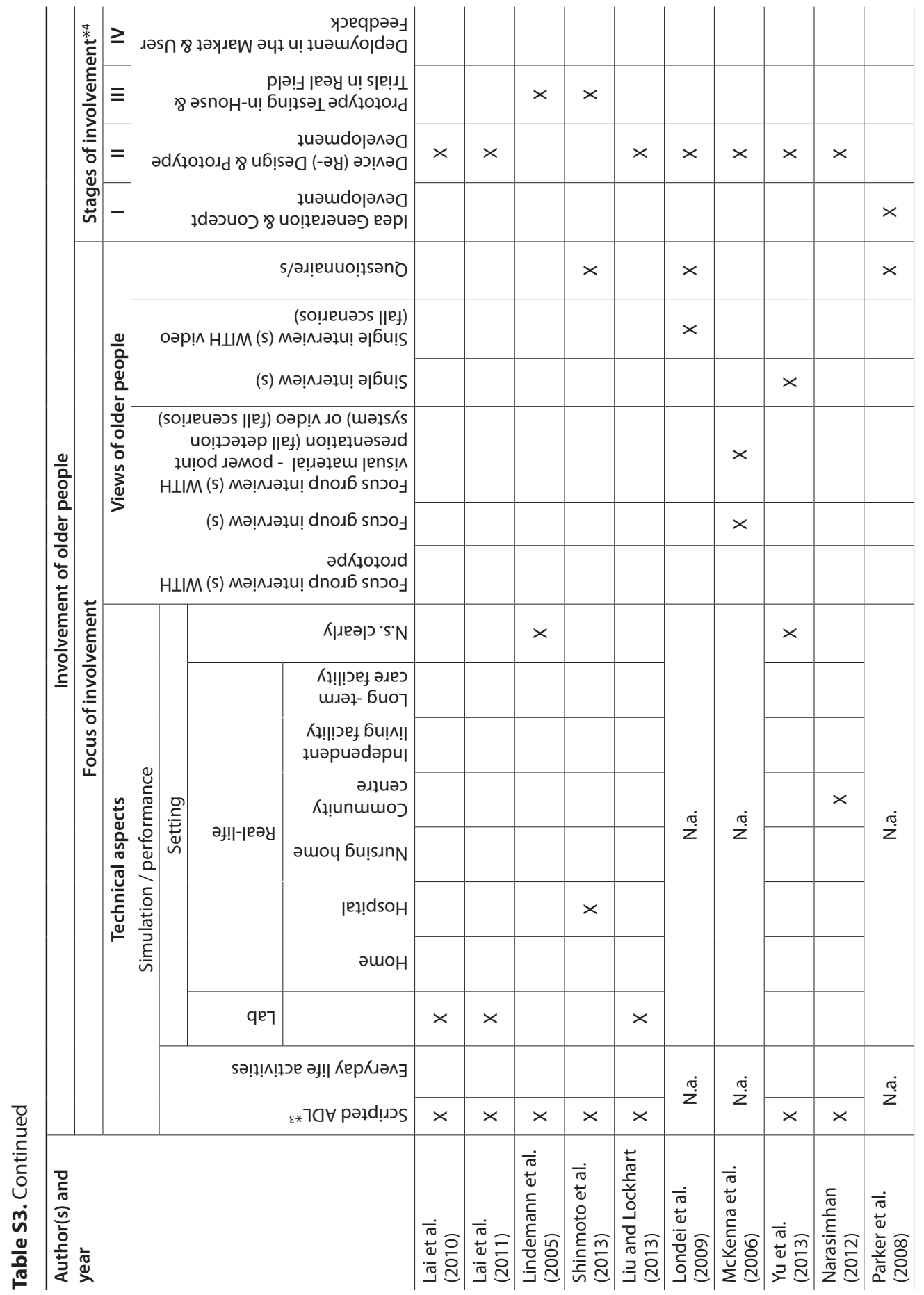


Table S3. Continued

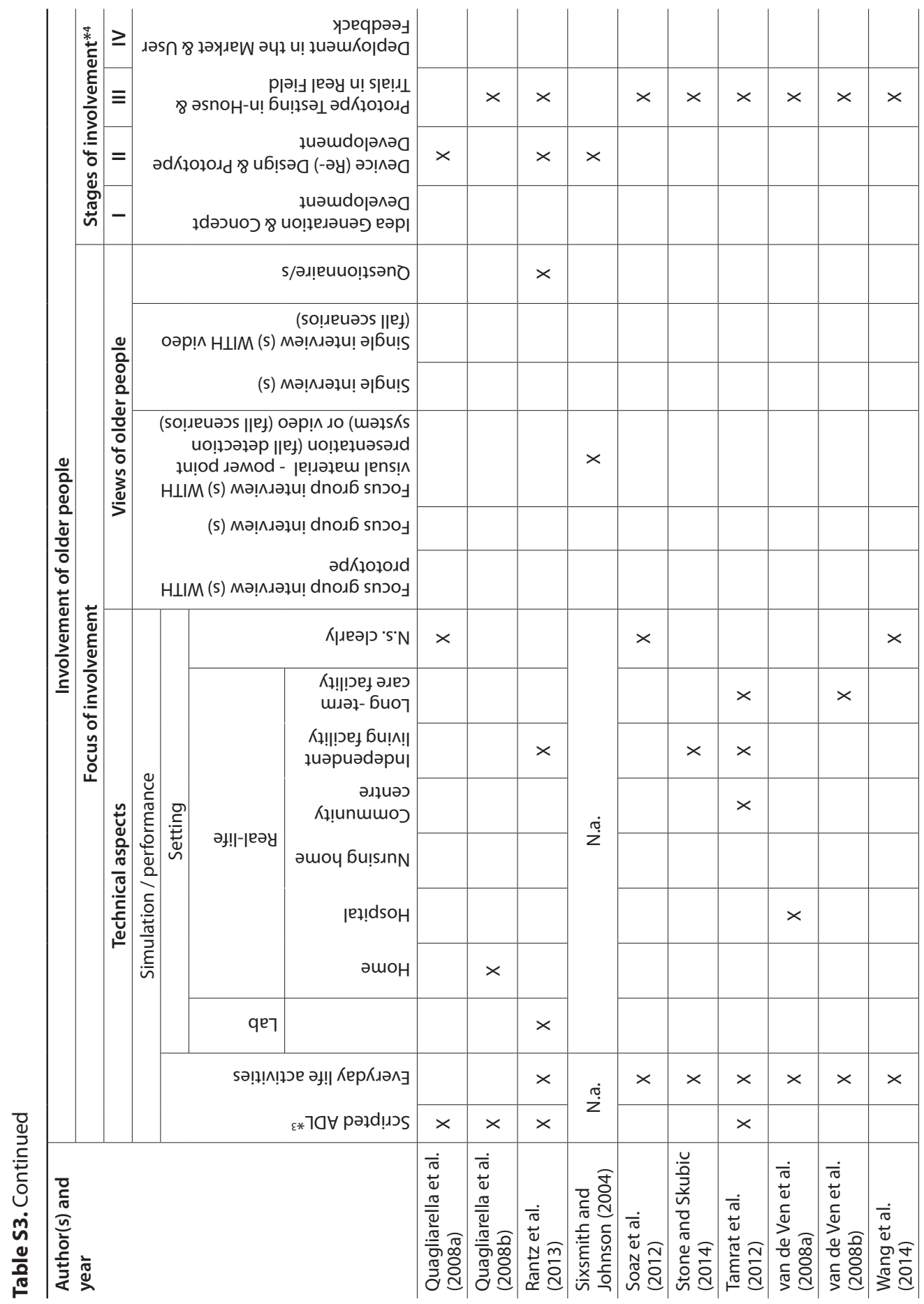




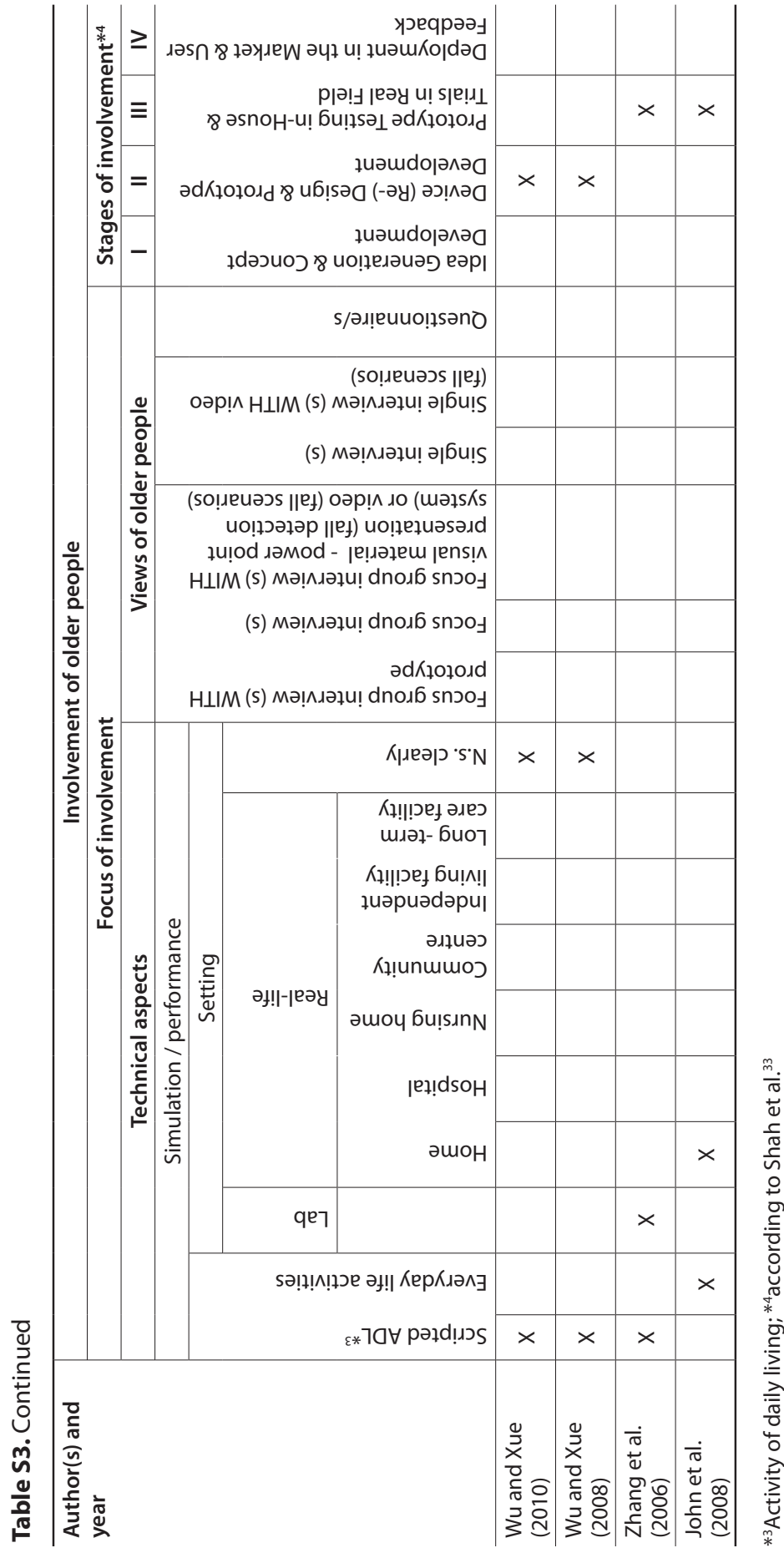



Chapter 3

Involvement of the end user: exploration of older people's needs and preferences for a wearable fall detection device - a qualitative descriptive study

This chapter was published as: Thilo, F.J.S., Bilger, S., Halfens, R.J.G., Schols, J.M.G.A., and Hahn, S. (2017). Involvement of the end user: exploration of older people's needs and preferences for a wearable fall detection device - a qualitative descriptive study.

Patient Preference and Adherence, 11, 11-22. doi:10.2147/PPA.S119177 


\section{Abstract}

Purpose: To explore the needs and preferences of community-dwelling older people, by involving them in the device design and mock-up development stage of a fall detection device, consisting of a body-worn sensor linked to a smartphone application.

Patients and methods: A total of 22 community-dwelling persons 75 years of age and older were involved in the development of a fall detection device. Three semi structured focus group interviews were conducted. The interview data were analysed using qualitative descriptive analysis with deductive coding.

Results: The mock-up of a waterproof, body-worn, automatic and manual alerting device, which served both as a day-time wearable sensor and a night-time wearable sensor, was welcomed. Changes should be considered regarding shape, colour and size along with alternate ways of integrating the sensor with items already in use in daily life, such as jewellery and personal watches. The reliability of the sensor is key for the participants. Issues important to the alerting process were discussed, for instance, who should be contacted and why. Several participants were concerned with the mandatory use of the smartphone and assumed that it would be difficult to use. They criticized the limited distance between the sensor and the smartphone for reliable fall detection, as it might restrict activity and negatively influence their degree of independence in daily life.

Conclusion: This study supports that involving end users in the design and mock-up development stage is welcomed by older people and allows their needs and preferences concerning the fall detection device to be explored. Based on these findings, the development of a "needs-driven" prototype is possible. As participants are doubtful regarding smartphone usage, careful training and support of community-dwelling older people during real field testing will be crucial. 


\section{Introduction}

Population ageing is a worldwide trend. ${ }^{1}$ The process of ageing is accompanied by increasing health concerns, which have economic repercussions on the health care systems, including higher costs linked to the treatment of chronic illness. ${ }^{2-4}$ The promotion of a self-determined and safe lifestyle for citizens is a part of recent political strategies., ${ }^{5,6}$ These strategies entail promoting active ageing in the home care setting ${ }^{7}$ and prioritizing living in the community instead of in long-term care facilities and are associated with lower costs. ${ }^{8}$ Living in the community is also the preference of older people. ${ }^{9}$

Experiencing a fall may, however, impede safe and active living. A fall is defined as "an unexpected event in which the participants come to rest on the ground, floor, or lower level" (p.1619). ${ }^{10} \mathrm{~A}$ fall is a serious health problem among the ageing population. In persons aged 65 years and older $25 \%-35 \%$ experience a fall once or more per year. ${ }^{11,}$ 12 The consequences of falls are well documented and involve a negative impact on mortality, morbidity and quality of life and hence on the health care costs for older people. ${ }^{13-19}$ Estimates suggest that in Europe, 25 billion euros per year are spent on the medical and social care related to fall injuries in older people (aged $\geq 65$ years). ${ }^{20}$ As a consequence of a fall, older people can experience psychological difficulties such as fear of falling, decreased self-efficacy, physical activity avoidance and self-restriction, all of which may negatively influence their ability to live at home. ${ }^{21,22}$

A critical factor affecting the severity of fall consequences in older people is the time spent lying on the floor/ground. ${ }^{23,24}$ Lying on the floor due to a fall event, particularly for $\geq 1$ hour, is associated with higher mortality rates and hospital admissions, serious injuries and consequent care home admissions..$^{23-25}$ This is why receiving prompt assistance after a fall is very important. A fall detection or alerting device may immediately alert designated individuals or emergency services. ${ }^{26,27}$ Therefore, the use of technology for fall detection or alerting is very relevant in order to avoid life-threatening conditions and to support active, safe and self-determined living at home.

However, improper and infrequent use of fall detection or alerting devices in community-dwelling older people has been reported. ${ }^{24,28-33}$ This is not surprising, as a great number of devices have been developed without sufficiently considering the needs and preferences of older people themselves as the end users. ${ }^{34}$ Dissatisfaction and difficulties with the device may result in using it less often or not using it at all. Moreover, many devices currently available on the market, such as watches and bracelets, require manual activation of the alert. ${ }^{33}$ This becomes impossible when a person loses consciousness or loses the ability to activate the alarm due to injury. In addition, older people sometimes remove such devices during sleep and will consequently be without the possibility to alert. 
Hence, considering users' needs and preferences in the development of healthrelated technologies may promote their daily use of the fall detection and alerting devices. Involving users and exploring their needs may facilitate a comprehensive understanding of aspects linked to feasibility, usability or practical aspects related to daily life. ${ }^{35,36}$ User involvement allows improvements in handling and in the level of acceptance and hence facilitates long-term usage of health-related technologies. ${ }^{36-41}$

Therefore, the aim of this study was to involve community-dwelling older people in device design of a fall detection sensor, including its smartphone application, through the evaluation of the mock-up. A mock-up is a model similar to the prototype, which is not yet fully operational. Thus, with this study, the prototype can be developed according to needs, preferences, feasibility and practical aspects related to its daily use. The research question was what are the needs and preferences of community-dwelling older people regarding a wearable fall detection sensor and its smartphone application during the design and mock-up stage?

\section{Patients and methods}

\section{Design}

A qualitative descriptive study was conducted using focus group interviews to involve community-dwelling older people in the development of a fall detection device. The definition of user involvement referred to the well-known classification of consultation, collaboration and user control. ${ }^{42,}{ }^{43}$ We chose the level of consultation, meaning that insight regarding needs and preferences gained from the target users informed our decision-making process in the development of the fall detection device. This low level of involvement was considered appropriate because for the first time, researchers from electronic and communication technology and researchers from nursing science worked from the very beginning together with target users.

We planned the approach based on the theoretical framework for user involvement, the "medical device technology development process", from Shah et al. ${ }^{44}$ The health-related context of this framework made it suitable for the underlying study. The framework suggests various methods of involvement, possible target users for involvement and the following four stages of involvement: (1) idea generation and concept development, (2) device (re-)design and prototype development, (3) prototype testing involving in-house and trials in the real field, and (4) device deployment in the market and user feedback. This study refers to stage II. Stage I was carried out previously without user involvement based on our practical experiences as nurses, our exchange with nursing practice, our interdisciplinary discussion with engineers from electronic 
and communication technology and evidence in the literature. Stages III and IV will occur as the next steps.

\section{Sample and recruitment}

Participants were recruited via eight seniors' associations, one municipal agency for senior citizens and two ambulant health care institutions, utilizing convenience sampling. ${ }^{45}$ All these organizations were located in the Canton of Bern, Switzerland. A seniors' association, which is organized on a regional/national level, provides a forum for discussion and exchange of information and gives a voice to seniors in the society. The municipal agency is responsible for handling the concerns of retired people on a local level, in order to promote their quality of life and independent living. In ambulant health care institutions, health care professionals and care laypersons are providing services in order to maintain and promote the well-being of older people on a regional level. These institutions were chosen for pragmatic reasons, as the data collection took place at the Institute of Nursing Science, which is located in the city of Bern.

The researchers contacted the management of these organizations and inquired if they would support recruitment for the study and act as gatekeeper. A gatekeeper works closely with the researcher and ensures access to the study population. If management agreed to support recruitment, paper-based and/or electronic flyers were distributed within the organization through face-to-face contact, email or a display. The flyer was focused upon the importance of the study, study timeline and possible interview dates, participants' tasks, inclusion criteria, registration information, ethical considerations and information regarding the research team.

Study registration occurred online or via reply card. The online link was provided in the study flyer. The reply card, which was one part of the study flyer, was sent via mail to the Institute of Nursing Science. Participants were responsible to register themselves. Once registered for the study, information regarding date and venue of the interview along with consent for participation was sent to the participants via mail by the researcher. The inclusion criteria consisted of living in the community, living alone or with a partner, being aged 75 years or older, being Swiss German/German speaking and being able to give written and oral informed consent. The exclusion criteria were use of a wheelchair and living in a nursing home or an assisted living facility.

\section{Data collection}

A semi structured interview guideline was used to stimulate and thematically structure the focus group discussion. It was developed by the research team and focused on the needs, preferences, feasibility and practical aspects concerning design and functions that were relevant for the prototype. Additionally, in accordance to Krueger and Casey, ${ }^{46}$ 
the following five stages for focus group interviews were adhered to: (1) opening question, (2) introductory section, (3) transition question, (4) key questions and (5) concluding question (Supplementary material). In the "Introduction" section, in order to facilitate discussion, the following materials were handed out to the participants: two mock-ups of the body-worn fall detection sensor (a bendable and a rigid model, $6 \times 3 \times 0.7 \mathrm{~cm}$ ), a copy of the screenshots showing the three smartphone application screens and four patch patterns for fixation of the sensor on the body (Figure 1).

One researcher (FJST) demonstrated, using the abovementioned material, the function and planned usage of the fall detection device, in accordance to the information in Figure 1. It was indicated that the sensor was intended to be fixed on the torso with a patch and that the sensor should be wearable for 24 hours and during personal hygiene (taking a shower/bath). The researcher emphasized that this information was the starting point of the focus group interview. The participants should then critically discuss and think about their needs, preferences as well as feasibility and practical aspects when conceiving that they would use this fall detection device in their daily life. In order to describe the sociodemographic characteristics of each participant, a short-self-administered questionnaire was handed out at the end of the focus group interview. The interview guideline was pilot tested in the first focus group interview, resulting in minor adaptations regarding the structure of the "Introduction" section (order of information given to the participants). No questions required modification.

In July 2014, three semi-structured focus group interviews were conducted at the Institute of Nursing Science. In these interviews, the participants consisted of nine, eight and five older people. Each focus group interview was audio recorded and lasted on average 100 minutes. The first and second authors carried out the interviews. No one else was present during the interviews except the participants and the researchers. One researcher acted as a moderator (FJST), and the other researcher acted as an assistant moderator (SB). The moderator led the discussion by posing open-ended questions, thereby encouraging the participants to elaborate on their views, and by ensuring that the discussion between the participants was pertinent to the topic. The assistant moderator prepared the focus group discussion (room and material), provided support to participants (e.g. location, beverages and lavatory) and observed the interview in order to discuss the course of the interview with the moderator. 


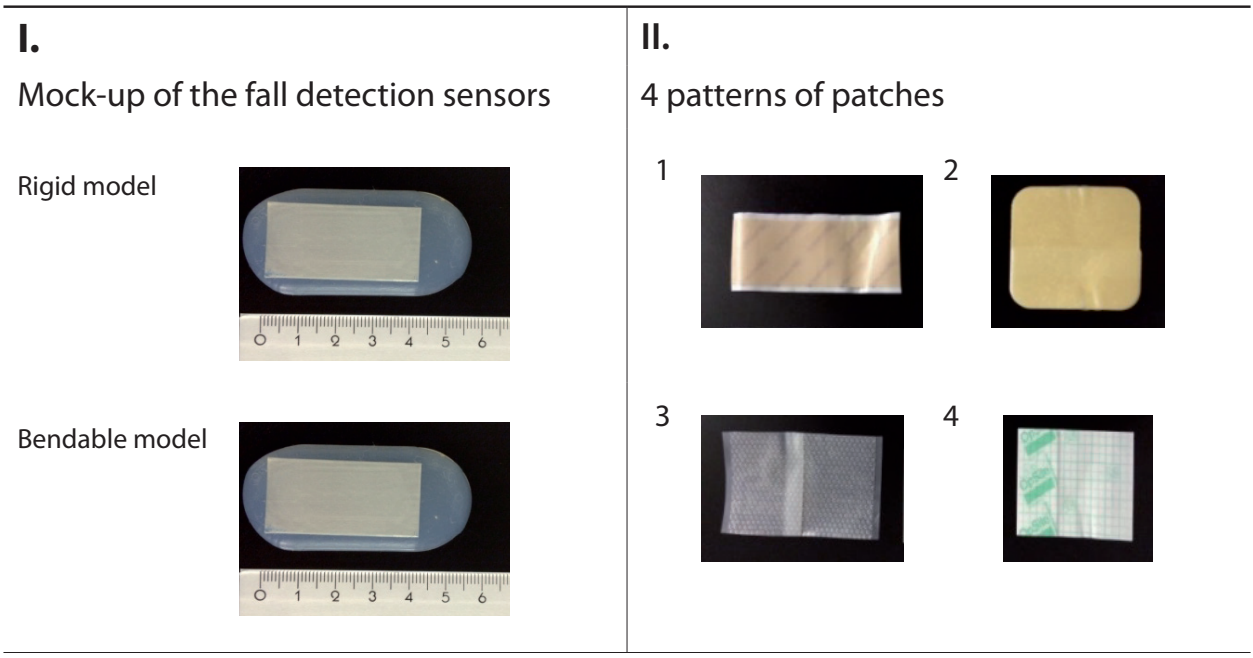

III.

Mock-up smartphone application screens (screenshots)

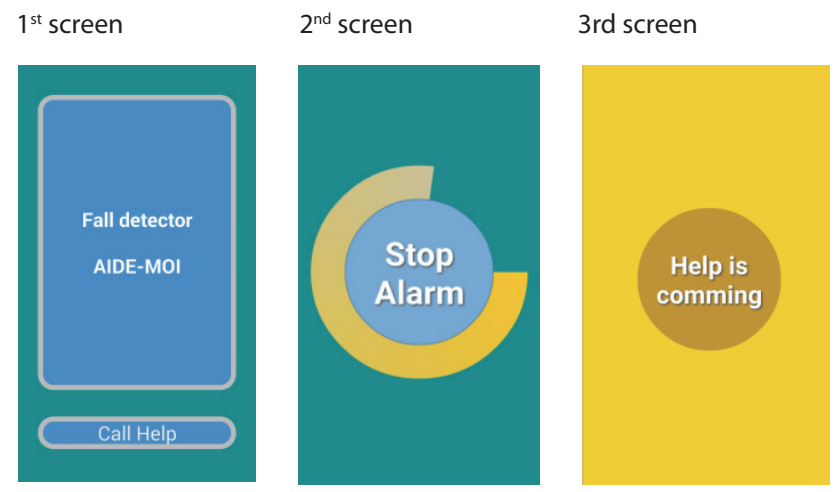

IV.

Alert message (short message)

FALL ALERT!

Hello Tobias. I fell at 15:08 on

June 18 2014!!

My actual Position:

http://maps.google.com/.

maps? $q=47.06267+7.614173$

Figure 1. Mock-up fall detection sensor, mock-up smartphone application and their functioning 
V.

Planned guidelines for the fall detection device

1. Fall detection sensor is fixed by a patch on the torso.

2. Fall detection sensor is connected via Bluetooth to a smartphone application, which has to be in a range of 8 to 10 meters. When a fall has occurred, the application will open automatically (III. second screen). An alert may be stopped according an individually adjustable timeframe, illustrated by a closing cycle (III. second screen). As soon as the alert is confirmed by one of the contact persons, the application window changes and indicates that help is coming (III. third screen).

3. Additionally: an alert may also be emitted manually by its user (III. second button on first screen).

4. An alert is emitted, indicating the location (GPS) of the fallen person, which is automatically transmitted via SMS successively to predefined contact persons until one person answers the alert.

\section{Description}

- The fall detection device was developed in cooperation between nursing researchers and researchers from electrical and communication engineering, both from the same university in Switzerland. Researchers from electrical and communication engineering developed (in their laboratory) the mock-up of the fall detection device.

- The waterproof fall detection device, wearable for more than 24 hours, is targeted for community-dwelling older people.

- The size of the mock-up of the fall detection sensors was $6 \mathrm{~cm} \times 3 \mathrm{~cm} \times 0.7 \mathrm{~cm}$ with a weight of 10 grams.

- A rigid and bendable mock-up of the fall detection sensor was suggested in order to understand which one fits best the needs of the target users (I.).

- Four patterns of patches were handed out to the participants so that they could visually and tactually decide what kind of patch they would prefer for fixing the sensor on the body. The choice of patterns was carefully selected by the research team in order to take into account the needs of sensitive skin (II.).

- A coloured copy of the screenshots showing the three smartphone application screens along the alerting process (III.) and the content of the alert message was distributed to each participant (IV.).

Figure 1. Continued

Abbreviations: GPS, Global Positioning System; SMS, short message. 


\section{Data analysis}

A qualitative descriptive analysis was applied using deductive coding. ${ }^{47}$ This data analysis approach is appropriate for studies aiming for a descriptive summary of the data. ${ }^{47}$ Hence, in accordance to the aim of the underlying study, precise and specific feedback regarding the fall detection sensor and smartphone application under development was obtained. Prior to data analysis, a deductive coding system was developed (FJST, SB and SH) utilizing the themes addressed in the interview guideline during focus group discussion, as listed in Table 1.

Table 1. Deductive coding system

\begin{tabular}{lll}
\hline $\begin{array}{l}\text { Sensor - needs and preferences } \\
\text { related to }\end{array}$ & $\begin{array}{l}\text { Smartphone - needs and } \\
\text { preferences related to }\end{array}$ & $\begin{array}{l}\text { App - needs and preferences } \\
\text { related to }\end{array}$ \\
\hline Colour & Operating distance & Design colours / information \\
Size / shape & Triggering / alerting process & Option «stop alert» \\
Weight & Messaging in context of alerting & Option «need help» \\
Material & Contacts of alert & Use (feasibility and practicability) \\
$\begin{array}{l}\text { Body location } \\
\text { Duration of wearing } \\
\text { Sensor fixation on body }\end{array}$ & Use (feasibility and practicability) & \\
Use (feasibility and practicability) & & \\
\hline
\end{tabular}

The data analysis was conducted in the following seven steps:

1. Transcription of the interviews was combined with a first analysis by deductively assigning the text passages to the corresponding codes of the coding system (using software programs $\mathrm{f} 4^{\oplus}$, Microsoft Word ${ }^{\oplus}$ and Excel $^{\oplus}$ ) (SB).

2. The assignments were checked by the first author (FJST). Differences in the assignments of text passages were discussed until agreement was reached (FJST and SB).

3. Two researchers independently summarized the informational content of the interview text assigned to the deductive codes (FJST and SB).

4. The summarized informational content of both versions was critically compared and discussed, and an integrated version was approved (FJST and SB).

5. Steps $1-4$ were critically reviewed by a third researcher $(\mathrm{SH})$, ensuring accuracy and that no critical findings were omitted. Later, this critical review was discussed until agreement was reached, which resulted in minor changes (naming of the deductive codes) (FJST, SB and SH). 
6. Similarly, codes were summarized into categories and subcategories (FJST and SB). For each subcategory, the most salient phrases were selected as quotes, which adequately represented the content of the subcategories contained in the interview data.

7. The categories and subcategories were discussed in the research team, which resulted in minor modifications regarding their final, appropriate wording (FJST, SB, SH, RJGH and JMGAS).

\section{Ethical approval}

According to Swiss legislation, the study protocol was submitted to the responsible local Swiss ethical board (Ethical Committee of the Canton of Bern). In June 2014, the ethical board decided (Z020/2014) that this study was beyond the responsibility of the Swiss Federal Act on Research Involving Human Beings. This study was conducted in compliance with the protocol, the current version of the Declaration of Helsinki, the ICH-GCP or ISO EN 14155 (as far as applicable), as well as with all national legal and regulatory requirements. Written and oral informed consent was obtained prior to focus group interview participation. No company partner was involved in this study in order to ensure that device development would be driven primarily by the needs of the end users.

\section{Results}

A total of 22 participants were included. As listed in Table 2, the mean age was 80 years (standard deviation 4.5). A total of 14 participants lived alone and 16 participants required no assistance in daily living. Further characteristics are listed in Table 2.

The analysis of needs, preferences, feasibility and practical aspects regarding the design and functions of the mock-ups resulted in two categories and four subcategories, which are described later.

\section{Fall detection sensor - needs and preferences}

The participants welcomed the idea of a body-worn and waterproof fall detection sensor. The following needs and preferences related to the fall detection sensor were identified. 
Table 2. Participants' characteristics ( $\mathrm{N}=22)$

\begin{tabular}{lc}
\hline Characteristics & Participants (N=22) \\
\hline Age (years), mean (SD) & $80(4.5)$ \\
$\quad$ (Min-max) & $75-89$ \\
Gender, $\mathrm{n}(\%)$ & \\
$\quad$ Female & $18(82)$ \\
$\quad$ Male & $4(18)$ \\
Living alone, $\mathrm{n}(\%)$ & $14(64)$ \\
No assistance in daily living, $\mathrm{n}(\%)$ & $16(73)$ \\
History of falls, $\mathrm{n}(\%)$ & $10(45)$ \\
Experiencing fear of falling, $\mathrm{n}(\%)$ & $9(41)$ \\
Mobile / smart phone use, $\mathrm{n}(\%)$ & $8(36)$ \\
Internet use at home, $\mathrm{n}(\%)$ & $13(59)$ \\
\hline
\end{tabular}

Abbreviations: SD, standard deviation; min, minimum; max, maximum

\section{Size, shape, colour, weight and material}

The preference for the bendable sensor mock-up was unanimous. Its size (Figure 1) was largely acceptable; however, some participants stated that they would need a thinner one, as it would be more adaptable/comfortable to the body. Others felt that the size should be defined primarily from a technical point of view in order to ensure reliability.

For some participants, the transparent colour of the presented mock-up sensor was suitable, while others were indifferent. However, other participants preferred an eye-catching colour, as per the following statement:

"The colour is important to me. I am a hobby gardener. If something drops in the shrubs, I can't find it any more. This is why I prefer [it] to be coloured, loud and trendy. Such a thing [sensor] isn't visible" [Fg1sll].

In regard to the shape of the sensor, the participants would prefer round, oval or the shape of a blossom. Some participants felt that the sensor should serve its purpose, and others mentioned that it should also serve as a trendy accessory. The weight of the sensor, which was $10 \mathrm{~g}$, was acceptable. The participants compared it with the weight of other assistive devices, such as glasses and hearing aids. The material of the sensor was organic silicon on the surface, which was in general well accepted by the participants due to its softness and it being waterproof as well as due to the practical aspect of it being hygienic because it was washable. However, some were concerned with possible sweating or the feel of its jelly-like surface. In general, the presented mock-up seemed to be well accepted; however, the important issue of reliability remained. 


\section{Feasibility and practical aspects related to daily use}

Wearing the sensor on the waist or chest seems feasible and practical, as it would barely affect one's movement and activity. In addition, these body locations are easy to reach and do not require the help of another person. Some participants would prefer to wear the sensor in the brassiere, as this would optimize fixation of the sensor. Other participants raised concerns about a possible negative interaction between the organs and the sensor. They felt that the Bluetooth connection between the sensor and smartphone might be harmful to the functioning of their organs. Thus, they would prefer to wear the sensor on the extremities. The participants emphasized that the issue of wearing might be better explored by actually testing this fall detection sensor under real-life circumstances and over a period of several days or weeks, as per the following comment: "I need to experience it for myself, otherwise, I can't really tell you" [Fg1sII]. The participants had varying ideas regarding the duration of wearing the sensor, ranging from 24 hours to more than several weeks. Some seniors emphasized that according to their experience regarding the risk of falling, wearing the sensor during the night is even more important than wearing it during the day. One comment was:

"If you have to get up from your bed at night, as every one of us has to do, then,

it [the sensor] is even more important than during the daytime" [Fg2sIl].

More than once the participants stressed the importance of self-testing in order to be able to evaluate all aspects related to the device's daily use.

The interviewed seniors evaluated four different patches for fixation of the sensor on the body (Figure 1) and emphasized the following: it should be gentle on the skin, simple to manipulate and have good adhesive performance. They consistently favoured patches 1 and 3 (Figure 1). Some participants were particularly concerned about the issue of skin hypersensitivity. Hence, they would need alternative ways to fix the sensor on the body.

"It stands to reason, you can stick it [patch] on your skin and detach it, but for people with delicate skin it will not work. For me, the main question is how to fix the sensor on without patch?" [Fg2sII].

One participant suggested "you should think about a belt with a slit, so you can tie it around the body" [Fg2sII]. For feasibility reasons, the fall detection sensor should be functioning constantly and worn everywhere, including at home, outdoors as well as in the basement or attic, as these places are isolated, and it would take time until someone would find a fallen person. Another practical aspect revealed during the focus group discussions was that some participants would prefer to combine the fall detection sensor with a device, which is familiar to them and already used in daily life, such as jewellery (pendant and bracelet) and a personal watch. "Personally, I would prefer a bracelet; I am used to it since my youth" [Fg1sII]. In general, the participants agreed that 
it is crucial that minimal effort be involved in the use of a fall detection sensor and that the range of mobility should not be hindered.

\section{Smartphone - needs and preferences}

The findings showed that the idea of using a smartphone when using the fall detection sensor created some general scepticism among the participants. The following needs and preferences related to the smartphone were identified.

\section{Design (colours and textual content), options "stop alert" and "need help"}

The suggested colours (Figure 1) of the smartphone application were in general accepted by the participants, although some would prefer it to be in red or green. Their suggestion of colours originated from traffic lights, with green indicating "no problem, no alert" and red indicating "problem, alert". However, it was argued that what is more important than the colour is that somebody would come to help. The textual content of the application met the needs of the older persons due to it being straightforward and readable. The option stop alert was identified as being very important. This would allow a false alert to be stopped and, therefore, not bother a contact person without reason. Not bothering without reason was viewed as very important. The option "need help" allows the manual activation of the alert independent of a fall. This is because there might be situations other than a fall, where receiving help would be important.

\section{Feasibility and practical aspects regarding alerting process}

The participants unanimously stressed that the suggested automatic alert is a clear advantage of this device. It was emphasized that reliable fall detection and alerting is key. The avoidance of false alerts such as during gymnastics, while stumbling or when accidentally bumping the device, is crucial in order to avoid bothering contact persons without reason. However, they were aware that no technology is completely secure. One participant stated "I believe that nothing is $100 \%$, but we should seek the optimum" [Fg2sII]. Once a fall alert has been emitted via smartphone application, the interviewees consistently preferred acoustic signals regarding the process of the alert transition and the confirmation of it by the contact person. This would allow them to be informed without looking at the smartphone, which might be impossible after a fall.

"From my point of view this is significant, if perhaps I fall in the kitchen and this device [smartphone] is in the living room. I won't be able to look at it. Then, I am lying on the floor and I am thinking; hopefully it works" [Fg2sII].

Furthermore, the participants suggested a melody instead of a spoken signal. The melody should be louder during alert transmission and as soon as the alert is confirmed, the melody should continue to occur but more quietly. During the night time, this 
process should include a blinking light. The participants suggested to also send an email when sending an alert via short message (SMS).

The participants had clear ideas about how to choose the contact person in case of a fall. The primary criterion was the availability of the person. It was emphasized that relatives should always be one of the contact persons. Even if they are not able to assist, they should at least be informed that a fall had occurred, as they might be able to organize assistance. Other contact persons could be neighbours because they could provide quick assistance. However, it could not be taken for granted that a neighbour would want to be included as a contact person or that they would be available, particularly if they were younger persons, who are less frequently at home. Health care professionals or a clergyman from the community could also be a contact person. Only as a very last option was the emergency call centre mentioned, due to possible high cost in case of a false alert.

A crucial point of discussion was the operating distance $(8-10 \mathrm{~m})$ between the sensor and the smartphone. In particular, participants living in houses with several floors, in apartments with several rooms or in those with regular gardening activities considered this distance as being neither feasible nor practical for daily life.

"It is possible to send signals to the moon; hence, more than eight meters should be feasible. This point is important. It should be possible that [the smartphone] remains in one place in the house" [Fg2sIl].

In contrast, the participants suggested that this operating distance would be suitable for smaller dwellings, for less mobile people or for people with physical restrictions.

A further aspect of discussion was related to the smartphone itself. Participants expressed their concern regarding the mandatory use of a smartphone when using this fall detection sensor. Few participants reported having experience in using a smartphone. They mostly assumed that a smartphone is difficult, that its different functions are unclear, that one should have it constantly in mind and switched on, and that it must be charged regularly. The preferred solution of many participants was to not use a smartphone at all and instead have a sensor that directly transmits the alert SMS to the predefined contacts. Moreover, having one device is more practical than having two devices. "The more devices you need, the more difficult it is for us aged people" [Fg3sII]. However, participants mentioned that it is important to develop such a device, as future generations will probably not have any difficulties with using a smartphone. Once again, the participants stressed that self-testing is important in order to explore the device thoroughly. In summary, the participants welcomed the automatic fall detection alert but were doubtful regarding the required operation distance between sensor and smartphone as well as the seemingly challenging use of a smartphone in daily life. Hence, some participants would prefer to solely use a sensor. 


\section{Discussion}

\section{Principal findings}

The aim of this study was to explore the needs and preferences of community-dwelling older people by involving them in the device design and mock-up development stage of a fall detection sensor and its smartphone application. Overall, the participants largely welcomed the automatic and manual alerting functions of the device, as well as that the sensor was waterproof and served both as a day-time wearable device and a night-time wearable device. The sensor mock-up was also well-accepted in regard to its weight and material. The bendable model of the sensor mock-up was consistently preferred. These aspects can therefore be directly considered for prototype development.

The needs and preferences differed regarding the size, shape and colour of the sensor mock-up. It was discussed that the sensor prototype should be thinner than the mock-up and that it should be available in different shapes and colours. However, the participants emphasized that requirements regarding the reliability of the sensor should determine its size.

\section{Relationship to current literature}

Although the participants felt that wearing the sensor on the body was practicable, they instead suggested combining it with an item that is normally worn in everyday life. The feasibility of this finding should be considered for the prototype development. However, this could be challenging, as a sensor for automatic fall detection has to fulfil a number of technical requirements, such as remaining in a fixed position on the body in order to detect a fall in a sensitive and specific way. ${ }^{48}$

This might be an issue to consider further as items such as jewellery and watches are very familiar to older people. Familiarity seems to play an important role in designing technologies for older people, as it may promote the acceptance and usage of the technology. ${ }^{20,49}$ Design questions are likely to influence acceptability and practicability, as described in the literature on the development of medical devices. ${ }^{50}$ Hence, ensuring familiarity could be a successful way of making technologies accessible to the world and language of older people. ${ }^{49}$ In order to address older people's need for familiarity, their perspective must be included in the design development of fall detection devices. However, during the last decade, research involving end users has focused mainly on fall detection algorithms. ${ }^{34,51,52}$

The participants had doubts regarding smartphone usage. Several end user participants were not confident in the use and handling of it and suggested the use of a sensor without a smartphone. An aversion to smartphone usage is concordant with Abbate et al. ${ }^{53}$ who developed a smartphone-based fall detector for older people 
attached to the belt. They found that their participants were pessimistic regarding using this device in daily life. A review on "challenges, issues and trends in fall detection systems", emphasized that no previous studies suggesting smartphone-based fall detection devices involved older people. ${ }^{54}$

Difficulties of older people in the use of smartphones are reported in the literature and are considered as being part of the ageing process..$^{55}$ Ageing is an ongoing process in which the eyesight, touch sensitivity and cognition often gradually decrease. These functions are particularly crucial in the use of a smartphone. In order to overcome these age-related difficulties, technical solutions are required. Smartphones should remain accessible for the ageing population. Moreover, this finding shows that involving end users is highly valuable, as it allows the identification of possible barriers for using a device that is under development and helps to classify future end users. Although the criticism of smartphones is legitimate, using a smartphone for fall alerts offers the advantage of being able to use the same device both indoors and outdoors. ${ }^{48,53}$ In addition, the smartphone represents a sustainable device with the potential for future development.

Currently, the use of smartphones as a fall detection device presents a possible barrier; however, in the long-term, smartphone usage will steadily increase among older people. This suggests that in the upcoming years, an increasing number of older people will be familiar with it. ${ }^{56}$ In order to promote this trend, it is important that smartphone developers seriously consider these age-related declines, such as eyesight and touch sensitivity, in the development of smartphones.

As the participants were involved only in the design and mock-up stage, their needs and preferences regarding smartphone usage remain hypothetical until they have tested it. The results of this finding highlight the necessity of older persons' involvement in the next stage of device development. Sensor prototype testing in the real field must entail carefully developed training and support for community-dwelling older people in regard to smartphone usage.

Criticism of smartphones may not be limited solely to the handling of them as participants emphasized their need for being mobile when using such a device. The distance between the sensor and the smartphone is limited due to reliability aspects. As sustaining physical activity and engagement in social life are crucial for active ageing, there is a need for being mobile when using a fall detection device. ${ }^{6}, 57$ Moreover, independence is described as one of the key factors for older people in the use of technologies..$^{58}$ There are several implications of this finding for the prototype development and for the real field trial. First, technical solutions are required in order to extend the reliable distance between the sensor and the smartphone. Second, alternate ways of transmitting the data to the device should be considered. Third, depending 
upon the technical feasibilities, the training of the older people in the upcoming stage must provide information regarding the management of sensor-to-smartphone radius in daily life. Fourth, in the real field trial, it will be important to explore which end user group might benefit the most from this kind of fall detection device.

A very relevant finding was the repeated emphasis on real-life testing, both in regard to the sensor and to the smartphone. This reveals the positive attitude that end users have regarding their involvement. Furthermore, it demonstrates the adequacy of the applied theoretical framework, which recommends involving the end users in all four steps of device development. ${ }^{44}$

The needs and preferences from the perspective of the involved older people were quite homogenous regarding the mock-up sensor and its smartphone application. This seems surprising as older people are described as being a highly heterogeneous age group. ${ }^{59}$ However, this can be considered as a sign of data saturation, as the possibility to obtain any additional new information had been reached. ${ }^{60}$ It might also have been attributable to the included sample, which may have consisted of individuals who were interested in exploring technologies.

\section{Strengths and weaknesses}

Some limitations should be considered when interpreting the findings. In this study, end users were not involved in the first stage of device development (idea generation and concept development). Through involving end users starting instead at the second stage, we saved resources during the first stage by drawing upon our available interdisciplinary expertise, which consisted of nursing researchers, engineers and a former geriatric medicine nurse. Moreover, discussing possible technological solutions without a mock-up might have been overwhelming for older people, especially those who were less familiar with current technological developments. ${ }^{37,61}$

The convenience sampling is a limitation of the study. It is possible that our sample consisted of older people, who were more motivated, rather than those who were at high risk of falling or those who were more resistant toward technology. This self-selection bias is an ongoing challenge in interview-based research. ${ }^{45}$ The sampling strategy was utilized due to difficulties in recruiting community-dwelling older people for research involvement. Bridgelal et al. ${ }^{37}$ and Shah and Robinson ${ }^{36}$ described the challenges of user involvement in research, but their focus was limited to researchers and industry.

The rigor of the analysis was enhanced by conducting it at different levels with three members of the research team. The primary focus on manifest content during analysis reinforces the trustworthiness of results. ${ }^{47,62}$ 


\section{Further research}

Based on the findings of this study, the fall detection device prototype will be developed by the research team. In accordance with the underlying theoretical framework, users will be reinvolved in stage III and will test the fall detection sensor prototype in real life.

\section{Conclusion}

This study findings show that older people, as end users, are able to contribute in the mock-up design stage in the development of a fall detection device, by indicating what really matters to them. The exploration of their needs and preferences, along with their input into the feasibility and practical aspects of the device, reveals the value that userinvolvement has for researchers and engineers, especially in guiding development of the device.

The study revealed that this wearable, waterproof sensor for fall detection and alerting is feasible, although the shape, colour, size and fixation of the sensor should be modified during the development of the prototype. Several of the participants did not feel comfortable with the use of smartphones. Therefore, careful training and support of participants in smartphone usage during real-life testing will be crucial. Participants indicated that the limited reliable distance for fall detection and alerting between sensor and smartphone should be extended, as it would restrict them in their daily activities.

This study also indicates that older people's perception of activity, independence and familiarity should be considered in the development of a device, as it may influence the acceptance and usage of a fall detection device. These influencing aspects can only be revealed when end users' perspectives are involved. As emphasized by the participants, user involvement in the third stage, the prototype real field testing stage, is necessary in order to go beyond the hypothetical considerations of the second stage. Based on these findings, the prototype of the fall detection device can be developed with a "needs-driven" focus.

\section{Acknowledgments}

We are thankful to the study participants for their engagement and accorded time. We are grateful to Tannys Helfer from the Bern University of Applied Sciences, Bern, Switzerland, for her linguistic support. This work was supported by the Bern University of Applied Sciences, Switzerland (grant number 14118DPT).

\section{Disclosure}

The authors report no conflicts of interest in this work. 


\section{References}

1. WHO. Number of people over 60 years set to double by 2050; major societal changes required. 201530 Septembre 2015 [cited 201523 October]; Available from: http://www.who.int/mediacentre/news/ releases/2015/older-persons-day/en/.

2. Jacobzone, S. and H. Oxley Ageing and Health Care Costs. Internationale Politik und Gesellschaft, 2002. 1, 1-20.

3. WHO The World Health Report 2008.

4. Nowossadeck, E., Demografische Alterung und Folgen für das Gesundheitswesen. 2012, Robert KochInstitut.

5. BAG Bericht Gesundheit 2020 - Die gesundheitspolitischen Prioritäten des Bundesrates, 2013.

6. WHO Active Aging: A Policy Framework. Department NDPaHP, 2002.

7. WHO Policies and priority interventions for healthy ageing. 2012.

8. Thomson, S., et al. Economic crisis, health systems and health in Europe: impact and implications for policy. 2014.

9. Hahn, S., et al., Panorama Gesundheitsberufe 2030 Projektbericht, F.G. Berner Fachhochschule, angewandte Forschung und Entwicklung / Dienstleistung Pflege, Editor. 2013: Bern.

10. Lamb, S.E., et al., Development of a common outcome data set for fall injury prevention trials: the Prevention of Falls Network Europe consensus. J Am Geriatr Soc, 2005. 53(9): p. 1618-22.

11. BFS. Gehvermögen und Stürze. 201309 Dec 2016]; Available from: http://www.bfs.admin.ch/bfs/portal/ de/index/themen/14/02/01/key/07/05.html.

12. WHO WHO Global Report on Fall Prevention in Older Age. 2007.

13. Centers for Disease Control and Prevention. Falls Among Older Adults: An Overview. 201220.09 .201209 Dec 2016]; Available from: http://www.cdc.gov/homeandrecreationalsafety/falls/adultfalls.html.

14. Hanley, A., C. Silke, and J. Murphy, Community-based health efforts for the prevention of falls in the elderly. Clin Interv Aging, 2011. 6: p. 19-25.

15. Gründler, B.M., Sturzprävention für Senioren und Seniorinnen. Die rolle des Hüftprotektors in der SturzFraktur-Prävention. 2006, Schweizerische Beratungsstelle für Unfallverhützung bfu: Bern.

16. Hester, A.L. and F. Wei, Falls in the community: state of the science. Clin Interv Aging, 2013. 8: p. 675-9.

17. Stenhagen, M., et al., Accidental falls, health-related quality of life and life satisfaction: a prospective study of the general elderly population. Arch Gerontol Geriatr, 2014. 58(1): p. 95-100.

18. Tuunainen, E., et al., Risk factors of falls in community dwelling active elderly. Auris Nasus Larynx, 2014. 41(1): p. 10-6.

19. Sartini, M., et al., The epidemiology of domestic injurious falls in a community dwelling elderly population: an outgrowing economic burden. Eur J Public Health, 2010. 20(5): p. 604-6.

20. Turner, S., R. Kisser, and W. Rogm Falls among older adults in the EU-28: Key facts from the available statistics.

21. Legters, K., Fear of Falling. Physical Therapy, 2002. 82: p. 264-272.

22. WHO What are the main risk factors for falls amongst older people and what are the most effective interventions to prevent these falls?. Health Evidence Network, 2004.

23. Lord, S.R., C. Sherrington, and H.B. Menz, Falls in oder people. Risk, factors and strategies for prevention. 2001, Cambridge: Cambridge University Press.

24. Fleming, J. and C. Brayne, Inability to get up after falling, subsequent time on floor, and summoning help: prospective cohort study in people over 90. BMJ, 2008. 337: p. a2227.

25. Ryynanen, O.P., et al., Falls and lying helpless in the elderly. Z Gerontol, 1992. 25(4): p. 278-82.

26. Chaudhuri, S., H. Thompson, and G. Demiris, Fall Detection Devices and Their Use With Older Adults: $A$ Systematic Review. J Geriatr Phys Ther, 2014.

27. Ward, G., et al., Fall detectors: a review of literature. Journal of Assistive Technologies, 2012. 6(3): p. 202215 . 
28. Johnston, K., K. Grimmer-Somers, and M. Sutherland, Perspectives on use of personal alarms by older fallers. Int J Gen Med, 2010. 3: p. 231-7.

29. Johnston, K., et al., Personal alarm use to call the ambulance after a fall in older people: characteristics of clients and falls. Journal of Emergency Primary Health Care (JEPHC), 2010. 8(4): p. 1-9.

30. Mann, W.C., et al., Use of personal emergency response systems by older individuals with disabilities. Assist Technol, 2005. 17(1): p. 82-8.

31. Heinbuchner, B., et al., Satisfaction and use of personal emergency response systems. Z Gerontol Geriatr, 2010. 43.

32. Nyman, S.R. and C.R. Victor, Use of personal call alarms among community-dwelling older people. Ageing \& Society, 2014. 34(1): p. 67-89.

33. Zingaro, S. Nottelefone teils untauglich und überteuert. 2012.

34. Thilo, F.J.S., et al., Involvement of older people in the development of fall detection systems: a scoping review. BMC Geriatrics, 2016. 16(42).

35. Shah, S. and I. Robinson, Medical device technologies: who is the user. Int. J. Healthcare Technology and Management, 2008. 9(2): p. 181-197.

36. Shah, S.G. and I. Robinson, Benefits of and barriers to involving users in medical device technology development and evaluation. Int J Technol Assess Health Care, 2007. 23(1): p. 131-7.

37. Bridgelal Ram, M., P. Grocott, and H. Weir, Issues and challenges of involving users in medical device development. Health Expect, 2007. 11: p. 63-71.

38. Rodeschini, G., Gerotechnology: a new kind of care for aging? An analysis of the relationship between older people and technology. Nurs Health Sci, 2011. 13(4): p. 521-8.

39. Gulliksen, J., et al., Key principles for user-centred systems design. Behaviour and Information Technology, 2003. 22(6): p. 397-409.

40. De Vito Dabbs, A., et al., User-centered design and interactive health technologies for patients. Comput Inform Nurs, 2009. 27(3): p. 175-83.

41. Facey, K., et al., Patients' perspectives in health technology assessment: a route to robust evidence and fair deliberation. Int J Technol Assess Health Care, 2010. 26(3): p. 334-40.

42. INVOLVE Involving Consumers in Research and Development in the NHS. Briefing Notes for Researchers. 2003.

43. Morrow, E., et al., Handbook of Service User Involvement in Nursing \& Healthcare Research. 2012, West Sussex, UK: Wiley-Blackwell.

44. Shah, S., I. Robinson, and S. AlShawi, Developing medical device technologies from users' perspectives: A theoretical framework for involving users in the development process. International Journal of Technology Assessment in Health Care, 2009. 25(4): p. 514-521.

45. Robinson, O.C., Sampling in Interview-Based Qualitative Research: A Theoretical and Practical Guide. Qualitative Research in Psychology, 2014. 11(1): p. 25-41.

46. Krueger, R.A. and M.A. Casey, Focus Groups A Practical Guide for Applied Research. 2009, London: SAGE.

47. Sandelowski, M., Whatever happened to qualitative description? Research in Nursing \& Health, 2000. 23(4): p. 334-340.

48. Pannurat, N., S. Thiemjarus, and E. Nantajeewarawat, Automatic Fall Monitoring: A Review. Sensors, 2014. 14(7): p. 12900-12936.

49. Leonardi, C., et al. Designing a Familiar Technology For Elderly People in The 6th International Conference of the International Society for Gerontechnology. 2008. Pisa, Tuscany, Italy

50. Jennifer, L.M., et al., Capturing user requirements in medical device development: the role of ergonomics. Physiological Measurement, 2006. 27(8): p. R49.

51. Schwickert, L., et al., Fall detection with body-worn sensors A systematic review. Zeitschrift fuer Gerontologie und Geriatrie, 2013. 46(8): p. 706-719.

52. Chen, K. and A.H.S. Chan, A review of technology acceptance by older adults. Gerontechnology, 2011. 10(1).

53. Abbate, S., et al., A smartphone-based fall detection system. Pervasive and Mobile Computing, 2012. 8(6): p. 883-899.

54. Igual, R., C. Medrano, and I. Plaza, Challenges, issues and trends in fall detection systems. Biomed Eng Online, 2013. 12: p. 66. 
55. Wang, Q., The Effects of Interface Design About Mobile Phones On Older Adults' Usage. 4th International Conference on Wireless Communications, Networking and Mobile Computing 2008: p. 1-4.

56. Deloitte. The smartphone generation gap. 2014 [cited 2016 June 7]; Available from: https://www2. deloitte.com/ug/en/pages/technology-media-and-telecommunications/articles/2014predictions-thesmartphone-generation-gap.html.

57. WHO, Strategy and action plan for healthy ageing in Europe, 2012-2020. 2012, World Health Organization: Copenhagen.

58. Hawley-Hague, $\mathrm{H}_{\text {., }}$ et al., Older adults' perceptions of technologies aimed at falls prevention, detection or monitoring: A systematic review. International Journal of Medical Informatics, 2014. 83(6): p. 416-426.

59. Grigsby, J.S., The meaning of heterogeneity: An introduction. Gerontologist, 1996. 36(2): p. 145-146.

60. Fusch, P.I. and L.R. Ness, Are We There Yet? Data Saturation in Qualitative Research. Qualitative Report, 2015. 20(9): p. 1408-1416.

61. Kujala, S., User involvement: a review of the benefits and challenges. Behaviour \& Information Technology, 2003. 22(1): p. 1-16.

62. Elo, S., et al., Qualitative Content Analysis: A Focus on Trustworthiness. SAGE Open, 2014. 4(1). 


\section{Supplement material}

\section{Focus group interview guideline}

1. Start: welcome, introduction to researchers, process, communication forms during focus group interview, data confidentiality, audio recording, questions, informed consent

2. Research project: short overview

\section{Opening question}

- What are your experiences regarding falls?

\section{Introduction}

o Hand out material to participants

o Describe the fall detection device - sensor; patch; smartphone; smartphone app; charging; and demonstration of its functions.

- Emphasize: starting point; discuss and think critically about your needs, preferences as well as its feasibility and practical aspects of use in your daily life.

\section{Transition question}

- What are your first impressions when looking at this fall detection device?

o What is pleasant to you?

o What is less pleasant to you?

\section{Key questions}

- What do you think regarding the following aspects of the sensor:

- Material / size / shape / weight / colour / wear, comfort / duration of wearing / location of the sensor on the body

- What do you think about the different patches? Which one do you prefer and why?

- What do you think regarding the smartphone application?

o Different functions - stop, alarm, manual alerting / Colours / Comprehension of the text / Contact persons / Short message in case of an alert

- What do you think regarding the smartphone and its use?

- Distance between sensor and smartphone

- Imagine your everyday life - what do you like and why?

o while using this sensor / while using the smartphone application / while using the smartphone

\section{Concluding question}

- What do you think regarding the feasibility of using this fall detection device in your daily life?

- Is there any topic, which we have not yet discussed?

8. Closing: Thank you, short-questionnaire sociodemographic characteristics. 



\section{Chapter 4}

\section{Usability of a wearable fall detection prototype from the perspective of older people A real field testing approach}

This chapter was published as: Thilo, F.J.S., Hahn, S., Halfens, R.J.G., \& Schols, J.M.G.A. (2018). Usability of a wearable fall detection prototype from the perspective of older people-A real field testing approach. Journal of Clinical Nursing. doi:10.1111/jocn.14599 


\section{Abstract}

Aims and objectives: Community-dwelling older people were involved in the testing of a fall detection device to improve its utilisation and acceptance in everyday life.

Background: The usability of alerting devices remains unsatisfactory, as they are scarcely utilised by older people, despite wide recognition of the importance of rapid assistance after a fall. Moreover, the time a person remains on the floor negatively impacts the severity of fall consequences. However, it is unclear how to increase alerting device utilisation in everyday life. Therefore, older people were involved in this research to consider their perspective during prototype development.

Design: A qualitative focus group study was conducted, following a real field testing approach, underpinned by the theoretical framework "Medical Device Technology Development Process".

Methods: Fifteen community-dwelling older people tested the prototype in daily living over a period of nine days. Different means of involvement were exploited such as "user seminars" or "discussion with users". On day 9, data were collected using focus groups and analysed with qualitative content analysis.

Results: The participants' perspectives yielded positive aspects of the prototype along with aspects requiring improvement. They indicated that technical requirements are essential. They also revealed that a minimal change in daily routines, support for physical activity and independent living and the inclusion of trusted contact persons could lead to wider use of the alerting device.

Conclusions: Involving users is crucial in gaining a deeper understanding of aspects influencing utilisation of an alerting device. The study revealed that usability is influenced both by technical requirements as well as habits and personal preferences. This finding is vital, as habits and personal preferences can only be identified through the involvement of target users.

Relevance to clinical practice: The study provides key insights for health practitioners interested in promoting the use of an alerting device in community-dwelling older people. 


\section{What does this paper contribute to the wider global clinical community?}

- This study shows how older peoples' needs regarding practical aspects of everyday life can be considered during fall detection device development.

- This article explains why a qualitative study design with a real field testing approach is a meaningful way of involving older people in the investigation of the usability of a fall detection prototype.

- Integration of a fall detection device into daily life should consider technical aspects as well as habits and personal preferences, such as daily routines, maintenance of independent living, staying physically active, the possible burden for relatives and the qualifications of health professionals. The study provides key insights for healthcare professionals interested in promoting the use of an alerting device. These insights, could, for instance, help health practitioners in supporting independent living among community-dwelling older people. 


\section{Introduction}

The global population of people 60 years of age and older is expected to double to more than 2 billion by 2050, ${ }^{1}$ representing a major societal challenge. Therefore, the concept of active ageing is gaining importance in both politics and health care. Its goal is to enable seniors to live independently, actively and safely, integrated in society and enjoying a good quality of life. ${ }^{2}$ Active ageing, however, can be interrupted or ended by a fall.

\section{Background}

Twenty-five per cent of people aged 65 and over experience a fall each year; ${ }^{3}$ moreover, fall rates and their associated negative consequences are up to twice as high for persons 75 years of age and older. ${ }^{4}$ Falls are often associated with loss of independence, and increased mortality and disability. ${ }^{5,6}$ Also, developing a fear of falling and consequently avoiding certain activities of daily life initiates a vicious circle of fear, avoidance and functional decline, which further increases the risk of falling. ${ }^{7,8}$ One crucial factor influencing the physical, mental and social well-being of older people after a fall is the length of time the person remains on the floor. ${ }^{9}$ A long duration helplessly lying on the floor increases mortality and severity of injuries and is associated with subsequent hospital and care home admissions. ${ }^{10,11}$ Community-dwelling older people are particularly at risk of a long life after falling and, thus, the consequences of falls jeopardise active ageing.

Call alarm devices provide the solution of calling for assistance. ${ }^{12}$ Different devices exist, including a base station centrally located at home, along with a wristband, necklace or a device which is integrated to enable remote use (e.g., a blood pressure device). ${ }^{13,14}$ However, call alarm devices are not yet commonly used by older people. ${ }^{15}$ Approximately $80 \%$ of older people who have a device do not call for help even after they have fallen. ${ }^{10,16}$ Reasons for not using a device are, for example, uncertainty about the alarm range, forgetting to put it on, discomfort or fear of false alarms. ${ }^{14}$ This highlights the fact that a device should be comfortable to wear both day and night for several days or weeks, and should not require frequent resetting. Commercially available personal emergency response systems, often in the form of a pendant, are criticised for not being waterproof, for lacking a global positioning system (GPS), ${ }^{14}$ and for their poor design. ${ }^{17}$ Additionally, most of the devices are manually activated, but a person with incapacitation after a fall, for example, unconsciousness or injury, would require an automatic fall alert. It seems that the currently available call alarm systems fail to satisfy 
the requirements of older people. This is not surprising, as fall detection and alerting devices are, to a large extent, developed from a technical point of view ${ }^{18}$ without the involvement and consultation of older people. This means that crucial information regarding older peoples' needs, preferences and technological difficulties are lacking ${ }_{1}{ }^{19}$ although usability is described as a main criterion influencing acceptance and adoption of health-related technologies. ${ }^{20}$ For these reasons, it is pivotal to involve users in all stages of device development. Field studies are needed for successful introduction of a device, ${ }^{12}$ both to enhance acceptance of the technology and to facilitate its long-term use. ${ }^{21,22}$ Qualitative methods are recommended for prototype testing, as they allow for gaining a deeper understanding of factors influencing usability and acceptability. ${ }^{20}$

The aim of this study was to investigate the usability of a wearable, waterproof, automatically alerting, fall detection prototype, through the involvement of communitydwelling older people in a qualitative study using a real field testing approach. For the purposes of this study, usability was understood as the prototype's practical aspects, its ease of use, and the users' satisfaction with its handling and manipulation in everyday life. To add knowledge to the field of "needs-driven" device development, we designed a research project that involved older people in the various development stages of a fall detection device. In a previous phase of this larger project, older peoples' needs and preferences regarding device design, using a mock-up, were explored and used to inform prototype development. ${ }^{23}$

\section{Methods}

\section{Design}

A qualitative focus group study design was followed, using a real field testing approach underpinned by the theoretical framework "medical device technology development process", of Shah, Robinson and AlShawi. ${ }^{24}$ This framework operationalises the involvement of users in the following four stages of technology development: (a) idea generation and concept development; (b) device (re-) design and prototype development; (c) prototype testing in-house and trials in the real field; and (d) device deployment in the market and user feedback. ${ }^{24}$ It provides guidance in determining the users of a technology as well as the method of involvement corresponding to every stage of development. The results of stages I and II are reported in Thilo et al. ${ }^{23}$ This study reports on the results of stage III, the usability testing of a fall detection prototype consisting of a wearable sensor linked via Bluetooth to a smartphone application. 


\section{Wearable fall detection prototype}

The fall detection prototype was developed by an interdisciplinary research team, including researchers from nursing as well as from electrical and communication engineering. No business partner was involved. The sensor uses two characteristics to recognise a fall and to automatically send an alert: (a) impact on a lower level, (b) resting position of the fallen person. This information is obtained via processing of the person's fall acceleration data. Table 1 depicts the fall detection prototype, including a description of how it works.

The prototype was designed between August 2014-July 2015, according to the results of stages I and II of device development. The newly developed prototype was evaluated for 5 days in May 2015 by six members of the study team and by one research colleague external to the team, to ensure reliable alerting and functioning as well as to solve any major usability problems.

Table 1. Description and functioning of fall detection prototype (sensor, smartphone app and smartphone)

\begin{tabular}{|c|c|}
\hline Item & Description \\
\hline Sensor & $\begin{array}{l}\text { Size: } 6 \mathrm{~cm} \times 3 \mathrm{~cm} \times 0.7 \mathrm{~cm} \\
\text { Weight: } 10 \text { grams } \\
\text { Material: Bio silicon } \\
\text { The sensor is worn on the torso day and night. Bio silicon ensures that it is waterproof. }\end{array}$ \\
\hline $\begin{array}{l}\text { Sensor } \\
\text { charging shell }\end{array}$ & $\begin{array}{l}\text { Every participant received two sensors, one for wearing and one for charging. The } \\
\text { remaining charge of the battery is indicated on the app. For charging, the sensor is } \\
\text { simply placed on the provided shell. }\end{array}$ \\
\hline Patches & $\begin{array}{l}\text { Two kinds of patches were available for fixing the sensor on the torso, and both were } \\
\text { suitable for sensitive skin. }\end{array}$ \\
\hline Smartphone & $\begin{array}{l}\text { Android dimension is } 137 \mathrm{~mm} \times 70 \mathrm{~mm} \times 7.9 \mathrm{~mm} \text {. Screen is } 5 \text { inches. The sensor is } \\
\text { connected via Bluetooth to the smartphone. The Bluetooth is a prerequisite for reliable } \\
\text { fall detection and alerting. Hence, the sensor has to be within a range of eight to ten } \\
\text { meters from the smartphone. }\end{array}$ \\
\hline App & $\begin{array}{l}\text { A first screen indicates the open app. The sensor that is currently working is indicated } \\
\text { on the screen. The battery status of the sensor is also visible. A button «need help» } \\
\text { allows for a manual call for help. Another button has to be initiated for connecting } \\
\text { and activating the worn sensor. A second screen opens automatically when a fall has } \\
\text { occurred. The alert may be stopped according to an individually adjustable time frame, } \\
\text { made visible by a closing cycle. The alert is transmitted to the previously defined } \\
\text { contact persons, and a third screen appears. As soon as one of the contact persons } \\
\text { validates the alert, a fourth screen pops up. Screens 2, } 3 \text { and } 4 \text { each appear with a } \\
\text { different melody. }\end{array}$ \\
\hline $\begin{array}{l}\text { Alert message } \\
\text { (text message) }\end{array}$ & $\begin{array}{l}\text { Content: Fall alert! I fell at } 14: 55 \text { on January } 13^{\text {th }}, 2015 . \text { My actual position http://maps. } \\
\text { google.com/maps? } g=47.06557+7.6140575 \\
\text { The fall alert is emitted to several predefined contact persons, chosen by the user. The } \\
\text { content of the emitted fall alert is described. GPS transmits the location of the person. }\end{array}$ \\
\hline
\end{tabular}




\section{Sample}

Community-dwelling older people living in the Canton of Bern (Switzerland) were included in the study according to the following criteria: being 75 years of age or older, being able to give verbal and written informed consent and the ability to walk with or without aids. Wheelchair users, institutionalised, hospitalised and older people living in assisted living facilities, as well as people with dementia, were excluded.

Participants were recruited using a convenience sampling strategy. Considering the heterogeneous recommendations regarding sample size in usability tests, ${ }^{25}$ we aimed for 16 participants to discover both major and minor usability problems. Available printed or electronic flyers provided the necessary information, such as relevance of the study, study timeline, participants' tasks, inclusion criteria or registration information. Additionally, participants were recruited with assistance from the management of: four seniors' associations, one municipal agency for senior citizens and one healthcare service organisation for older people. They distributed flyers through face-to-face contact, e-mail or via displays. Study registration occurred online, via a reply card which was part of the study flyer, or via a telephone call.

\section{Procedure of involvement and testing}

From August-October 2015, the real field testing of the fall detection prototype occurred in four test periods, each of nine days. In each test period, four participants could be involved. This ensured close coaching and support, which allowed the participants to feel secure. The real field testing, summarised in Table 2, started with a user seminar conducted at the Institute of Nursing Science, to ensure adequate preparation for study participation. Two researchers (FT, SB) conducted the seminar to provide face-to-face information, as required. Participants were asked to bring mobile phone numbers of one or two persons (relatives, friends or neighbours), who were willing to respond to possible alerts during the real field testing. The phone numbers were then installed on the smartphone application. A user manual was provided to support participants with written information during testing. In the user seminar, participants were instructed in how to use and activate the prototype (sensor, smartphone, app), how the alert process worked, as well as in battery loading and use of the 24-h telephone helpline. 
Table 2. Procedure of prototype real field testing

\begin{tabular}{|c|c|c|c|c|}
\hline & \multicolumn{4}{|l|}{ Prototype real field testing } \\
\hline & \multicolumn{4}{|c|}{ Between August and October 2015} \\
\hline & Day 1 & Day 2 & Days 3 - 8 & Day 9 \\
\hline \multirow[t]{6}{*}{ Procedure } & $\begin{array}{l}2 \mathrm{~h} \text { user seminar (by } 2 \\
\text { members of research } \\
\text { team) }\end{array}$ & $\begin{array}{l}1 \mathrm{~h} \text { discussion with } \\
\text { user (by } 1 \text { member of } \\
\text { research team) }\end{array}$ & $\begin{array}{l}\text { Testing in } \\
\text { everyday life }\end{array}$ & $\begin{array}{l}2 \mathrm{~h} \text { focus group } \\
\text { (by } 2 \text { members of } \\
\text { research team) }\end{array}$ \\
\hline & \multicolumn{4}{|l|}{ Location } \\
\hline & $\begin{array}{l}\text { Institute of Nursing } \\
\text { Science }\end{array}$ & Participants' homes & $\begin{array}{l}\text { Participants' } \\
\text { homes }\end{array}$ & $\begin{array}{l}\text { Institute of Nursing } \\
\text { Science }\end{array}$ \\
\hline & \multicolumn{4}{|c|}{$24 \mathrm{~h}$ telephone helpline - technical problems or handling } \\
\hline & \multicolumn{4}{|c|}{ Study diary participants - reflecting tool } \\
\hline & \multicolumn{4}{|c|}{ Research team diary - reflecting tool } \\
\hline Description & $\begin{array}{l}\text { - Explanation of } \\
\text { study procedure } \\
\text { - Verbal and informed } \\
\text { consent obtained } \\
\text { - Testing materials } \\
\text { handed out* } \\
\text { - Functioning of fall } \\
\text { detection prototype } \\
\text { demonstrated } \\
\text { - Presentation of user } \\
\text { manual } \\
\text { - Training: handling of } \\
\text { prototype } \\
\text { - 2-3 contact persons per } \\
\text { participant individually } \\
\text { added to smartphone } \\
\text { - Explanation how to use } \\
\text { the study diary } \\
\text { - Questions answered }\end{array}$ & $\begin{array}{l}\text { - Focusing on challenges } \\
\text { and questions } \\
\text { regarding daily use of } \\
\text { the prototype } \\
\text { - As necessary, } \\
\text { additional personalized } \\
\text { training in prototype } \\
\text { usage } \\
\text { - Checked reliable } \\
\text { functioning of } \\
\text { prototype (fall } \\
\text { simulation by dropping } \\
\text { down the sensor in } \\
\text { order to activate the } \\
\text { alerting process with } \\
\text { researcher as contact } \\
\text { person) } \\
\text { - Socio-demographic } \\
\text { data by interviewing } \\
\text { - As necessary, } \\
\text { additional information } \\
\text { in use of the study } \\
\text { diary }\end{array}$ & $\begin{array}{l}\text { - Wearing and } \\
\text { use of fall } \\
\text { detection } \\
\text { prototype } \\
\text { during day and } \\
\text { night }\end{array}$ & $\begin{array}{l}\text { - Semi-structured, } \\
\text { using an interview } \\
\text { guide } \\
\text { - Returning of } \\
\text { testing material }\end{array}$ \\
\hline
\end{tabular}

*Testing materials: 1 user manual, 2 fall detection sensors, 1 android smartphone with the fall detection app, 1 charging shell, 1 charging cable smartphone, 2 types of patches and 1 study diary.

On day 2 of real field testing, one researcher (FT) from the user seminar visited the participants in their homes for $1 \mathrm{hr}$ to support and enable ongoing testing. The topics outlined in Table 2 were discussed. On day 9, at the end of real field testing, the participants returned to the Institute of Nursing Science to participate in a focus group convened to discuss the usability of the prototype. 
A study-specific diary, which served as a reflection tool, had been provided: (a) to enable the participants to write daily evaluation notes regarding wearing comfort and handling of the prototype and (b) to help them reflect on and recall the field testing during the focus group discussion. During the entire real field testing phase, the first author followed and critically reflected on the progress of the test, making written notes in the research team's daily diary. These written notes included, for example, questions from the participants, phone calls, technical problems that occurred, assistance/solutions provided, impressions from user seminars and home visits. The user manual and the study diary were specifically developed for the study. The comprehensibility of the user manual was checked with two persons between 40-55 years of age (colleagues from the University) and one person 74 years of age (family member of a researcher). Based on their feedback, the simplicity of phrasing and structure were optimised, for example using more common terms and keeping sentences short. The comprehensibility of the study diary was checked with two people aged 70 years of age and older (each a family member of a researcher). Only minor modifications were needed, such as optimisation of the layout and order of the topics.

\section{Data collection}

At the end of each real field testing period, a semi-structured focus group was conducted, as this approach is ideal in guiding product development. ${ }^{26}$ Each focus group was digitally recorded. Two researchers conducted the discussion, with one acting as the moderator (FT) and the other as the assistant moderator (SB). The focus group guide was developed prior to real field testing and was based on the recommendations of Krueger and Casey. ${ }^{26}$ It was used to stimulate and structure the discussion, which covered impressions and experiences, positive aspects as well as any aspects of usability requiring improvement of the sensor, smartphone or app.

The socio-demographic data were collected through interviews on day 2 of real field testing (Table 2).

\section{Data analysis}

The focus groups were transcribed verbatim according to a transcription guideline utilising the software program ${ } 4^{\circledR}$. The transcripts were analysed applying deductive content analysis, which is suitable for providing new insights and a condensed description of a phenomenon. ${ }^{27}$ Prior to data analysis, a categorisation matrix was developed based on the deductive coding system of the previous study. ${ }^{23}$ In this study, the analysis focused on aspects of usability of sensor, smartphone and app in daily life. The categorisation matrix was applied to the data in three iterative coding cycles using provisional, simultaneous and structural coding. ${ }^{28}$ This analysis was reviewed 
by a second researcher (SH). Disagreements of code assignments were resolved by discussion. The codes were clustered into categories and subcategories according to similarity and regularity and were descriptively summarised. Additionally, notes from the research team diary supported decision-making during the clustering process, along with the thematically recurrent topics from the user's perspective. The categories and subcategories were then critically reviewed and discussed in the research team. After minor modifications regarding their naming, the final version was approved by the team. MAXQDA ${ }^{\oplus}$ (version 12) supported the qualitative data management. Sociodemographic data were described using descriptive statistics (e.g., mean or absolute and relative frequencies). The study diary notes were introduced by the participants during the focus group interviews.

\section{Ethical consideration}

The Ethical Committee of the Canton of Bern (KEK-BE 091/15) approved the study. Written and verbal informed consent was obtained prior to the study participation.

\section{Results}

A total of 15 participants with a mean age of 81 years participated in the real field testing of the fall detection prototype. Further characteristics are displayed in Table 3. Two participants opted out on day 2 but later participated in the focus group. One of those participants considered the handling of the smartphone too difficult and the other participant felt overly strained due to bereavement. Each focus group lasted on average $100 \mathrm{~min}$.

No fall was reported. Ten false fall alerts were indicated, which were due to the sensor being dropped or accidentally manually activated. The results of the usability prototype testing are divided into positive aspects and aspects requiring improvements for each part of the fall detection device, namely sensor, smartphone and application.

\section{Sensor}

\section{Positive aspects}

Overall, the size, weight, thickness and the material of the body-worn waterproof sensor were experienced as being comfortable. The preferred body location for wearing the sensor was the abdomen and its comfort was rated as high for both day and night. Gradually, the participants forgot the sensor: "I didn't realize I was wearing the sensor. 
Table 3. Participant characteristics $(\mathrm{N}=15)$

\begin{tabular}{lc}
\hline Characteristics & Participants (N=15) \\
\hline Age (years), mean (SD) & 81 (5.6) \\
Age (years): (min-max) & $75-92$ \\
Gender & 11 \\
Female & 4 \\
Male & 9 \\
Living alone & 6 \\
Assistance in daily living & 4 \\
History of fall(s) & 8 \\
Fear of falling & 2 \\
Use of walking aid & 4 \\
Instability during walking & 6 \\
Smartphone use prior to study participation & 4 \\
Mobile phone use prior to study participation & 8 \\
\hline Internet use at home & 10 \\
\hline
\end{tabular}

Abbreviations: $\mathrm{SD}=$ standard deviation; $\min =$ minimum; $\max =$ maximum

The wearing comfort is 100\%" [FgPA] the two patches provided were highly praised both for fixing to and removing from the skin, as well as for their wearing comfort. Even participants who mentioned having highly sensitive skin were able to use the patches. The battery duration of 24 to $36 \mathrm{~h}$ was considered as acceptable by the participants, as they had two sensors each. Charging the sensor by simply placing it on the charging shell was considered to be very convenient:

"Me either, I haven't had a problem. I quite simply put the sensor on the charging shell in the evening. In the morning it was charged. I changed them and so the sensor was useable for the whole day" [FgPC/D].

\section{Aspects requiring improvements}

Although the battery duration was acceptable, the participants would have preferred a sensor that could be worn for several days or weeks without having to recharge it. Some participants explicitly emphasised that the daily charging and changing of the sensor bothered them, as they felt disturbed in their daily activities, especially when going out or when they were active for the entire day.

A further aspect requiring improvement was the poor visibility of the sensor after having fallen upon the floor. Therefore, they recommended a signal, such as a manually activated blinking light. 
Several participants explicitly preferred to wear and use the sensor alone, without having the smartphone, particularly when at home. Its usability would then be further increased, as only one device would be necessary.

"What about a bigger sensor, perhaps twice the size, thus, the sensor could also have an alert function. This would be perfect, as no smartphone would be needed" [FgPA].

\section{Smartphone}

The smartphone represented a considerable barrier to the use of this fall detection device. Therefore, the discussion focused mainly on aspects of improvement, which were regarded as essential for further development of the device.

\section{Aspects requiring improvements}

In general, several participants felt unable coping with the smartphone. They added that most of their generation would need extensive training and coaching regarding handling a smartphone, to be able to deal with it on a day to day basis. However, some participants argued that with training, it would be possible to feel more comfortable with it.

The touch screen sensitivity of the smartphone was repeatedly criticised: Either the touch was too brief, too long, too weak, too strong or several keys were activated simultaneously. Once reactivated from the standby mode, several windows of different apps were often open. This caused problems and frustration because it was difficult to find the fall detection app:

Participant 1 (P1) "I was bothered by this [smartphone]. After a while, it was just ticking over, and the screen was black. I had to reactivate it, I pushed the button from below, sometimes I saw it [fall detection app] directly, but more often other windows appeared. I pushed them back and forth, and finally, thank goodness, the fall app was in the middle of the screen."P2"Cor, thank you for this description! I thought, this happened only to me!" P3 "No, as if! We are all badly off" [FgPC/D].

Therefore, the participants suggested as follows: The smartphone should only provide the apps that are actually used by the person. For some participants, the font size, contrast and brightness were inadequate. To enable older people with deteriorating eyesight to use a smartphone, the participants revealed the need to individualise its colour, font size, contrast or brightness. The duration of the smartphone battery was approximately six hours, due to the continuous processing of data, which were unanimously considered to be too short for everyday life. It was burdensome to check the charging status of the smartphone several times a day, to remember to recharge it, to plug it in overnight and, along with all of that, it could not be placed too far from the 
bed. "I had the feeling, I am not a slave, but a full-time supercharger of the smartphone and the sensors" $[\mathrm{FgPA}]$. The annoyance with the battery duration increased when users left home for a whole day or even for a few hours.

The required distance to maintain a reliable connection between the sensor and smartphone was hardly usable in everyday life ( 8 to $10 \mathrm{~m}$ ). In particular, seniors who were living in a house or a larger apartment, and who had a garden, complained of feeling limited in their mobility and activity. Using this fall detection prototype meant not only having a main outlet where the smartphone could remain while moving around in the house, but also having to think to pick it up when going to another floor or when going the garden.

"I was not only annoyed... dragging it with me all the time...I forgot it, it was on the wrong floor or something else, and I thought: I would rather throw it out the window" [FgPC/D].

As the status of connectivity between sensor-smartphone was only indicated on the app, the point when users went beyond the reliable fall detection distance was not perceivable without the smartphone.

\section{App}

\section{Positive aspects}

Overall, the app was described as being easy to manipulate and the textual content was clear, comprehensible and readable.

"It (the application) was very positive, with big writing and touch buttons, and

"change sensor" was clearly written in the lower part" [FgPA].

The suggested colours (green, blue, yellow and orange) of the app were evaluated as pleasant. The automatic fall alert function along with the possibility to manually deactivate an alert was judged to be crucial for use of the device in everyday life. Two to three minutes allowance time for manual deactivation was thought to be optimal, as reaction time declines with age and not disturbing contact persons without a good reason was viewed as being important. It was considered helpful that the alert text message contained the localisation data (GPS) of the alarming person. The participants described themselves as active and on the move. Hence, the outdoor localisation seemed very important to them.

\section{Aspects requiring improvement}

Several times during real field testing, the contact person only recognised an alert hours after it had been sent and became very frightened: 
"Two hours later, my neighbour came to my apartment very agitated and said 'I am very sorry, I didn't notice your alert. Is something wrong with you?' And I said, happily nothing happened to me; I was only testing [the fall detection device]. She was so hugely relieved ..." [FgPA].

Hence, it was considered crucial that the contact person who could not answer the alert should be informed by an automatic text message that the alert no longer required their attention.

Additionally, the participants believed that it may not be reasonable to expect that relatives, friends or neighbours are available $24 \mathrm{~h}$ a day. This is why an institutional telephone number, a specialised call centre and healthcare professionals, such as nurses, should always be on the contact person's list. It was suggested that it might also be desirable to develop an app for the contact persons, to allow them to easily validate the alert.

The participants revealed some challenges regarding the choice of a contact person. It could be burdensome for relatives to act as a contact person because they are asked to be available even during the night and to react appropriately when help is needed. Moreover, they mentioned that relatives should also receive training. A few older people said that they did not have relatives or other persons who could be asked, or who were willing to provide this availability. Furthermore, the question of how the contact person would access the apartment / house needs to be clarified when using a fall detection device. In summary, Figure 1 provides an overview of the positive aspects and the aspects requiring improvements regarding sensor, smartphone and application.

\section{Discussion}

Community-dwelling older people were involved in real field testing to investigate the usability of a fall detection prototype in daily life. They described the waterproof sensor prototype as being very comfortable over a $24 \mathrm{~h}$ period, and as having a high degree of usability, with little need for improvement. Of added value was the automatic fall alert, including GPS, combined with the possibility of manual alert. The app was viewed as being pleasant and easy to comprehend, but improvements were required regarding the alerting process and the choice of contact persons. In contrast, most of the participants encountered usability problems with the smartphone, due to its handling, its short battery duration or due to difficulty maintaining the right distance for reliable fall detection.

A particularly significant result is that, on the one hand, the application was evaluated as requiring little improvement; however, on the other, the handling of the 
smartphone was considered to be challenging. First, although the seniors in the study who were already using a smartphone were in a minority, the prototype was still viewed by others as having the potential to be a usable device if the required optimisations regarding sensor and smartphone were addressed. Second, feeling overstrained in handling a smartphone may be attributable to a need for more training and coaching. The need for training when using a call alarm is described in the literature..$^{29}$ Although the research team ensured face-to-face contact during the user seminars as well as during the home visit, repeated coaching and training over a longer period of time would likely be necessary. For outdoor activity, the use of a smartphone to call for rapid help would be important. Recently, more research has focussed on the accessibility of older people to mobile communication options, ${ }^{30,31}$ and a smartphone might be a usable solution for upcoming generations. Consequently, to offer a desirable option for the current generation, a second version should be developed, which would enable those seniors who do not use a smartphone to take advantage of this waterproof, invisible, 24-hr wearable and automatically alerting fall detection sensor. In particular, the results demonstrate that recommendations regarding the use of a smartphone should be carefully considered, which contrasts with the suggestion of Lee and Carlisle, $^{32}$ who recommend that a smartphone for fall detection and alerting represent a highly attractive option from the perspective of older people. The underlying study indicates that persons using a smartphone should fulfil some criteria, for example, prior smartphone usage, being motivated to learn how to use a smartphone, or being homebound and having daily contact with carers.

Third, however, the majority of participants called for a solution without a smartphone. This result is important and is understandable, as older people are a heterogeneous age group..$^{33}$ It is not reasonable to expect that "one device would fit all." The findings suggest that usability of a device goes beyond technical requirements. In particular, longer battery duration (smartphone, sensor), maintenance of a reliable connection between the sensor - smartphone also with longer distances and utilisation of the sensor without smartphone were found to be significant requirements. These findings indicate that usability is largely influenced by the desire to be independent - also in terms of physical activity - and to have confidence in a device's reliability for one's entire living space without expending much effort on its maintenance (e.g., for charging). These concerns are congruent with the findings of Fleming and Brayne ${ }^{10}$ and Johnston et al., ${ }^{34}$ who investigated, among other things, the reasons for non-use of a call alert system. Hence, it seems obvious that high acceptance of alerting devices is not correlated with high use in older people. ${ }^{15}$

This is an interesting finding, because it indicates that the device on its own might be accepted as helpful by older people; however, to be utilised in daily life, it should 
have the capacity to be easily integrated into daily routines. As older people are a heterogeneous age group, ${ }^{33}$ the current prototype may be suitable for homebound people or people with daily contact with carers, who could then be responsible for its maintenance.

Another specific finding suggests that the fall detection device may not have yet sufficiently met the concerns of older people with visual problems. The participants asked for a blinking light or a bright colour, which would help to more easily relocate a dropped sensor. This is hardly surprising, as visual impairments are common among older people, and the risk of experiencing such impairments increases with advancing age. ${ }^{35}$ Additionally, visual impairment is described as being related to falls. ${ }^{36}$ Thus, reallife testing indicates that fall detection devices need to be adapted to people with visual impairments.

A further point of discussion is the alerting process and the choice of contact persons. It was perceived as complex when choosing the right persons with adequate knowledge, skills and availability as well as the kind of information to share in case of an alert. Additionally, the findings support that contact persons should be trained in their role. Service organisations, including healthcare professionals such as nurses, should always be included as contact persons to ensure 24-h availability. It was considered too burdensome to require 24-h availability from private contact persons. This preference is congruent with the findings of Stokke. ${ }^{14}$ In particular, healthcare professionals are important, because if users are unsure about the helpers' qualifications, it could be a reason for non-use. ${ }^{14}$ These aspects may provide a salient contribution in supporting older people in using a device in daily life. Moreover, it suggests that relatives and healthcare professionals should also be involved in the development and testing of the device, to thoroughly investigate their roles in the alerting process and how to optimally train, support and advise seniors in the use of a fall detection device.

A limitation of the study could be the sample used, as the majority of participants lived in the community without need of assistance. However, according to Stokke, ${ }^{14}$ the typical alarm call system user is over 80 years of age and lives alone. This study involved older people with an average age of 81 years; nine of 15 participants lived alone. Another interesting variable might be a history of falls, as it is conceivable that those with a history of one or more falls might be more willing to use a device than those without. In this study, four of 15 participants had a history of falls. However, a recent study found no significant difference regarding history of falls between participants who had purchased an alerting device and those who had not. ${ }^{37}$ Thus, the underlying sample also seems appropriate in terms of risk of falls. In addition, it could be argued that more physical problems would have little influence on the results, as smartphone usage was already problematic, and care-dependency would actually result in the user 
Positive aspects

Aspects requiring improvement

$\rightarrow$ Wearing duration

$\rightarrow$ Adding blinking light

$\rightarrow$ Extending battery

duration

$\rightarrow$ Using only the sensor

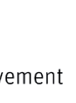

ing comfort
on the body
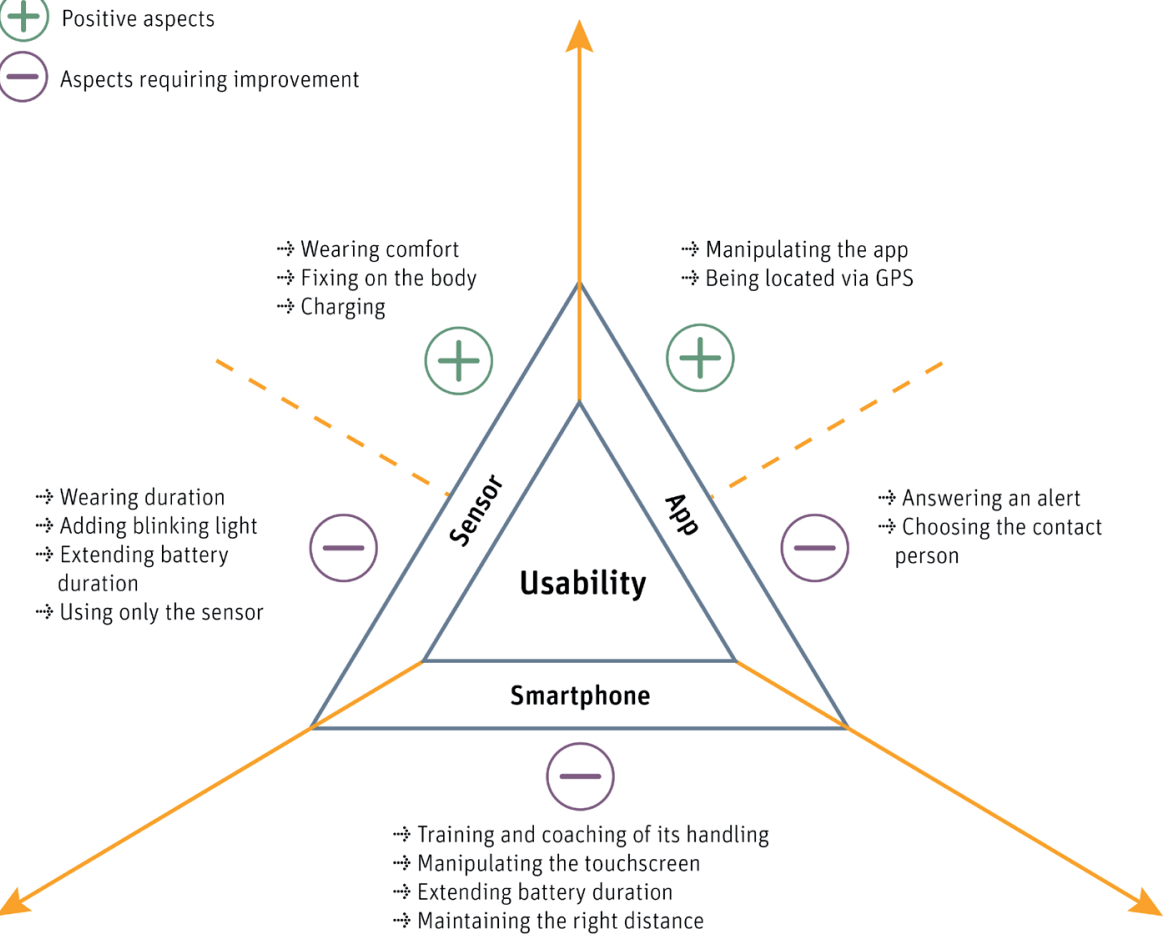
$\rightarrow$ Fixing on the body
$\rightarrow$ Charging

Manipulating the app

$\rightarrow$ Being located via GPS

Figure 1. Results of the usability testing of the fall detection prototype in everyday life (author's illustration)

being more homebound and perhaps they would then have a carer or relatives who could be responsible for the device. Consequently, it seems even more important to include those older people who are still able to actively engage in the community.

This study indicated that including other user groups, such as relatives and healthcare professionals, especially nurses, is critical when using a device. Their involvement would have provided beneficial additional insight. However, due to limited financial resources, the research team narrowed the variety of users involved.

Fifteen of 16 participants took part in the study; thus, according to Faulkner, ${ }^{38}$ in a group of 15 people, $90 \%$ of usability problems of a device will be found. Although known for its numerous benefits, ${ }^{21,22}$ user involvement might be challenging in terms of collaboration with users. ${ }^{21,39}$ Thus, different methods of involvement and smaller groups of participants were chosen. This enabled the participants to be personally coached, thereby establishing trust and collaboration with the nurse researchers, and ensuring that participants felt secure during testing. Additionally, researchers from nursing 
science are highly skilled in communicating and collaborating with older people. This can be considered as a strength of the study, because even those who had severe problems in using the prototype participated in the focus groups, and thus provided valuable insights regarding optimisations of the device.

\section{Conclusion}

This study encourages the development of a 24-h wearable, waterproof, automatic alerting (including GPS location) fall detection device but emphasises that a solution without a smartphone should also be provided. To meet the heterogeneous needs of older people, several versions of this device are needed. It is hardly reasonable to aim for a "one device fits all" solution. First, we recommend development of the "original" version of the device, in which the sensor is linked to a smartphone, and in which the requirements for optimisation are considered. Persons already using a smartphone should be able to download the application from the app store, thereby only purchasing the sensor. Second, a sensor version without smartphone should be provided. This could be accomplished by linking the sensor to a centrally located base station at home, with reliable fall detection and alerting in the indoor living area, as well as outdoors in the garden area. Thus, those seniors who do not (yet) use a smartphone could also take advantage of the waterproof, invisible, 24-h wearable and automatically alerting fall detection sensor. A further possibility might be that the smartphone could be used only when away from home (when going for a walk, when in town or when travelling).

The study revealed that the integration of a fall detection device into daily life goes beyond its technical requirements. It is also strongly influenced by habits and personal preferences such as daily routines, physical mobility, maintenance of the perception of being able to live independently, as well as by the role that relatives and healthcare professionals have with the participant. This valuable insight can only be operationalised by involving older people and their relatives in device development. Healthcare professionals seem to play an important role when fall detection devices are used. This signifies that healthcare professionals, such as nurses, require enough knowledge to support and advise on everyday usage, and that they should be part of the alerting process. Also, the competencies and skills of the contact persons involved should be reviewed and, if necessary, they should receive training, which could be provided by healthcare professionals. It is also important that being a contact person does not represent a burden to the relative.

Additional research is needed to investigate further factors influencing the use and non-use of fall detection devices in community-dwelling older people. This could be 
accomplished through a qualitative approach investigating the perspectives of these people and their persons of trust, namely relatives and healthcare professionals. Thus, the topic of falls and device use could be better understood and supported, which would assist in promoting older peoples' active and safe living in the community.

\section{Relevance to clinical practice}

The integration of a fall detection device into the everyday life of community-dwelling older people could improve their ability for independent living in old age. Health care practitioners assisting in the use of a fall detection device in community-dwelling older people could make a significant contribution towards the promotion of active ageing. However, to ensure successful consultations and the sustainable utilisation of such a device, nurses require the appropriate knowledge to support, coach, train and offer advice regarding its everyday use.

Additionally, health care practitioners need to assess the suitability of the fall detection device with personal preferences, skills and habits. They should identify and teach how the device could be included in daily life. Furthermore, depending upon the availability of relatives, health care practitioners should ensure that contact persons for the alerting process are involved are able to access the apartment and are also knowledgeable in reassessing the adequacy of the device.

The study also indicates that health care practitioners can significantly contribute to "need-driven" technology development, by translating user-related contextual knowledge and requirements to the developers of the technology.

\section{Acknowledgements}

We are grateful to the study participants for their engagement and accorded time. We are thankful to Tannys Helfer, from Bern University of Applied Sciences, Bern, Switzerland, for her linguistic support and to Selina Bilger (SB) for her support in the recruitment and data collection of the study. Special thanks go to Prof. Dr. Monika Linhart for her collegial inspiring exchange and critical questions. This study was supported by the Bern University of Applied Sciences, Switzerland (grant number 14118DPT).

Contributions Study design: FJST, SH; data collection and analysis: FJST, SH, RJGH, JMGAS and manuscript preparation: FJST, SH, RJGH, JMGAS.

ORCID Friederike J. S. Thilo http://orcid.org/0000-0002-5085-3664 


\section{References}

1. WHO The World Health Report 2008.

2. WHO, Strategy and action plan for healthy ageing in Europe, 2012-2020. 2012, World Health Organization: Copenhagen.

3. Centers for Disease Control and Prevention. Falls Among Older Adults: An Overview. 201220.09 .201209 Dec 2016]; Available from: http://www.cdc.gov/homeandrecreationalsafety/falls/adultfalls.html.

4. Rubenstein, L.Z., Falls in older people: epidemiology, risk factors and strategies for prevention. Age Ageing, 2006. 35 Suppl 2: p. ii37-ii41.

5. Gill, T.M., et al., Association of injurious falls with disability outcomes and nursing home admissions in community-living older persons. Am J Epidemiol, 2013. 178(3): p. 418-25.

6. Spaniolas, K., et al., Ground level falls are associated with significant mortality in elderly patients. J Trauma, 2010. 69(4): p. 821-5.

7. Liu, J.Y.W., Fear of falling in robust community-dwelling older people: results of a cross-sectional study. Journal of Clinical Nursing, 2015. 24: p. 393-405.

8. Zijlstra, G.A., et al., Prevalence and correlates of fear of falling, and associated avoidance of activity in the general population of community-living older people. Age Ageing, 2007. 36(3): p. 304-9.

9. Lord, S.R., C. Sherrington, and H.B. Menz, Falls in oder people. Risk, factors and strategies for prevention. 2001, Cambridge: Cambridge University Press.

10. Fleming, J. and C. Brayne, Inability to get up after falling, subsequent time on floor, and summoning help: prospective cohort study in people over 90. BMJ, 2008. 337: p. a2227.

11. Simpson, P.M., et al., Epidemiology of emergency medical service responses to older people who have fallen: a prospective cohort study. Prehosp Emerg Care, 2014. 18(2): p. 185-94.

12. Satariano, W.A., A.E. Scharlach, and D. Lindemann, Aging, place, and Technology: Toward Improving Access and Wellness in Older Populations. Journal of Aging and Health, 2014. 26(8): p. 1373-89.

13. Chaudhuri, S., H. Thompson, and G. Demiris, Fall Detection Devices and Their Use With Older Adults: A Systematic Review. J Geriatr Phys Ther, 2014.

14. Stokke, R., The Personal Emergency Response System as a Technology Innovation in Primary Health Care Services: An Integrative Review. J Med Internet Res, 2016. 18(7): p. e187.

15. Nyman, S.R. and C.R. Victor, Use of personal call alarms among community- $d$ welling older people. Ageing \& Society, 2014. 34(1): p. 67-89.

16. Heinbuchner, B., et al., Satisfaction and use of personal emergency response systems. Z Gerontol Geriatr, 2010. 43 .

17. Chaudhuri, S., et al., Older Adluts' Perceptions of Fall Detection Devices. Journal of Applied Gerontology, 2015. 36(8): p. 915-930.

18. Bridgelal Ram, M., P. Grocott, and H. Weir, Issues and challenges of involving users in medical device development. Health Expect, 2007. 11: p. 63-71.

19. Thilo, F.J.S., et al., Involvement of older people in the development of fall detection systems: a scoping review. BMC Geriatrics, 2016. 16(42).

20. Schulz, R., et al., Advancing the Aging and Technology Agenda in Gerontology. Gerontologist, 2015. 55(5): p. 724-734.

21. Kujala, S., User involvement: a review of the benefits and challenges. Behaviour \& Information Technology, 2003. 22(1): p. 1-16.

22. Rodeschini, G., Gerotechnology: a new kind of care for aging? An analysis of the relationship between older people and technology. Nurs Health Sci, 2011. 13(4): p. 521-8.

23. Thilo, F.J.S., et al., Involvement of the end user: exploration of older people's needs and preferences for a wearable fall detection device - a qualitative descriptive study Patient Preference and Adherence 2017. 11: p. 11-22. 
24. Shah, S., I. Robinson, and S. AlShawi, Developing medical device technologies from users' perspectives: $A$ theoretical framework for involving users in the development process. International Journal of Technology Assessment in Health Care, 2009. 25(4): p. 514-521.

25. AlRoobaea, R. and P. Mayhew, How Many Participants are Really Enough for Usability Studies?, in Science and Information Conference. 2014: London, UK.

26. Krueger, R.A. and M.A. Casey, Focus Groups A Practical Guide for Applied Research. 2009, London: SAGE.

27. Elo, S. and H. Kyngäs, The qualitative content analysis process. Journal of advanced nursing, 2007. 62(1): p. 107-115.

28. Saldana, J., The Coding Manual for Qualitative Reserachers. 2 ed. 2013, London Thousand Oaks New Delhi Singapore: SAGE.

29. Fallis, W., et al., Client and responder perceptions of a personal emergency response system: Lifeline. Home Health Care Serv Q, 2007. 26(3): p. 1-21.

30. Diaz-Bossini, J.-M. and L. Moreno, Accessibility to mobile interfaces for older people. Procedia Computer Science, 2014. 27: p. 57-66.

31. Nguyen, T., et al., Access to mobile communications by older people. Australasian Journal on Ageing, 2015. 34(2): p. E7-12.

32. Lee, R. and A. Carlisle, Detection of falls using accelerometers and mobile phone technology. Age and Ageing, 2011. 40(6): p. 690-696.

33. Grigsby, J.S., The meaning of heterogeneity: An introduction. Gerontologist, 1996. 36(2): p. 145-146.

34. Johnston, K., et al., Personal alarm use to call the ambulance after a fall in older people: characteristics of clients and falls. Journal of Emergency Primary Health Care (JEPHC), 2010. 8(4): p. 1-9.

35. Evans, J.r., et al., Prevalence of visual impairment in people aged 75 years and older in Britain: results from the MRC trial of assessment and management of older people in the community. Br J Ophthalmol, 2002. 86(7): p. 795-800.

36. Källstrand-Ericson, J. and C. Hildingh, Visual impairment and falls: a register study. Journal of Clinical Nursing, 2009. 18: p. 366-72.

37. De San Miguel, K., et al., Exploring risk profiles and emergency frequency of purchasers and non-purchasers of personal emergency alarms: a prospective cohort study. BMC Geriatr, 2015. 15(1): p. 140.

38. Faulkner, L., Beyond the five-user assumption: Benefits of increased sample size in usability testing. Behavior Research Methods, Instruments, and Computers, 2003. 35(3): p. 379-83.

39. Shah, S.G. and I. Robinson, Benefits of and barriers to involving users in medical device technology development and evaluation. Int J Technol Assess Health Care, 2007. 23(1): p. 131-7. 


\section{Chapter 5}

\section{How older persons consider using a Personal Safety Alerting Device: a qualitative study}

This chapter is submitted to the Journal of Advanced Nursing as: Thilo, F.J.S., Schols, J.M.G.A., Halfens, R.J.G., Linhart, M. and Hahn, S. How older persons consider using a Personal Safety Alerting Device: a qualitative study. 


\title{
Deciding about the use of a Personal Safety Alerting Device- The need for a legitimation process: A qualitative study
}

\author{
Friederike J. S. Thilo,2 (D) | Jos M. G. A. Schols ${ }^{2,3}$ | Ruud J. G. Halfens ${ }^{2}$ | \\ Monika Linhart $^{1}$ | Sabine Hahn ${ }^{1}$
}

\author{
${ }^{1}$ Applied Research \& Development in \\ Nursing, Department of Health Professions, \\ Bern University of Applied Sciences, Bern, \\ Switzerland \\ ${ }^{2}$ School CAPHRI, Department of Health \\ Services Research, Maastricht University, \\ Maastricht, The Netherlands \\ ${ }^{3}$ School CAPHRI, Department of Family \\ Medicine, Maastricht University, Maastricht, \\ The Netherlands
}

\section{Correspondence}

Jos M. G. A. Schols, Maastricht University, School CAPHRI, Department of Health Services Research, Duboisdomein 30, 6229 GT Maastricht, P.O. Box 616, 6200 MD Maastricht, The Netherlands.

Email: jos.schols@maastrichtuniversity.nl

Funding information

This study was supported by Symphasis Foundation.

\begin{abstract}
Aims: To explore reasons, thoughts, motives, and influencing factors regarding the use or non-use of Personal Safety Alerting Devices (PSADs) in the daily lives of community-dwelling older persons.

Design: A qualitative descriptive study design was used.

Methods: Six focus groups were conducted with a total of 32 older persons between February-August 2016. Data analysis followed the Qualitative Analysis Guide of Leuven.

Results: The participants described the use or non-use of PSADs as a decision resulting from a "legitimation process". This process implies that a person needs to perceive the necessity for a PSAD and then determine the right moment at which to start using it. During this process, each person weighs her or his "ageing self" and "perception of technology" then decides whether to start using a device or to delay its use. "Critical events" initiate this process, compelling the person to consider their own safety and their possible need for assistance.

Conclusion: The legitimation process suggests that the initiation of PSAD use represents a turning point in life. Using a PSAD is not simply a matter of obtaining one. It is a complex decision-making process establishing legitimation for its use, which is interwoven with one's individual ageing, self-perception, and the meaning attributed to the device.

Impact: Older persons need to be supported; in particular, they require time to go through the legitimation process for PSAD use. Nurses can empower them in this process, such that they perceive using a PSAD as a means to restore their frailty balance and feel enabled to (re)gain control over their own life and thus to preserve their independence.
\end{abstract}

\section{KEYWORDS}

ageing in place, community-dwelling, decision-making, empowerment, focus group, gerontechnology, independent living, nurses, patient safety, technology adoption 


\section{1 | INTRODUCTION}

"Ageing in place" is embraced by health care and political agendas worldwide (International Federation on Ageing, 2011). Ageing in place promotes the well-being of older persons by enabling them to live independently, while safely and socially integrated in their accustomed surroundings in the community (Scharlach \& Diaze Moore, 2016).

Community care is often considered a precondition for ageing in place (Vasunilashorn et al., 2012) and community nurses specifically facilitate and support ageing in place (Greenfield et al., 2019). Community nurses assist older persons in maintaining their activities of daily living, in identifying any early symptomatic changes and in enabling a safe way of life (Smolowitz et al., 2015; Young et al., 2015).

\section{2 | BACKGROUND}

The safety of older persons is of primary concern for community nurses, as many falls occur in the home environment (Hefny et al., 2016; National Council for Aging Care, 2018). International studies show that the rate of falls is between $25 \%-35 \%$ for community-dwelling older persons older than 65 years of age. This age group experiences at least one fall per year (Gillespie et al., 2012) and fall rates are up to twice as high for persons aged 75 years and older (Gale et al., 2016). A fall is "an unexpected event in which the participants come to rest on the ground, floor, or lower level" (Lamb et al., 2005). A considerable number of older persons, from 53\%$80 \%$, are unable to get up after a fall and $13-30 \%$ of them endure a so-called "long lie" (Fleming et al., 2008; Simpson et al., 2014), i.e. lie on the ground/floor for longer than one hour, leading to a high risk for adverse outcomes, such as hypothermia, hospital admission, or serious injuries like hip fractures or head trauma (Bloch, 2015; Gill et al., 2013).

Therefore, Personal Safety Alerting Devices (PSADs) are pivotal for safe ageing in place. PSADs can reduce health-threatening consequences by enabling rapid assistance in emergency situations (Agboola et al., 2017; Nyman \& Victor, 2014). Even though older persons consider PSADs to be helpful or report being satisfied with them, they are still rarely used in the daily life (Heinbüchner et al., 2010; McLean, 2016; Nyman \& Victor, 2014). Non-usage, minimal-usage, or refusal of usage has been shown to be related to usability problems such as difficulty in activating an alert, economic issues, or forgetting to wear/activate the device (Heinbüchner et al., 2010; Stokke, 2016).

Although increasing international attention is being given to the "need-driven" development of PSADs by involving older persons (Chaudhuri et al., 2015; Thilo et al., 2016, 2018), the discrepancy between their acceptance and their non-usage/minimal usage, continues to be a significant healthcare challenge (Lapierre et al., 2018; Nyman \& Victor, 2014; Stokke, 2016). Several researchers have reported that the acceptance of technology by older persons can be influenced by health professionals (Peek et al., 2014; Stokke, 2016).
For instance, community nurses' perceptions of the usefulness and appropriateness of assistive technologies for patient care was shown to be meaningful to older persons (Piscotty et al., 2015). However, there is a gap in the current literature regarding the understanding of the influencing factors around PSAD use and non-use in daily life. Far too little attention has been given to the reasons and motives of community-dwelling older persons. Gaining more insight may generate new strategies as to how community nurses can support older persons in PSAD use, thus enhancing safe ageing in place.

\section{3 | THE STUDY}

\section{1 | Aim}

The aim of this research was to answer the question: What are the reasons, thoughts, motives and influencing factors regarding the everyday use and non-use of a PSAD from the perspective of communitydwelling older persons?

\section{2 | Design}

A qualitative descriptive research design was adopted (Kim et al., 2017; Sandelowski, 2010), using focus groups (Stewart \& Shamdasani, 2015) to explore and uncover factors and rationales for behaviour related to PSAD use and non-use. Most research focused on the acceptability and usability of technologies is quantitative in nature and conducted in disciplines other than health care and nursing; thus, the context of acceptable technologies for older persons has hardly been investigated (Holden \& Karsh, 2010; Marangunić \& Granić, 2015; Taherdoost, 2018). Furthermore, a qualitative approach sampling the perspective of the user group itself was chosen as most likely to advance understanding.

\section{3 | Sample/participants}

Through purposeful and snowball sampling, community-dwelling older persons who were ambulatory, German-speaking, and aged 75 or older were recruited. The age limit was based on data indicating that adults 75 years of age and older are part of a late technology adopters generation (Smith, 2014) and also because they are at a high risk for falls (Rubenstein, 2006). Moreover, the participants should have had some experience with PSADs or with situations of falls or fear of falling. Persons using a wheelchair, living in an institution or an assisted-living facility, or who were cognitively impaired were excluded.

It is well-known that recruiting community-dwelling older persons for study participation is challenging (Hawranik \& Pangman, 2002). We contacted over 25 organizations such as seniors' associations or healthcare service organizations by distributing printed and electronic information leaflets. Faculty members, who were not part of 
the research team or in other research project collaborations, were contacted via email and asked to forward the leaflet to their (grand-) parents, other relatives, and neighbours. Additionally, older persons who had already participated in a previous study from the Institute of Nursing Science were contacted. We assumed that they might be interested in participating in a new study due to the thematic proximity of falling.

\subsection{Data collection}

We organized a focus group once at least four participants agreed to participate in the study. Six focus groups with four to eight participants each were conducted between February-August 2016. Each discussion lasted $2 \mathrm{hr}$ and was audio recorded. All focus groups were moderated by the first author (FJST), who is experienced in qualitative interviewing and were assisted by a research assistant. Different strategies were used to foster group dynamics and interactions: emphasizing that personal and conflicting viewpoints were welcomed, active listening, follow-up questions, or non-verbal signs (eye-contact, nodding) (Brinkmann \& Kvale, 2015).

A topic-guide was used. The sequence of a focus group discussion is displayed in Table 1.

The presentation of ten PSADs (Table 1) stimulated the discussion, provided information on PSAD diversity, use and function, allowed hands-on experiences and better understanding of reasons for liking or disliking a PSAD or considering it helpful or awkward. Finally, study sample participants completed a short questionnaire.

Following each discussion, field notes were made, and a research diary was kept (FJST) to document the study process and decisions made. The moderator and research assistant reflected on the themes discussed. Insights were incorporated into subsequent focus groups.

\subsection{Ethical considerations}

The study was conducted in accordance with the Swiss Federal Act on Research Involving Humans, confirmed by the cantonal Ethics Committee in October 2015. Written and verbal informed consent were obtained prior to study participation. The study leaflet explained the purpose of extending knowledge on falls and currently available personal alerting technologies. This study was conducted in compliance with the protocol, the current version of the Declaration of Helsinki, the ICH-GCP or ISO EN 14155 (as far as applicable), as well as with national legal and regulatory requirements.

\subsection{Data analysis}

Each focus group discussion was transcribed verbatim, using the software program $f 4^{\circledR}$. Identifying information was pseudonymized. Data were analysed using the Qualitative Analysis Guide of Leuven (QUAGOL), which allows a comprehensive and systematic but flexible analysis process consisting of two parts: in-depth preparation of the coding process and the actual coding process (Dierckx de Casterlé et al., 2012). The QUAGOL was supplemented in steps seven to nine, using the methods of open and axial coding and memo writing (Boehm, 1994; Saldana, 2016). Please refer to Table 2. This combination allowed for enhanced depth of interpretation during data analysis.

TABLE 1 Sequence of a focus group discussion

\section{Focus group}

First part:
Topics addressed:

- Everyday experiences with electronics

- Experiences with the topic of fall/PSADs

- One's own view of being a user or non-user of a PSAD

Presentation of ten PSADs

- An emergency button;

- A watch;

- A house emergency call combined with an alert bracelet or necklace;

- A mobile phone with speed dial buttons;

- A senior-friendly telephone combined with an alert bracelet or necklace;

- A sensor mat for a chair and for the floor;

- A radio transmitter fall detector;

- An infrared sensor;

- A camera-based-system;

- A wearable fall detection sensor (prototype)

Second part:

Topics addressed:

- Reasons for liking or disliking a PSAD

- Reasons for considering a device as helpful/pleasant or awkward/unpleasant

- Any additional thoughts regarding PSAD use and non-use 


\begin{tabular}{|c|c|c|}
\hline Methods & $\begin{array}{l}\text { Focus group } \\
\text { (FG) } n=6\end{array}$ & Researchers \\
\hline $\begin{array}{l}\text { QUAGOL Steps 1-5 carried out independently: thorough } \\
\text { (re)reading; narrative report; from narrative report to } \\
\text { inductive developed conceptual topic scheme; fitting- } \\
\text { test of the topic scheme; constant comparison process, } \\
\text { summary list of themes consolidated by mutual consensus }\end{array}$ & $\begin{array}{l}\text { FG } 1 \text { to } 6 \\
\text { FG } 1-3-5 \\
\text { FG } 2-4-6\end{array}$ & FJST; $\mathrm{BH} ; \mathrm{CG}$ \\
\hline $\begin{array}{l}\text { QUAGOL Step 6: Summary list of themes -> discussion of } \\
\text { inductively developed themes and consolidation by mutual } \\
\text { consensus }\end{array}$ & \multirow[t]{6}{*}{ FG 1 to 6} & \multirow[t]{5}{*}{ FJST, SH; ML } \\
\hline $\begin{array}{l}\text { QUAGOL Steps 7-8: coding process using } \\
\text { list of themes (back to the data); analysis } \\
\text { of themes (meaning, dimensions \& } \\
\text { characteristics) and memo writing; }\end{array}$ & & \\
\hline $\begin{array}{l}\text { Supplemented by: open coding (questions } \\
\text { to the text, verification of additional/ } \\
\text { other inductive themes), and axial coding } \\
\text { (matrix coding family comprising conditions, } \\
\text { context, consequences and strategies to } \\
\text { identify "the" phenomenon), consolidation } \\
\text { by mutual consensus }\end{array}$ & & \\
\hline $\begin{array}{l}\text { QUAGOL step 9: extraction of the essential } \\
\text { structure }\end{array}$ & & \\
\hline $\begin{array}{l}\text { Supplemented by: axial coding (as described } \\
\text { above) }\end{array}$ & & \\
\hline QUAGOL step 10: description of the findings & & $\begin{array}{l}\text { FJST; SH; ML; } \\
\text { JMGAS; } \\
\text { RJGH }\end{array}$ \\
\hline
\end{tabular}

TABLE 2 Data analysis and interpretation process
The first author (FJST) was responsible for data analysis. Steps seven to nine (Table 2) occurred iteratively until the phenomenon was identified and a nuanced understanding of the themes grounded in the data was achieved. These steps were mainly carried out by the first author and continuously and critically discussed and reflected on with two senior researchers (SH, ML) experienced in qualitative research. Step ten of the QUAGOL was critically discussed and reflected on in the research team. Table 3 shows a data trail of the themes developed according to the QUAGOL process. From step seven data management was supported by MAXQDA software (VERBI GmbH, Berlin, Germany; Version 12 and 2018).

\section{7 | Rigour}

Scientific rigor was ensured through a variety of techniques (Engward \& Davis, 2015; Lincoln \& Guba, 1985) such as memo writing, using a coding paradigm (see QUAGOL steps 6-8) and keeping a reflexive record of the decisions made during analysis. Weekly discussions of the analysis process (FJST, SH, ML) ensured that the emerging findings were credible, that the findings were grounded in the data and that a critical stance in the analysis and interpretation was maintained. Credibility and confirmability were enhanced by means of researcher triangulation (FJST, BH, CG) in the first six steps and by on-going debriefing throughout the entire process.

\section{4 | FINDINGS}

\section{1 | Participant characteristics}

In total 32 community-dwelling persons, including 24 women, aged 75-90 (mean 82) participated in the study. Eight participants had a history of falls in the prior 12 months and 12 participants sometimes experienced fear of falling. One participant was currently using a PSAD. Further characteristics are displayed in Table 4.

\subsection{Decision process on use versus non-use of a PSAD in daily life}

The analysis identified an iterative decision-making process comprising an interplay of three core themes: "Critical Events", "Ageing Self", and "Perception of Technology". Each of these themes were then further described using 3-6 subthemes, which were marked in bold and italicized in the text. This interplay illuminated the participants' reasoning processes before they ultimately decided whether or not to use a PSAD in their daily life. 
TAB LE 3 Exemplarily data trail of themes developed according to the QUAGOL process

\section{Method QUAGOL}

See also description of Table 2

\section{Preparation Steps 1-5: narrative report}

of Coding of each FG, based upon

Process inductively developed summary list of themes per FG

Actual Coding Step 6: Consolidated list of

Process themes of all six FGs

Steps 7-8 (iteratively with step 9): coding process using the list of themes from step 6 (FGs 1-6)
Examples (not comprehensive)

FG 2: choosing the right moment; influence of health professional and relatives; deciding oneself

FG 5: safety need; social network; being allowed to die; being reserved about technology

FG 6: perception of technology based on experience; positive and negative influence of relatives; criteria of the "right moment"

FG 1-6: "the" right moment; health status; safety need; relational status; technology experience; technology attitude; recognizing fall/risk of fall as a problem; device as "stigma of ageing"; the challenge of ageing; being allowed to die

Health status

FG1/3-321

Participant (P) 5: I would say frailty.

Several Ps: $\mathrm{mhm}$ agreeing.

P3: well-being, health condition

P1: losing one's mind

P2: yes, yes

P1: suddenly, you have trouble knowing where you are.

Several Ps: mhm agreeing.

P4: dementia or something like that

P1: Alzheimer, yes

P4: In those cases, it (PSAD) would be very reasonable, for sure.

FG5/360

P2: I think there are days when you feel better, you can take a lot. Then there are days when you feel dizzy or unwell. Then you think: now you must do something. It depends on your [physical] form for the day. Then there are days when it goes great again, then I don't even think about something like that (PSAD).

Safety need

FG2/1,095-1,098

P2: So, somewhere the stamp is cancelled (image for: life is finite). Then you must go. I think we can't insure everything in our life, that's unfortunately the case.

P3: No, no.

$\mathrm{P} 2$ : There is no hundred percent security either.

FG6/359-362

P1: Well, I'm going to say something nasty.

P4: Go ahead.

P1: Until you fall «on your face» for the first time. And then maybe your rethinking will come. Then, you say, I will feel safer when I have such a thing (PSAD) [so that] help comes quickly. It is very difficult to think oneself into another situation when someone is physically still very well off.

P4: Yes, it is individual.

The challenge of ageing

FG4/504

P3: Life is uncertain.

P1: Yes, Yes.

P3: You can't do everything...

P1: Yes, Yes.

P3: If you're just scared, it's not good.

Interviewer (I): Mhm

P1: Then he (a friend) said: watch out, don't think too much about that stuff (devices) otherwise you'll get the feeling that now, you need that (PSAD) too.

Several Ps: Mhm, yes.

I: that goes in the direction of that you prefer not to deal with it and you think nothing will happen to me?

Several Ps: Laughing, yes, yes.

P1: Well, but he said there are those who take it so seriously (...).

P3: A lot of things are simply very abstract, even growing old, suddenly you're 80 years old, but it's not quite so tangible. It seems to me that you just think a little too little about it.

FG3/388-393

P3: I have already experienced it myself, so my husband and I are still quite active. But then he had a back operation once and then the other one is looking out. But if the other one is also not well off at the same time, it will be bad. Then you notice how quickly you reach your limits. (...) It isn't a straight-line hike, what do you do then? Mostly it goes up again sometime, but the older you get, the more such situations happen. And when you have had something serious, then it doesn't get quite as good before anymore, it always leaves some effect.

P1: Yeah, you can't get back on your feet as before.

P3: Yes, exactly!

P1: You just stay a little bit behind of what has been before.

P2: yes, that's it!

$\mathrm{P} 1$ : And it can suddenly go very fast. 
TABLE 3 (Continued)

\section{Method QUAGOL}

Technology attitude

FG3/244

Everything that is so 'highly technical', I already have a kind of defense, an inner defense, yes.

FG5/91-97

P4: I would like to say that my husband came in the beginning (of the 'computer age'), he is probably the oldest

here, and when he stopped working, he said that a computer would never come into our house. He'd had it up

to here. And I stuck to it for about eight years. Until I just felt like, no way, I don't want to be left behind.

I: Mhm

P4: I have fun and am interest in technical things.

I: Yes

P4: And, also considering that the family was not nearby, I had no help from them, I just got into (these technical things).

Step 9 (iteratively with steps

7-8): extraction of the

essential structure (FGs 1-6)

Step 10: description of the essential findings
Figure 1: Legitimation process "The need to perceive its necessity"; Critical Events for Use and Non-use; Ageing Self; Perception of Technology; Decision

See section results

\subsection{1 | Critical events}

The participants mentioned that critical events, often situations related to safety issues in everyday life, caused them to reflect on their need for assistance and on PSAD use and non-use. Several critical events were highlighted: They reported that experienced and reported falls of others, initiated thoughts about their own risk. Some of those falls had no health-related consequences, while others included severe injuries or were even fatal, as the person was not found immediately. Some participants intended to use a PSAD after a first fall, while others preferred to wait as long as possible:

I postpone it [use of PSAD] and I am very careful not to fall. (FG4/139/P2).

Participants felt that if someone lived with a partner without cognitive impairments, or was in daily contact with another person, they did not need a PSAD, because they were looking out for one another Living with another person was described as providing a feeling of safety and confidence and that, if required, mutual help would be provided. As soon as a partner was no longer present, they noted, the situation changed (loss of a close relationship) and they started to question their safety.

Concern of relatives was another critical event. Participants said that mostly their children suggested the use of a PSAD, because they were worried about the parent's safety. However, the participants emphasized that their children were more fearful about their safety than they themselves were. Thus, several added that they would use a PSAD for the sake of their children, because it represented a kind of reassurance for them. Nevertheless, relatives' concern might not entirely legitimate its use:

I know a lady, whose children feel permanently stress, because she falls frequently. However, she refused to wear a (safety) watch. Her children gave her one; she put it on for several days and then she threw it away. (FG3/50/P3).

Interestingly, when thinking about who might use a PSAD, the participants consistently differentiated between older persons who were cognitively fit and in good physical health and those who were not (perceived deterioration of health). It seems that this distinction is crucial in establishing what would justify the use of a PSAD, for example, being cognitively impaired, or having physical health issues, such as dizziness or frailty. Although participants mentioned this clear criterion of use, most of them underlined that their current physical and cognitive health did not yet require PSAD use. However, self-perception might contrast with an external view:

Just because I stagger a bit in the street - this is not a reason for such a device, I am too young, it is too early, even if I will turn 78 soon. (FG1/445/P1).

Furthermore, perceived deterioration of mobility, for example, instability or insecurity while walking, was mentioned by some of the participants as another event which would make them, or already made them, reflect on their own safety. Physical limitation like a low level of mobility was considered a suitable reason for using a PSAD.

Most of the focus groups brought up the topic of dying. It was the only critical event explicitly mentioned as a possible reason for non-use (longing for death). They expressed a kind of serenity or fatalism regarding their "remaining" life. Dying was characterized as a natural process of life; however, the discussions remained ambivalent. The participants emphasized, on the one hand, that suffering should be avoided:

If you have a broken leg, it's nicer to be rescued after $2 \mathrm{hr}$ than to lie in pain all day because you can't call anyone. (FG5/431/P1). 
TABLE 4 Participant characteristics $(N=32)$

\begin{tabular}{|c|c|}
\hline Characteristics & $\begin{array}{l}\text { Participants } \\
\left(\mathrm{N}=31^{\mathrm{a}}\right)\end{array}$ \\
\hline Age (years), mean (SD; min-max) & $82(4.25 ; 75-90)$ \\
\hline \multicolumn{2}{|c|}{$\begin{array}{l}\text { Abbreviations: SD, standard deviation; min, minimum; max, } \\
\text { maximum }\end{array}$} \\
\hline & $n(\%)$ \\
\hline \multicolumn{2}{|l|}{ Gender } \\
\hline Female & $24(77.4)$ \\
\hline Male & $7(22.6)$ \\
\hline \multicolumn{2}{|l|}{ Overall health } \\
\hline Rather good & $10(32.3)$ \\
\hline Good & $20(64.5)$ \\
\hline No answer & $1(3.2)$ \\
\hline \multicolumn{2}{|c|}{ History of fall(s) in the last 12 months } \\
\hline Once & $6(19.4)$ \\
\hline Twice & $1(3.2)$ \\
\hline Three times or more & $1(3.2)$ \\
\hline No & $22(71)$ \\
\hline No answer & $1(3.2)$ \\
\hline \multicolumn{2}{|l|}{ Experiencing fear of falling } \\
\hline Sometimes & $12(38.7)$ \\
\hline No & $18(58.1)$ \\
\hline No answer & $1(3.2)$ \\
\hline \multicolumn{2}{|c|}{ Experiencing instability while walking } \\
\hline Sometimes & $15(48.4)$ \\
\hline No & $16(51.6)$ \\
\hline \multicolumn{2}{|l|}{ Walking aid usage } \\
\hline No & $27(87.1)$ \\
\hline Yes & $4(12.9)$ \\
\hline \multicolumn{2}{|l|}{ Household situation } \\
\hline Living alone & $15(48.4)$ \\
\hline Living with another person & $16(51.6)$ \\
\hline \multicolumn{2}{|l|}{ Household size } \\
\hline Living in a house & $7(21.9)$ \\
\hline Living in an apartment & $24(77.4)$ \\
\hline \multicolumn{2}{|l|}{ Assistance in daily living } \\
\hline Cleaning & $21(70)$ \\
\hline Washing clothes & $1(3.3)$ \\
\hline Shopping & $1(3.3)$ \\
\hline Transport & $4(13.3)$ \\
\hline Medication & $2(6.5)$ \\
\hline \multicolumn{2}{|c|}{ Usage of electronic devices/Internet } \\
\hline Smartphone use & $7(22.6)$ \\
\hline iPad/Tablet use & $6(19.4)$ \\
\hline Laptop use & $8(25.8)$ \\
\hline PC/Computer use & $13(41.9)$ \\
\hline Mobile phone use & $10(32.3)$ \\
\hline Internet use at home & $21(67.7)$ \\
\hline
\end{tabular}

${ }^{a}$ One participant did not fill in the questionnaire.
On the other hand, some insisted one had to accept one's death and that destiny should decide what will happen in the case of an emergency:

If it is necessary, I must endure pain. I have reached an age where dying is close...I don't want to live 20 more years. [...] I have reached the age (for dying), without doubt! That's why, I am not impressed by those things (PSADs). (FG3/294/P1).

\subsubsection{Ageing self}

The second core theme, the ageing self, was raised and intensively discussed by all participants. Interestingly, discussing PSAD use and non-use spontaneously evoked the topic of ageing across all focus groups. They emphasized that ageing is unavoidably linked to declining health and physical changes and that these can occur "out of the blue". As a way of dealing with age-related changes, some avoided thinking about them, as if doing so might influence their emotions negatively. Additionally, not thinking about age-related changes might help to prevent them. Several participants were, however, convinced that anticipating ageing would enable them to cope more appropriately and that it might help them with living independently (e.g., with the use of a PSAD).

Although knowing that one should ideally use a PSAD before something happened, most participants admitted thinking:

Well, basically you would need it [PSAD] before it happens [fall or emergency]. But, you think: I still have time. (FG6/303/P3).

This moment of PSAD use is ideally situated in the future as it is linked to the moment of requiring assistance, which is attached to the transition from a person "growing older" to one "being old" (becoming a person requiring assistance):

Well, I guess that the feeling at the back of one's mind is: as soon as I use a [PSAD] device, I perceive myself as already old. (FG4/156/P4).

The transition towards becoming a person requiring assistance seems to evoke changes in self-perception and challenge the person to re-define themselves (re-defining the self). Using a PSAD was discussed as transitioning from being independent to becoming dependent. It seems to be a considerable step to admit to oneself that one requires assistance and is old:

I knew a lady, she was already 80 years old and she always travelled with a "normal" train ticket. I said to her: why aren't you buying a (cheaper) train ticket for seniors? She replied: well, the train conductor doesn't need to know that I am that old! (FG1/865/P2). 


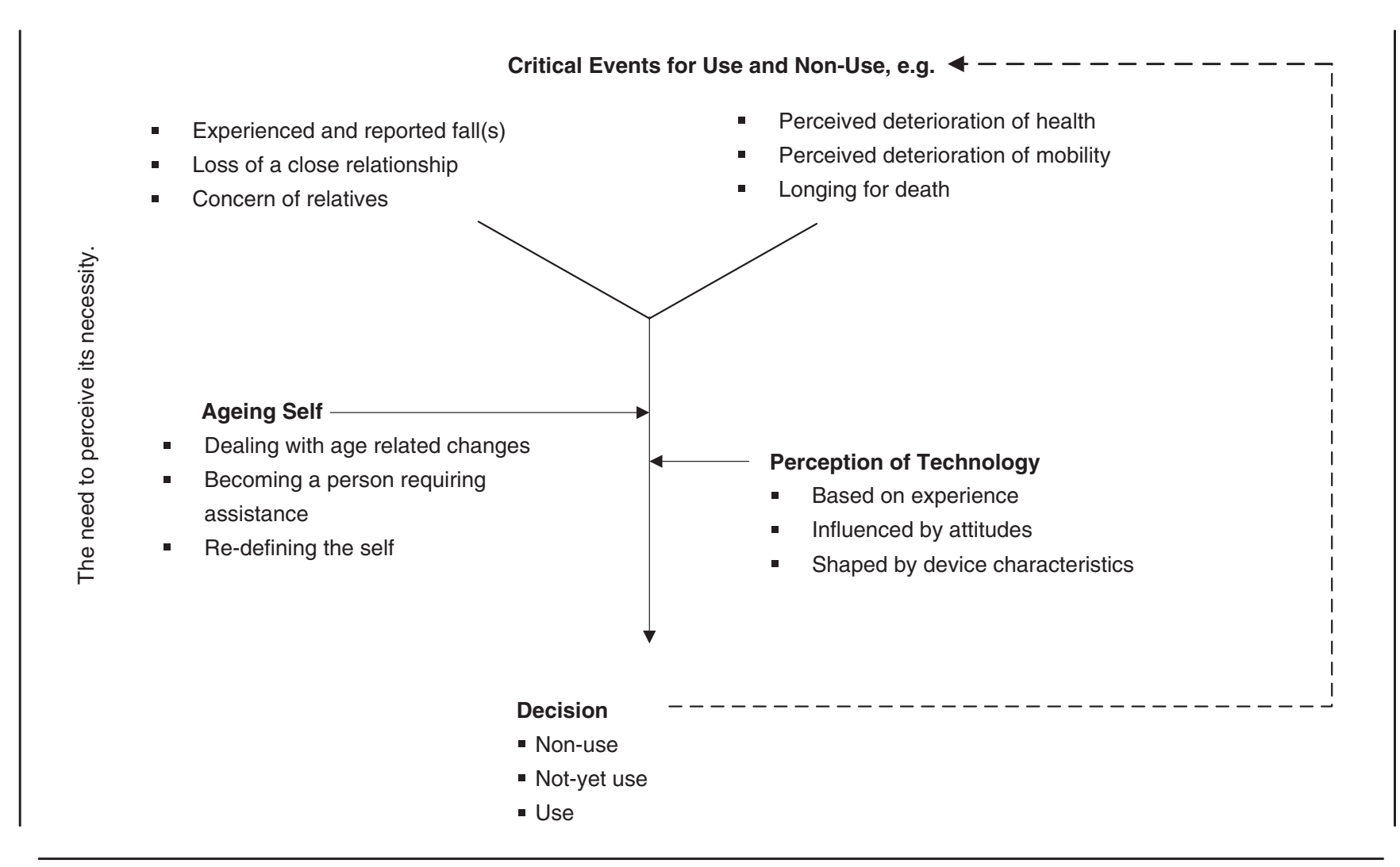

FIGURE 1 Descriptive model of the legitimation process of the use or non-use of a PSAD

\subsection{3 | Perception of technology}

Technology yielded the third core theme. Our analysis revealed that the process of deciding whether or not to use a PSAD can be influenced by an individual's perception of technology. Many of the participants described themselves and their generation as being strangers in the world of today's technologies. Consequently, they felt disconnected and sometimes socially excluded, particularly when they read phrases like "further information is available online". Some participants reported feeling overwhelmed and experiencing fear and negative emotions, as in:

I don't want to admit that I have no clue about [...] the new technologies anymore. Because I was never a fool (laughing) and now I realize that the others are better than me and I must admit that I'm a fool in the context of new technologies. (FG1/813/P5).

Participants who used digital devices frequently, however, experienced it as being life-facilitating, especially when communicating with their children and grandchildren.

I often text with my grandchildren. And now we have a son who is in Asia for four years. I've also learned to skype. (FG6/87/P5).
Their experiences were closely linked to their attitudes towards new technology. Several participants felt favourable towards technology, since it could make life more interesting. Others described themselves as having negative attitudes towards technology. For example, they depicted themselves as being suspicious, in opposition to or being against technology.

Furthermore, device characteristics were key to their perception of technology. Most of the participants emphasized that a PSAD should be nice to look at and feel. Wearing a device on the body is highly attractive, as it is easily "accessible" for use and can be hidden. A panoply of devices should be on offer and should take into consideration age-related changes such as impaired sight, hearing and motor skills, as well as reduced reaction time and learning speed. Additionally, the range of reliable alert transmission should include both indoors and outdoors, to maintain mobility. The most crucial device characteristic, however, was its ease of use. This was summarized as being able to manipulate a PSAD without thinking, as falling induces stress, which often hinders clear thinking.

Finally, the alerting process and the person who comes to give assistance should be clearly defined; health professionals were explicitly preferred as contact persons, as they are available $24 \mathrm{hr}$ a day and trained for emergencies. The feeling of safety can be supported by personal voice contact when an alert is triggered. Another important PSAD-related characteristic was how and 
where to find an overview of available PSADs, along with related "neutral" information about their strengths and limitations (e.g. tested by health professionals). Most participants were unsure as to where to access PSADs and obtain information. They would prefer to touch, test, play with, and receive advice about the most suitable model for their individual needs and requirements (e.g. relatives, neighbours, or housing). Becoming familiar with the available devices in a non-binding way would support the decision-making process.

\section{3 | PSAD use and non-use-a decision process requiring legitimation}

Based on our data analysis, a decision process regarding PSAD use and non-use in daily life was identified that comprised the interplay of the three core themes: Critical Events, Ageing Self, and Perception of Technology. Furthermore, the study revealed that this decision process required an additional aspect which was called "legitimation". Participants needed to perceive the necessity of using a PSAD, as illustrated in the following statement:

It is clear for me. As soon as [a PSAD] is necessary for me and as soon as I get the feeling that, yes, something might happen and nobody would notice me, well, I would buy such a watch. But, still, I really don't perceive its necessity. (FG3/83/P2).

Thus, this decision process can be termed a "Legitimation Process", which is initiated by a critical event compelling the older person to reflect on their perceived safety, on their need for assistance and the right moment to start using a PSAD in daily life. During the legitimation process the older person weighs up their 'Ageing Self' and their 'Perception of Technology' as summarized in Figure 1.

\section{5 | DISCUSSION}

This study focused on the reasons, thoughts, motives, and factors influencing the use and non-use of PSADs in daily life from the perspective of community-dwelling older persons. The findings revealed that the decision to use or not use a PSAD is the result of a legitimation process which involves an interplay of the ageing self, e.g. dealing with age-related changes and the person's perception of technology, e.g. their technology experience. The legitimation process is initiated by a critical event, which causes the person to reflect on her/his own safety and a possible need for assistance. This process leads the older person to a decision about PSAD use or non-use. As time goes on, depending on new critical events, another cycle of the legitimation process may be re-initiated.

The process was labelled a legitimation process, as the use of a PSAD requires reasons to support its perceived necessity. As long as this necessity is not perceived by the older person, s/he will decide on "not-yet use" or non-use. It can be argued that the device is not yet appropriate, unlike for others who are in poorer health or in unsafe living situations. This finding concurs with the literature: older persons, in general, appreciate technology, but are convinced that current users are older persons and that they are not yet "that old" (Holender et al., 2018). It seems that participants implicitly postponed the initial usage of a PSAD, so that they could transition as late as possible into this group of "really frail and dependent" older persons. This observation has important implications for nursing practice. Older persons want to stay in control and thus influence the decision of PSAD acceptance or rejection. Nurses need to involve older persons in the decision-making, provide PSADs information about (dis-)advantages and usage, adapted to the individual living context and accord time for the decision.

The findings suggest that a critical event where the individual experienced feelings of insecurity and/or helplessness is required to initiate the legitimation process for using a PSAD. A fall is often followed by fear of falling, which may in turn lead to a need for support (De San Miguel et al., 2015; Trotman \& MorrissRoberts, 2016). This finding suggests that nurses should systematically assess critical events, to evaluate the possibility for initiation of PSAD usage.

Surprisingly, the concern expressed by relatives could be described as an ambiguous critical event. Relatives might facilitate PSAD use, but this study revealed that such concern may lead to ambivalence among older persons. Some decide to put relatives' minds at ease by starting to use a device, which is in line with the findings of Stokke (2016). However, our study also revealed that relatives' concern is not automatically related to regular PSAD use and can even turn into nonuse. Recent research suggests that children, being driven by worry, try to convince their parents to purchase and use technology, which can make older persons feel coerced (Luijkx et al., 2015). Therefore, it could be argued that although relatives tend to promote PSAD use, they can also be a reason for its non-use. This contradiction might be explained by the legitimation process elucidated by our study: an older person needs to personally legitimise PSAD use and perceive its necessity before deciding to own one. Thus, the study extends current knowledge by suggesting that although relatives may play a crucial role in the acquisition of a PSAD, they might also be a reason for its nonuse. Further research should shed more light on this promoting and hindering influence of relatives.

The topic of longing for death emerged, somewhat curiously, in the discussion on PSAD use and non-use. It is hardly unexpected that people in their eighties ruminate on dying. What is surprising is that long lies and increased morbidity after a fall seem to be blanked out and replaced by the notion that "a fall is fatal". This finding could be interpreted as an indication that older persons lack knowledge about long lies and their consequences, as well as about the function of a PSAD in this situation. Prior research reveals that older persons have difficulty accessing PSADs (Stokke, 2016) and thus might have idiosyncratic or partly incorrect assumptions regarding PSADs. This finding implies that nurses should provide appropriate information regarding falls, fall consequences, and what the added value of a 
PSAD can be, enabling their older clients to take an informed decision on whether to use a PSAD.

Another pivotal finding was the strong need to perceive the necessity of using a PSAD, before deciding to use it. This is consistent with previous research on assistive technologies (Chen \& Chan, 2011; De San Miguel et al., 2015; Peek et al., 2014). Since technology acceptance in older persons remains a challenge (Schulz et al., 2015), it seems important to ask what perceived necessity might signify from the perspective of PSAD users themselves. The ageing self was a dominant topic in the focus groups; therefore, the findings suggest that PSAD use and ageing are closely related. The literature describes the process of ageing as partly dealing with the maintenance of a sense of self, which can be affected by apparently 'superficial' events, such as giving up a driver's license or other long-standing activities (Lloyd et al., 2014). As striving for independence and maintaining control over one's life is central to older persons' selfhood (Hale et al., 2010), it is conceivable that a PSAD evokes similar losses in the self-concept of older persons. Consequently, the core influencing factor concerning PSAD use does not seem to be technology, but, instead the process of ageing and the older person's perception and attitude towards ageing. Additionally, participants clearly differentiated between older persons who are cognitively and physically fit and those who are not. This implies that those who are not fit are the ones who should use a PSAD. It could be further deduced that the participants equated PSAD use with "becoming-a-dependent-person", substantiating previous findings, where persons in their eighties described the use of a walker, cane, or wheelchair as "crossing a boundary into old age" (Heikkinen, 2000). These key insights imply that a PSAD cannot be considered a "simple" gadget in the everyday life of community-dwelling older persons.

\section{1 | Limitations}

Some limitations should be considered when interpreting the findings. One might be the purposeful and snowball sampling method. However, data collection and analysis supported data saturation, which equates with rich and thick data (Fusch \& Ness, 2015). Themes were confirmed across all focus groups. Additionally, conducting six focus groups is considered sufficient to generate adequate and saturated data (Jayasekara, 2012), which can be confirmed by the research team. Since community-dwelling older persons are difficult to recruit, no strategy to maximise the sample variation within a focus group was used.

PSADs are particularly useful for fall incidents, as rapid assistance can prevent or shorten long lies. However, PSADs can also be used in other emergency situations, such as acute pain or discomfort, or in cases of threat. When interpreting the findings, it should be considered that the participants were introduced to example of fall incidents, but the PSADs presented were also deployable for other emergency situations. Moreover, it is possible that Swiss attitudes to topics like ageing, technology and dying might differ from those in other European, Asian or North American countries.

\section{6 | CONCLUSION}

The study suggests that the initial use of a PSAD represents a turning point in life. This turning point is activated by a critical event, such as a fall, by concerned relatives or other persons and by declining health or decreased mobility. Using a PSAD in everyday life is not simply a matter of obtaining a device. It is a complex process entailing the perception of necessity, which is interwoven with notions of individual ageing, self-perceptions, and the meanings attributed to the device. Our description of the legitimation process provides an in-depth understanding of a long and iterative process that allows older persons themselves to accept (or reject) the use of a PSAD. Knowledge about the legitimation process can be used, e.g., in the communication with older persons, to help reflect on their thoughts, fears and questions regarding PSADs. In addition, this knowledge can be applied to develop targeted interventions aimed at enabling older persons to take an informed decision regarding PSAD use.

Additionally, the findings extend current knowledge by revealing that older persons need to be empowered in such a way that they perceive using a PSAD as a means to restore their frailty balance, (re)gain control over their own life and preserve their independence. In this, it is important that nurses clarify the individual advantages of using a PSAD in daily life and explain how and in what situations safe living and perceived independence are supported.

Furthermore, older persons require information regarding the types and functioning of PSADs, as well as where to access them and how to integrate them into daily life. This is important in enabling them to make informed decisions either for or against PSAD use. Using a PSAD has the potential to support ageing in place, despite illness or functional decline. Further research might investigate which interventions are effective in supporting the legitimation process.

\section{ACKNOWLEDGEMENTS}

We are grateful to the study participants for their engagement and accorded time. Special thanks go to Tannys Helfer, editing support and to Dr. Birgit Heckemann and Christoph Golz for her data collection and analysis support.

\section{CONFLICT OF INTEREST}

No conflict of interests has been declared by the authors.

\section{PEER REVIEW}

The peer review history for this article is available at https://publo ns.com/publon/10.1111/jan.14566. 


\section{ORCID}

Friederike J. S. Thilo (iD https://orcid.org/0000-0002-5085-3664 Sabine Hahn (iD https://orcid.org/0000-0002-2697-2014

\section{REFERENCES}

Agboola, S., Golas, S., Fischer, N., Nikolova-Simons, M., op den Buijs, J., Schertzer, L., Kvedar, J., \& Jethwani, K. (2017). Healthcare utilization in older patients using personal emergency response systems: An analysis of electronic health records and medical alert data Brief Description: A Longitudinal Retrospective Analyses of healthcare utilization rates in older patients using Personal Emergency Response Systems. BMC Health Services Research, 17(1), 282. https:// doi.org/10.1186/s12913-017-2196-1

Bloch, F. (2015). Les complications non traumatiques des chutes: Des conséquences trop souvent négligées chez la personne âgée. NPG Neurologie - Psychiatrie - Gériatrie, 15(88), 188-190.

Boehm, A. (1994). Grounded Theory - wie aus Texten Modelle und Theorien gemacht werden. Univ.-Verl.

Brinkmann, S., \& Kvale, S. (2015). InterViews learning the craft of qualitative research interviewing. SAGE.

Chaudhuri, S., Kneale, L., Le, T., Phelan, E., Rosenberg, D., Thompson, H., \& Demiris, G. (2015). Older Adluts' perceptions of fall detection devices. Journal of Applied Gerontology, 36(8), 915-930.

Chen, K., \& Chan, A. (2011). A review of technology acceptance by older adults. Gerontechnology, 10(1), 1-12. https://doi.org/10.4017/ gt.2011.10.01.006.00

De San Miguel, K., Lewin, G., Burton, E., Toye, C., Boldy, D., \& Howat, P. (2015). Exploring risk profiles and emergency frequency of purchasers and non-purchasers of personal emergency alarms: A prospective cohort study. BMC Geriatrics, 15(1), 140. https://doi.org/10.1186/ s12877-015-0139-4

Dierckx de Casterlé, B., Gastmans, C., Bryon, E., \& Denier, Y. (2012). QUAGOL: A guide for qualitative data analysis. International Journal of Nursing Studies, 49(3), 360-371. https://doi.org/10.1016/j.ijnur stu.2011.09.012

Engward, H., \& Davis, G. (2015). Being reflexive in qualitative grounded theory: Discussion and application of a model of reflexivity. Journal of Advanced Nursing, 71(7), 1530-1538. https://doi.org/10.1111/ jan.12653

Fleming, J., Brayne, C. (2008). Inability to get up after falling, subsequent time on floor, and summoning help: prospective cohort study in people over 90. BMJ, 337, a2227. https://doi.org/10.1136/ bmj.a2227

Fusch, P. I., \& Ness, L. R. (2015). Are we there yet? Data saturation in qualitative research. Qualitative Report, 20(9), 1408-1416.

Gale, C. R., Cooper, C., \& Aihie Sayer, A. (2016). Prevalence and risk factors for falls in older men and women: The English Longitudinal Study of Ageing. Age and Ageing, 45(6), 789-794. https://doi.org/10.1093/ ageing/afw129

Gill, T. M., Murphy, T. E., Gahbauer, E. A., \& Allore, H. G. (2013). Association of injurious falls with disability outcomes and nursing home admissions in community-living older persons. American Journal of Epidemiology, 178(3), 418-425. https://doi.org/10.1093/ aje/kws554

Gillespie, L. D., Robertson, M. C., Gillespie, W. J., Sherrington, C., Gates, S., Clemson, L. M., \& Lamb, S. E. (2012). Interventions for preventing falls in older people living in the community. Cochrane Database Systematic Review, 9, CD007146. https://doi.org/10.1002/14651 858.CD007146.pub3

Greenfield, E. A., Black, K., Buffel, T., \& Yeh, J. (2019). Community gerontology: A framework for research, policy, and practice on communities and aging. The Gerontologist, 59(5), 803-810. https://doi. org/10.1093/geront/gny089
Hale, B., Barret, P., \& Gauld, R. (2010). The age of supported independence in voices of in-home CareSpringer (p. 149). Dordrecht Heidelberg.

Hawranik, P., \& Pangman, V. (2002). Recruitment of community-dwellling older adults for nursing research: A challenging process. Canadian Journal of Nursing Research, 33(4), 171-184.

Hefny, A. F., Abbas, A. K., \& Abu-Zidan, F. M. (2016). Geriatric fall-related injuries. African Health Sciences, 16(2), 554-559. https://doi. org/10.4314/ahs.v16i2.24

Heikkinen, R. L. (2000). Ageing in an autobiographical context. Ageing and Society, 20, 467-483. https://doi.org/10.1017/S0144686X9 9007795

Heinbüchner, B., Hautzinger, M., Becker, C., \& Pfeiffer, K. (2010). Satisfaction and use of personal emergency response systems. Zeitschrift Fur Gerontologie Und Geriatrie, 43, 219-223. https://doi. org/10.1007/s00391-010-0127-4

Holden, R. J., \& Karsh, B.-T. (2010). The Technology Acceptance Model: Its past and its future in health care. Journal of Biomedical Informatics, 43(1), 159-172. https://doi.org/10.1016/j.jbi.2009.07.002

Holender, A., Sutton, S., \& De Simoni, A. (2018). Opinions on the use of technology to improve tablet taking in $>65$-year-old patients on cardiovascular medications. Journal of International Medical Research, 46(7), 2754-2768. https://doi.org/10.1177/0300060518770578

International Federation on Ageing. (2011). Global ageing issues \& action, ageing in place. International Federation on Ageing, 7, 1-60.

Jayasekara, R. S. (2012). Focus groups in nursing research: Methodological perspectives. Nursing Outlook, 60(6), 411-416. https://doi.org/10.1016/j.outlook.2012.02.001

Kim, H., Sefcik, J. S., \& Bradway, C. (2017). Characteristics of qualitative descriptive studies: A systematic review. Research in Nursing \& Health, 40(1), 23-42. https://doi.org/10.1002/nur.21768

Lamb, S. E., Jorstad-Stein, E. C., Hauer, K., Becker, C.; Prevention of Falls Network, E. \& Outcomes Consensus, G. (2005). Development of a common outcome data set for fall injury prevention trials: The Prevention of Falls Network Europe consensus. Journal of the American Geriatrics Society, 53(9), 1618-1622. https://doi. org/10.1111/j.1532-5415.2005.53455.x

Lapierre, N., Neubauer, N., Miguel-Cruz, A., Rincon, A. R., Liu, L., \& Rousseau, J. (2018). The state of knowledge on technologies and their use for fall detection: A scoping review. International Journal of Medical Informatics, 111, 58-71. https://doi.org/10.1016/j.ijmed inf.2017.12.015

Lincoln, Y. S., Guba, E. G., \& Pilotta, J. J. (1985). Naturalistic inquiry. SAGE Publications.

Lloyd, L., Calnan, M., Cameron, A., Seymour, J., \& Smith, R. (2014). Identity in the fourth age: Perseverance, adaptation and maintaining dignity. Ageing \& Society, 34(1), 1-19. https://doi.org/10.1017/S0144 $686 \times 12000761$

Luijkx, K., Peek, S., \& Wouters, E. (2015). "Grandma, You Should Do It-It's Cool" older adults and the role of family members in their acceptance of technology. International Journal of Environmental Research and Public Health, 12(12), 15470-15485.

Marangunić, N., \& Granić, A. (2015). Technology acceptance model: A literature review from 1986 to 2013. Universal Access in the Information Society, 14(1), 81-95. https://doi.org/10.1007/s10209-014-0348-1

McLean, P. A. (2016). In Exploring older adults' perceptions of the utility and ease of use of personal emergency response systems. CUNY Academic Works. Retrieved from https://academicworks.cuny.edu/ gc_etds $/ 1327$

National Council for Aging Care. (2018). Fact Sheet: Falls - The Biggest Threat to Senior Health and Safety. Retrieved from https://www/ aging.com/falls-fact-sheet/

Nyman, S. R., \& Victor, C. R. (2014). Use of personal call alarms among community-dwelling older people. Ageing \& Society, 34(1), 67-89. https://doi.org/10.1017/S0144686X12000803 
Peek, S. T. M., Wouters, E. J., van Hoof, J., Luijkx, K. G., Boeije, H. R., \& Vrijhoef, H. J. (2014). Factors influencing acceptance of technology for aging in place: A systematic review. International Journal of Medical Informatics, 83(4), 235-248. https://doi.org/10.1016/j.ijmed inf.2014.01.004

Piscotty, R. J. Jr, Kalisch, B., \& Gracey-Thomas, A. (2015). Impact of healthcare information technology on nursing practice. Journal of Nursing Scholarship, 47(4), 287-293. https://doi.org/10.1111/ jnu.12138.

Rubenstein, L. Z. (2006). Falls in older people: Epidemiology, risk factors and strategies for prevention. Age and Ageing, 35(suppl_2), ii37-ii41. https://doi.org/10.1093/ageing/afl084

Saldana, J. (2016). The coding manual for qualitative researchers. SAGE.

Sandelowski, M. (2010). What's in a name? Qualitative description revisited. Research in Nursing \& Health, 33(1), 77-84. https://doi. org/10.1002/nur.20362

Scharlach, A. E., \& Diaze Moore, K. (2016). Aging in place. In R. A. Settersten \& R. A. Settersten (Eds.), Handbook of theories of aging (pp. 407-425). Springer.

Schulz, R., Wahl, H. W., Matthews, J. T., Dabbs, A. D., Beach, S. R., \& Czaja, S. J. (2015). Advancing the aging and technology agenda in gerontology. Gerontologist, 55(5), 724-734. https://doi.org/10.1093/ geront/gnu071

Simpson, P. M., Bendall, J. C., Tiedemann, A., Lord, S. R., \& Close, J. C. (2014). Epidemiology of emergency medical service responses to older people who have fallen: A prospective cohort study. Prehospital Emergency Care, 18(2), 185-194. https://doi.org/10.3109/10903 127.2013.856504

Smith, A. (2014). Older adults and technology use. Pew Research Center.

Smolowitz, J., Speakman, E., Wojnar, D., Whelan, E. M., Ulrich, S., Hayes, C., \& Wood, L. (2015). Role of the registered nurse in primary health care: Meeting health care needs in the 21st century. Nursing Outlook, 63(2), 130-136. https://doi.org/10.1016/j.outlook.2014.08.004

Stewart, D., \& Shamdasani, P. (2015). Focus groups. Theory and practice. SAGE.
Stokke, R. (2016). The personal emergency response system as a technology innovation in primary health care services: An integrative review. Journal of Medical Internet Research, 18(7), e187. https://doi. org/10.2196/jmir.5727

Taherdoost, H. (2018). A review of technology acceptance and adoption models and theories. Procedia Manufacturing, 22, 960-967. https:// doi.org/10.1016/j.promfg.2018.03.137

Thilo, F. J. S., Hahn, S., Halfens, R. J. G., \& Schols, J. M. G. A. (2018). Usability of a wearable fall detection prototype from the perspective of older people-A real field testing approach. Journal of Clinical Nursing, 28(1-2), 310-320. https://doi.org/10.1111/jocn.14599

Thilo, F. J. S., Hürlimann, B., Hahn, S., Bilger, S., Schols, J. M. G. A., \& Halfens, R. J. G. (2016). Involvement of older people in the development of fall detection systems: A scoping review. BMC Geriatrics, 16, 42. https://doi.org/10.1186/s12877-016-0216-3

Trotman, M., \& Morriss-Roberts, C. (2016). The lived experiences of the fear of falling in the elderly patient: An Interpretive phenomenological study. JSM Foot and Ankle, 1(3), 1015.

Vasunilashorn, S., Steinman, B. A., Liebig, P. S., \& Pynoos, J. (2012). Aging in place: Evolution of a research topic whose time has come. Journal of Aging Research, 52, 306-316. https://doi.org/10.1155/ 2012/120952

Young, Y., Kalamaras, J., Kelly, L., Hornick, D., \& Yucel, R. (2015). Is aging in place delaying nursing home admission? Journal of the American Medical Directors Association, 16(10), 900.e1-900.e6. https://doi. org/10.1016/j.jamda.2015.07.017

How to cite this article: Thilo FJS, Schols JMGA, Halfens RJG, Linhart M, Hahn S. Deciding about the use of a Personal Safety Alerting Device-The need for a legitimation process: A qualitative study. J Adv Nurs. 2021;77:331-342. https://doi. org/10.1111/jan.14566

The Journal of Advanced Nursing (JAN) is an international, peer-reviewed, scientific journal. JAN contributes to the advancement of evidence-based nursing, midwifery and health care by disseminating high quality research and scholarship of contemporary relevance and with potential to advance knowledge for practice, education, management or policy. JAN publishes research reviews, original research reports and methodological and theoretical papers.

For further information, please visit JAN on the Wiley Online Library website: www.wileyonlinelibrary.com/journal/jan

Reasons to publish your work in JAN:

- High-impact forum: the world's most cited nursing journal, with an Impact Factor of 1.998 - ranked 12/114 in the 2016 ISI Journal Citation Reports $@$ (Nursing (Social Science)).

- Most read nursing journal in the world: over 3 million articles downloaded online per year and accessible in over 10,000 libraries worldwide (including over 3,500 in developing countries with free or low cost access).

- Fast and easy online submission: online submission at http://mc.manuscriptcentral.com/jan.

- Positive publishing experience: rapid double-blind peer review with constructive feedback.

- Rapid online publication in five weeks: average time from final manuscript arriving in production to online publication.

- Online Open: the option to pay to make your article freely and openly accessible to non-subscribers upon publication on Wiley Online Library, as well as the option to deposit the article in your own or your funding agency's preferred archive (e.g. PubMed). 


\section{Chapter 6}

\section{Advancing Personal Safety Alerting Device Use of Older Persons - the Views of Relatives and Health Care Professionals}

This chapter is submitted to the Journal The Gerontologist as: Thilo, F.J.S., Hahn, S., Halfens, R.J.G., Heckemann, B. and Schols, J.M.G.A. Advancing Personal Safety Alerting Device Use of Older Persons - the Views of Relatives and Health Care Professionals. 
Featured Article

\title{
Facilitating the use of personal safety alerting device with older adults: The views, experiences and roles of relatives and health care professionals
}

\author{
Friederike JS Thilo, PhD, RN ${ }^{\mathrm{a}, \mathrm{b}, *}$, Sabine Hahn, PhD, RN ${ }^{\mathrm{a}}$, Ruud JG Halfens, $\mathrm{PhD}^{\mathrm{b}}$, \\ Birgit Heckemann, PhD, RN, ${ }^{\mathrm{a}, \mathrm{c}, \mathrm{e}}$, Jos MGA Schols, MD, PhD ${ }^{\mathrm{b}, \mathrm{d}}$ \\ ${ }^{a}$ Applied Research E Development in Nursing, Department of Health Professions, Bern University of Applied Sciences, Bern, Switzerland \\ ${ }^{\mathrm{b}}$ School CAPHRI, Department of Health Services Research, Maastricht University, Maastricht, The Netherlands \\ ${ }^{\mathrm{c}}$ Institute of Health and Care Sciences, Sahlgrenska Academy, Gothenburg University, Gothenburg, Sweden \\ ${ }^{\mathrm{d}}$ School CAPHRI, Department of Family Medicine, Maastricht University, Maastricht, The Netherlands \\ e Department of Anaesthesiology, Surgery and Intensive Care, Sahlgrenska University Hospital, Gothenburg, Sweden
}

\section{A R T I C L E I N F O}

\section{Article history:}

Received 22 January 2021

Received in revised form 21 May 2021

Accepted 24 May 2021

Available online 12 June 2021

\section{Keywords:}

Falls

Home and community-based care services

Technology, Independence

\begin{abstract}
A B S T R A C T
To explore relatives', community nurses' and general practitioners' perspectives and experiences in promoting Personal Safety Alerting Device (PSAD) use among community-dwelling older adults, we applied a qualitative study design. Altogether 15 focus groups and 11 semi-structured interviews were conducted. Dataanalysis followed the Qualitative Analysis Guide of Leuven. PSAD use was considered to be complex. Relatives and health care professionals are involved in a negotiation process comprising three phases: A) waiting for a critical event in the older adult's everyday life; B) introducing the idea of a PSAD; C) deciding on and supporting PSAD use. In conclusion, the actors involved in PSAD use should be aware of the negotiation process, which is complex, dynamic, iterative and needs time. While nurses play a crucial role, they lack sufficient knowledge for comprehensive PSAD counselling. The negotiation process could serve as an example for other technologies in the context of aging in place.
\end{abstract}

(c) 2021 The Author(s). Published by Elsevier Inc. This is an open access article under the CC BY license

(http://creativecommons.org/licenses/by/4.0/)

\section{Introduction}

Aging societies are a common issue on political and health care agendas across the globe. ${ }^{1}$ Currently, one focus is on 'aging in place' which promotes the wellbeing of aging societies and refers to enabling older adults to live as independent, safe and socially integrated persons in their accustomed home in the community. ${ }^{2} \mathrm{~A}$ majority of older adults prefer aging in place to institutionalized living. ${ }^{3,4}$ Furthermore, international estimates indicate that independent living costs can be lower than the cost of institutional living. ${ }^{5}$

Assistive technologies may significantly contribute to successful aging in place. ${ }^{6}$ They may assist older adults in issues of mobility, physical and mental health, safety, social connectedness as well as in daily activities. ${ }^{6,7}$ The current non-use of assistive technologies in community-dwelling older adults is a major concern, ${ }^{8,9}$ as it can ensure safe aging in place. Particularly emergency situations like falls

\footnotetext{
*Corresponding author.

E-mail addresses: friederike.thilo@bfh.ch (F.J. Thilo), sabine.hahn@bfh.ch (S. Hahn), birgit.heckemann@gu.se (B. Heckemann),jos.schols@maastrichtuniversity.nl (J.M. Schols)
}

illustrate how the use of technology can lead to increasing safety and reducing harmful consequences in older adults. Between $25 \%-35 \%$ of persons aged 65 and older experience at least one fall per year. ${ }^{10}$ Being unable to get up after a fall and thus enduring a 'long lie', defined as lying on the floor/ground for longer than one hour, ${ }^{11}$ can compromise the health and well-being of older adults, and can also lead to long-term care admission. ${ }^{12,13}$ Therefore, Personal Safety Alerting Devices (PSADs) could be considered a pivotal technology for aging in place, to facilitate communication ${ }^{7}$ and to get rapid assistance, e.g. after a fall. ${ }^{14,15}$

Despite well-documented advantages, community-dwelling older adults are often reluctant to use PSADs. ${ }^{16,17}$ Research investigating the perspective of older adults has revealed that their technology acceptance can be positively influenced by relatives and health professionals. ${ }^{18-20}$ Despite this, research has focused on older adults' acceptance of different types of technologies for aging in place 9,14 and from a nursing perspective, ${ }^{21}$ but not on the antecedents of PSAD use or non-use from a multi perspective approach. However, the perspectives of relatives, community nurses and general practitioners (GPs) regarding PSAD use and non-use in community-dwelling older adults is crucial; they are actively involved in aging in place and close 
to older adults, supporting their safety and serving as contact persons in case of an emergency when a PSAD is activated. In addition, recent research suggests that understanding technology acceptance requires knowledge about all those involved in its use. ${ }^{15,22,23}$ It is pivotal to answer the 'why, when and how' of technology use ${ }^{22,24}$ instead of considering assistive technologies as black boxes that can be integrated in daily life without modifying practices or routines. ${ }^{15}$ Exploring the perspectives of relatives, community nurses and GPs enables us to understand their experiences, perceptions and involvement in PSAD use or non-use in community-dwelling older adults. In this research, the following research questions were addressed:

1. What are the reasons for PSAD use or non-use among communitydwelling older adults according to relatives, community nurses and GPs?

2. In what situations are PSADs used or not used by communitydwelling older adults according to relatives, community nurses and GPs?

3. What is the involvement of relatives, community nurses and GPs in the use or non-use of PSADs?

\section{Methods}

A qualitative descriptive research design was applied, ${ }^{25}$ using focus groups (relatives and community nurses) and semi-structured interviews (general practitioners), ${ }^{26}$ to uncover and explore rationales for behavior and the involvement of relatives, community nurses and GPs related to PSAD use and non-use among community-dwelling older adults.

\section{Sampling and recruitment}

Using a combined purposeful and snowball sampling strategy, relatives, community nurses and GPs who care for community-dwelling older adults in two Swiss cantons were invited to participate in this study. The inclusion criteria were: 1) relatives: daughter / son / spouse of a community-dwelling person aged 70 or older; 2) community nurses (RNs): working for a community care service provider, with at least oneyear professional experience in caring for older adults; 3) GPs: working with one-year minimum professional experience caring for older adults. The recruitment strategies are displayed in Table 1.

\section{Data collection}

Data were collected between February and December 2017: Six focus groups with relatives (4-7 participants each) with an average duration of 108 minutes (min-max 87-120), nine focus groups with community nurses ( $3-5$ participants each) with an average duration of 93 minutes (min-max 80-108) and eleven interviews with GPs with an average duration of 58 minutes (min-max 50-85) were conducted.
After the focus groups/interviews, the participants were asked to complete a short questionnaire on socio-demographics and their experience with PSADs (use).

The site of data collection was at the Institute of Nursing Science (relatives), at the organization of the community nurses and at the medical practice. All focus groups and interviews were audio-recorded.

\section{Focus group and semi-structured interview}

All focus groups were moderated, and all interviews conducted by the first author, who is experienced in qualitative interviewing and has a professional background in nursing. The focus groups with relatives and two with community nurses were attended by a research assistant for administrative tasks and support with the PSAD presentation. A semi-structured interview-guide with open-ended questions (Table 2) developed by the research team, based on the literature presented in the background and the researchers' expertise, was utilized to moderate the focus groups and conduct the interviews.

In the second part of the focus group and interview ten PSADs were presented to the participants to: (i) provide the same information on PSAD diversity, use and function, (ii) to stimulate the discussion based on real devices and (iii) to better understand opportunities and challenges of PSADs and technical aspects possibly influencing use and non-use.

The first author reflected on each focus group/interview and took written notes regarding the course of the discussion/s and recurrent/ conflicting/surprising/new themes in order to maintain a reflective stance and to incorporate insights into the subsequent data collection.

\section{Data analysis}

All focus groups and interviews ( $=26$ cases) were fully transcribed verbatim, using the software program $\mathrm{f} 4{ }^{\circledR}$. The analysis was an iterative team process. The research team included members with different professional backgrounds, i.e. nursing, gerontology and psychology. The researchers met regularly to discuss the analysis across the different coding cycles. Any discrepancies were discussed until consensus was reached.

The data were analyzed following the ten stages of the Qualitative Analysis Guide of Leuven (QUAGOL). ${ }^{27}$ QUAGOL comprises two main processes, a Preparation of Coding Process and the Actual Coding Process. Each process consists of five stages. However, although the processes are described as linear in the literature, the actual analysis is an iterative process, where the different stages are not necessarily distinct, but may overlap. The QUAGOL framework enabled the researchers to become deeply familiar with the data prior to commencing any systematic coding. It also encouraged the researchers to move stepwise from the concrete interview data towards an increasing level of abstraction during the course of the analysis.

Initially, the researchers familiarized themselves with the data thorough (re-) reading of the interviews (stage 1). Following the

Table 1

Recruitment strategies.

\begin{tabular}{|c|c|c|}
\hline \multicolumn{3}{|c|}{ Recruitment strategies - potential participants } \\
\hline Relatives & Community Nurses & General Practitioners \\
\hline \multicolumn{3}{|c|}{ Study advertising via: } \\
\hline $\begin{array}{l}\text { Flyer ( } \mathrm{n}=770 \text { ) distribution: } \\
\square \text { Public institutions, e.g. for the education of health professionals } \\
\square \text { Faculty members (not part of the research team, } \\
\text { nor in project collaboration) } \\
\square \text { Physiotherapists } \\
\square \text { Fitness centers }\end{array}$ & $\begin{array}{l}\square \text { Short article in specialized national } \\
\text { magazine } \\
\text { Flyer distribution: } \\
\square 42 \text { community care service providers } \\
\text { randomly selected from public list } \\
\text { and nurse manager contacted } \\
\text { (email and telephone) }\end{array}$ & $\begin{array}{l}\square \text { Professional association of family physicians } \\
\text { informed members via email } \\
\square \text { GPs from one city and its environs contacted } \\
\text { via telephone and email (pragmatic choice) }\end{array}$ \\
\hline
\end{tabular}


Table 2

Semi-structured interview-guide for focus groups and interviews.

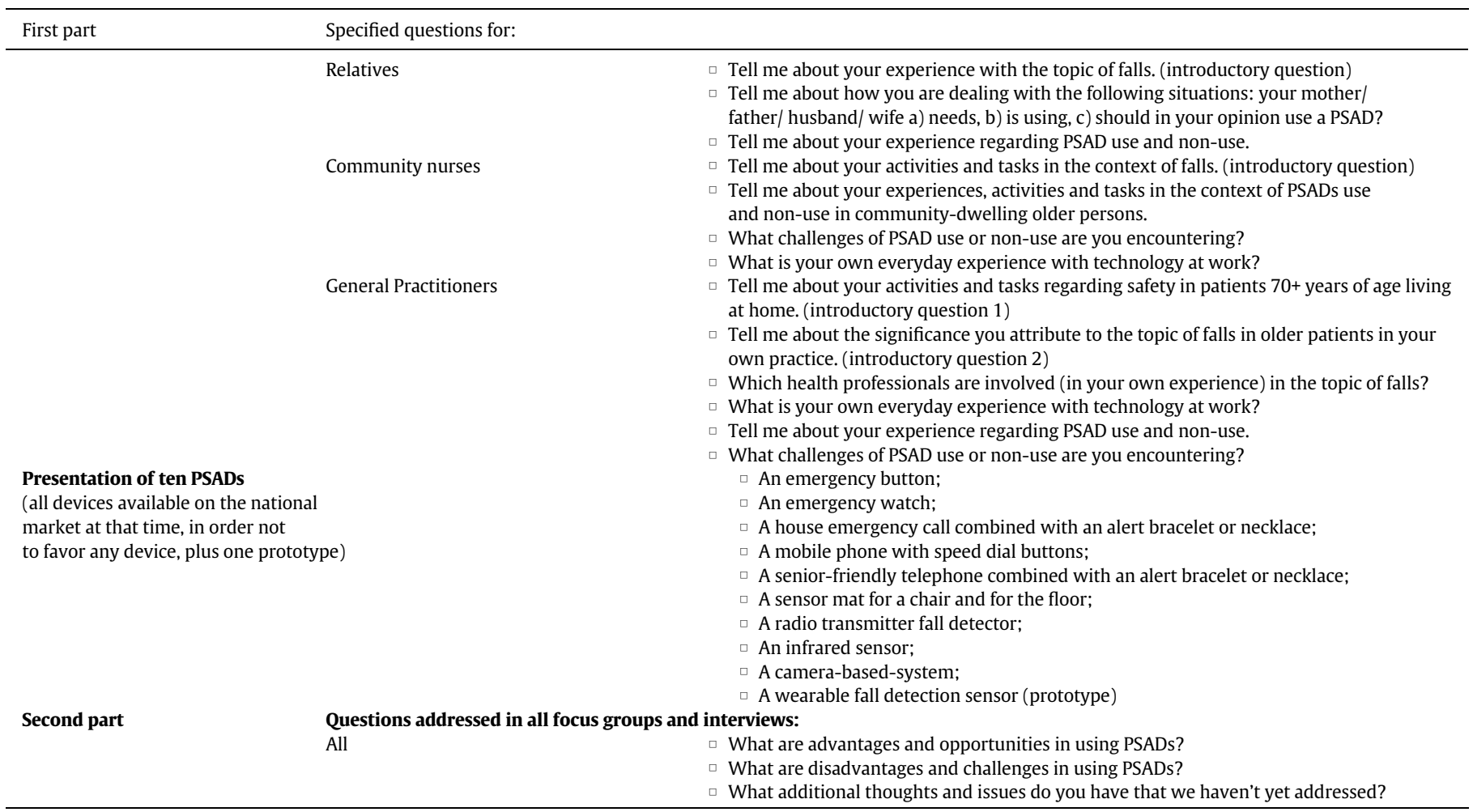

reading, two researchers individually produced a narrative storyline of each interview, which were compared and discussed in team meetings (stage 2). During this stage, the team focused on gaining an initial understanding of the particular content of the stories as they were told from the perspectives of the relatives, community nurses and GPs. In stage 3, the researchers discussed the story lines and the analysis proceeded from the concrete, interview, storyline level to a more abstract concept level. The emerging concepts were then organized into a first, tentative coding scheme. This coding scheme was subsequently applied, tested, refined in five iterative coding cycles of open and focused coding. ${ }^{28}$ The codes were compared within and across the cases. Data were linked to codes, and the coding was discussed. The coding scheme was thus successively adapted and refined into a final coding scheme (stages 4-7). The continued discussion ensured a good fit between the codes and the data. The final coding scheme was applied to all 26 cases.

Throughout all analysis stages, memos containing questions or comments regarding the development of the coding scheme were written and discussed during team meetings.

To deepen the level of abstraction, the codes were merged to categories and subcategories. The characteristics of categories and subcategories were described, and the descriptions compared within and among the categories and subcategories to ensure there was no overlap in meaning. The descriptions were also compared to the original interview data. The comparison and review of original data and the coding enabled the researchers to identify the relationships between the categories and subcategories (stages 8-10). This review and comparison at an abstract level lead to a model describing the negotiation process about the use of the PSAD from perspectives of relatives, community nurses and GPs (Fig. 1).

A research diary was kept during the whole analysis and interpretation process, in order to keep a reflexive record of decisions made and trace emerging thoughts and questions, as well as to ensure the grounding of the findings in the data. Data management was supported by MAXQDA software (VERBI GmbH, Berlin, Germany; Version 12 and 2018).

The study's scientific rigor was ensured through a variety of techniques. The iterative analysis, stepwise move towards abstraction, and regular discussions of interpretations in the research team strengthened the criticality and integrity of the analysis. ${ }^{29}$ The research diary, memos and the parallel analysis process of two coders ensured that the findings reflect the participants' experience and are grounded in the data. ${ }^{29}$ Since the transferability of all qualitative research is limited, ${ }^{30}$ we described the setting and sample precisely and illustrated our findings with quotes from the interviews.

\section{Ethical consideration}

The study was conducted in compliance with Swiss national, legal and regulatory requirements. A cantonal ethics committee confirmed that the Swiss Federal Act on Research Involving Humans did not apply to the research project. Written and verbal informed consent was obtained prior to study participation. Personal data were deidentified in the transcripts.

\section{Findings}

\section{Participant characteristics}

Fifteen focus groups and 11 semi-structured interviews were conducted. A total of 78 persons participated: 33 relatives (24 daughters, 8 sons, 1 husband) with an average age of 55 years; 34 community nurses with on average 19 years of experience; 11 GPs with on average 29 years of experience. PSAD experience differed among the participants: 14 relatives, 18 community nurses and six GPs indicated experience with using a PSAD in the care of an older adult. Further characteristics are displayed in Tables 3 and 4. 


\section{A) Waiting For a Critical Event in the Older Adult's Everyday Life}

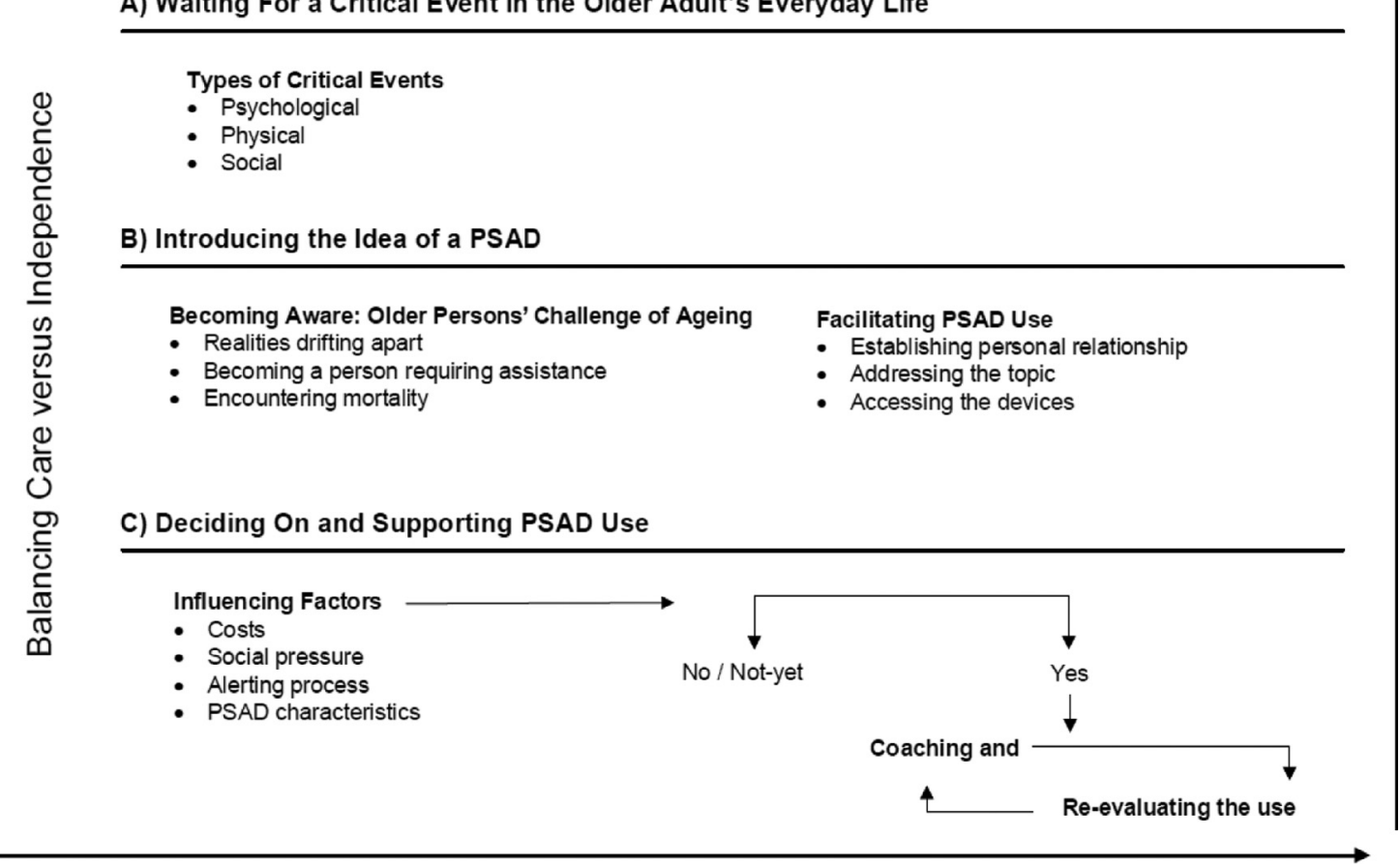

Fig. 1. Descriptive model of the negotiation process.

Table 3

Characteristics of study participants - relatives.

\begin{tabular}{|c|c|c|c|}
\hline & $\mathrm{N}(\%)$ & Mean & Range \\
\hline \multicolumn{4}{|l|}{ Relatives $(\mathrm{N}=33)$} \\
\hline Age & & 55.2 & $(31-72)$ \\
\hline Female & $24(72.7)$ & & \\
\hline \multicolumn{4}{|l|}{ For whom is the PSAD in your family? } \\
\hline Father & $14(42.4)$ & & \\
\hline Mother & $21(63.3)$ & & \\
\hline Wife & $1(3.0)$ & & \\
\hline Mother-in-law & $1(3.0)$ & & \\
\hline Aunt & $2(6.0)$ & & \\
\hline $\begin{array}{l}\text { Is 'the older person' already using } \\
\text { a PSAD? - yes }\end{array}$ & $7(21.2)$ & & \\
\hline $\begin{array}{l}\text { Do you have experience with } \\
\text { PSADs? - yes }\end{array}$ & $14(42.4)$ & & \\
\hline \multicolumn{4}{|l|}{$\begin{array}{l}\text { Do you think 'the older person' } \\
\text { will use a PSAD? }\end{array}$} \\
\hline Yes & $18(54.5)$ & & \\
\hline No & $13(39.4)$ & & \\
\hline Don't know & $2(6.1)$ & & \\
\hline \multicolumn{4}{|l|}{$\begin{array}{l}\text { Did 'your' older person fall in the last } \\
12 \text { months? }\end{array}$} \\
\hline Yes & $18(54.5)$ & & \\
\hline No & $11(33.3)$ & & \\
\hline I don't know & $4(12.1)$ & & \\
\hline \multicolumn{4}{|l|}{$\begin{array}{l}\text { Do you think that 'your' older person } \\
\text { is unstable while walking? }\end{array}$} \\
\hline Yes & $11(33.3)$ & & \\
\hline No & $9(27.3)$ & & \\
\hline Sometimes & $13(39.4)$ & & \\
\hline \multicolumn{4}{|l|}{$\begin{array}{l}\text { Does 'your' older person use } \\
\text { a walking aid? }\end{array}$} \\
\hline Yes & $6(18.2)$ & & \\
\hline No & $24(72.7)$ & & \\
\hline I don't know & $3(9.1)$ & & \\
\hline \multicolumn{4}{|l|}{$\begin{array}{l}\text { Do you fear that 'your' older person } \\
\text { might fall? }\end{array}$} \\
\hline Yes & $11(33.3)$ & & \\
\hline Sometimes & $13(39.4)$ & & \\
\hline No & $9(37.3)$ & & \\
\hline
\end{tabular}

A negotiation process

PSAD use was considered to be complex. Relatives, community nurses and GPs were often involved in a relatively long negotiation process with older adults (Fig. 1).

In this process, whereas the relatives, community nurses and GPs perceive a safety issue and thus a need to protect the older adult by suggesting a PSAD, they described how this suggestion is often experienced as a threat to the older adult's independence. The negotiation process therefore requires balancing care versus independence. Three phases were distinguished: A) Waiting for a critical event in the older adult's everyday life; B) Introducing the idea of a PSAD; and C) Deciding on and supporting PSAD use. These phases are characterized by subthemes marked below in bold and italics.

\section{Phase A) Waiting for a critical event}

Relatives, community nurses and GPs typically reported that the negotiation process was initiated because of their concern for the safety of the older adult. This safety concern was often related to a pivotal psychological, physical and/or social event that opened a window of opportunity to discuss the need for a PSAD. A psychological event is an incident, often after a fall, which involves feeling helpless, needing assistance, or experiencing anxiety or fear of falling. A deterioration of mobility and health, e.g. gait instability or dizziness, is referred to as a physical event, while the term social event describes, e.g., the situation in which an older adult falls or experiences an emergency, but the event goes unnoticed because of a lack of social contacts or because frail partners cannot assist each other.

\section{Phase B) Introducing the idea of a PSAD}

In taking advantage of a critical event, relatives, community nurses and GPs shared the same experience: talking about PSAD use involved surprisingly confrontational discussions, especially when 
Table 4

Characteristics of study participants - community nurses and general practitioners (GPs).

\begin{tabular}{|c|c|c|c|c|c|c|}
\hline \multirow[b]{2}{*}{ Characteristics } & \multicolumn{3}{|c|}{ Community Nurses $(\mathrm{N}=34)$} & \multicolumn{3}{|c|}{$\mathrm{GP}(\mathrm{N}=11)$} \\
\hline & $\mathrm{N}(\%)$ & Mean & Range & $\mathrm{N}(\%)$ & Mean & Range \\
\hline Age & & 43.5 & $23-60$ & & 59.1 & $44-74$ \\
\hline Female & $32(94.1)$ & & & $1(9.1)$ & & \\
\hline \multicolumn{7}{|l|}{ Professional Education $(\mathrm{n}=32)$} \\
\hline RN with vocational training & $30(93.8)$ & & & & & \\
\hline RN with University degree BScN & $2(5.9)$ & & & & & \\
\hline Professional experience as Registered Nurse (years) & & 19.1 & $0.3-40.0$ & & & \\
\hline Professional experience as Medical Doctor (years) $(n=10)$ & & & & & 28.5 & $9-50$ \\
\hline Working experience in current position (years) & & 6.4 & $0.3-29.0$ & & 17.1 & $0.6-35$ \\
\hline Do you have experience with PSADs? Yes & $18(52.9)$ & & & $\begin{array}{l}6(54.5) \\
\quad(N=10)\end{array}$ & & \\
\hline \multicolumn{7}{|l|}{ What kind of PSADs have you already 'used' in patient care? } \\
\hline Manual emergency button & $25(73.5)$ & & & $9(81.8)$ & & \\
\hline Manual emergency necklace & $19(55.9)$ & & & $2(18.2)$ & & \\
\hline Watch with voice speakerphone and GPS & $19(55.9)$ & & & $6(54.5)$ & & \\
\hline Mobile & $9(26.5)$ & & & $3(27.3)$ & & \\
\hline Sensor mats & $5(14.7)$ & & & $6(54.5)$ & & \\
\hline
\end{tabular}

relatives made the older adults aware of their aging process (Becoming aware: older adults' challenge of aging). While the participants suggested the use of a PSAD increase safety of the older adult, the older adult often first denied such a need and felt that a PSAD would undermine his/her independence:

"In the case of my parents, the (PSAD) was a long process of raising awareness. We can fully understand you, they told us: But why are you (children) intruding into our life? We've managed it until now and that will continue" (Relative (R)-FG6-60).

Relatives said they often felt challenged by encountering conflictive discussions with their parent/s, who often do not share their children's safety concerns. Likewise, community nurses and GPs reported often encountering these conflicting views concerning safety and ability to manage everyday life (realities drifting apart). GPs explained these different realities by noting that the home environment has for decades been a place for older adults to feel safe, contrary to the perception of relatives. Community nurses agreed that the PSAD opens up a discussion not solely about using a device, but also about becoming a person requiring assistance, citing a client who said:

"First of all, I'm healthy, I'm fit as a fiddle, I'm not old, even if I am 98. Why should I fall, what are you suggesting? You (the nurse) want to disable me, you are going to make me dependent" (Community nurses (N)-FG4-195).

Relatives, community nurses and GPs had experienced older adults concealing falls or fall consequences because they feared receiving more support/assistance at home or relatives pushing for institutionalization. Some relatives critically reflected that although it would be sensible to use a PSAD, they observed that the PSAD triggers complex feelings of loss:

"It looks simple and common-sense from the outside, not limiting at all, but, in the older adult it causes melancholy. Simply realizing that they are no longer at the wheel (in charge of one's life) ... I believe that is the resistance (to the PSAD)" (R-FG3-54).

GPs recognized this observation, namely the feeling of losing control. From their perspective this loss is underlined by the fact that PSAD use often reveals unclarity about the alerting process (e.g. Does it work? Who will answer?) and what might happen afterwards (e.g. hospitalization).
The focus groups/interviews revealed that talking about PSADs may also signify encountering mortality. Relatives, community nurses and GPs agreed that older adults frequently express a strong wish to live at home until death. This strong wish seems to explain why they might conclude that a PSAD is unnecessary: first, a PSAD is directly connected with a hospital, a place where life is artificially prolonged, and, second, a hospital stay might be a possible gateway to a long-term care institution. Additionally, particularly community nurses and GPs added, older adults frequently believe - or want to believe - that a fall is fatal.

“I had several patients who told me: I don't like it (a PSAD) I would like to die in my apartment. If I should fall and it's the end, that's just how it is. Therefore, I don't want a button (PSAD). They told me clearly about that" (N-FG9-197).

Relatives, community nurses and GPs brought up the topic of facilitating PSAD use, which takes time, often months. Mainly community nurses underlined that establishing a personal relationship of mutual trust is pivotal. This echoes the finding that community nurses and relatives wait for the right situation to address the topic of PSADs, with relatives choosing among siblings as to who can best address it. Addressing the topic of PSADs was reportedly delicate for all participants, as it goes hand in hand with the topic of falling. Relatives, community nurses and GPs reported that older adults not only suffer from physical consequences, such as injuries, but that in their perception a fall is often recognized as a clear sign of emerging frailty.

Community nurses and GPs addressed the topic of PSADs mostly in the context of a critical event or as coming from a relative or the older adult her-/himself. Additionally, the analysis revealed that addressing the topic of PSADs also depends on the health professional's perception, i.e. how relevant s/he considers the topic.

Addressing the topic of PSADs necessitates accessing the devices. Relatives pointed out that they first have to acquire the relevant knowledge themselves. They complain that access to PSADs is challenging and time-consuming, requiring internet searches, identifying relevant institutions and talking to friends, colleagues or neighbors. Relatives would welcome the possibility to look at, touch and test various PSADs in a public health-care institution with their parent/s.

In contrast, the participating community nurses and GPs had access to PSAD information and distributed contact details of providers and/or information. Nevertheless, most delegated the examination and consideration of PSADs to the older adult and/or their relatives. Only a few nurses 
said they provided additional information by comparing devices, sharing experiences from other users, discussing advantages and drawbacks as well as talking about costs. A majority mentioned that they would like to have more knowledge about PSADs, remarking that older adults and relatives would like information from a neutral source such as themselves. Some community nurses added a reason for advising in passing: there is no financial reimbursement for such counselling services. GPs indicated that PSAD advice is not their responsibility. However, most of them provided flyers on PSADs, which they received as publicity, in their waiting room. A few GPs said they would like to have more knowledge about PSADs, suggesting an online platform summarizing all providers and information.

\section{Phase C) Deciding on and supporting PSAD use}

Relatives, community nurses and GPs discussed three types of decision they are confronted with in older adults: no, not-yet and yes (Deciding on PSAD use). Those decisions are valid at a particular point in time, but need to be revisited and modified, depending on the trajectory of the older adult's life. Especially community nurses and GPs highlighted that negative decisions should be accepted, and the question of whether to use a PSAD should be re-initiated after a next critical event. Whereas some relatives thought that PSAD use could be imposed upon their parent/s, others tried to convince them with steady pressure, possibly with the help of health professionals. In contrast, community nurses and GPs agreed that the decision should be made by the older adult, because their independent decision also increases the chances they will use a PSAD.

"They tend to use it if they can decide for themselves. I believe this is really crucial." (N-FG6-154).

Nevertheless, the health care professionals added that relatives are frequently involved in the decision-making.

According to the relatives, community nurses and GPs, different influencing factors affect the decision-making, namely, costs, social pressure, the alerting process and PSAD characteristics. They pointed out that costs are an important issue, because PSADs currently have to be paid for by users (although in some cases social allowances are possible). Particularly community nurses challenged this reason, however. They viewed costs as a primary counterargument when the older adult is not convinced a PSAD is necessary, observing that most pensioners are too wealthy for social allowances or refuse to request them. Similarly, GPs mentioned costs, arguing that health or social insurance should bear the expenses of PSADs, because in the end they save money by allowing therapies to be started earlier and hospitalizations to be shortened or avoided.

Social pressure refers to the influence of the older adult's social network on PSAD use. Surprisingly, relatives, community nurses and GPs attributed greater influence to others than to themselves. Relatives might turn to nurses or to GPs to negotiate more successfully on PSADs. Some community nurses were convinced that in particular situations relatives or GPs might have a greater impact. GPs considered themselves to have only limited influence, less than community nurses and relatives. Some relatives pleaded with their parent/s to use a device for their sake. Others instead 'imposed' a deal:

"The deal is that she (mother) concedes us a certain peace of mind, although she first disliked the watch (PSAD). We told her that this is the price of her independence, which she accepted. (...) She must also make concessions to us" (R-FG2-50).

Social pressure can also reverse acceptance, mainly when a PSAD was obtained without the approval of the older adult, which is quite commonly observed by community nurses and some GPs. Especially community nurses often experienced older adults owning a PSAD but not using it. In this case, it had often been supplied by a relative.

A further influencing factor was the alerting process, defined by how (technical) and to whom (contact persons) the alert is transmitted and how the contacted person will intervene. Several community nurses and GPs were convinced that clarity about the alerting process is a key to PSAD use.

"If you want to ensure that the PSAD is used, you have to make clear to the patient that their preferences are considered. (...) there should be no automatism for hospitalization. Because this is often what they fear. The bottom line is that the patients must know that activating an alert signifies that they will be helped, but only in a way they prefer, accepting that it might be different. I think this is key" (GP-I8-53).

The nurses emphasized that, in general, older adults want to have a community nurse as a contact person, which is not yet widespread. Furthermore, community nurses believe that being a contact person and deciding on the next steps in an emergency might be overstepping relatives' right. GPs mentioned that older adults are often suspicious of unknown people entering their home; therefore, relatives should be part of the alerting process.

Relatives were particularly concerned with PSAD characteristics. Beyond ease of use and aesthetic aspects of the device, e.g. color and design, they emphasized, in agreement with community nurses and GPs, that reliable alerting is crucial and should function in- and outdoors. Thus, older adults would be more likely to use a PSAD. Whereas nurses and GPs typically advocate a manually activated alerting device, relatives prefer an automatic one, to cover situations where consciousness is lost. Nurses and GPs argued for manual devices because this underpins the perception of independence and control for the older adult:

"Whether she/he pushes the button when she/he falls or tries to get up for two hours, it is still her/his decision" (GP-I6-59).

If a PSAD is used, a post-decision stage called coaching and reevaluating PSAD use should follow. Relatives, community nurses and GPs reported that, when a PSAD is chosen, the providing company oversees installation of the device and explains how it works. Some providers require the older adult to test the PSAD once a month, while relatives reported that they acted as the contact person. The involvement of community nurses during PSAD use was hardly discussed, some arguing that this is managed between the older adult and the provider. Some community nurses reported that they monitored everyday use, which might even be requested by relatives. However, few nurses check on how regularly a PSAD is used or think about how to improve everyday use. Several self-critically added that they should not only focus on enabling PSAD use, but also on providing more coaching and re-evaluation of use. In the case of non-use, community nurses and GPs said they would wait for another critical event to re-initiate the negotiation process.

\section{Discussion and recommendations}

This study aimed to explore the perspectives of relatives, community nurses and GPs on why and when PSADs are used by community-dwelling older adults and on their involvement in PSAD use and non-use. The findings revealed that PSAD use is the result of a negotiation process between these participants and the older adult, comprising three major phases: A) waiting for a critical event in the older adult's everyday life; B) introducing the idea of a PSAD and C) 
deciding on and supporting PSAD use. Core to the negotiation process is the balancing of care versus independence.

Overall, it is noteworthy that all participants agreed that suggestions about using a PSAD are often perceived by older adults as a threat to their independence. This reflects research describing that independence and control over daily life are pivotal for older adults. $^{31,32}$ Furthermore, older adults might regard using a PSAD as synonymous with a 'declaration of frailty. ${ }^{21}$ Becoming dependent on others can be related to decreased well-being and feelings of helplessness. ${ }^{33}$ This finding suggests that in order to increase PSAD acceptance, community nurses and GPs should explain how a PSAD supports independence by increasing safety, and elucidate a transparent alerting process with the older adult to address the fear of being hospitalized or institutionalized. This should promote a more positive attitude to PSAD use.

Although it might be surprising, many older adults seem to regard a PSAD as an invisible link between their home and an institution (care home or hospital). As a consequence, they may perceive a threat to their wish to die at home. This concern about not being able to die at home is not unjustified however: until 2011 in Switzerland, some $80 \%$ of older adults died in a hospital or care home. ${ }^{34}$ Our findings suggest that the conversation of health professionals about personal safety and the use of a PSAD should include an in-depth discussion about PSDA response chains in relation to personal wishes and needs regarding hospitalization and institutionalization. Older adults have to trust the response system and those involved. Thus, preferences for interventions in an emergency, their preferred location for dying and the meaning of 'living as long as possible at home' can be clarified with the older adult and their relatives.

Our study offers a model with three iterative phases of negotiation to explain why PSADs, which are advisable for improving safety, are infrequently used by older adults and how their use can be facilitated. Regarding the phase A) Waiting for a critical event in the older adult's everyday life: Older adults are reported to be more motivated to use a PSAD when they have experienced a fall or related insecurity. ${ }^{9,16}$ This resonates with our findings by demonstrating that critical events are important for choosing the right moment to address the use of PSAD. Additionally, our findings provide valuable insights firstly by identifying further critical events and secondly by suggesting that although a critical event may occur, as long as the older adult does not perceive it as critical, she/he will not use a PSAD. Therefore, relatives and health professionals felt 'constrained' to wait for another window of opportunity. At first glance, this finding seems difficult to explain, as a critical event may mean physical and psychological suffering. However, a possible explanation is that older adults perceive themselves as secure and independent when living at home in the community; ${ }^{35}$ thus, experiencing insecurity might be a prerequisite for PSAD use.

Regarding phase $\boldsymbol{B}$ ) Introducing the idea of a PSAD: That relatives, community nurses and GPs may all act as PSAD facilitators is consistent with other study findings. ${ }^{9,15,20}$ Our study provides additional insight by indicating that a trusting relationship is considered to be a precondition. This is interesting, as a trusting healthcare professional-patient relationship is also acknowledged to be essential for effective health counselling ${ }^{36}$ and related to more beneficial patient health behaviors. ${ }^{37}$

Regarding relatives, our findings go beyond depicting a solely facilitative role ${ }^{18}$ by showing that relatives can also affect PSAD use negatively. Although our study indicates that relatives often play a critical role in providing information and are involved in the decision-making process, health professionals mentioned that relatives may exert pressure or provide a PSAD without consent, consequently pushing older adults to refuse it. A possible negative influence on technology use is described by Luijkx, Peek, Wouters, ${ }^{19}$ who found that older adults may generally feel coerced by their children into using technology. However, relatives may be driven by a sense of duty. ${ }^{38}$ Therefore, it seems essential that relatives know the importance of critical events and their role in the negotiation process. They should be enabled to use the right moments to (re-) initiate PSAD negotiations as well as to balance their desire for care and security with their parent's desire to maintain independence in daily life. The findings also suggest that community nurses and GPs should question their practice of delegating the negotiation process to relatives.

Regarding phase C) Deciding on and supporting PSAD use: Our study shows that particularly relatives and community nurses were involved in the decision process. Surprisingly, all actors lacked knowledge and knowhow regarding PSADs, e.g. diversity, concrete use or advantages and disadvantages of a device. We argue that particularly community nurses need to be aware of the negotiation process and have enough knowledge to provide appropriate and comprehensive PSAD counselling, as their professional role is to help individuals manage daily life and safe living. ${ }^{39,40}$ Additionally, counselling is needed for older adults without children, and information for relatives whose parent/s is/are not yet in contact with community nurses of a community care service provider. It is conceivable that a specialized community nurse might provide PSAD counselling. This could be combined with the possibility to touch and test PSADs, which we identified as being crucial for the decision process. GPs might systematically assess critical events, provide first information and refer to community nurses.

\section{Strengths and limitations}

A strength of this study is the reflexivity during data collection and the inductive and deductive coding analysis process. Regarding data collection, the first author critically reflected on the thematic course of each interview and focus group in terms of similarities and new insights and integrated them into the subsequent data collection. Thus, rich perspectives could be captured. A further strength is the range of perspectives provided by three different types of participants. In addition, the research group was involved in the analysis and interpretation of the findings.

A few limitations of this study should be considered when interpreting the findings. First, most of the focus groups with community nurses were conducted with three participants, which could have led to a lower thematic diversity in the discussions. It was not possible to recruit community nurses outside of their working hours and community care services agreed to releasing only three nurses at a time.

Second, the purposeful and snowball sampling method might also be considered a limitation. We recruited relatives through flyers in official places such as pharmacies, fitness centers, etc., and via mail. We did not directly approach potential participants. This method precluded us from tracking the number of relatives invited and how many refused to participate. The community nurses were recruited via community nurse care managers. We approached 42 community care service providers, seven agreed to participate. The community nurse managers recruited 3-5 community nurses per provider. Since staff resources are scarce in the community, we abstained from asking how many persons they asked and how many refused to participate. We did not want to impose an additional burden and jeopardize the care service provider study participation. Finally, we approached 94 GPs, and 11 agreed to participate (response rate 11\%). We anticipated that recruiting participants might be challenging and thus aimed to reach as many potential participants as possible with our strategy, instead of focusing on a clearly defined number of potential participants. Moreover, we potentially attracted volunteers with a specific interest in the topic and more relatives of robust than of frail older adults might have participated. However, the sample size, ${ }^{41}$ the data collection and analysis supported data saturation, as rich perspectives were captured and themes were confirmed across interviews and focus groups. Lastly, the findings apply to the population studied and may not be applicable to other populations with different cultural and societal perspectives. 


\section{Conclusions}

The actors involved in PSAD use and non-use, relatives, community nurses and GPs, should be aware of the PSAD negotiation process, which is complex, dynamic, iterative and needs time. This process can enable the older adult to make an informed decision about PSAD use, which might be reconsidered later. Throughout the negotiation process relatives, community nurses and GPs need to balance the perceived care need versus the perceived need of the older adult for independence in daily life.

Relatives and community nurses are predominantly involved in the negotiation process. GPs are less involved but can identify critical events, positively influence older adults' decision-making and refer to community nurses for further counselling.

The PSAD perception of the older adult is essential. To date, it seems that a PSAD is regarded as an invisible link between home and an institution. Health professionals need to clarify the alerting process, i.e., to discuss mortality, hospitalization and institutionalization. Relatives and health professionals can influence older adults at an early stage by explaining how a PSAD can substantially support living independently longer.

Although community nurses may play a pivotal role during the negotiation process, they lack knowledge regarding comprehensive counselling on PSADs, e.g. different models of PSADs or the alerting process. Relatives are interested in user experiences, the pros and cons of different models, and in the opportunity to touch and test the devices with their parent/s. Older adults and relatives need to be supported, as conflicting situations are probable at the beginning of the negotiation process. Therefore, specialized community nurses may be the key to further improving and facilitating the decision about PSAD use and thus to supporting safe aging in place.

The suggested descriptive model could benefit from further exploration, particularly elucidating the kind of support communitydwelling older adults need, and from whom, when using a PSAD. Thus, supportive interventions for community-dwelling older adults could be developed and tested. In addition, the negotiation process described could serve as an example for decisions on the use or nonuse of other technologies in the context of aging in place.

\section{Conflict of interest}

We have no conflict of interest to declare.

\section{References}

1. Pruchno R. International aging: spotlighting the spotlights. Gerontologist. 2017; 57:392-395.

2. Scharlach AE, Diaze Moore K. Aging in place. In: Bengtson VL, Settersten RA, eds. Handbook of theories of aging. New York: Springer; 2016:407-425.

3. Hajek A, Lehnert T, Wegener A, Riedel-Heller SG, König HH. Langzeitpflegepräferenzen der Älteren in Deutschland - Ergebnisse einer bevölkerungsrepräsentativen Umfrage. Das Gesundheitswesen. 2018;80:685-692.

4. Lehnert T, Heuchert M, Hussain K, König H-H. Stated preferences for long-term care: a literature review. Ageing Soc. 2019;39:1873-1913.

5. European Network on Independent Living. Comparing the Costs of Independent Living and Residential Care. Dublin: European Network on Independent Living; 2014:29.

6. Kim K-I, Gollamudi SS, Steinhubl S. Digital technology to enable aging in place. Exp Gerontol. 2017;88:25-31.

7. Fischer SH, David D, Crotty BH, Dierks M, Safran C. Acceptance and use of health information technology by community-dwelling elders. Int $\mathrm{J}$ Med Inform. 2014;83:624-635.

8. Schulz R, Wahl HW, Matthews JT, Dabbs AD, Beach SR, Czaja SJ. Advancing the Aging and Technology Agenda in Gerontology. Gerontologist. 2015;55:724734.

9. Peek STM, Wouters EJ, van Hoof J, Luijkx KG, Boeije HR, Vrijhoef HJ. Factors influencing acceptance of technology for aging in place: a systematic review. Int J Med Inform. 2014;83:235-248.
10. Gillespie LD, Robertson MC, Gillespie WJ, et al. Interventions for preventing falls in older people living in the community. Cochrane Database Syst Rev. 2012;9: CD007146.

11. Simpson PM, Bendall JC, Tiedemann A, Lord SR, Close JC. Epidemiology of emergency medical service responses to older people who have fallen: a prospective cohort study. Prehosp Emerg Care. 2014;18:185-194.

12. Bloch F. Les complications non traumatiques des chutes: des conséquences trop souvent négligées chez la personne âgée. NPG Neurologie - Psychiatrie - Gériatrie. 2015;15:188-190.

13. Gill TM, Murphy TE, Gahbauer EA, Allore HG. Association of injurious falls with disability outcomes and nursing home admissions in community-living older persons. Am J Epidemiol. 2013;178:418-425.

14. van Hoof J, Kort HSM, Rutten PGS, Duijnstee MSH. Ageing-in-place with the use of ambient intelligence technology: Perspectives of older users. Int J Med Inf. 2011;80:310-331.

15. Stokke R. The personal emergency response system as a technology innovation in primary health care services: an integrative review. J Med Internet Res. 2016;18:e187.

16. McLean PA. Exploring older Adults' Persceptions of the Utility and Ease of Use of Personal Emergency Response Systems. New York: Faculty in Nursing, CNUY Academic Works; 2016.

17. Nyman SR, Victor CR. Use of personal call alarms among community-dwelling older people. Ageing Soc. 2014;34:67-89.

18. Peek STM, Luijkx KG, Vrijhoef HJM, et al. Origins and consequences of technology acquirement by independent-living seniors: towards an integrative model. BMC Geriatr. 2017:17.

19. Luijkx K, Peek S, Wouters E. “Grandma, you should do it-it's cool” older adults and the role of family members in their acceptance of technology. Int J Environ Rese Public Health. 2015;12:15470-15485.

20. Thilo FJS, Hahn S, Halfens RJG, Schols JMGA. Usability of a wearable fall detection prototype from the perspective of older people-A real field testing approach. J Clin Nurs. 2018.

21. Stokke R. Older people negotiating independence and safety in everyday life using technology: qualitative study. J Med Internet Res. 2018;20:e10054.

22. Connelly K, ur Rehman Laghari K, Mokhtari M, Falk TH. Approaches to Understanding the Impact of Technologies for Aging in Place: A Mini-Review. Gerontology. 2014;60:282-288

23. Nieboer ME, van Hoof J, van Hout AM, Aarts S, Wouters EJM. Professional values, technology and future health care: The view of health care professionals in The Netherlands. Technol Soc. 2014;39:10-17.

24. Bagozzi RP. The legacy of the technology acceptance model and a proposal for a paradigm shift. J Assoc Inf Syst. 2007;8.

25. Doyle LM, McCabe C, Keogh B, Brady A, McCann M. An overview of the qualitative descriptive design within nursing research. J Res Nursing. 2019;0:1-13.

26. Ravitch SM, Mittenfelner Carl N. Qualitative Research - Bridging the Conceptual, Theoretical, and Methodological. Thousand Oaks. London, New Delhi, Singapore: SAGE; 2016

27. Dierckx de Casterlé B, Gastmans C, Bryon E, Denier Y. QUAGOL: a guide for qualitative data analysis. Int J Nurs Stud. 2012;49:360-371.

28. Saldana J. The Coding Manual for Qualitative Researchers. 3 ed. Los Angeles, London, New Delhi, Singapore: Washington DC SAGE; 2016.

29. Whittemore R, Chase SK, Mandle CL. Validity in qualitative research. Qual Health Res. 2001;11:522-537.

30. Graneheim UH, Lundman B. Qualitative content analysis in nursing research: concepts, procedures and measures to achieve trustworthiness. Nurse Educ Today. 2004;24:105-112

31. Hale B, Barret P, Gauld R. The Age of Supported Independence Voices of In-home Care. Dordrecht Heidelberg London New York: Springer; 2010:149.

32. Linhart M. Independence in Old Age - Older German Women Living Alone: The development of a substantive theory about the maintenance of independence in old alge. Saarbrücken: LAP Lambert Academic Publishing; 2010.

33. Nicholson C, Meyer J, Flatley M, Holman C, Lowton K. Living on the margin: Understanding the experience of living and dying with frailty in old age. Soc Sci Med. 2012;75:1426-1432.

34. Junker C. Inventar der Datensituation über Palliatvie Care. Neuchâtel: Bundesamt für Statistik BFS;; 2012.

35. Bereitholtz A, Snellman I, Fagerberg I. Living with uncertainty: older persons' lived experience of making independent deicsions over time. Nursing Res Pract. 2013. https://doi.org/10.1155/2013/403717.

36. Eriksson I, Nilsson K. Preconditions needed for establishing a trusting relationship during health counselling - an interview study. J Clin Nurs. 2008;17:2352-2359.

37. Birkhäuer J, Gaab J, Kossowsky J, et al. Trust in the health care professional and health outcome: a meta-analysis. PLoS One. 2017;12: e0170988.

38. Gibbons SW, Ross A, Bevans M. Liminality as a Conceptual Frame for Understanding the Family Caregiving Rite of Passage: An Integrative Review. Res Nurs Health. 2014;37:423-436.

39. ANA. Nursing's social policy statement. Washington, DC: American Nurses Association; 2003.

40. Spichiger E, Kesselring A, Spirig R, De Geest S. Professionelle Pflege - Entwicklung und Inahlte einer Definition. Pflege: Die wissenschaftliche Zeitschrift für Pflegeberufe. 2006;19:45-51.

41. Stewart D, Shamdasani P. Focus Groups. Theory And Practice. 3 ed. Los Angeles: SAGE; 2015. 
Chapter 7

\section{General Discussion}





\section{Introduction}

Ageing in place is not only a priority of health care and political agendas but also a strong desideratum of older persons. ${ }^{1,2}$ Safety is regarded as a crucial component of ageing in place. ${ }^{3}$ One important safety issue is the problem of falls, since falls and particularly long lies after a fall impact negatively the health and wellbeing of older persons. ${ }^{4,5}$ Although the prevention of falls among community-dwelling older persons is seen as crucial and multifactorial and multicomponent interventions can mitigate fall rates and risk of falls, so far the evidence of their effectiveness is of poor quality. ${ }^{6}$ Therefore, Personal Safety Alerting Devices (PSAD) are a solution to support the safety of older persons ageing in place.

Unfortunately, older persons are still reluctant to use PSADs. ${ }^{7-9}$ Therefore, it is essential to gain a meaningful understanding of factors influencing PSAD use and nonuse in older persons from the key stakeholders of ageing in place, i.e. older persons, their relatives, community nurses and General Practitioners (GPs). This, in turn, requires taking aim at both, usability issues and underlying processes of use and non-use.

Thus, the overall aim of this doctoral thesis was to investigate the PSAD use and non-use of community-dwelling older persons from a multiperspective approach. After conducting a scoping review, the needs and preferences of community-dwelling older persons were considered in various stages of a newly developed wearable, waterproofed and automatically fall detection PSAD. Next, older persons' reasons, thoughts and motives as well as the influencing factors of PSAD use and non-use when ageing in place and finally the perspectives and experiences of relatives, community nurses and GPs were studied.

This final chapter discusses the main findings of the five individual studies comprising this dissertation. Following that, methodological and theoretical considerations are discussed. The chapter closes with the implications of the findings for research and practice.

\section{Summary of the main findings}

The summary of the main findings is presented in the form of answers to the research questions of this thesis.

1. What is the nature and extent of user involvement of people 65 years of age and older in the development, testing and/or evaluation of fall detection systems? (Chapter 2) 
The first study (Chapter 2), a scoping review of the scientific literature covering the state of research from 2004 to 2014, described the nature and extent of user involvement of people 65 years of age and older in the development, testing and/or evaluation of PSADs. ${ }^{10}$ The 53 analysed studies showed that older persons are mostly involved in one or two stages of PSAD development, most often during the stage/s prototype design and or testing, e.g. algorithms, according to the development stages of the theoretical framework "medical device technology development process" of Shah, Robinson and AlShawi. ${ }^{11}$ Meaning, the focus of involvement was predominantly on the development of technical aspects. In sum, the review revealed that little attention has been given to the views, needs, preferences or practical aspects of usefulness in the daily life of older persons themselves.

2. What are the needs and preferences of community-dwelling older people regarding a wearable fall detection sensor and its smartphone application during the design and mock-up stage? (Chapter 3)

3. What is the usability of a wearable, waterproof, automatically alerting, fall detection prototype, according to the community-dwelling older persons involved? (Chapter 4)

The second and third studies were conducted based on the theoretical framework of Shah et al. ${ }^{1 "}$ mentioned above, to develop an innovative PSAD, in the form of a wearable sensor linked to a smartphone application (app).

The second study (Chapter 3 ) involved a total of 22 community-dwelling older persons in device design and mock-up development, focusing on feasibility and practical aspects related to daily use. ${ }^{12}$ The participants welcomed the idea of this sensor, which is waterproofed and alerts automatically in case of a fall. They considered the sensor as feasible in terms of weight, material, size, shape and colour and emphasized their need for reliable alert functioning. Remaining physically mobile and being unrestricted in daily activities were mentioned as pivotal. However, the idea of using a smartphone for automatic fall detection and alert transmission evoked some general scepticism. Yet, participants mentioned that future generations will probably be able to deal with a smartphone. The second study indicated that older persons' perception of activity and independence in daily life may influence the acceptance and usage of a PSAD. But the participants emphasised that real-life testing should be carried out to thoroughly consider practical aspects of use and not to remain hypothetical.

Based on those insights, a "needs-driven" PSAD prototype was developed. The third study (Chapter 4) investigated its usability in a real field testing trial. ${ }^{13} \mathrm{~A}$ total of 15 community-dwelling older persons tested this prototype in daily living over a period of nine days. The findings yielded positive aspects and aspects requiring 
improvement. The participants highlighted high wearing comfort and easy battery charging of the sensor as positive. However, the sensor would need a longer duration of battery charge in order to extend the wearing time. The manipulation of the app was clear and easy and being located via GPS was an advantage mentioned by all. In contrast, the alerting process and the choice of contact persons as well as their related tasks were identified as quite complex, e.g. who to choose or availability of contact persons. The use of the smartphone was criticised for requiring too much effort and training to learn its handling. In addition, the battery duration was insufficient and the reliable alerting distance between smartphone and wearable sensor not practicable in everyday life. The participants suggested different versions of this type of PSAD, i.e. one without a smartphone as the wearable sensor was highly appreciated. Furthermore, the study revealed that the integration of a PSAD in daily life goes beyond technical requirements, in terms of habits and personal preferences, e.g. modification of daily routines, maintenance of independent living or the roles of relatives and healthcare professionals particularly in the alerting process.

4. What are reasons, thoughts, motives and influencing factors regarding the use and non-use of a PSAD in daily life from the perspective of communitydwelling older persons? (Chapter 5)

The fourth study (Chapter 5) addressed the broader context, and investigated reasons, thoughts, motives and influencing factors regarding PSAD use and non-use of community-dwelling older persons. The exploration of 32 older persons' perspectives revealed that the decision to use or not to use results from a "legitimation process".14 The participants highlighted the need to perceive the necessity for using a PSAD. The decision to use or not to use involves an interplay of the ageing self, e.g. dealing with age-related changes, and with the person's perception of technology, e.g. technology experience. The legitimation process is triggered by a critical event, e.g. a fall or deterioration of health, which causes the person to reflect on her/his own safety and possible need for assistance as well as the right moment to start using it. As times goes on, depending upon new critical events occurring in daily life, another cycle of the legitimation process may be re-initiated.

5. What are the reasons for PSAD use and non-use among community-dwelling older persons according to relatives, nurses and GPs? In what situations are PSADs used or not used by community-dwelling older persons according to relatives, nurses and GPs? What is the involvement of relatives, nurses and GPs in the use and non-use of PSADs? (Chapter 6) 
To enable a comprehensive insight into the "bigger picture" of PSAD use and non-use, the fifth study explored relatives', community nurses' and GPs' perspectives and experiences in decision making around PSAD use and non-use in the daily life of communitydwelling older persons (Chapter 6). Altogether, 33 relatives, 34 community nurses and eleven GPs were interviewed. ${ }^{15}$ The participants disclosed that they were involved in a longer lasting negotiation process comprising three major phases: A) waiting for a critical event in an older person's everyday life; B) introducing the idea of a PSAD; C) deciding about and supporting PSAD use. The process was characterized by a balancing of care with independence. Whereas all participants perceived a need to care for the older person by suggesting the use of a PSAD, the older person mostly experienced this suggestion as a threat to losing her/his independence as an adult. The study suggests that an informed decision of PSAD use and non-use requires a negotiation process which is iterative, complex and time-intensive. Relatives and community nurses are predominantly involved; GPs may positively influence the decision making. While community nurses play a crucial role, they seem not sufficiently prepared to provide comprehensive PSAD counselling.

\section{Discussion of the main findings}

Since the overall objective of this doctoral thesis is on extending current knowledge regarding the PSAD use and non-use of community-dwelling older persons in everyday life, the discussion considers the main findings predominantly in the light of PSAD acceptance, adoption and use / non-use.

\section{User involvement in PSAD development - a demand with need for clarification and advancement}

User involvement is recommended in order to address usability issues of technologies. ${ }^{11,16-19}$ It requires that users are actively and iteratively involved in several stages of product /device development, from the beginning, through the design and prototype stages, until its implementation. ${ }^{17,20,21}$ Usability issues are considered an antecedent of the "perceived ease of use", which significantly influences technology acceptance. $^{22}$ Despite this internationally acknowledged significance of user involvement, the scoping review (Chapter 2) of this thesis showed that the involvement of older persons in the development of PSADs is still limited. This finding is pivotal since usability issues are reasons for PSAD non-use. ${ }^{23-25} \mathrm{~A}$ closer look at the findings revealed that older persons are involved, but with a primary focus on technical aspects, e.g. algorithms. ${ }^{10}$ Researchers seem to answer the demand for user involvement, but 
without necessarily including the "real" needs and preferences of older persons. Further explorations should include the perspectives of older persons.

By considering user involvement to be active and iterative involvement, ${ }^{11,17}$ critical analysis leads to the identification of tokenism. This term was particularly shaped by Arnstein's ${ }^{26}$ participation ladder in the context of citizens' participation, then further developed, meaning that users are involved but hardly influencing the decisions taken during product / service / device development. ${ }^{20,27}$ The risk of tokenism during technology development was already described 20 years ago in the information technology field. ${ }^{20}$ Damodaran ${ }^{20}$ pointed out that involving users does not guarantee their influence on the device development process; the team needs to ensure that users are actively involved in the whole process. She suggested clarifying the degree of involvement by how much influence users specifically have on the decision making. Damodaran ${ }^{20}$ differentiated three degrees of involvement: informative, consultative or participative. While informative involvement signifies that users obtain and provide information, consultative involvement requires the user to give more comprehensive feedback on the product/device under development. And the third degree of involvement, participative involvement, allows the user to decide about further development.

In addition, beyond the influence on decision making described, ${ }^{20,27}$ it seems necessary to also focus on involvement throughout the process. In line with Shah et al., ${ }^{11}$ users should be involved iteratively in all stages of device development. Thus, amongst other things, users can already reflect on the "real-life feasibility" of technology development ideas or can provide critical feedback at various stages of modifications and developments. This suggestion is underpinned by the findings of the second and third study of this doctoral thesis (Chapters 3 and 4). These studies showed, e.g. that as early as their first involvement the participants mistrusted the feasibility of the smartphone in daily life. This was confirmed by the second involvement during real field testing. From a self-critical perspective, this criticism of the older persons was not taken very seriously by the research team, as the project plan suggested "only" the smartphone version. Especially since, some participants with smartphone experience were keen on testing this prototype PSAD in daily life.

Up to now, and despite various efforts, active and iterative user involvement in the development of PSADs remains a desideratum that needs clarification and advancement. At the same time, it is important to note that user involvement is not as simple as it might appear. Among other things, it requires: translating users' needs and expectations into technical requirements, establishing and maintaining a relationship with users, dealing with a considerable amount of user feedback or the handling of "different" languages (technical, scientific and everyday language). ${ }^{16,19,28}$ Recently, 
Romsland, Milosavljevic and Andreassen ${ }^{29}$ pointed out that non-tokenistic and active user involvement requires not only an anchored interest of the researchers in the users' needs, but also preparing for participation, e.g. by developing a working relationship, promoting active engagement, e.g. by ensuring comprehensive terminology, gathering user perspectives and valuing and encouraging criticism. The risk of tokenism and the expectations related to user involvement also indicate that "real" user involvement requires appropriate knowledge and skills from those applying it. ${ }^{16,30,31}$

Another highly interesting insight regarding the added value of user involvement, using the example of PSADs, was provided by studies two and three (Chapters 3 and 4). Those studies ${ }^{12,13}$ revealed that beyond usability issues, defined as primarily functional aspects, e.g. wearing comfort or ease of manipulation, the impact of the device on daily life as well as the meaning attributed to a device seems to have considerable influence on later PSAD use. In terms of impact, the participants wanted to know/to ensure: if the sensor could be integrated into an already used item (jewellery, personal watch), if the PSAD would limit their physical activity, how their daily routines would be affected or if health professionals like nurses might be part of the alerting process, as they preferred having trusted contact persons. These findings confirm those observed in earlier studies on barriers to PSAD use: not knowing the qualification of the contact persons or not knowing when to wear the device or when to activate an alarm. ${ }^{23}$ In terms of meaning, whereas some participants believed that a PSAD is a highly reliable way of calling for assistance, others were unconvinced about and favoured waiting to see how life would decide about their fate. Participants pondered possible influences on their perceived independence in daily life. This was particularly related to the preservation of their physical mobility or their status as an independent adult: some disclosed a preference for wearing the PSAD hidden from the view of others. Adding insight from the fourth study (Chapter 5), the legitimation process showed that most of the participants considered a PSAD as "transforming" them into a dependent person. The literature shows that older persons who believed the PSAD was important for them wore it significantly more often. ${ }^{23}$ Other older persons will not use it because they want to manage their life by themselves or they associate a PSAD with a stigmatizing appearance ${ }^{23}$ or regard it as a symbol for being dependent and frail. 8

A possible explanation for this "discovery" of the dimensions impact and meaning of a device such as a PSAD might be rooted in the interdisciplinary approach chosen for this PSAD development (Chapters 3 and 4). Nursing researchers worked together with engineers. The nursing researchers endowed the team with a different professional lens and knowledge regarding contextualisation of older persons' challenges when ageing in place. The nursing researchers were also trained on an advanced level regarding communicative competences as well as equipped with several years of 
clinical experiences in the care of older persons. Thus, it is conceivable that challenges of user involvement, such as establishing and maintaining a relationship with users, dealing with a considerable amount of user feedback or the handling of "different" languages (technical, scientific, everyday language), ${ }^{19,28}$ were successfully addressed. This argumentation can be underpinned by another observation: nearly all participants from the third study had already taken part in the second study. One year later they were still motivated and engaged, which might be due to the nursing researchers' expertise.

\section{The legitimation process for PSAD use and non-use - establishing perceived necessity}

The fourth study (Chapter 5) of this doctoral thesis revealed that deciding about PSAD use induces a process in which the older person deals with their own ageing and thoughts about becoming a dependent person. ${ }^{14}$ It is somewhat surprising that this rather small and simple device challenges the ageing-self of the older person. While the idea of a PSAD is to support safe and independent living when ageing in place, ${ }^{32,33}$ the findings (Chapter 4 and 5) suggest that, when considering the topic of PSADs, older persons often perceive a threat to their independent living. This perceived threat was also identified by the relatives and health professionals involved (Chapter 6). It may be explained by the fact that older persons are striving for independence and maintaining control over their life. ${ }^{34}$ In addition, dealing with ageing implies maintaining a sense of self, which can be undermined by "superficial" events such as giving up a long-standing activity or "driving license".35

Furthermore, particularly the health professionals (Chapter 6) shared their experience that older persons might be worried that their social environment would "treat" them as frail and old if they wore a PSAD. This might not only be a sign of needing more assistance, but also of having a higher risk of soon being unable to live any longer at home. In addition, the health professionals revealed that some older persons consider a PSAD as a possible gateway to a long-term care institution. Those reflections show that PSAD use might be perceived as a threat to the older person's desideratum: to live as long as possible in the accustomed environment ${ }^{1,2}$ in order to maintain independent living and control over daily life. ${ }^{34}$ This finding is significant, as it emphasizes that those perceptions may inform a negative attitude towards PSAD use. This is in line with Nyman and Victor ${ }^{8}$ and Chaudhuri et al. ${ }^{25}$, who suggested that a negative meaning attributed to PSADs might result in PSAD non-use. In the same sense, the current literature already hints at the fact that older persons recognising a PSAD as supportive in daily life, are more favourable to its use. 36,37

Another pivotal finding of this doctoral thesis was the importance of perceived necessity, i.e. the need of the older persons to establish a perceived necessity in order 
to legitimate PSAD use for themselves (Chapter 5). The perceived necessity from the perspective of the older person is related to the right moment for PSAD use, i.e. it determines the beginning of using a PSAD. But importantly, establishing perceived necessity requires one or often several critical events, which again must be perceived as critical by the older person (Chapter 5). This perception by the older person might be in contrast with the perception of the social environment, as was found in the fifth study (Chapter 6). It highlights that PSAD use in daily life requires a decision on the part of the older person or shared decision making by the involved persons, since an older person who does not perceive the necessity for PSAD use will most probably abstain from using it. Furthermore, it might be argued that either giving the decision to the older person or participating in shared decision making emphasizes and supports that person's need for independence and control over daily life.

Furthermore, the perceived necessity may explain the discrepancy in the frequently reported phenomenon of PSAD acceptance, in terms of having a PSAD at home, but hardly using it in daily life. ${ }^{7-9,38}$ Moreover, it may also explain why the majority of older persons might be favourably disposed towards a PSAD, but in fact only a minority would use or are using one. ${ }^{7,8,39,40}$ Those situations, based on the legitimation process (Chapter 5) and the negotiation process (Chapter 6), seem to represent the moment where the older person opts for "not-yet-use", i.e. feels that in principle a PSAD can be helpful, but the perceived necessity for their own daily life is not yet fully established. These processes can be time-intensive and can be accompanied by several critical events that can even cause suffering for the older person. However, the community nurses in particular (Chapter 6) observed that only those agreeing to PSAD use will actually use it.

Relating this finding to the technology-acceptance technology literature, perceived necessity seems to equal perceived usefulness from the Technology Acceptance Model (TAM). ${ }^{22,41}$ While in the context of the original model (Chapter 1) perceived usefulness is defined as "the prospective user's subjective probability that using a specific application system will increase his or her job performance within an organizational context".22 In the context of the Senior Technology Acceptance Model (STAM), perceived usefulness is operationalized as, e.g.: "You will find technology useful in your life"(p.640). ${ }^{42}$ Thus, it seems worthwhile to consider whether perceived necessity might be a more suitable term than perceived usefulness in the context of PSADs or even the general technology use supporting ageing in place.

In line with the request of several researchers, ${ }^{43-46}$ it can be stated that particularly studies four (Chapter 5) and five (Chapter 6) may significantly contribute to answering the questions of the "when, why and how" of technology use. In addition, both studies contributed to disclosing the meaning and/or motivation of non-use, which, according to the literature, is crucial to investigate. ${ }^{47-49}$ 


\section{A negotiation process - an iterative, complex decision process over time needing} facilitation by different actors

From a multiperspective exploration, the fifth study (Chapter 6) clearly indicates from a multiperspective exploration that deciding on PSAD use or non-use requires a complex decision process over time..$^{15}$ During this process relatives and or health care professionals, community nurses and or GPs, negotiate the topic of PSAD use with the community-dwelling older person.

Even at a first glance, the negotiation process indicates that negotiating PSAD use or non-use is an iterative multiphase process between the involved stakeholders. As a result, different decisions are possible: non-use, not-yet-use or use. A decision is temporary in nature, i.e. it can be reversed some time later. This finding is particularly relevant when compared to technology acceptance research. Most of the technology acceptance models (Chapter 1), like the TAM or the Unified Theory of Acceptance and Use of Technology (UTAUT), represent a one-way process. ${ }^{22,41}$ In contrast, studies four and five (Chapters 5 and $\mathbf{6}$ ) highlight a dynamic decision-making process affected by critical events and influencing factors like costs or PSAD characteristics (Chapters 6). This finding supports Yousafzai, Foxall and Pallister ${ }^{50}$ who criticised that the TAM does not take into account fluctuating technology acceptance over time. In addition, it is in line with other researchers who recently stated that technology use is not static and may change over time. ${ }^{40,51}$

There is a further reason why different "PSAD-user-typologies" seem desirable. Research on the internet use of older persons found that there are those who use the internet intensively, others, occasionally and some, rarely. ${ }^{52}$ Another (non-)user typology is: "active resistance", disenchantment, disenfranchisement, displacement or disinterest. ${ }^{49}$ Baumer et al. ${ }^{48}$ recommend that a dichotomous distinction should be avoided, and that various forms of use and non-use should be recognized. It is conceivable that, on the one hand, those with a selective use are not excluded from the term user and, on the other, differentiating the kind of use might enable the tailoring of better information and/or interventions to a possible need. Alternatively, there is another explanation. Innovations (definition see Chapter 1 ) are adopted at a different pace by individuals of a society. ${ }^{53}$ Some are first, some require more time and others are laggards..$^{53}$ Five adopter categories are internationally recognized: innovators, early adopters, early majority, late majority and laggards. ${ }^{53}$ This classification might be suitable for obtaining a first indication about a person in regard to technology use.

Most of acceptance research disregards the possibility of rejection. ${ }^{54}$ However, particularly studies four and five (Chapters 5 and 6 ) demonstrated clearly that rejection is part of the legitimation as well as the negotiation process. That is, depending on the older person and the critical events occurring in her/his daily life, not-yet use or non-use 
were frequently a first step in the process, since one or more critical events and time were needed to decide on PSAD use. Additionally, this thesis shows that rejection can be an option after someone has used a PSAD for a certain time (Chapter 6). The literature suggests that implementing an innovation requires time to try out or actual "real life" use before a first adoption can be confirmed. ${ }^{53,55}$ According to the Diffusion of Innovations Theory $^{53}$ (Chapter 1), the phase of implementation informs the confirmation phase in which the person decides on continued adoption, later adoption, discontinuation or continued rejection. According to Rogers, ${ }^{53}$ adoption is a step following the acceptance of an innovation. In other words, acceptance occurs first, in the decision phase, then in the implementation phase the person needs to try out the device in daily life, and only then, in the confirmation phase, the decision is taken about adoption or discontinuance or rejection. ${ }^{53}$ Both phases seem suitable for the PSAD process, since older persons and relatives expressed the need and preference for trying out (Chapters 3, 5 and 6), which implies a first decision, in order to facilitate the decision about use, in terms of continuing use or not-yet (later) use.

This doctoral thesis found in studies two to five (Chapters 3 to 6) a pivotal influence of relatives and health professionals on PSAD use and non-use. Thus, this finding is in line with research on general technology acceptance. ${ }^{23,32,33,56-60}$ Relatives and health care professionals carry out various "tasks" in the context of PSAD use and non-use (Chapters 3 to 6): e.g. identifying critical events, introducing the idea of a PSAD, facilitating PSAD use or providing information about or access to PSADs. Surprisingly, it was revealed that although coaching and re-evaluation of PSAD use by older persons is required, most of the community nurses involved did not provide it due to a lack of competence and skills. Accordingly, the GPs stated that the issue of PSADs is in fact highly relevant for older persons' safety, but their tasks are focused on identifying critical events, if possible, and on the medication for fall prevention. They would benefit from more knowledge about PSADs, however, they do not consider it as a must for their work. Furthermore, it is interesting that although all community care organisations involved provided access to PSADs, only a few went beyond PSADs brochure delivery.

There are several possible explanations. It is acknowledged that a mismatch between technology provision and the consultation competences and skills of health professionals still exists. ${ }^{61}$ De Veer et al..$^{62}$ found that although an increasing number of technologies are implemented within nursing care, nurses themselves report a lack of skills required to use them. A study from the UK identified that community nurses are still not well enough trained in handling information technologies. ${ }^{63}$ Similarly, another study found a need to train health professionals for technology use in health care. ${ }^{64}$ In addition, health professionals require support in linking a technology to patients' needs. Risling ${ }^{65}$ calls for a curricular shift in order to prepare the future generation of health 
practitioners. Consequently, it seems to be an international phenomenon that the education of nurses' lags behind the technology development and that technologies are still insufficiently integrated into nursing and caring processes.

A further aspect seems pivotal for understanding the "bigger picture" of PSAD use and non-use. The alerting process was a dominant topic of almost all studies of this doctoral thesis (Chapters 3 to 6). Knowing that older persons are attached to their home, which represents a familiar place of independent living and social connectivity ${ }^{66}$ "Suddenly" it seems obvious that the perceived threat to their independence through the alerting process might also exist because using a PSAD can imply that "strangers" might enter their house. Normally, the home is considered to be a place which allows personal control, preservation of a sense of self and environmental mastery., ${ }^{1,68}$ But with the use of a PSAD, the home as a private space becomes a public space. It must be "shared" in a moment of helplessness. This transformation of the home, when older persons are increasingly in need of assistance in order to deal with daily life, is extensively discussed by Hale et al. ${ }^{34}$, who suggest that this transformation is a transition process at home for the older person. Another study found that community care, requiring health professionals to enter the private space, may evoke feelings of being exposed. ${ }^{69}$ It seems that a PSAD and the implicit alerting process evokes a similar transformation of a private space into a public one, which might affect the decision concerning its use.

This chapter, then, has provided an overview of the findings of studies one to five of this doctoral thesis (Chapters 2 to 6). It disclosed that the technology of a PSAD itself was thematically pushed into the background. Apart from perception of technology and PSAD characteristics, the following themes came to the fore from the perspectives of the participants: the impact of a PSAD on daily life (Chapter 3 and 4), the meaning attributed to a PSAD (Chapter 4 to 6), influencing factors like costs or social pressure (Chapter 5 and 6), critical events related to psychological, physical and social concerns (Chapters 5 and 6), being confronted with the ageing-self (Chapter 5), the ageing process (Chapter 6), encountering mortality (Chapter 5 and 6) or personal relationship (Chapter 6). This observation leads to one possible conclusion that the usability of the technology itself is an important basis, but the impact on daily life, the individually meaning attributed to the PSAD as well as the decision-making processes seems more dominant in influencing PSAD use and non-use. 


\section{Theoretical considerations}

This paragraph discusses the knowledge gained regarding PSAD use and non-use through this doctoral thesis in the context of the technology acceptance/adoption models outlined in the general introduction (Chapter 1 ).

A suggestion for a theoretical model is presented in Figure 1, summarizing as follows the findings of this doctoral thesis:

Studies two and three (Chapter 3 and 4) underscored that user involvement is a meaningful method for developing a needs-driven PSAD. A pivotal finding was that beyond usability, the meaning attributed to the PSAD as well as its impact on daily life matter from the perspective of community-dwelling older persons. In the literature (Chapter 1 ) usability is related to the perceived ease of use of a technology. The findings (Chapter 3 to 5) suggest that the perceived ease of use should include, beyond usability, the meaning attributed to a PSAD from the perspectives of the users and the impact on daily life (Figure 1). In addition, the relevance of usability, meaning and impact related to PSADs was endorsed by relatives and health professionals (Chapter 6). Perceived ease of use defined as usability, impact and meaning might solely apply to PSAD development, but seems a promising path of investigation as well for other technologies in the context of ageing in place.

Study four (Chapter 5) uncovered the legitimation process. The participants revealed that they go through this process to establish the perceived necessity of a PSAD, which can legitimate its use (Figure 1). Simultaneously, relatives and health professionals are engaged in a negotiation process (Chapter 6) to enable the older person to come to an informed decision regarding PSAD use and/or non-use (Figure 1). In addition, the findings (Chapters 5 and 6) highlighted that trying-out a PSAD is an important step towards an informed decision. Trying-out was thus interpreted as a first form of decision making, as the person agrees to deal with the topic of a PSAD (Figure 1). The "whole" process of PSAD use and non-use interacts in a balancing of independence and care. While the older person aims to maintain her/his independence in daily life, which can be perceived as threatened by a PSAD use, the relatives and health professionals are negotiating according their perceived necessity for care by suggesting the use of a PSAD (Figure 1).

The aim of this process shown in Figure 1 is an informed decision by the older person regarding PSAD use and non-use in her/his daily life. This process is particularly characterised as follows:

- PSAD use and non-use is based on a decision-making process that is iterative, time-intensive and multi-phased, between older persons, relatives and/or community nurses; GPs seem less involved. (Chapters 5 and 6) 


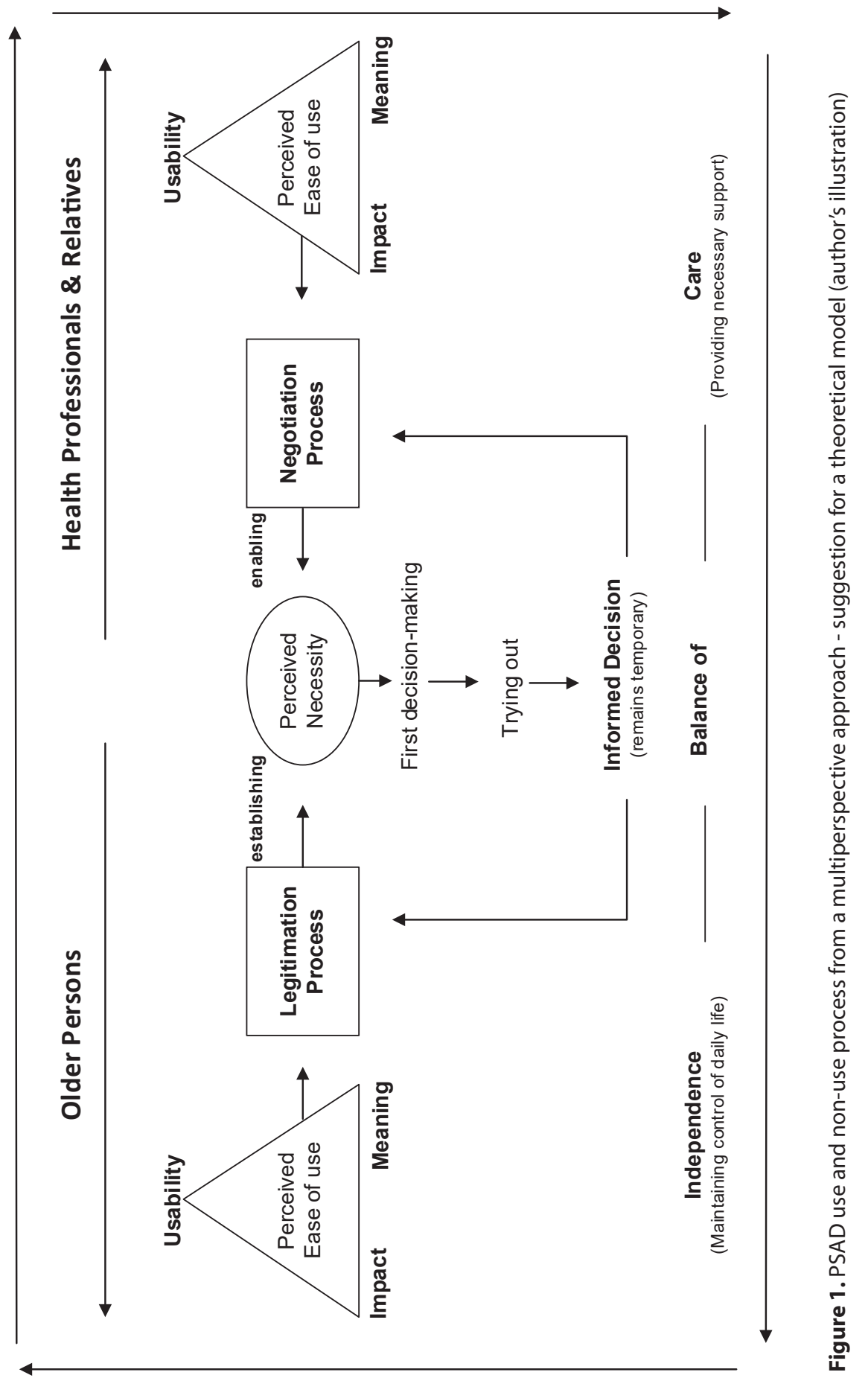


- The user attaches meaning to a PSAD (a technology "has" meaning) and this applies not only to the older person, but also to relatives (caring for the older person) and health professionals (supporting independent living). (Chapters 4 to 6)

- A PSAD impacts daily life, which has to be elucidated comprehensively (e.g. how it works, when to use it, how to integrate it into daily routines or how "strongly" daily routines will be affected by PSAD use). (Chapters 4 to 6 )

- Despite PSAD use, the older person requires keeping her/his perceived independence and control over daily life. (Chapters 4 to 6)

- Identifying the right moment of starting PSAD use is key for later use and nonuse, which should be identified in discussions between older persons, relatives and or community nurses, possibly GPs. (Chapters 5 and 6)

- Various typologies of users are needed; dichotomous differentiation is insufficient as some users are excluded. Being able to assess various PSAD use behaviours enable community nurses and or relatives to identify with the older person if interventions are needed to support PSAD use. (Chapters $\mathbf{5}$ and 6)

- Non-use (rejection) should be included as an iteration in the decision-making processes and thus in the technology acceptance / adoption / use process. (Chapters 5 and 6)

- Acceptance should be considered an intermediate step, i.e. the thesis findings suggest that acceptance is a first decision, agreeing to try out a PSAD, but the decision about adopting / using a PSAD will occur later. (Chapters 7)

- PSAD use and non-use of older persons needs to be enabled and supported (need for human contact) by relatives and/or health professionals, particularly community nurses, as they are still present in the home environment of the older person, unlike GPs. (Chapters 5 and 6)

On the one hand, this thesis suggests that the findings support the literature-based variables (Chapter 1) attitude, social norms, perceived usefulness, perceived ease of use and perceived behavioural control, as suggested in Table 1. However, this needs to be validated by further research. 
Table 1. Overview and comparison of literature-based variables with influencing factors of PSAD use and non-use found in this doctoral thesis

\begin{tabular}{|c|c|c|}
\hline \multicolumn{2}{|c|}{ Variables from the scientific literature (Chapter 1) } & \multirow{2}{*}{$\begin{array}{l}\text { Influencing factors of PSAD use and non-use } \\
\text { found in this doctoral thesis } \\
\text { - Meaning (attributed to PSADs) (Chapter } 3 \text { and } \\
\text { 4) } \\
\text { - Perception of technology (Chapter 5) } \\
\text { - Ageing-self (Chapter 5) } \\
\text { - Critical event - longing for death (Chapter 5) }\end{array}$} \\
\hline $\begin{array}{l}\text { - Theory of Reasoned Action (TRA) } \\
\text { (attitude towards behaviour) } \\
\text { - Technology Acceptance Model } \\
\text { (TAM) } \\
\text { (attitude towards using a technology) } \\
\text { - Unified Theory of Acceptance and } \\
\text { Use of Technology (UTAUT) })^{41} \text { - not } \\
\text { included } \\
\text { - Senior Technology Acceptance } \\
\text { Model (STAM) }{ }^{42} \text { (attitude towards } \\
\text { life and satisfaction) } \\
\text { - Diffusion of Innovations } \\
\text { Theory (DIT) })^{53} \text { (attitude towards } \\
\text { innovations) }\end{array}$ & Attitude & \\
\hline $\begin{array}{l}\text { - TRA (subjective norm) } \\
\text { - TAM - not included in first version, } \\
\text { but in later versions } \\
\text { - UTAUT (social influence) } \\
\text { - STAM (social relationships) } \\
\text { - DIT (norms of social system) }\end{array}$ & Social norms & $\begin{array}{l}\text { - Ageing-self (Chapter } 5 \text { ) } \\
\text { - Critical events (Chapter } 5 \text { and } 6 \text { ) } \\
\text { - Facilitating PSAD use by relatives and health } \\
\text { professionals (Chapter } 6 \text { ) }\end{array}$ \\
\hline $\begin{array}{l}\text { - } \text { TAM } \\
\text { - UTAUT (performance expectancy) } \\
\text { - } \text { STAM } \\
\text { - DIT (felt needs / problems) }\end{array}$ & $\begin{array}{l}\text { Perceived } \\
\text { usefulness }\end{array}$ & $\begin{array}{l}\text { - Perceived necessity (Chapter 5) } \\
\text { - Critical events (Chapter 6) }\end{array}$ \\
\hline $\begin{array}{l}\text { - } \text { TAM } \\
\text { - UTAUT (effort expectancy) } \\
\text { - } \text { STAM } \\
\text { - } \text { DIT (persuasion and } \\
\text { implementation stages) } \\
\text { - (TRA: similarity to control beliefs) } \\
\end{array}$ & $\begin{array}{l}\text { Perceived } \\
\text { ease of use }\end{array}$ & $\begin{array}{l}\text { - Usability (Chapter } 3 \text { and 4) } \\
\text { - Impact (on daily life) (Chapter } 3 \text { and 4) } \\
\text { - Perception of technology (Chapter 5) } \\
\text { - Influencing factor - PSAD characteristics } \\
\text { (Chapter 6) }\end{array}$ \\
\hline $\begin{array}{l}\text { - Theory of Planned Behaviour and } \\
\text { the Reasoned Action Approach } 71,72 \\
\text { - STAM (Gerontechnology self- } \\
\text { efficacy; cognitive ability) } \\
\text { - DIT (persuasion and } \\
\text { implementation stages) }\end{array}$ & $\begin{array}{l}\text { Perceived } \\
\text { behavioural } \\
\text { control }\end{array}$ & $\begin{array}{l}\text { - Becoming a person requiring assistance } \\
\text { (Chapter 5) } \\
\text { - Perception of technology (Chapter 5) } \\
\text { - Influencing factor - alerting process (Chapter 6) } \\
\text { - Encountering mortality (Chapter 6) } \\
\text { - Balancing care and independence (Chapter 6) }\end{array}$ \\
\hline
\end{tabular}

On the other hand, from this dissertation, using the case of PSADs, further insights were gained into technology acceptance/adoption/use and non-use models, beyond those reported in literature (Chapter1).

- One perspective, e.g. from the older person or from relatives, provides only limited understanding. A multiperspective investigation allows a comprehensive understanding, as shown in this dissertation.

- Attitude towards, a variable of the models TRA, TAM, STAM and DIT, was also found to be crucial in influencing the decision making about PSAD use and nonuse. However, this thesis found that not only the attitude to the technology or 
the behaviour enabling its use mattered, but also the attitude of the older person towards her/his own ageing process.

- The multiperspective investigation of this thesis revealed that the verbalised attitude toward a technology (a PSAD might be or is useful) may diverge from the observable behaviour in use (irregularly or having but not using). Therefore, communication among people involved in the use of a PSAD is crucial in order to identify reasons and motives and to consider possible interventions or further steps in regards of technology use.

- It seems particularly relevant for the health care context, since "others" suggest use of a technology due to an identified care need, to bring together the attitudes towards the technology from all those involved, because not only the perception of its necessity might differ (as in the case of critical events), but also the possible added-value of the technology itself; e.g. the PSAD is considered to be supporting independence from the perspectives of health professionals and relatives, but from the perspective of the older person is a possible threat to their independence. Communication among those involved should make clear the underlying assumptions of why a technology might be supportive or not.

- Technology use and non-use does not happen "by itself", nor without social context. More metaphorically expressed, it is hardly a soloist who uses a PSAD, but a duo, trio, quartet, etc. It will depend on the technology. Therefore, technology use and non-use related to ageing in place should to be enabled, agreed upon in a decision-making process.

- The social context is expressed as the variable social norms in the models TRA, TAM, UTAUT and STAM. The findings of this doctoral thesis show a strong influence of relatives and health professionals on PSAD use and non-use. Some older persons emphasized "openly" that the thoughts of their friends, neighbours, family and/or of health professionals were very welcome in helping them take a decision. Meaning, the social system does not only influence the decision making, but is key to enabling PSAD use itself, by providing support in the handling or in the context of the alerting process. In other words, the social system moderates the process, i.e. mostly relatives and/or community nurses. This active role of the social system is in line with the DIT. Additionally, it might be argued that the variables "gerontechnology anxiety" or "physical functioning" of the STAM, or "effort expectancy" of the UTAUT lose importance, because those variables can be influenced by the social system.

- The perceived usefulness is a specific variable of the technology acceptance models TAM, UTAUT and STAM. The DIT also broaches the issue of usefulness by describing that an innovation requires the antecedent of a need and/or a 
problem. This doctoral thesis disclosed that from the perspectives of the older persons, relatives and health professionals, it is less about the usefulness of the technology itself, which is covered by the perceived ease of use, but more importantly, the necessity of the "living situation" of the older person which necessitates a PSAD. Therefore, it is suggested to modify the term and to use perceived necessity in the context of PSAD and in the context of technology use for ageing in place.

- This thesis findings confirm the importance of perceived ease of use (variable from the models TAM, UTAUT and STAM, DIT), but provide further details. The perceived ease of use should entail not only the aspects of usability, but also the impact on daily life and the meaning attached to the technology.

- Similarities with the variable perceived behavioural control from the Theory of Planned Behaviour and the Reasoned Action Approach (Chapter 1 and Table 1) were identified. The topic of behavioural control is also part of the STAM and the DIT (Table 1). However, this dissertation reports that behaviour control should not predominantly focus on the technology itself, but also on the ageing process in general. The older person links the technology to the control of daily life as well as to her/his perceived independence in daily life.

- When comparing the dissertation's findings with the TRA, TAM, UTAUT and STAM, the following aspects could be considered as particularly distinctive from those models: The process of PSAD use and non-use has a defined onset, a critical event. The above-mentioned models do not provide a starting point for the technology acceptance process. In addition, this onset needs to be perceived by the older person him/herself. The perceived need of the social environment is not enough. This finding is, however, in line with the DIT. The DIT emphasizes a need or the awareness of an innovations as a beginning of the innovationdecision process. Furthermore, as depicted in Figure 1, the nature of PSAD use and non-use is iterative, different decision options are possible, i.e. use, non-use or not-yet-use. The decision regarding PSAD use is dynamic and only valid for a certain time. Those characteristics make the PSAD use and non-use process highly comparable to the DIT. However, the abstraction level of this theory is broad and can be applied to various domains of innovation diffusion. Therefore, it was key to understand first the phenomenon of PSAD use and non-use itself. Without this understanding, no rigorous scientific and empirically based criteria would have allowed arguing for one or another model. Furthermore, uncovering those similarities was enabled by the methodological approach of this thesis. No specific model "imprinted the lens" the data collection and analysis, i.e. the predetermined assumptions of a specific model. 
To close this section, it should be noted that these theoretical considerations need and will benefit from further research. The aim of this dissertation was not to extend available technology acceptance models, but to investigate multiperspectively the "bigger picture" of PSAD use and non-use of community-dwelling older persons. This was required, since only little knowledge was available about the phenomenon of PSAD use and non-use by older persons ageing in place.

\section{Methodological considerations}

The specific strengths and limitations pertaining to each individual study of this dissertation were reported in the respective chapters (Chapter 2 to 6). This paragraph examines the overall methodological considerations of this thesis by addressing first the strengths and then the limitations.

Altogether, a predominantly qualitative methodological approach was applied for several essential reasons:

So far, the scientific literature disclosed that the use and non-use of technologies in general, and PSADs in particular, by older persons remains a considerable challenge and is not yet comprehensively understood. However, non-use of PSADs may represent a serious threat to ageing in place and thus to the safety and wellbeing of communitydwelling older persons (Chapter 1). Therefore, it is important to elucidate the uncertainty regarding the phenomenon of PSAD use and non-use in order to bridge this knowledge gap, which concerned not only the perspective of older persons themselves but also those of relatives, community nurses and GPs.

Additionally, if available knowledge failed to tackle a present concern, a different approach to knowledge generation was assumed to be meaningful. Most of the technology acceptance research is based on quantitative research as well as coming from disciplines different from health and nursing care (Chapter 1). Topical similarities with other disciplines need to be carefully examined when used for hypothesising in nursing. ${ }^{73}$ Therefore, a qualitative methodology was considered both, promising for revealing new insights and relevant to providing needed answers to the research questions in the context of ageing in place from the perspective of the various stakeholders.

Two further aspects were taken into account: (1) qualitative methods allow us to gain an understanding of a new field and to formulate tentative theoretical constructs; ${ }^{74}$ (2) qualitative research can be considered an approach which is "subjective rather than objective, value-laden rather than value-free, engaged rather than detached [...]"(p.190). ${ }^{75}$ The subjective knowledge, thoughts and experiences of the participants 
were a core interest of this dissertation. The chosen qualitative approach provided "space" to the participants to unfold their values. The researcher "walked in their shoes". Qualitative research postulates that the researcher is part of the research endeavour and close to the participants. ${ }^{76}$ This was enabled by the chosen methodology of inquiry: focus groups and semi-structured interviews. Proximity to the participants was also the PhD candidate's desideratum.

Besides, due to the explorative nature of the research questions (Chapter 1), aiming to understand needs, preferences (Chapters 2 to 4), thoughts, reasons, motives and experiences multiperspectively (Chapters 5 and 6), the following components of qualitative research applied to this doctoral thesis: interest in fieldwork and naturalistic engagement, seeking contextualization and complexity, concentrating on processes and relationships and being interested in meaning and meaning making. ${ }^{76} \mathrm{~A}$ qualitative approach allows for constructing knowledge from the data in an inductive way. ${ }^{76}$ An inductive approach means to building concepts, hypotheses and theories by identifying and conceptualizing themes and patterns from data, obtained through inquiry, particularly through observations and dialogue with participants. ${ }^{75,76}$ In contrast, a deductive approach might have meant choosing a technological acceptance model for investigation, by "ignoring" that much uncertainty existed regarding their validity for the underlying phenomenon of interest, i.e. PSAD use and non-use when ageing in place. However, understanding a phenomenon means, amongst other things, giving answers about what it is, when and where it occurs or if and how the phenomenon varies or what behaviours are related to it. ${ }^{77}$ Therefore, it was deemed methodologically consistent and straightforward to apply a qualitative methodological approach. This enabled elucidating the underlying phenomenon of PSAD use and non-use when ageing in place from the perspective of community-dwelling older persons, relatives, community nurses and GPs.

Another reflection also played a role. Nursing is a discipline which can be characterised by two types of knowledge: "knowing how" and "knowing that" knowledge. ${ }^{78}$ Consequently, this thesis followed the rationale of investigating the "knowing that" knowledge in order to establish a scientific basis for enabling the exploration of "knowing how" knowledge. Developing a descriptive theory is indicated when little is known about a phenomenon. ${ }^{78}$ Thus, a phenomenon can be described appropriately and relationships among its characteristics can be identified. ${ }^{78}$

The carefully reflected methodological approach can be considered a strength of this doctoral thesis. Another strength is the large sample size of the different studies (Chapters 3 to 6). The literature on qualitative sample sizes is still under debate and there are no standardised recommendations as with quantitative approaches. Therefore, the sample sizes included were based on several considerations and recommendations 
from the scientific literature. ${ }^{79-85}$ Additionally, data collection and analysis supported data saturation according to the definition of Ravitch and Mittenfelner Carl. ${ }^{76}$ Themes were recurrently identified and confirmed across focus groups and interviews; the richness of the data allowed answering the research questions.

Some limitations of this dissertation should be acknowledged as well.

First, concerning studies two and three (Chapters 3 and 4), although user involvement is recommended from the first idea of technology development, ${ }^{11}$ this thesis involved community-dwelling older persons from the mock-up stage. The decision was based on the following reasons: The research team aimed to develop an innovative PSAD which was not already available on the market in Switzerland; one that featured automatic alerting, invisible wear during day and night for several days, waterproof. Therefore, the participants were involved as soon as the PSAD idea was presentable in the form of a mock-up. Therefore, the openness regarding the kind of PSAD was not an option anymore and was thus communicated to the participants. In this way, community-dwelling older persons were successfully involved in developing a needs-driven prototype (Chapters 3 and 4).

Second, a possible limitation might be that the PhD candidate was the main person responsible for data collection and analysis, which might have been influenced the trustworthiness (validity) ${ }^{76,86}$ of the findings. To enhance the trustworthiness of this dissertation several methods were used:

- Prolonged engagement enabled the researcher with the possibility to build trust with the field of investigation. ${ }^{86}$ The overall empirical data collection of this doctoral thesis lasted from July 2014 until December 2017 (Chapters 3 to 6).

- Method of triangulation: ${ }^{76}$ (a) methodological triangulation, i.e. study diary participants (Chapter 4), fieldnotes (Chapters 3 to 6), research team diary (Chapters 4), focus groups (Chapters 3 to 6), interviews (Chapter 6), questionnaire (Chapters 3 to 6); (b) data triangulation, i.e. studies two and three included a number of different persons in the mock-up and prototype testing stages (Chapters 3 and 4); and (c) perspectival triangulation, i.e. to answer the research questions four different perspectives were included: community-dwelling older person, relatives, community nurses and GPs (Chapters 5 and $\mathbf{6}$ ).

- Dialogic engagement: ${ }^{76}$ during data collection and particularly during analysis and interpretation, regularly critical discussions with the supervising team, peer exchange with $\mathrm{PhD}$ fellows (PhD programme, during conferences and during the 3 year participation in the European Academy of Nursing Sciences Summer School), with colleagues from the nursing science research unit and with a research colleague $(\mathrm{PhD})$ from the field of nursing science and the topic ageing in place. In addition, data analysis and interpretation of studies four and five was 
carried out in a close, critical and reflective way with a $\mathrm{PhD}$ fellow experienced in qualitative data analysis and with whom a prior collaboration from other qualitative research projects existed.

Furthermore, to enhance the trustworthiness of the findings, the research process was critically pursued by documented (research diary) and a careful data collection, as well as a data analysis and interpretation process with regularly exchanges between authors and co-authors. In addition, the PhD candidate followed continuing reflexivity of the research process based on recommendations from the scientific literature, ${ }^{87,88}$ e.g. thoughts about what is unclear and what are possible reasons and explanations from different perspectives or which decision in which step (e.g. recruitment or data collection) was taken or modified. In addition, it should be noted that in qualitative research, trustworthiness represents a goal and a process, it can never be completely ensured..$^{89}$

Third, it is conceivable that a "full" grounded theory approach would have been an interesting methodological alternative for studies four and five (Chapters 5 and 6). This reflection is rooted in the fact that the two studies uncovered a process grounded in the data. Grounded theory is rooted in the symbolic interactionism and constructivism, which is particularly suitable for exploring beliefs and meanings of underlying actions and for investigating nonrational and rational aspects of behaviour. ${ }^{90,91}$ However, this theoretical and philosophical perspective needs to be adopted beforehand, since the conduct of a grounded theory study is particularly characterized by the methods of theoretical sampling and constant comparison. ${ }^{91}$ Self-critically acknowledged, this alternative approach was recognised during the trajectory of this doctoral thesis. Studies two and three (Chapters 3 and 4), in accordance with the research questions, applied a content analysis approach to data analysis and interpretation. Coming to studies four and five, due to the explorative research questions, the nature of the collected data changed. The content analysis approach was experienced as limiting with regard to remaining thematically open and grasping the depth of the data. Therefore, the analytical and interpretative approach was adapted. On the other hand, it might be argued that this modification could also be considered as a strength, as it was recognised and transferred into action that the nature of the data required a different analysis method. The findings of the two studies show that the analytical adaptation was beneficial to grasping the essence of the data and to elucidating the underlying processes.

Lastly, technology use itself might be shaped by a cultural context. Claßen ${ }^{92}$ reported that generational technological imprinting can influence technology use. This suggests considering, for the interpretation of this thesis, that the findings result from 
a generation born in the thirties/early forties of the $20^{\text {th }}$ century. They are familiar with technologies to which they were exposed in this time. Exposure is also influenced by the professional activity or non-activity. Women of this generation were often responsible for managing the family and household. In addition, being exposed to a technology is also influenced by personal traits, attitudes and interests. ${ }^{92}$ This was also observed in this dissertation, which included both women and men. Some male participants expressed their dislike of technology and some women told us about their technical passion, which led them to learn how to deal with a computer, a smartphone and to use the internet. Therefore, trustworthiness of findings is also influenced by both contextual (generation) and personal aspects.

To close this section, it should be stated that the PhD candidate's lens on the world and approach to human inquiry is influenced by constructivist thinking. This lens was adopted during the PhD trajectory. "Relativism characterises the research endeavour rather than objective, unproblematic prescriptions and procedures. Research acts are not given; they are constructed. Viewing the research as constructed rather than discovered fosters researchers' reflexivity about their actions and decisions"(p.13). ${ }^{91}$ It means acknowledging subjectivity and the involvement of the researcher in the construction and interpretation of the data. ${ }^{91}$ An emphasis on "the world of experience as it is lived, felt, undergone by social actors"(p.236). ${ }^{93}$ Truth is the result of perspective, truth and knowledge are created and reality is pluralistic and shapeable. ${ }^{93}$

\section{Implications}

Based on the research presented in this doctoral thesis implications were drawn for research and practice.

\section{For research}

This dissertation extends scientific knowledge by providing a comprehensive and multiperspective immersion into PSAD use and non-use of community-dwelling older persons. The principal contributions entail, on the one hand, new insights into the user involvement approach when developing a technology for ageing in place, using the case of a PSAD. On the other hand, it discloses the processes leading to decision making about PSAD use and non-use from the perspectives of community-dwelling older persons, relatives, community nurses and GPs. 


\section{A new and needs-driven PSAD}

A new PSAD was developed by the research team, consisting of nursing researchers and engineers, together with community-dwelling older persons 75 years of age and older. The PSAD prototype comprised a body-worn sensor (bio-silicon) linked to a smartphone application (app) for the transmission of the alerting process. The sensor can be worn invisibly, during day and night, is waterproof, functions in- and outdoors and with integrated GP access. The alert will be automatically transmitted in case of a fall. Manual alerting is also possible. Three aspects concerning further research should be discussed.

First, the findings showed that older persons need clear and comprehensive information about the alerting process, particularly how it works and who is involved and who comes in the case of an alert. Hence, the alerting process was already an important topic during early PSAD development. Therefore, to obtain richer information about an optimal alerting process and clarify real-life feasibility issues (e.g. disposability or competence to react appropriately in an emergency situation), relatives and health professionals should be involved in the further PSAD development, since they are the preferred and trusted contacts of older persons during the alerting process.

Second, although the sensor was highly appreciated, the smartphone handling was a problem for most of the participants. Additionally, they felt limited in their perceived independence, as this PSAD prototype required having the smartphone within a range of about eight meters for reliable alert transmission. Therefore, further development and testing should consider, amongst other things, extending battery durations of sensor and smartphone. Additionally, this PSAD should be provided in different versions, by continuing the current version for those older persons who use a smartphone (can be also increasingly expected for upcoming generations). The suggestions are:

a. To provide a technical alternative to the smartphone for reliable alert transmission covering of the whole apartment / house and, as the case may be, the garden, e.g. providing a home base station for the sensor;

b. Those with a home base station would need a solution for outdoors; either they can use a smartphone, or another device should be provided;

c. According to the participants, the optimal version would be to integrate the alert transmission process into the sensor, in order to use only one device; this might be a long-term aim, as it depends on the technological feasibility; It should be noted that this suggested version, one device, might be reminiscent of the PSAD watch, however, the participants emphasized that the characteristics of the sensor are preferable, since it is waterproof, invisibly worn, GPS equipped, high wearing-comfort both night and day and thus no need to remove it at night, which most older persons do with a watch. 
The need for different versions underscores that older persons prefer individualization in order to fit the PSAD to their capabilities, technical preferences and daily routines. However, a reliable PSAD supporting the safety of the older person should be wearable 24 hours a day.

Third, a further implication should be the preparation of the market entrance of this PSAD, i.e. deciding about the business model and collaborating partners, e.g. community care organisations.

\section{User involvement approach}

The user involvement approach used indicated that considering needs and preferences of the target users enables development of a needs-driven PSAD. However, target users of a PSAD are not solely the older persons, but also relatives and health professionals, as they are particularly involved in the alerting process. In addition, the subsequent studies of this dissertation showed that they also play a crucial role in providing access to and information about PSADs. They are key players in the decision-making process of use and non-use and are involved in the coaching and re-evaluation of PSAD use. Therefore, their involvement in the development of the new PSAD would have been of added value in order to clarify early in the process their possible/feasible tasks and responsibilities. Further research should elucidate early on "who are the users" of the technology in its daily life application, i.e. older persons and/or relatives and/or other informal carers and/or formal carers (see also ${ }^{94}$ ). According to the recommendations of Shah et al. ${ }^{11}$, methods of involvement should be chosen in accordance with the target user and the development stage of the technology, e.g. brainstorm session, observation, cognitive walkthrough or expert users meeting.

Another aspect was that the involvement of the older persons did not occur from the beginning of PSAD development, as recommended by the applied framework. ${ }^{11}$ This was decided by the research team for appropriate reasons, particularly the previous decision to develop a technically specific PSAD in accordance with the available project budget as well as the technical expertise of the engineers. From the perspective of the research team this was not a disadvantage of the study, as the mock-up stage allowed them to receive precise feedback from the participants. This approach to user involvement shows that, in additional to the state of the technological development, ${ }^{11}$ other factors may influence the user involvement. Another factor might be earlier experiences of the users with the kind of technology under development, or the researcher's experience applying a user involvement approach. Therefore, a user involvement framework should include this flexibility and suggest corresponding recommendations.

Furthermore, there is the issue of "user-typology". The findings of this thesis indicated that technology use can fluctuate over time, which is in line with the 
literature. ${ }^{40,50-52}$ Therefore, acknowledging different user types allows for capturing "reallife users", meaning that all kinds of users can be included, even when they are hardly using a PSAD, or a technology. Particularly for nurses it is relevant to know a client's user-type and thus have knowledge about the manner and frequency of use. With this, they can assess and figure out reasons for use behaviour and decide with the user about possible interventions. Therefore, based on the literature and the thesis findings, further research should develop (1) a suitable user typology for technology use and its assessment instrument in the context of ageing in place and (2) validate it with health professionals, older persons and relatives.

Although various studies about user involvement ${ }^{11,16,27}$ and a large body of user-centred design literature exist, ${ }^{17,21,28}$ the perspective of health and nursing care research is still underrepresented in this regard. This can be considered a drawback, as terminologies, methods, experience-based user-involvement knowledge of research teams in the health and nursing sciences are not yet integrated. Further research should update and adapt a user involvement framework to the context of technology development related to ageing in place. This is important to provide guidance, among other things, on the following topics: added-value of user-involvement from the various user perspectives (e.g. older person, patient, informal caregiver, formal caregiver), shared values and understanding regarding user involvement, challenges from the different perspectives (research team and users) applying the user involvement approach, competences and skills necessary to carry out user involvement, factors for deciding about the target users to involve, deciding about the phases of involvement, methodological choices with related possible outputs, strategies to communicate and maintain relationship with the users and addressing later financing models of the technology under development.

\section{Role perceptions of health professionals and relatives}

The evidence generated by this thesis revealed that in the context of PSADs older persons and relatives needed the support of community nurses. This was particularly during the negotiating of PSAD use and non-use, for accessing devices, the provision of PSAD information and coaching and re-evaluation of PSAD use. However, only a minority of the community nurses involved were aware of their crucial role in enabling older persons to use a PSAD in daily life.

Since GPs are hardly present in the home environment, they perceived their role as predominantly concerned with medication management for fall prevention, the identification of critical events, recommending a PSAD due to an assessment, connecting older persons and/or relatives with community nurses, and supporting recommendations towards an older person of relatives or community nurses regarding 
PSAD use. GPs believed that they had hardly any influence on PSAD use, however, which was in contrast to some older persons and relatives.

The relatives included in this thesis reported a clear role in the context of PSAD use of their parents. However, they were often driven by safety concerns about their parent/s leading to conflicting negotiation situations. Further, they experienced the access to PSADs as challenging and highly time-intensive. This situation shows that health professionals, particularly community nurses, should intervene and support relatives and older persons in the negotiation process as well as providing access to PSADs. Further research should explore the roles in more depth and clarify the competences, skills and responsibilities of community nurses, GPs and relatives in the context of PSAD use and non-use, specifically and technology use in general in connection with clients who want to age in place.

\section{Technology use when ageing in place - a transition process?}

The legitimation and negotiation processes disclosed that the idea of a PSAD often confronts the older person with their own ageing process. This means that the older person becomes "suddenly" aware of a possible need for assistance, which in turn challenges the current self/identity. Additionally, the findings showed that with PSAD use, a "stranger" might enter the apartment/house. Consequently, the private home becomes a public place.

Hale et al. ${ }^{34}$ provide extensive research on older persons with increasing need for support in daily life and its impacts on the meaning of home, on the self and on informal caregivers. Coming from the field of social gerontology, they are using the term transition to denote changes in status and identity, in the process of becoming frailer and more dependent. In the field of health and nursing science, the term transition relates to the well-known transition theory from nursing research and practice particularly shaped by Meleis. ${ }^{95}$ Transition "is a process triggered by a change. Transitions are characterized by different dynamic stages, milestones and turning points and can be defined through processes and/or terminal outcomes"(p.11). ${ }^{95}$ This theory can be used to understand stressful responses to changes in human life which might be predictable or unpredictable. Transition theory research from the nursing sciences was conducted in the context of older adults in relation to care models, different settings of living, in the context of palliative care and hospitalization..$^{95}$ To date, technology use when ageing in place does not appear as part of the transition theory research. However, in comparing the legitimation and negotiation processes with the definition of transition theory, it seems that the legitimation process might be rooted in a transition process on the part of the older person, whereas the negotiation process might benefit and draw on evidence-based nursing interventions from the transition theory. Since, the transitions 
theory provides a comprehensive body of scientific knowledge, ${ }^{95}$ this evidence might be beneficial in the context of technology use when ageing in place. Therefore, further research should explore how the legitimation and negotiation process might benefit from this transition theory and subsequent consequences for nursing care, interventions, nursing research and nursing education/training.

\section{Theoretical models - further development and validation}

This dissertation disclosed the legitimation and the negotiation processes in the context of PSAD use when ageing in place. Both processes allow us to understand what "is going on" when the idea of PSAD use appears (Figure 1). This knowledge is relevant for community nurses, to enable them to help with an informed decision about PSAD use and non-use together with older persons and relatives. Additionally, based on those processes, tailored interventions and support can be provided. GPs can extend their understanding and particularly integrate the assessment of critical events in their daily practice. However, further research should ascertain the applicability and transferability of both processes in Switzerland and other countries.

Another research need was identified regarding technology acceptance/ adoption/explanation and prediction model research. The overview and comparison of technology acceptance/adoption variables from the literature compared with the influencing factors of PSAD use and non-use of this doctoral thesis (Table 1) should be considered as a deductive suggestion for further research. For example, in addressing the drawbacks of available acceptance models (Chapter 1) and adaptations for the health care context. Further research also should explore the possibilities of modifying technology acceptance/adoption models and to develop and validate a model suitable for the context of technology use when ageing in place.

\section{A complex intervention - enabling decision making and support}

The legitimation and negotiation processes revealed the "knowing that" knowledge and established a scientific basis for enabling the exploration of "knowing how" knowledge. Thus, further research should identify the evidence for interventions and implement the legitimation and negotiation processes in the daily practice of community care. A nurse-led intervention should enable community nurses:

- to assess critical events,

- to introduce the idea of a PSAD to older persons and their relatives,

- to support older persons in their legitimation process,

- to facilitate PSAD use (e.g. providing information and access to PSADs for trying them out), 
- to enable older persons and their relatives to take an informed decision and, depending on the decision,

- to provide tailored support in the case of PSAD non-use and to coach and reevaluate PSAD use.

In addition, the collaboration between community nurses and GPs as well as with the relatives should be clarified and implemented. Furthermore, different tools and instruments should be provided, e.g. assessment instruments for critical events, technology preferences or the perceived necessity of a PSAD from the perspective of the older persons, and information summarizing available PSADs with a description of functionalities and typical "situations" of use.

Due to the nature of this comprehensive nurse-led intervention outlined, a complex intervention approach ${ }^{96}$ to its development should be suggested. This, because the complex intervention approach provides a stepwise, thoroughly and iterative guidance to intervention development, feasibility testing/piloting, evaluation and implementation. An intervention is defined as an activity or action which is carried out by a nurse or other health care professional or person of health care. ${ }^{96}$ The term complexity refers to an intervention made up of several components, acknowledges interpersonal relationships, takes into account context, and that the intervention works in the real-life of health care. ${ }^{96}$

\section{Integrated development and monitor studies}

Lastly, the findings revealed that a multiperspective approach to technology development and implementation can be beneficial in gaining new knowledge and evidence for later technology use. Thus, new understanding could be identified regarding potential linkages and relationships. Therefore, more integrated development studies should be conducted for different kinds of technologies in the context of ageing in place from a multiperspective approach. This means: (1) applying a user involvement approach; (2) understanding the processes leading to use and non-use; (3) and identifying interventions needed for technology use. Furthermore, monitor studies of technology use in daily life should generate knowledge regarding the impact of technology on the older person and their informal caregivers, e.g. wellbeing, length of stay at home, care burden, fall prevalence or related costs when ageing in place. Establishing evidence regarding technology use when ageing in place provides transparency and arguments to "distribute" health care costs accordingly. 


\section{For practice}

Qualitative research methodology does not aim for generalisability. ${ }^{76}$ But implications can be drawn for clinical practice by considering characteristics such as context, person, place, time, culture or sex. ${ }^{73}$ The characteristics named are defined by this dissertation and the respective individual studies. Therefore, by considering those characteristics the following implications for practice are suggested.

\section{PSAD use / non-use when ageing in place - a seminal case}

Community care organizations and community nurses can learn from the various dimensions of technology use by using the example of PSAD. The legitimation process as well as the negotiation process show "what goes on" when older persons are confronted with the idea of PSAD use. Furthermore, the legitimation process underscores the importance that later use will be influenced by the perceived necessity of PSAD use from the older persons' perspective. The negotiation process highlights the role of relatives in the decision-making process. It also emphasizes the role, tasks and responsibilities of community nurses towards the older person and their relatives. In addition, the negotiation process shows interfaces for collaboration with GPs, e.g. assessment of critical events or a possible influence on the decision-making process. This should be considered in daily practice.

Furthermore, the findings might be significant for those community care organizations which aim to offer patient-tailored services. Thus, in utilising the findings, they might create a competitive advantage in the health care system. This could be achieved by providing access for older persons and relatives to PSADs for trying-out and by providing the service of being a contact person of the alerting process.

Finally, gaining insight into the example of PSAD use and non-use, allows community care organizations to raise awareness regarding the current and seminal technology development in the context of ageing in place. It might enable them to reflect on how they want to anticipate and integrate this development in health and nursing care.

\section{Technology use - role, skills competences and responsibilities}

The dissertation's findings pointed out that role uncertainty exists particularly among community nurses regarding competences, skills and responsibilities related to enabling and coaching PSAD use in older persons and their relatives. This finding seems relevant for community care managers and teaching institutions, as it indicates a need for further education of community nurses. Technologies are increasingly present in nursing care. The case of PSAD use and non-use revealed that, in line with their trustful relationship with the older persons, community nurses should play a more prominent role. In addition, community nurses are in close and regular contact with older persons and 
know their living environment. In this regard, this thesis can be regarded as sensitizing to the fact that the community nurses require necessary knowledge not only about the technology, but also about how to enable decision making and technology use in older persons when they chose to age in place. 
... Coming back to Mathilde, our lovely community-dwelling older lady. She has fallen twice since we met her last time and her gait appears to be hesitant. She holds a walking cane in one hand and has linked arms on the other side with her oldest daughter. Even though she seems satisfied, her facial expression shows that walking requires her effort and attention. Recently, Mathilde started to use a "Personal Safety Alerting Device" (PSAD), invisibly worn on her left arm, only activated upon manipulation by her. Her decision was preceded by intense negotiations over months with her children. They were concerned about her safety since she lived alone and due to her decreased stability of gait. Her very worried youngest daughter asked a community nurse to tell Mathilde what it takes to live safely at home in the community. They talked about emergency situations, fall prevention and how she can increase safe walking. Additionally, her general practitioner asked her to perform several exercises related to her gait and body balance and questioned her about her medication.

For a moment, Mathilde remembers, she felt invaded in her personal life by this increased attention around her person and even her daily activities. The PSAD is not bad. Indeed, it gives her rapid assistance when needed. However, it is still her decision, and she is still an independent woman and not senile. The months of negotiations were pivotal, since they allowed her to get the necessary information, to become aware of her increasing need for assistance and to test different devices before she "legitimised" herself to use it.

But, there is still something Mathilde hasn't told her family. Dying in her cosy apartment is her priority. She can't imagine going into a nursing home. Additionally, she is convinced that never again will she put a foot in a hospital.This decision was already taken with her dear old friend Joy, when their husbands passed away.

Mathilde realised with this "PSAD story" that lifelong learning is not only a saying, but an incontestable reality. She never thought that a PSAD could give her back the feeling of independence by simultaneously increasing her safety. She is very grateful for this, but also for her life. Nevertheless, her beloved husband has already left her. Once, Mathilde knows, it will be her turn. Life is colourful and changing, like "her" autumns. 


\section{References}

1. Ahn, M., H.J. Kwon, and J. Kang, Supporting Aging-in-Place Well: Findings From a Cluster Analysis of the Reasons for Aging-in-Place and Perceptions of Well-Being. Journal of Applied Gerontology, 2017.

2. Gitlin, L.N., Conducting research on home environments: lessons learned and new directions. The Gerontologist, 2003. 43(5): p. 628-37.

3. Carpenter, D., et al. Patient Safety in the Home. 2017.

4. Hefny, A.F., A.K. Abbas, and F.M. Abu-Zidan, Geriatric fall-related injuries. African health sciences, 2016. 16(2): p. 554-559.

5. Gill, T.M., et al., Association of injurious falls with disability outcomes and nursing home admissions in community-living older persons. Am J Epidemiol, 2013. 178(3): p. 418-25.

6. Hopewell, S., et al., Multifactorial and multiple component interventions for preventing falls in older people living in the community. Cochrane Database of Systematic Reviews, 2018. 7.

7. Heinbüchner, B., et al., Satisfaction and use of personal emergency response systems. Z Gerontol Geriatr, 2010. 43.

8. Nyman, S.R. and C.R. Victor, Use of personal call alarms among community-dwelling older people. Ageing \& Society, 2014. 34(1): p. 67-89.

9. McLean, P.A., Exploring older Adults' Persceptions of the Utility and Ease of Use of Personal Emergency Response Systems, in Faculty in Nursing. 2016, CNUY Academic Works: New York.

10. Thilo, F.J.S., et al., Involvement of older people in the development of fall detection systems: a scoping review. BMC Geriatrics, 2016. 16(42).

11. Shah, S.G.S., I. Robinson, and S. AIShawi, Developing medical device technologies from users' perspectives: $A$ theoretical framework for involving users in the development process. International Journal of Technology Assessment in Health Care, 2009. 25(4): p. 514-521.

12. Thilo, F.J.S., et al., Involvement of the end user: exploration of older people's needs and preferences for a wearable fall detection device - a qualitative descriptive study Patient Preference and Adherence 2017. 11: p. 11-22.

13. Thilo, F.J.S., et al., Usability of a wearable fall detection prototype from the perspective of older people-A real field testing approach. Journal of Clinical Nursing, 2018.

14. Thilo, F.J.S., et al., How older persons consider using a Personal Safety Alerting Device: a qualitative study submitted.

15. Thilo, F.J.S., et al., Advancing Personal Safety Alering Device Use of Older Persons - the Views of Relatives and Health Care Professionals. submitted.

16. Bridgelal Ram, M., P. Grocott, and H. Weir, Issues and challenges of involving users in medical device development. Health Expect, 2007. 11: p. 63-71.

17. De Vito Dabbs, A., et al., User-centered design and interactive health technologies for patients. Comput Inform Nurs, 2009. 27(3): p. 175-83.

18. Gulliksen, J., et al., Key principles for user-centred systems design. Behaviour and Information Technology, 2003. 22(6): p. 397-409.

19. Kujala, S., User involvement: a review of the benefits and challenges. Behaviour \& Information Technology, 2003. 22(1): p. 1-16.

20. Damodaran, L., User involvement in the systems design process - A practical guide for users. Behaviour \& Information Technology, 1996. 15(6): p. 363-377.

21. Abras, C., D. Maloney-Krichmar, and J. Preece, User-centered design. Bainbridge, W. Encyclopedia of Human-Computer Interaction. Thousand Oaks: Sage Publications, 2004. 37(4): p. 445-456.

22. Davis, F.D., R.P. Bagozzi, and P.R. Warshaw, User Acceptance of Computer Technology: A Comparison of Two Theoretical Models. Management Science, 1989. 35: p. 982-1003.

23. Stokke, R., The Personal Emergency Response System as a Technology Innovation in Primary Health Care Services: An Integrative Review. J Med Internet Res, 2016. 18(7): p. e187. 
24. Doughty, K., R. Lewis, and A. McIntosh, The design of a practical and reliable fall detector for community and institutional telecare. Journal of Telemedicine and Telecare, 2000. 6: p. 150-154.

25. Chaudhuri, S., et al., Older Adluts' Perceptions of Fall Detection Devices. Journal of Applied Gerontology, 2015. 36(8): p. 915-930.

26. Arnstein, S.R., Ladder of Citizen Participation. Journal of the American Institute of Planners, 1969. 35(4): p. 216-224.

27. Morrow, E., et al., Handbook of Service User Involvement in Nursing \& Healthcare Research. 2012, West Sussex, UK: Wiley-Blackwell.

28. Vermeulen, J., et al., Experiences of Multidisciplinary Development Team Members During User-Centered Design of Telecare Products and Services: A Qualitative Study. Journal of Medical Internet Research, 2014. 16(5): p. 238-248.

29. Romsland, G.I., K.L. Milosavljevic, and T.A. Andreassen, Facilitating non-tokenistic user involvement in research. Research Involvement and Engagement, 2019. 5(1): p. 18.

30. Eisma, R., et al., Early user involvement in the development of information technology-related products for older people. Universal Access in the Information Society, 2004. 3(2): p. 131-140.

31. Hahn, S., et al., Panorama Gesundheitsberufe 2030 Projektbericht, F.G. Berner Fachhochschule, angewandte Forschung und Entwicklung / Dienstleistung Pflege, Editor. 2013: Bern.

32. Lapierre, N., et al., The state of knowledge on technologies and their use for fall detection: A scoping review. International Journal of Medical Informatics, 2018. 111: p. 58-71.

33. Peek, S.T.M., et al., Older Adults' Reasons for Using Technology while Aging in Place. Gerontology, 2016. 62(2): p. 226-237.

34. Hale, B., P. Barret, and R. Gauld, The Age of Supported Independence in Voices of In-home Care. 2010, Springer: Dordrecht Heidelberg London New York. p. 149.

35. Lloyd, L., et al., Identity in the fourth age: perseverance, adaptation and maintaining dignity. Ageing \& Society, 2014. 34(1): p. 1-19.

36. Stokke, R., Older People Negotiating Independence and Safety in Everyday Life Using Technology: Qualitative Study. J Med Internet Res, 2018. 20(10): p. e10054.

37. McKenna, A.C., et al., Purchasing and Using Personal Emergency Response Systems (PERS): how decisions are made by community-dwelling seniors in Canada. Bmc Geriatrics, 2015. 15.

38. Lai, C.K., et al., A survey of older Hong Kong people's perceptions of telecommunication technologies and telecare devices. Journal of Telemedicine and Telecare, 2010. 16(8): p. 441-446.

39. Chaudhuri, S., H. Thompson, and G. Demiris, Fall Detection Devices and Their Use With Older Adults: A Systematic Review. J Geriatr Phys Ther, 2014.

40. Künemund, H. and N.M. Tanschus, The technology acceptance puzzle. Results of a representative survey in Lower Saxony. Z Gerontol Geriatr, 2014. 47(8): p. 641-7.

41. Venkatesh, V., et al., User acceptance of information technology: Toward a unified view. Mis Quarterly, 2003. 27(3): p. 425-478.

42. Chen, K. and A.H. Chan, Gerontechnology acceptance by elderly Hong Kong Chinese: a senior technology acceptance model (STAM). Ergonomics, 2014. 57(5): p. 635-52.

43. Bagozzi, R.P., The Legacy of the Technology Acceptance Model and a Proposal for a Paradigm Shift. Journal of the Association for Information Systems, 2007. 8(4).

44. Connelly, K., et al., Approaches to Understanding the Impact of Technologies for Aging in Place: A MiniReview. Gerontology, 2014. 60(3): p. 282-288.

45. Lorenzen Huber, L., et al., Aging in intra-and intergenerational contexts: the family technologist, in Gerontechnology : Research, Practice, and Principles in the Field of Technology and Aging S. Kwon, Editor. 2017.

46. Mostaghel, R., Innovation and technology for the elderly: Systematic literature review. Journal of Business Research, 2016. 69(11): p. 4896-4900.

47. Schulz, R., et al., Advancing the Aging and Technology Agenda in Gerontology. Gerontologist, 2015. 55(5): p. 724-734. 
48. Baumer, E.P.S., et al., On the Improtance and Implications of Studying Technology Non-Use. INTERACTIONS, 2015. 22(March + April): p. 52-6.

49. Satchell, C. and P. Dourish, Beyond The User: Use and Non-Use in HCl, in OZCHI. 2009: Melbourne.

50. Yousafzai, S.Y., G.R. Foxall, and J.G. Pallister, Technology acceptance: a meta冈analysis of the TAM: Part 2. Journal of Modelling in Management, 2007b. 2(3): p. 281-304.

51. Alexandre, B., et al., Acceptance and acceptability criteria: a literature review. Cognition, Technology \& Work, 2018. 20(2): p. 165-177.

52. Seifert, A. and H.R. Schelling, Alt und offline? Befunde zur Nutzung des Internets durch Menschen ab 65 Jahren in der Schweiz. Zeitschrift für Gerontologie und Geriatrie, 2016. 49(7): p. 619-25.

53. Rogers, E.M., Diffusion of Innovations. 5th ed. ed. 2003, New York, USA: The Free Press.

54. Vishwanath, A. and G.A. Barnett, The Diffusion of Innovations A Communication Science Perspective, ed. A. Vishwanath and G.A. Barnett. 2011, New York: Peter Lang.

55. Grol, R. and M. Ouwens, Planning of change implementation, in Improving Patient Care, R. Grol, et al., Editors. 2013, Wiley Blackwell BMJ Books: Oxford.

56. Johnston, K., K. Grimmer-Somers, and M. Sutherland, Perspectives on use of personal alarms by older fallers. Int J Gen Med, 2010. 3: p. 231-7.

57. Peek, S.T.M., et al., Origins and consequences of technology acquirement by independent-living seniors: towards an integrative model. Bmc Geriatrics, 2017. 17.

58. Dahms, R. and M. Haesner, Akzeptanz von Informations- und Kommunikationstechnologien bei Senioren. Prävention und Gesundheitsförderung, 2018. 13(1): p. 46-52.

59. Luijkx, K., S. Peek, and E. Wouters, "Grandma, You Should Do It-It's Cool" Older Adults and the Role of Family Members in Their Acceptance of Technology. International Journal of Environmental Research and Public Health, 2015. 12(12): p. 15470-15485.

60. Peek, S.T.M., et al., Factors influencing acceptance of technology for aging in place: a systematic review. Int $J$ Med Inform, 2014. 83(4): p. 235-48.

61. Waights, V., P.D. Bamidis, and R. Almeida, Technologies for care - the imperative for upskilling carers, in Northern Ireland Assembly Knowledge Exchange Seminar Series (KESS). 2018. p. 2017-8.

62. de Veer, A.J., et al., Successful implementation of new technologies in nursing care: a questionnaire survey of nurse-users. BMC Medical Informatics and Decision Making, 2011. 11(1): p. 67.

63. The Queen's Nursing Institute Nursing in the Digital Age - Using technology to support patients in the home. 2018.

64. Nieboer, M.E., et al., Professional values, technology and future health care: The view of health care professionals in The Netherlands. Technology in Society, 2014. 39: p. 10-17.

65. Risling, T., Educating the nurses of 2025: Technology trends of the next decade. Nurse education in practice, 2017. 22: p. 89-92.

66. Wiles, J.L., et al., The Meaning of "Aging in Place" to Older People. The Gerontologist, 2012. 52(3): p. $357-366$.

67. Roy, N., et al., Choosing between staying at home or moving: A systematic review of factors influencing housing decisions among frail older adults. PLoS ONE, 2018. 13(1).

68. Stones, D. and J. Gullifer, 'At home it's just so much easier to be yourself': older adults' perceptions of ageing in place. Ageing \& Society, 2016. 36(3): p. 449-481.

69. Jarling, A., et al., Becoming a guest in your own home: Home care in Sweden from the perspective of older people with multimorbidities. International Journal of Older People Nursing, 2018. 13(3): p. e12194.

70. Fishbein, M. and I. Ajzen, Belief, attitude, intention and behavior: An introduction to theory and research, ed. D. Mills. 1975, New York: Addison Wesley.

71. Fishbein, M. and I. Ajzen, Predicting and Changing Behavior: The Research Action Approach. 2010, New York, USA: Taylor \& Francis.

72. Ajzen, I., The Theory of Planned Behavior. Organizational Behavior and Human Decision Processes, 1991. 50(2): p. 179-211.

73. Munhall, P.L., Nursing Research A Qualitative Perspective. 5 ed. 2012, Ontario: Jones \& Bartlett Learning.

74. Klenow, D.J., Qualitative methodology: A neglected resource in nursing research. Research in Nursing \& Health, 1981. 4(3): p. 281-282. 
75. Risjord, M., Nursing Knowledge. 2010, Oxford, lowa: Wiley-Blackwell.

76. Ravitch, S.M. and N. Mittenfelner Carl, Qualitative Research - Bridging the Conceptual, Theoretical, and Methodological, ed. S.M. Ravitch and N. Mittenfelner Carl. 2016, Thousand Oaks, London, New Delhi, Singapore: SAGE.

77. Meleis, A.I., Theoretical Nursing, Development \& Progress. 5 ed. 2012, Philadelphia: Wolters Kluwer, Lippincott, Williams \& Wilkins.

78. McKenna, H., Nursing Theories and Models. 1997, London and New York: Routledge

79. Tashakkori, A. and C. Teddlie, SAGE Handbook of Mixed Methods in Social \& Behavioral Research. 2 ed, ed. A. Tashakkori and C. Teddlie. 2010, Oaks: SAGE.

80. Krueger, R.A. and M.A. Casey, Focus Groups A Practical Guide for Applied Research. 2009, London: SAGE.

81. Mason, M. Sample Size and Saturation in PhD Studies Using Qualitative Interviews. 2010. 11.

82. Guest, G., A. Bunce, and L. Johnson, How many interviews are enough? An experiment with data saturation and variability. Field Methods, 2006. 18(1): p. 59-82.

83. Faulkner, L., Beyond the five-user assumption: Benefits of increased sample size in usability testing. Behavior Research Methods, Instruments, and Computers, 2003. 35(3): p. 379-83.

84. Jayasekara, R.S., Focus groups in nursing research: Methodological perspectives. Nursing Outlook, 2012. 60(6): p. 411-416.

85. Stewart, D. and P. Shamdasani, Focus Groups. Theory And Practice. 3 ed. 2015, Los Angeles: SAGE.

86. Lincoln, Y.S. and E.G. Guba, Naturalistic Inquiry. 1985, Newbury Park: SAGE Publications.

87. Engward, H. and G. Davis, Being reflexive in qualitative grounded theory: discussion and application of a model of reflexivity. J Adv Nurs, 2015. 71(7): p. 1530-8.

88. Birks, M., Y. Chapman, and K. Francis, Memoing in qualitative research: Probing data and processes. Journal of Research in Nursing, 2008. 13(1): p. 68-75.

89. Cho, J. and A. Trent, Validity in qualitative research revisited. Qualitative Research, 2006. 6(3): p. 319-340.

90. Corbin, J. and A. Strauss, Basics of Qualitative Research - Techniques and Procedures for Developing Grounded Theory. 4 ed. 2015, Los Angeles: SAGE.

91. Charmaz, K., Constructing Grounded Theory. 2 ed. 2014, Los Angeles: SAGE.

92. Claßen, K., ZurPsychologie von Technikakzeptanz im höheren Lebensalter:Die Rolle von Technikgenerationen, in Fakultät für Verhaltens- und Empirische Kulturwissenschaften. 2012, Ruprechts-Karls-Universität Heidelberg: Heidelberg.

93. Schwandt, T.A., Constructivist, interpretivist approaches to human inquiry, in Handbook of qualitative research, N.K. Denzin and Y.S. Lincoln, Editors. 1994, Sage Publications, Inc.: Thousand Oaks, CA, US.

94. Shah, S.G.S. and I. Robinson, Medical device technologies: who is the user. Int. J. Healthcare Technology and Management, 2008. 9(2): p. 181-197.

95. Meleis, A.I., Transitions Theory, Middle -Range and Situation-Specific Theories in Nursing Research and Practice. 2010, New York: Springer Publishing Company.

96. Richards, D.A. and I.R. Hallberg, Complex Interventions in Health - an overview of research methods. 2015, Cornwall: Routledge. 
Chapter 8

Summary

Samenvatting

Valorisation

Acknowledgements

About the author

List of publications 



\section{Summary}

The safety of older persons has been identified as a crucial component of ageing in place. ${ }^{1}$ In particular, long-lies after a fall jeopardize the safety of community-dwelling older persons. ${ }^{2-5}$ Therefore, Personal Safety Alerting Devices (PSAD) are recommended to support safe ageing in place.

Unfortunately, older persons are still reluctant to use PSADs..$^{6-9}$ Although a majority of older persons view PSADs favourably; only a minority of older persons actually use them. ${ }^{10,11}$ Suggested technology acceptance models exhibit several limitations, e.g.: technology acceptance may fluctuate over time, which is not taken into account; ${ }^{12}$ do not include the step of adoption of a technology $i^{13}$ omits potential user's attitude towards a technology $i^{14}$ are not yet sufficiently empirically adapted to the context of community-dwelling older persons; ${ }^{15,16}$ the scientific literature indicates that technology acceptance models should be adapted to the health care context. ${ }^{17}$

Thus, research focusing on PSAD use and non-use would benefit from an inductive approach to enable new insights into determinants and related processes of acceptance/ adoption/use. Additionally, little is known about the perspective of relatives, community nurses and general practitioners, who are both pivotal for ageing in place and PSAD use and non-use in daily life. Lastly, to date, it is unclear how PSAD use and non-use is viewed and affected by community-dwelling older persons, relatives, community nurses and general practitioners.

Therefore, it is essential to gain a meaningful understanding of processes and factors influencing PSAD use and non-use in older persons from the key stakeholders of ageing in place, i.e. older persons, their relatives, community nurses and General Practitioners (GPs).

The overall objective of this doctoral thesis is to investigate the PSAD use and non-use of community-dwelling older persons from a multi-perspective approach. The thesis aims to extend current knowledge by providing a deeper understanding and insight into user involvement during PSAD development, as well as reasons, thoughts, motives and influencing factors of PSAD use and non-use from the perspectives of older persons, relatives, community nurses and general practitioners. Therefore, the following research questions are addressed:

1. What is the nature and extent of user involvement of people 65 years of age and older, in the development, testing and/or evaluation of fall detection systems? (Chapter 2) 
2. What are the needs and preferences of community-dwelling older people regarding a wearable fall detection sensor and its smartphone application during the design and mock-up stage? (Chapter 3)

3. What is the usability of a wearable, waterproof, automatically alerting, fall detection prototype, according to the community-dwelling older persons involved? (Chapter 4)

4. What are the reasons, thoughts, motives and influencing factors regarding the use and non-use of a PSAD in daily life from the perspective of communitydwelling older persons? (Chapter 5)

5. What are the reasons for the PSAD use and non-use among community-dwelling older persons according to relatives, nurses and GPs? In what situations are PSADs used or not used by community-dwelling older persons according to relatives, nurses and GPs? What is the involvement of relatives, nurses and GPs in the use and non-use of PSADs? (Chapter 6)

This dissertation applied a predominantly qualitative methodological approach and comprises five studies, described in Chapters 2 to 6 .

In Chapter 2, the first study, ${ }_{1}^{18}$ a scoping review of the scientific literature identified the state of research from 2004 to 2014 involving older persons in the development of PSADs. The aim was to describe the nature and extent of user involvement of people 65 years of age and older in the development, testing and/or evaluation of PSADs. The nature of involvement focused on two elements: (1) general aspects of the literature involving older persons, e.g. kind of PSAD, sample size or length of time involved, as well as on (2) descriptive characteristics of the involved older persons involved, e.g. age, gender, state of health or fall risk. The extent of user involvement referred to the focus (A) and stage(s) of involvement (B). The focus of involvement was divided into technical aspects, e.g. simulation or performance of activities of daily living, and usability aspects from the point of view of older persons. To scrutinize the stage(s) of involvement (B), the literature included was sorted according to the four development stages of the theoretical framework "medical device technology development process" from Shah et al. ${ }^{19}$ The scoping review included a total of 53 studies and showed that older persons are mostly involved in one or two stages of PSAD development, namely during the stages prototype design and/or testing. The focus of the developers was predominantly on technical aspects, for instance algorithm development. This study revealed that little attention has been given to the views, needs, preferences or practical aspects of usefulness in the daily life of older persons.

The second and third study were set up based on the basis of the mentioned theoretical framework of Shah et al., ${ }^{19}$ to develop an innovative PSAD, a wearable sensor 
linked to a smartphone application (app).

Chapter 3, the second study, ${ }^{20}$ involved a total of 22 community-dwelling older persons in the device design and mock-up development. The participants welcomed the idea of this sensor, which is waterproofed, and automatically and manually alerting in case of a fall. The sensor was well accepted regarding to its weight and material. The preferences regarding size, shape and colour were specified. The participants emphasized their need for reliable alert functioning and that this should, however, be prioritized above size and shape. In addition, the findings showed that the idea of using a smartphone for automatically reliable fall detection and alerting evoked some general scepticism, but participants mentioned that future generations will probably be able to deal with a smartphone. Based on these insights, a "need-driven" PSAD prototype was developed.

Chapter 4, the third study, ${ }^{21}$ investigated the prototype's usability in a real field testing trial. A total of 15 community-dwelling older persons tested this prototype in daily living over a period of nine days. The findings yielded positive aspects and aspects requiring improvement. The participants underlined the high wearing comfort and a sensor that was easy to handle and recharge. However, it was found that the sensor would need a longer battery duration in order to extend the wearing time. The manipulation of the app was clear and easy and being located via GPS was a preference of all. In contrast, the alerting process and the choice of contact persons as well as their related tasks were identified as complex, e.g. who to choose or availability of contact persons. The use of the smartphone was criticised for requiring too much effort and training to learn how to handle. In addition, the participants agreed that its battery life was insufficient and the reliable distance between smartphone and wearable sensor not practicable in daily life. The participants suggested different versions of this type of PSAD, i.e. one without a smartphone, as the wearable sensor was highly appreciated. Furthermore, the study revealed that the integration of a PSAD in daily life goes beyond technical requirements, in terms of habits and personal preferences, e.g. modification of daily routines, maintenance of independent living or the roles of relatives and healthcare professionals particularly in the alerting process.

Chapter 5, the fourth study, ${ }^{22}$ addressed the broader context and investigated reasons thoughts, motives and influencing factors regarding the PSAD use and nonuse of community-dwelling older persons. The exploration of thirty-two older persons perspectives revealed that the decision to use or not to use results from a "legitimation process". The participants highlighted the need to perceive the necessity of using a PSAD. The decision to use or not to use involves an interplay of the aging self, e.g. dealing with age-related changes, and with the person's perception of technology, e.g. technology experience. The legitimation process is triggered by a critical event, e.g. a 
fall or deterioration of health, which causes the person to reflect on her/his own safety and possible need for assistance as well as the right moment to start using it. As times goes on, depending upon new critical events occurring in daily life, another cycle of the legitimation process may be re-initiated.

Chapter 6, the fifth study, ${ }^{23}$ explored relatives', community nurses' and GPs' perspectives and experiences in decision making around PSAD use and non-use in the daily life of community-dwelling older persons to enable a comprehensive insight into PSAD use and non-use. Altogether, 33 relatives, 34 community nurses and eleven GPs were interviewed. The participants disclosed that they were involved in a longer lasting negotiation process comprising three major phases: A) waiting for a critical event in an older persons' everyday life; B) introducing the idea of a PSAD; C) deciding about and supporting PSAD use. The process was characterized by a balancing of care with independence. Whereas all participants perceived a need to care for the older person by suggesting the use of a PSAD, the older person mostly experiences this suggestion as a threat to losing her/his independence as an adult. The study suggests that an informed decision for PSAD use or non-use requires a negotiation process which is iterative, complex and time-intensive. Relatives and community nurses are predominantly involved, although GPs may positively influence the decision making. While community nurses play a crucial role, they seem not sufficiently prepared to provide comprehensive PSAD counselling.

Chapter 7 provides a summary and discussion of the main findings resulting from this dissertation. Subsequent theoretical considerations regarding the PSAD use and non-use knowledge gained through this doctoral thesis are integrated, discussed in the context of technology acceptance / adoption models from the scientific literature and a theoretical model of the dissertation findings is suggested. Moreover, methodological considerations regarding the predominantly qualitative methodological approach of this doctoral thesis are presented. The chapter closes with implications for research and practice.

Chapter 8, Finally, possibilities for valorisation of the knowledge that was gained throughout this doctoral thesis are explored. 


\section{References}

1. Carpenter, D., et al. Patient Safety in the Home. 2017.

2. Lord, S.R., C. Sherrington, and H.B. Menz, Falls in oder people. Risk, factors and strategies for prevention. 2001, Cambridge: Cambridge University Press.

3. Simpson, P.M., et al., Epidemiology of emergency medical service responses to older people who have fallen: a prospective cohort study. Prehosp Emerg Care, 2014. 18(2): p. 185-94.

4. Fleming, J. and C. Brayne, Inability to get up after falling, subsequent time on floor, and summoning help: prospective cohort study in people over 90. BMJ, 2008. 337: p. a2227.

5. Johnston, K., et al., Personal alarm use to call the ambulance after a fall in older people: characteristics of clients and falls. Journal of Emergency Primary Health Care (JEPHC), 2010. 8(4): p. 1-9.

6. Nyman, S.R. and C.R. Victor, Use of personal call alarms among community-dwelling older people. Ageing \& Society, 2014. 34(1): p. 67-89.

7. Lai, C.K., et al., A survey of older Hong Kong people's perceptions of telecommunication technologies and telecare devices. Journal of Telemedicine and Telecare, 2010. 16(8): p. 441-446.

8. McLean, P.A., Exploring older Adults' Persceptions of the Utility and Ease of Use of Personal Emergency Response Systems, in Faculty in Nursing. 2016, CNUY Academic Works: New York.

9. Heinbüchner, B., et al., Satisfaction and use of personal emergency response systems. Z Gerontol Geriatr, 2010. 43.

10. Chaudhuri, S., H. Thompson, and G. Demiris, Fall Detection Devices and Their Use With Older Adults: A Systematic Review. J Geriatr Phys Ther, 2014.

11. Künemund, H. and N.M. Tanschus, The technology acceptance puzzle. Results of a representative survey in Lower Saxony. Z Gerontol Geriatr, 2014. 47(8): p. 641-7.

12. Yousafzai, S.Y., G.R. Foxall, and J.G. Pallister, Technology acceptance: a meta-analysis of the TAM: Part 2. Journal of Modelling in Management, 2007b. 2(3): p. 281-304.

13. Kiwanuka, A., Accpetance Process: The Missing Link between UTAUT and Diffusion of Innovation Theory. American Journal of Information Systems, 2015. 3(2): p. 40-4.

14. Renaud, K. and J. van Biljon. Predicting technology acceptance and adoption by the elderly: a qualitative study. in Annual research conference of the South African Institute of Computer Scientists and Information Technologists on IT research in developing countries: riding the wave of technology. 2008. New York: ACM.

15. Chen, K. and A.H. Chan, Gerontechnology acceptance by elderly Hong Kong Chinese: a senior technology acceptance model (STAM). Ergonomics, 2014. 57(5): p. 635-52.

16. King, W.R. and J. He, A meta-analysis of the technology acceptance model. Information \& Management, 2006. 43(6): p. 740-755.

17. Holden, R.J. and B.-T. Karsh, The Technology Acceptance Model: Its past and its future in health care. Journal of Biomedical Informatics, 2010. 43(1): p. 159-172.

18. Thilo, F.J.S., et al., Involvement of older people in the development of fall detection systems: a scoping review. BMC Geriatrics, 2016. 16(42).

19. Shah, S.G.S., I. Robinson, and S. AIShawi, Developing medical device technologies from users' perspectives: A theoretical framework for involving users in the development process. International Journal of Technology Assessment in Health Care, 2009. 25(4): p. 514-521.

20. Thilo, F.J.S., et al., Involvement of the end user: exploration of older people's needs and preferences for a wearable fall detection device - a qualitative descriptive study Patient Preference and Adherence 2017. 11: p. 11-22.

21. Thilo, F.J.S., et al., Usability of a wearable fall detection prototype from the perspective of older people-A real field testing approach. Journal of Clinical Nursing, 2018.

22. Thilo, F.J.S., et al., How older persons consider using a Personal Safety Alerting Device: a qualitative study submitted.

23. Thilo, F.J.S., et al., Advancing Personal Safety Alering Device Use of Older Persons - the Views of Relatives and Health Care Professionals. submitted. 



\title{
Samenvattting
}

\author{
Thuis, veilig oud worden \\ Geleerde lessen uit onderzoek inzake het wel \\ of niet gebruiken van persoonlijke valalarmsystemen
}

Binnen het principe van "ageing-in-place", d.w.z. het in de eigen woonomgeving oud worden, neemt de veiligheid van ouderen een centrale plaats in. Als ouderen lang op de grond blijven liggen na een val, is dat funest voor hun veiligheid. Ter ondersteuning van het veilig oud worden in de eigen woonomgeving wordt derhalve het gebruik van persoonsgebonden valalarmsystemen (Personal Safety Alerting Devices, PSADs) aanbevolen.

Niettemin blijven ouderen terughoudend in het gebruik ervan. Weliswaar heeft het leeuwendeel van de ouderen een positief beeld van PSADs, toch gebruiken velen ze niet. De huidige theoretische modellen over de acceptatie van technologische hulpmiddelen vertonen op dit gebied verschillende beperkingen. Zo kan de acceptatie van technologische hulpmiddelen door de tijd heen variëren, hetgeen vaak niet is verdisconteerd. Ook ontbreekt veelal het adoptiestadium en laten de modellen de attitude ten opzichte van technologie bij de beoogde gebruiker buiten beschouwing. Ook is hun empirische aanpassing aan de context van zelfstandig wonende ouderen tot dusverre ontoereikend en moeten de huidige modellen voor acceptatie van technologie volgens de wetenschappelijke literatuur beter aangepast worden aan de context van de gezondheidszorg.

Onderzoek naar het wel of niet gebruiken van PSADs zou daarom gebaat zijn bij een inductieve benadering gericht op het verkrijgen van nieuwe inzichten in bepalende factoren en aanverwante processen met betrekking tot acceptatie, adoptie en gebruik. Er is daarnaast ook weinig kennis over het perspectief van verwanten, wijkverpleegkundigen en huisartsen, die zowel bij het ageing-in-place fenomeen als m.b.t. het gebruik van PSADs in het dagelijks leven een cruciale rol spelen. Tot nu toe is het immers onduidelijk hoe zelfstandig wonende ouderen, hun verwanten, wijkverpleegkundigen en huisartsen het wel of niet gebruiken van PSAD's beoordelen en beïnvloeden. Het is daarom belangrijk om van hen een goed begrip te verkrijgen van de processen en factoren die het wel of niet gebruiken van PSADs door ouderen mede bepalen. 
Dit proefschrift beoogt daarom om vanuit een pluriform perspectief het wel of niet gebruiken van PSADs door zelfstandig wonende ouderen te onderzoeken. Het doel is nadrukkelijk kennisverrijking, door het bieden van meer inzicht in de rol die gebruikers spelen bij de ontwikkeling van PSADs, alsmede het verschaffen van inzicht in de argumenten, gedachten, motieven en factoren, die van invloed zijn op het wel of niet gebruiken van PSADs.

De volgende onderzoeksvragen komen hierbij aan bod:

1. In hoeverre en in welke mate zijn 65-plussers betrokken bij het ontwikkelen, testen en beoordelen van valdetectiesystemen? (Hoofdstuk 2)

2. Welke behoeften en voorkeuren bestaan er onder zelfstandig wonende ouderen t.a.v. draagbare valdetectiesensoren en de gerelateerde smartphone-applicaties tijdens het ontwerp- en proefstadium? (Hoofdstuk 3)

3. Hoe gebruiksvriendelijk is een draagbaar, waterbestendig en automatisch waarschuwend prototype voor valdetectie volgens zelfstandig wonende ouderen die het gebruiken? (Hoofdstuk 4)

4. Welke argumenten, gedachten, motieven en factoren zijn van invloed op het wel of niet gebruiken van PSADs in het dagelijks leven vanuit het gezichtspunt van zelfstandig wonende ouderen? (Hoofdstuk 5)

5. Welke redenen voeren zelfstandig wonende ouderen aan voor het wel of niet gebruiken van PSADs volgens hun verwanten, verpleegkundigen en huisartsen? Wat zijn de omstandigheden waaronder zelfstandig wonende ouderen PSADs al dan niet gebruiken volgens hun verwanten, verpleegkundigen en huisartsen? Hoe zijn verwanten, verpleegkundigen en huisartsen betrokken bij het wel of niet gebruiken van PSADs? (Hoofdstuk 6)

De in dit proefschrift gekozen methodologische benadering is overwegend kwalitatief van aard en omvat vijf studies, die in hoofdstuk $2 \mathrm{t} / \mathrm{m} 6$ zijn beschreven.

Hoofdstuk 2, de eerste studie, biedt een overzicht van de wetenschappelijke literatuur over de stand van zaken in het onderzoek naar de betrokkenheid van ouderen bij de ontwikkeling van PSADs tussen 2004 en 2014. Dit geschiedt aan de hand van een scoping review. Dit hoofdstuk beschrijft op welke wijze en in welke mate 65-plussers betrokken waren bij het ontwikkelen, testen en beoordelen van de PSADs die zij zouden gaan gebruiken. Twee punten blijken van belang voor de wijze van betrokkenheid: (1) de algemene kenmerken van de studies zelf, zoals het design, het type PSAD, de steekproefgrootte of de periode van betrokkenheid én (2) de kenmerken van de betrokken ouderen zelf, waaronder hun leeftijd, geslacht, gezondheidstoestand of valrisico. Onder de mate van betrokkenheid vielen de focus $(A)$ en het stadium (B) van betrokkenheid van de gebruiker. De focus van hun betrokkenheid betrof 
ofwel technische elementen zoals simulatie of uitoefening van activiteiten uit het dagelijks leven, ofwel de gebruiksvriendelijkheid voor ouderen. Bij het te bestuderen stadium van betrokkenheid werd de gebruikte literatuur onderverdeeld in de vier ontwikkelingsstadia van het theoretisch kader zoals geboden door Shah et al. genaamd "medical device technology development process" [ontwikkelproces van technologie voor medische apparatuur]. De 53 onderzoeken binnen de scoping review toonden aan dat ouderen voornamelijk betrokken werden in een of twee ontwikkelingsstadia van PSADs, te weten het ontwerp van prototypen en/of de testfase. Hierbij richtten de ontwikkelaars zich veelal op technische elementen zoals de ontwikkeling van algoritmen. Verder bleek ook dat de eigen opvattingen, behoeften, voorkeuren of praktische situatie van ouderen slechts een geringe rol speelden in het bepalen van de bruikbaarheid in het dagelijks leven.

De structuur van het tweede en derde onderzoek volgde opnieuw het al genoemde theoretische kader van Shah et al. en dit werd toegepast bij de ontwikkeling van een innovatieve PSAD: een draagbare sensor die aan een smartphone-applicatie (app) is gekoppeld.

Hoofdstuk 3, In de tweede studie, waren 22 zelfstandig wonende ouderen betrokken bij het ontwerp en de ontwikkeling van een testapparaat. Het concept van de betreffende waterbestendige sensor, die een automatisch of handmatig gestuurd alarm afgeeft bij een val, bleek waardevol bevonden te worden. Ook het gewicht en het materiaal van de sensor werden als goed beoordeeld. De deelnemers gaven ook nog enige voorkeuren aan ten aanzien van grootte, vorm en kleur. Veel belangrijker dan grootte en vorm was evenwel de betrouwbare werking van het alarm. Hoewel uit deze studie opnieuw bleek dat de deelnemers in het algemeen nog bedenkingen hadden bij het concept van een smartphone voor betrouwbare detectie en automatische alarmering bij een val, gaven de deelnemers te kennen dat het gebruik van een smartphone voor de volgende generaties waarschijnlijk helemaal geen probleem meer zou zijn. Naar aanleiding van de vergaarde informatie werd een op behoeften gebaseerd PSAD-prototype ontwikkeld.

Hoofdstuk 4, De derde studie, betrof een realistische praktijktest om de gebruiksvriendelijkheid van het prototype te beoordelen. Gedurende negen dagen testten 15 zelfstandig wonende ouderen dit prototype in hun dagelijks leven. Uit deze proef kwamen zowel positieve punten als verbeterpunten naar voren. Enkele positieve aspecten waren het draagcomfort, het gebruiksgemak en het eenvoudig opladen van de sensor. Het bleek echter nodig de levensduur van de batterij te verlengen teneinde de sensor langer te kunnen dragen. Men was ook tevreden over de duidelijke en gemakkelijke bediening van de app en de wijze van lokalisatie via gps. Daarentegen vond men het activeren van het alarmproces, het kiezen van de juiste contactpersonen 
en hun aanverwante handelingen ingewikkeld. Ook kostte het de deelnemers veel moeite om de smartphone goed te leren bedienen. Men had verder kritiek op de ontoereikende levensduur van de batterij en men stipte de praktische onbruikbaarheid aan van de noodzaak om steeds een betrouwbare afstand tussen de smartphone en de draagbare sensor aan te moeten houden. De deelnemers waren met name zeer enthousiast over de draagbare sensor, en stelden derhalve een alternatieve versie van deze PSAD voor zonder smartphone. Uit de studie bleek overduidelijk dat niet alleen technische eisen een rol spelen bij de toepassing van PSADs in het dagelijks leven, maar ook gewoonten en persoonlijke voorkeuren zoals het aanpassen van dagelijkse routines, het zelfstandig kunnen blijven wonen of de inbreng van verwanten en zorgverleners in met name het alarmeringsproces.

Hoofdstuk 5, De vierde studie, beschrijft de bredere context alsook de argumenten, gedachten, motieven en factoren die het wel of niet gebruiken van PSADs door zelfstandig wonende ouderen beïnvloeden. Door onderzoek van de gezichtspunten van 32 ouderen bleek dat een "legitimeringsproces" ten grondslag ligt aan de keuze om een PSAD wel of niet te gebruiken. De deelnemers benadrukten dat de noodzaak van PSAD-gebruik eerst moest worden ervaren. Of zij besloten om een PSAD al dan niet te gebruiken, hing af van het samenspel tussen de persoonlijke omgang met ouderdomsverschijnselen en de individuele ervaring met technologie. Het legitimeringsproces begint door een significante gebeurtenis zoals een val of een achteruitgang in de gezondheid, als gevolg waarvan mensen gaan nadenken over hun eigen veiligheid, de eventuele behoefte aan hulpverlening en het juiste moment om tot gebruik over te gaan. Na verloop van tijd kan het legitimeringsproces ook weer opnieuw plaatsvinden, afhankelijk van nieuwe significante gebeurtenissen die in het dagelijks leven plaatsvinden.

Hoofdstuk 6, In de vijfde studie, werden de gezichtspunten en ervaringen m.b.t. de besluitvorming omtrent het wel of niet gebruiken van PSADs door zelfstandig wonende ouderen geëxploreerd bij verwanten, wijkverpleegkundigen en huisartsen. Er vonden gesprekken plaats met in totaal 33 verwanten, 34 wijkverpleegkundigen en 11 huisartsen. Volgens de deelnemers waren zij betrokken in een langduriger onderhandelingsproces met drie hoofdstadia: A) wachten op een significante gebeurtenis in het dagelijks leven van ouderen, B) het concept van PSAD-gebruik opperen en C) het besluiten tot én ondersteunen van het PSAD-gebruik. Kenmerkend voor dit proces was het afwegen van (aan te bieden) zorg en zelfstandigheid. Alle deelnemers waren zich weliswaar bewust van de noodzaak tot goede zorg voor ouderen door het gebruik van een PSAD voor te stellen, maar de meeste ouderen ervaren dit idee niettemin vaak als een dreigend verlies van eigen zelfstandigheid. Duidelijk is dat een herhaald, ingewikkeld en tijdrovend onderhandelingsproces nodig is voor het maken van een weloverwogen 
keuze voor het wel of niet gebruiken van een PSAD. Hoewel hierbij vooral verwanten en wijkverpleegkundigen betrokken zijn, kunnen huisartsen zeker een positieve invloed op de besluitvorming hebben. Wijkverpleegkundigen spelen dus zeker een cruciale rol, maar zij lijken vooralsnog onvoldoende voorbereid om het gebruik van PSADs integraal te begeleiden.

Hoofdstuk 7 bevat een samenvatting en een bespreking van de belangrijkste uitkomsten van dit proefschrift. In het hoofdstuk wordt de nieuw verworven kennis over het wel of niet gebruiken van PSADs geïntegreerd in de bestaande literatuur van modellen voor de acceptatie en adoptie van technologie. Ook wordt een theoretisch model van de uitkomsten van het proefschrift voorgesteld. Verder komen methodologische overwegingen omtrent de voornamelijk kwalitatieve aanpak van dit proefschrift aan de orde en tenslotte ook de implicaties voor nieuw onderzoek en de praktijk.

Hoofdstuk 8 beschrijft de valorisatie van de in dit proefschrift verworven kennis. 



\section{Valorisation}

The chapter valorisation makes available for social and economic use the scientific findings that emerged from this doctoral thesis. Lessons learned are deduced from the multi-perspective immersion into the use and non-use of Personal Safety Alerting Devices (PSAD) in community-dwelling older persons for the respective target groups. Furthermore, activities and products resulting from this dissertation are described and the innovation potential of the research conducted research is discussed.

\section{Relevance}

This doctoral thesis addresses the challenge of technology use and non-use in community-dwelling older persons, based on the case of PSADs, from a multiperspective approach.

Ageing societies are a common issue on political and health care agendas across the globe. ' One focus of this agenda is on "ageing in place", which promotes the wellbeing of ageing societies and refers to enabling older persons to live independent lives, safe and socially integrated in their accustomed homes in the community. ${ }^{2,3}$ This focus is both a preference of older persons ${ }^{4,5}$ and according to international estimates, advantageous in terms of societal costs, ${ }^{6}$ as ageing in place aims to avoid or delay institutionalization. To support ageing in place despite illness or functional decline, the number and extent of assistive technologies has increased substantially in the last decade.7, 8 The types of available technologies include devices to monitor health and to support safety and mobility, along with the promotion of daily activities and social connectedness. ${ }^{8}$

With regard to ageing in place the safety of older persons at home has been identified as a pivotal component. ${ }^{9}$ Although the prevention of falls in communitydwelling older persons is regarded as crucial, to date, multifactorial and multiple component interventions can moderate the fall rate and risk of falling, but evidence for their efficacy is of low quality. ${ }^{10}$ In addition, the home environment is widely documented as a common place for falls. ${ }^{11,12}$ When rapid assistance does not come, falls in particular, but also other emergency situations, have negative impacts on the health and psychological wellbeing of older persons. ${ }^{13}$ This in turn, may jeopardize ageing in place and lead to institutionalization. It is therefore pivotal that older persons obtain rapid assistance when a fall has occurred. Accordingly, assistive technologies like a PSAD can be considered to be an essential enabler of ageing in place.

However, the use of assistive technologies for older persons in general, and specifically the use of PSADs, is still problematic. Several attempts have been made 
to identify reasons for PSAD non-use, focusing mainly on usability issues. ${ }^{14}$ User involvement is recommended to solve usability issues, as it promotes a "need-driven" instead of a "technology-driven" approach. ${ }^{15}$ Furthermore, recent evidence suggests that no theory yet explains, nor do available technology acceptance models provide, sufficient descriptions or explanations of the technology use and non-use of older persons in the health care context. ${ }^{16,17}$ Health care professionals and relatives can positively encourage and facilitate technology acceptance, but, so far little attention has been given to their perspectives. ${ }^{14,18-20}$ In addition, health care professionals, particularly community nurses, can draw on an increasing multitude of assistive technologies for ageing in place. Thus, it can be argued that understanding technology use and nonuse is a key to promoting and supporting ageing in place. Research suggests that understanding technology acceptance requires knowledge about the actors involved in its use. Understanding technology use requires answers to the "when, why and how" of technology use. ${ }^{16,21,22}$ Technologies should not be considered as black boxes which can be integrated into daily life without modifying caring practice. ${ }^{14}$ Moreover, non-use should be investigated and not pathologized as it is often motivated and active. $8,23,24$

Therefore, the aim of this doctoral thesis was to investigate the use and non-use of an assistive technology, using the case of PSADs, by community-dwelling older persons from their perspective, the perspectives of relatives, community nurses and general practitioners.

\section{Target groups}

The target groups who can benefit from the results of this doctoral thesis are older persons, relatives and health professionals.

\section{Older persons}

Community-dwelling older persons were the core of this thesis and were part of all five conducted studies. Their involvement in the development and testing of a PSAD prototype resulted in an innovative device for those older persons who prefer an automatically alerting, waterproof, invisible worn PSAD that can be used both in- and outdoors. In addition, for indoor use, instead of a smartphone, a so-called base station was developed to ensure reliable alert transmission.

Those older persons who participated in the studies improved their knowledge about PSADs from the insights and information provided by the research team about the different PSADS available on the Swiss market at that time. They also benefited from the discussions. Discussing and exchanging with other persons in a similar living 
situation may have emphasized that the topics of safety, rapid assistance in case of an emergency and falling are issues which should be taken seriously when aging at home. In addition, the participants may have benefited from an informed understanding of how personal safety and independence can be supported by using a PSAD. In exchange with family, friends and neighbours they may have disseminated this knowledge and pursued the discussions.

Even those who did not participate in the thesis' studies can benefit from the findings. A plain language summary of the legitimation process in the format of an information brochure will be provided for distribution via community nurses, senior organizations and counselling services to older persons. Furthermore, based on this thesis, health care professionals can be taught and trained in the factors and processes of PSAD decision making, and thus older persons can benefit from an improved support and counselling service.

\section{Relatives}

Those relatives who did not participate in the thesis'studies will benefit from the findings. Similarly, to the deliverable to older persons, a plain language summary in the format of an information brochure will be provided for distribution via community nurses and counselling services to relatives. This brochure delineates the possible challenges of older persons related to PSAD use and non-use (the legitimation process) as well as recommendations for relatives (negotiation process).

\section{Health Care Professionals}

The thesis insights underline that community nurses and GPs should increase awareness regarding identifying technology need, such as a PSAD, counselling and support activities to enable older persons and their relatives to take an informed decision regarding ageing in place safely in general and PSAD use and non-use in particular. In addition, community nurses were described as a neutral source of information related to PSADs, which older persons would prefer in order to take an informed decision. GPs should be aware of their contribution by identifying critical events, by connecting older persons and their relatives with community nurses in the subject of ageing safely at home and positively influencing decision making regarding PSAD use and nonuse, as some situations showed that this decision was related to end-of life decisions (hospitalisation or institutionalisation).

The importance of assistive technologies for ageing in place has increased steadily in recent years and can be expected to increase further, due to ongoing technological development and the shortage of health care staff. It can be argued that the example of PSADs emphasizes that, on the one hand, user involvement in the development of 
technologies allows the identification of critical issues for later usability and thus use. On the other hand, the findings suggest in a surprising way that using or not-using a technology, such as a PSAD, is less about usability and ease of use, but more strongly about identifying the right moment to address PSAD use, knowing how to address it, having a favourable relationship with the older person, supporting the establishment of the perceived necessity, enabling access and trying out a PSAD in order to take an informed decision and balancing the necessary control in the daily life of the older person against the provision of the necessary care and support (see legitimation and negotiation process).

It is conceivable that these thesis findings are transferable to other assistive technologies, e.g. aids for mobility, hearing and vision or daily living aids, telemedicine or information- and communication technology ${ }^{25}$, which should be investigated. Furthermore, it is conceivable that with the growing number of assistive technologies for ageing in place, community nurses and GPs will need more expertise in assessing technology needs and addressing them.

\section{Nursing Discipline}

Assistive technologies for nursing care such as a walking cane, hearing aids or lifting equipment are not new. However, due to digitalization and the increasing confluence of nursing and informatics, the variety of assistive technologies is being continuously extended and today includes information- and communication technology (ICT), robotics, telemedicine and sensor technology. ${ }^{25}$

This thesis emphasizes that beyond understanding the technology/device itself in terms of usability and ease of use, nurses have a role to play in enabling an informed decision regarding technology use and non-use. In the case of PSADs, they are required for opening access to devices, providing information and knowing how to support, coach and evaluate their use as well as developing strategies for how to re-act in case of non-use. Additionally, they also contribute by identifying all those persons who are involved in device use, in order to clarify the path and activities of involvement. It is conceivable that with ongoing digitalisation this kind of support will also be required for other technologies relevant to nursing care and the interaction of nurses, patients, relatives and in the interprofessional context. It would seem important that nurses actively shape technological development and clarify their roles and activities.

This doctoral thesis indicates that using a PSAD is often influenced by the social network of the older person, i.e. particularly relatives but also health professionals. However today, relatives seem often to act on their own without professional support and enough knowledge, which may lead to conflicting situations with their parent/s, as their perception of the older person's safety differs. Stronger support and involvement 
by community nurses and GPs could facilitate the decision making of PSAD use and non-use. This requires competences and skills of the stakeholders involved, for instance, in identifying and assessing PSAD need, negotiating the decision process, counselling on PSAD usability and consequences regarding daily life and coaching in PSAD use or finding strategies in case of non-use. However, the challenge currently remains that community nurses are often not involved or only involved once the older person presents a more serious support need. Therefore, two strategies are suggested: on the one hand, GPs should refer older persons to community nurses when safety and ageing in place becomes a topic. On the other, community nurses should investigate, clarify and make transparent in public what role they play regarding counselling offers in terms of ageing in place.

It can be argued that the seminal field of assistive technology and digitalization will further influence the nursing discipline. Nurses are required to develop the necessary resources, competences and skills. This can be supported by research, teaching, publication, podium discussions, videos, conferences or event organization. Discussions among researchers and practitioners should enrich and accelerate the development of nursing regarding the seminal field of assistive technologies and digitalization. Furthermore, knowledge transfer and training are required, and should be provided by further education and integrated into the Bachelor and Master's Programs of Nurses. Based on this doctoral thesis, part of the knowledge transfer should be: aspects of ease of use (usability, impact and meaning), components and influencing factors of the decision-making processes and the different roles of the actors involved.

\section{Researchers}

Researchers in health and nursing sciences can benefit from this doctoral thesis. Until today, little research has focused on the "bigger" picture of technology use and nonuse in the health care context, taking one technology that is very relevant to ageing in place safely. The findings, namely the user involvement approach for technology development, the legitimation process, the negotiation process and the guided support by community nurses could be considered as an important step in establishing the need for detailed understanding of technology use and non-use processes. With the description and possible explanations of the phenomenon of technology use and non-use, further research can address intervention studies and outcome measurements on a meaningful basis.

Researchers from the fields of informatics and engineering who are involved in the development of technologies employed in the health care context as well as in the context of ageing in place might also benefit from the insights of this thesis. It found that user involvement can positively influence usability issues and ease of use 
in daily life. However, in the case of a PSAD, it was found that to understand use and non-use of a device it is necessary to go beyond technical issues, such as providing neutral information, and provide recommendations on how to include the device in daily life, transparency about the alerting process and the competences of the involved contact persons and others. Furthermore, this thesis suggested that involving those professionals who are involved in later technology use seems to be essential for communication with the participants, i.e. nurse researchers acted as "translators" of the technical language and created a productive working atmosphere.

Intervention studies are needed to evaluate the economic impact of using assistive technologies for ageing in place as well as longitudinal studies which inform about long-term use. Those findings might be of interest for health insurance companies to evaluate possible financial support of technologies such as PSADs to enable and or support ageing in place. At least in Switzerland, it is not yet common that PSADs can be accessed via the basic health insurance when ageing in place.

\section{Activities/Products}

The PSAD prototype was further developed in another study, i.e. a wearable sensor with a base station in addition to a smartphone application, and tested by institutionalized older persons to improve, amongst other things, the usability and the automatic fall detection algorithm. Up to today, a start-up has been founded as part of another company, and this PSAD is available on the market in Switzerland https://www.aidemoi. $\mathrm{ch} /$.

The findings (studies 1-4) were presented at national and international conferences: pflegekongress19; BFH Treffpunkt November 2019 "Gläserne Patienten - Wohin geht die Entwicklung"; Nursing Research 2018; 1st International Conference of the German Society of Nursing Science 2018; European Nursing Informatics 2017; 28th International Nursing Research Congress 2017; Conférence IUFRS 2016; 5th European Nursing Congress 2016; Swiss Congress for Health Professions 2016; Kongress für Gesundheitsberufe 2016; European Conference in Nursing Science (EDCNS) 2015; EDCNS 2018; 1st International German Nursing Science Conference; pflegekongress 19.

Furthermore, the findings were published in relevant national professional journals and in a book chapter: Thilo, F.J.S. and Hahn, S. (2018). Notrufsystem im häuslichen Setting - unerwartete Verknüpfungen und grosser Informationsbedarf. NOVAcura, 10, 33-34; Hahn, S. und Thilo, F.J.S. (2017) Mitsprache in der Digitalisierung: Systematischer und praxisnaher Einbezug der Nutzenden von gesundheitsrelevanten Technologien. In 'Digitale Transformation von Dienstleistungen im Gesundheitswesen III, Herausgeber 
Pfannstiel, M. Krammer, S., \& Swoboda, W. Springer Verlag; Thilo, F.J.S., \& Hahn, S. (2017). Innovation durch Einbezug der User. SocietyByte https://www.societybyte.swiss/?s=n novation+durch+Einbezug+der+User; Hahn, S., \& Thilo, F.J.S. (2017) Seniorinnen und Senioren entwickeln mit. NOVAcura, 48, 1, 45-47. Publications of study findings four and five are planned in national professional journals: Krankenpflege, Spitex Schweiz, Schweizerische Ärztezeitung and Primary and Hospital Care.

Beyond this, findings were shared in discussions with experts from the national commission "eHealth and Nursing" of the Swiss Nursing Association, of which F.J.S. Thilo is a member and the president from January 2020. The knowledge gained by this thesis also influenced the "position paper" called eHealth and nursing, which was called into being by the commission and published in September 2019 https://www.sbk. $\mathrm{ch} /$ pflegethemen/ehealth. It is the first statement in Switzerland which positions and describes current developments and possible consequences of digitalization for the nursing profession in the context of eHealth. Recommendations are made for clinicians, managers, teachers and researchers from nursing.

The knowledge gained through the PhD trajectory supported F.J.S. Thilo in positioning the Department of Health of Bern University of Applied Sciences (BFH) in the BFH Centre Digital Society (https://www.bfh.ch/de/forschung/forschungsbereiche/ bfh-zentrum-digital-society/), founded in 2016. F.J.S. Thilo is actively involved in its establishment. The BFH Centre Digital Society brings together different disciplines from the BFH, such as informatics, economics, nursing, gerontology, business studies or architecture, in order to address different aspects of the digital transformation of society, i.e. of the political, economic and health care system. The BHF Centre Digital Society releases the journal Society Byte monthly https://www.societybyte.swiss/. Two editions per year are the responsibility of F.J.S. Thilo.

Furthermore, the knowledge gained through the PhD trajectory has formed a basis for the development of a strategy for a new research field called Innovation Field Technology and Health which is still ongoing. This positioning is important in strengthening the research of technology and digitalization from a nursing and health perspective.

Another activity was also enabled by the PhD trajectory. A community care organization, present in a canton of Switzerland, was identified for collaboration on the topic of digitalization. This organisation is currently supported in the development of its organizational digitalization strategy. On the one hand, the possibilities will be discussed to develop a complex intervention based on the thesis findings. On the other, projects will be identified to advance digitalization in community care nursing and the interprofessional setting as well as to enable nurses to develop their role and necessary digital skills and competences in using technologies and to cope with digitalization to 
the advantage of patients, relatives and nursing.

The topic of digitalization and technology use and non-use is also part of the new curriculum of the Bachelor of Science in Nursing and the Master of Science in Nursing at $\mathrm{BFH}$. The development of this curriculum is still ongoing. Following this $\mathrm{PhD}$ and the knowledge gained from it, specific contents will be added to the curriculum and reflected in teaching activities.

In order to share the thesis findings with more community-dwelling older persons and their relatives, the following activities are planned: (1) two plain language summaries for each, older persons and relatives, which can be shared electronically and distributed via community nurses, senior organizations and counselling services; (2) in collaboration with a senior counselling organization (https://www.prosenectute.ch/ de.html) and the community care organization of the canton of Bern and a GP a caféafternoon under the general heading of ageing safely at home should be organized to address topics such as: what does safety at home include, what kind of PSADs are available, what does the legitimation process mean for the senior and what are the roles of relatives, community care nurses and GPs.

In order to share further the knowledge gained, the following dissemination strategy will be applied: (1) offering a presentation and discussion of the topics mentioned above at each community care organisation and for each general practitioner who participated in the study 5; (2) oral presentations at the (2a) national conference SBK Kongress 2020 https://www.sbk-asi-congress.ch/\%20_blank as well as international conferences, i.e. submitting an abstract to (2b) 2nd International Conference of the German Society of Nursing Science https://dg-pflegewissenschaft.de/veranstaltungen/call-for-abstracts2nd-international-conference-of-the-german-society-of-nursing-science/, and (2c) the GSA 2020 Annual Scientific Meeting https:/www.geron.org/meetings-events/futuregsa-annual-scientific-meetings. 


\section{References}

1. Pruchno, R., International Aging: Spotlighting the Spotlights. The Gerontologist, 2017. 57(3): p. $392-395$.

2. Vasunilashorn, S., et al., Aging in Place: Evolution of a Research Topic Whose Time Has Come. Journal of Aging Research, 2012. 52: p. 306-16.

3. Scharlach, A.E. and K. Diaze Moore, Aging in place, in Handbook of theories of aging, V.L. Bengtson and R.A. Settersten, Editors. 2016, Springer: New York. p. 407-25.

4. Ahn, M., H.J. Kwon, and J. Kang, Supporting Aging-in-Place Well: Findings From a Cluster Analysis of the Reasons for Aging-in-Place and Perceptions of Well-Being. Journal of Applied Gerontology, 2017.

5. Gitlin, L.N., Conducting research on home environments: lessons learned and new directions. The Gerontologist, 2003. 43(5): p. 628-37.

6. European Network on Independent Living Comparing the Costs of Independent Living and Residential Care. 2014. 29.

7. Yusif, S., J. Soar, and A. Hafeez-Baig, Older people, assistive technologies, and the barriers to adoption: $A$ systematic review. International Journal of Medical Informatics, 2016. 94: p. 112-116.

8. Schulz, R., et al., Advancing the Aging and Technology Agenda in Gerontology. Gerontologist, 2015. 55(5): p. 724-734.

9. Carpenter, D., et al. Patient Safety in the Home. 2017.

10. Hopewell, S., et al., Multifactorial and multiple component interventions for preventing falls in older people living in the community. Cochrane Database of Systematic Reviews, 2018. 7.

11. Hefny, A.F., A.K. Abbas, and F.M. Abu-Zidan, Geriatric fall-related injuries. African health sciences, 2016. 16(2): p. 554-559.

12. National Council for Aging Care. Fact Sheet: Falls - The Biggest Threat to Senior Health and Safety. 2018 [cited 2019 April 12]; Available from: https://www.aging.com/falls-fact-sheet/.

13. Agboola, S., et al., Healthcare utilization in older patients using personal emergency response systems: an analysis of electronic health records and medical alert data Brief Description: A Longitudinal Retrospective Analyses of healthcare utilization rates in older patients using Personal Emergency Response Systems from 2011 to 2015. BMC Health Services Research, 2017. 17(1).

14. Stokke, R., The Personal Emergency Response System as a Technology Innovation in Primary Health Care Services: An Integrative Review. J Med Internet Res, 2016. 18(7): p. e187.

15. Bridgelal Ram, M., P. Grocott, and H. Weir, Issues and challenges of involving users in medical device development. Health Expect, 2007. 11: p. 63-71.

16. Lorenzen Huber, L., et al., Aging in intra-and intergenerational contexts: the family technologist, in Gerontechnology: Research, Practice, and Principles in the Field of Technology and Aging S. Kwon, Editor. 2017.

17. Holden, R.J. and B.-T. Karsh, The Technology Acceptance Model: Its past and its future in health care. Journal of Biomedical Informatics, 2010. 43(1): p. 159-172.

18. Ward, G., et al., Fall detectors: a review of literature. Journal of Assistive Technologies, 2012. 6(3): p. $202-215$.

19. Satariano, W.A., A.E. Scharlach, and D. Lindemann, Aging, place, and Technology: Toward Improving Access and Wellness in Older Populations. Journal of Aging and Health, 2014. 26(8): p. 1373-89.

20. Peek, S.T.M., et al., Factors influencing acceptance of technology for aging in place: a systematic review. Int J Med Inform, 2014. 83(4): p. 235-48.

21. Bagozzi, R.P., The Legacy of the Technology Acceptance Model and a Proposal for a Paradigm Shift. Journal of the Association for Information Systems, 2007. 8(4).

22. Connelly, K., et al., Approaches to Understanding the Impact of Technologies for Aging in Place: A MiniReview. Gerontology, 2014. 60(3): p. 282-288.

23. Baumer, E.P.S., et al., On the Improtance and Implications of Studying Technology Non-Use. INTERACTIONS 2015. 22(March + April): p. 52-6.

24. Satchell, C. and P. Dourish, Beyond The User: Use and Non-Use in HCl, in OZCHI. 2009: Melbourne.

25. Khosravi, P. and A.H. Ghapanchi, Investigating the effectiveness of technologies applied to assist seniors: $A$ systematic literature review. International Journal of Medical Informatics, 2016. 85(1): p. 17-26. 



\section{Acknowledgements}

I am very grateful to all those who supported me before and during my PhD journey. This journey was importantly influenced by wonderful people who inspired, encouraged, nudged, laughed and shared challenging moments with me.

\section{My supervisors}

I sincerely thank my supervisors, Prof. Dr. Jos M.G.A. Schols, A/Prof. Dr. Ruud J.G. Halfens and Prof. Dr. Sabine Hahn. Your expert advice was the key to my progress. Your critical questions and feedbacks pushed my reflections and advanced my thinking, competences and skills.

Jos, if a synonym for speed of light should be found, it would be your name. Happy at the progress of my work as I clicked on "send the email", I thought I would have a day off. It often took just minutes, or a few hours and your feedback was back. From far away, at any time of day or night, your answer was sure! I highly appreciated your way of motivating and nudging me during my whole PhD trajectory.

Ruud, it is owing to you that I realized that "reduce to the max" is not only a scientific writing term but a real-world applicable, very helpful but challenging wisdom. Beyond, I am very grateful that you opened the way for me and gave me the opportunity to join the Summer School of the European Academy of Nursing Science (EANS). EANS is an unforgettable memory, opening up numerous networks all over Europe and lasting nursing-science-friendships.

Sabine, I am deeply grateful for your encouragement and trust in my capacities, that you challenged and promoted me over all those years since I met you as a supervisor of my Bachelor thesis. At that time, I knocked at the door of nursing science, but your advice, critical questioning and feedback, your leadership and determined nudging opened me wide the door to the academic world. You created the right opportunities at the right time, in terms of projects, collaborations, teaching, conferences and further education, particularly my PhD trajectory.

\section{The members of the assessment committee}

I would like to thank the members of the assessment committee Prof. Dr. G.I.J.M. Kempen, Prof. Dr. R.A. de Bie, Prof. Dr. S.M.G. Zwakhalen, Prof. Dr. A.-M. Brady and Prof. Dr. K.G. Luijkx for your effort and time in evaluating this doctoral thesis. 


\section{The academic advisors}

I would like to thank Prof. Dr. Christa Lohrmann for your critical and honest inputs during PhD seminars. Thank you, Prof. Dr. Gerjo Kok for those rich and inspiring moments of discussion and advice from social psychological theory.

\section{All study participants}

My sincerely thank you also goes to all community-dwelling older persons, relatives, community nurses and general practitioners who participated in the research projects. Your voluntary contribution, your invested time and effort made this dissertation possible.

\section{The co-authors}

Prof. Dr. Monika Linhart, my 2-years-of-office-sharing colleague and my "(football-) match-maker". I am deeply impressed about your store of knowledge regarding nursing theory and conceptual, critical and theoretical thinking. We spent exciting and inspiring moments which I very much appreciated. Thank you very much.

Dr. Birgit Heckemann, beyond co-authorship you influenced my decision to take the PhD trajectory, we pushed the EDCNS 2016 organization to perfection. You are "my" inspiring qualitative -exchange- source and above all, with you philosophising about life may last days and nights without getting tired. Thank you, Birgit, and I am looking forward to working together in other projects with you.

A big thank you also goes to you, wonderful Barbara Hürlimann. We had a great time not only in the PhD programme, but also collaborating during my first article.

Thank you, Selina Bilger, you are my co-author in the first and second article. I coached you during your Bachelor thesis and after, and you spent a while working at our Nursing Institute. You did a great job and it was highly enjoyable to work with you.

\section{My paranymphs}

Jane Cuendet, my fabulous paranymph, you, who won the Oscar for the Best Nurse in Switzerland in 2018. Your British humour, your beautiful English (I can listen to your narratives for hours and days - although I never told you!), your generosity, your amity, your vivid esprit, that's you! I am grateful and proud that our life paths crossed in 2003 ! Thank you for being my paranymph, thank you Jane for those multiple beautiful moments, exchanges and appreciated friendship.

Sarah Candrian, my wonderful paranymph! I would need pages and pages to tell about our fantastic, exciting and enjoyable adventures beyond our common Bachelor study time. Our often philosophical discourses about life, being a woman, doing a career in nursing, getting older,... we have so many topics to challenge us. Thank you for being 
my paranymph, thank you Sarah for this precious friendship.

\section{My PhD fellow students}

I would like to thank my fellow students from the European PhD programme MaastrichtGraz-Bern. What would I have done without you? The regular meetings in Maastricht, Graz and Bern were always full of enjoyable moments, critical and stimulating discussions, as they also nudged me to keep going on. It's time to say goodbye. My best wishes for PhD success and long-lasting scientific hunger go to: Monica Fliedner, Cosette Fakih, Gerhilde Schüttengruber, Julia Zschnegg, Simone Paulis, Caroline Gurtner, Nursis, Vivienne Huppertz, Karin Peter, Gabriele Fley, Andrea Eissler, Emily Gartshore, Silvia Thomann, Nick Bernet and Christoph Golz. You, amazing Dr. Manuela Hödl, already left the PhD programme, for me it is like it was yesterday and I can tell you: the world is less pink without you. I am sure, my dear fellows, we will see each other again.

\section{My colleagues aF\&E Pflege BFH}

A big thank-you goes to my colleagues from the Nursing Science and the Master of Science in Nursing Programme of Bern University of Applied Sciences. You are a wonderful team and I am happy spending inspiring and enjoyable moments with you. I want to thank especially: Prof. Dr. Monika Linhart, Prof. Dr. Eva Soom Ammann, Dr. Anne Kersten, Dr. Dirk Richter, Prof. Dr. Zumstein-Shaha, Prof. Dr. Christian Eissler, Iris Lipp, Eliane Gugler, Margarithe Schlunegger, Thomas Schwarze, Sabine Seiler, Sandra SiegristDreier, Christa Vangelooven, Dr. Birgit Heckemann, Tannys Helfer, Anouk Haldemann, Nick Bernet, Karin Peter, Christoph Golz and Madeleine Bernet.

\section{The "special support" colleagues}

A special thank goes to Iris Lipp. We first met us during my Master thesis and since then we almost never separated. I enjoy those inspiring and motivating business lunches with you; we have never stopped discussing the world of nursing science and practice as well as cultural events and travel destinations. I am looking forward to others.

I also want to thank Anne Borloz and Marie-José Waeber; you cared about my psychological and physical well-being during all those PhD years. Anne, the piano lessons and the concerts with fantastic Swiss musicians and from abroad were very precious for my mental well-being. Although my personal piano training progress wasn't comparable to Bach or Schumann, going on playing piano for the sake of those brief and intense moments of musical bonheur were worth it. Marie-Jo, perhaps the best physiotherapist in Switzerland, you were the coach of my physical well-being, responsible for the fact that my long $\mathrm{PC}$ sessions did not demolish my upper extremities and back muscles. 
Tannys Helfer, Dr. Heather Murray and Suzanne Rijken you are my important "special support" colleagues who contributed to the success of my doctoral thesis. Tannys and Heather you did the accurate and thoroughly proofreading. Suzanne, during all my PhD time, you were always available for every question and you supported me particularly in the last part of the thesis preparation. I am very grateful, Heather, Tannys and Suzanne, for your very supportive expertise and critical advices. Et: Je te n'ai pas oublié, of course, Prof. Dr. Leila Sadeghi-Reeves, "ma" Lausanne-Bern-Pendlerin-Companion, merci pour ces belles échanges et pour ton french proofreading.

Dr. Anne Kersten, thank-you for your encouragement, which occurred just at the perfect time. When you said that I must now only climb the last $15 \%$ to reach the summit, I was shocked, because I thought that I still had another $45 \%$ left to go. Suddenly, my view changed! I thought, yes, you are right! Thank you also very much for the exchanges during the Master programme teachings. They are highly appreciated!

Prof. Dr. Eva Cignacco, thank you for the inspiring research exchanges and enjoyable soups! I will never forget these beautiful moments. How tasty, our favourites, the Thai soup and black chocolate were!

Sarah Gianora, Mirjam Müller and Fabienne Roth, you will all likely be surprised to read your names here! You are the first three master students that I coached as a firsttime supervisor. However, this is not the main reason for being mentioned here. Your master theses dealt with the topic of technology in nursing. I very much appreciated our discussions, your critical thoughts and working with you. These exchanges contributed my PhD reflections. Also, I must say that I am very proud about the success of your master theses, and I am grateful for your high level of engagement and important knowledge contribution.

\section{My family}

Meine geliebten Eltern, mein tiefster Dank gilt euch. Liebe Mutti, deine ermutigenden Worte und deine Unterstützung waren mir sicher, auch wenn viele Kilometer zwischen uns liegen. Das emotionale Band kennt weder Kilometer noch Distanz. Deine forsche Art, dein unbändiger Drang nach Authentizität und dein emanzipiertes Denken haben mich geprägt. Lieber Papa, auch wenn du nicht mehr physisch anwesend bist in dieser Welt, du trägst mich, spendest mir Kraft und Mut. Die Weltoffenheit, die Lebensfreude, die Neugierde, den Wissensdurst, das Vorwärtsstreben, den Durchhaltewillen, ich glaube, die habe ich von dir. Du hast mich auf dem Weg in die Pflege besonders gefördert. Dein Interesse an meinem beruflichen Weg war nicht nur gross, sondern deine Fragen lösten bereichende und inspirierende Diskussionen aus. Du bist für immer in meinem Herzen und bleibst mein Vorbild. 
Xhek, "mon bonheur d'amour", mon mari, mon petit ami, mon compagnon. Grâce à toi et avec toi, mon "voyage de rêve" dans la recherche en sciences infirmières est devenu réalité. Ton humour imbattable, ton attitude terre-à-terre et ton amour inconditionnel $\mathrm{m}^{\prime}$ ont permit de me lancer dans cette trajectoire de $\mathrm{PhD}$. Tu savais et devais renoncé, tu étais patient et tu faisais en sorte que je quitte ma "grotte scientifique" de temps en temps pour profiter de la "vraie" vie avec toi. Des manifiques souvenirs et aventures, des moments intenses et chalereux m'ont porter et vont nous porter encore.

Danke liebe Geschwister, Anna-Maria, Sophia, Alexander und Hans-Georg. Meine liebe Nichte Marlen und lieben Neffen Emmanuel, Stephan, Raphael, Theodor und Antonius, ich bin stolz auf euch. Jetzt können wir uns wieder in neue Abenteuer stürzen.

\section{My friends}

Anne Doepper, my dear old friend!! We went to kindergarden together and had real fun! When your neighbour had a birthday party, we decided to go, it was "urgent" and didn't care about the worrying parents. We shared the same class and teachers for twelve years, how wired! Once, we had the Abitur in our pocket, we earned the necessary money in a bakery for exciting travels. My very imprinted memories belong to ours travels in Spain, Italy, France and Iceland. It was again so much fun! Not to forget our Dresden and Frankfurt trip! Those beautiful memories are still vivid in my mind! We are living quite far from each other! But our paths remain close and are crossing regularly, and each time it is deep, inspiring and full of positive long-lasting energy. Thank you for this beautiful and long-lasting friendship.

Marie-Hélène Guilbert, "ma" soeur d'âme, un rencontre d'une autre dimension, nos rires, nos folies languistiques, notre activité sportive au sein du Club... Avec toi, on s'aventure dans des reflections lointaines, parfois aberrantes, je l'avoue. Ta sagesse de reflection et ton emphatie pour l'être humain m'impressionne. Une eloquence parfaite, toujours élaborée, jamais maladroite, toujours supérieure, unique, un language comme un bouquet de fleurs! Enchantant et éclaireant! Ma soif languistique, qui dure depuis l'adolescence a su enfin trouver sa raison d'être. L'échange avec toi, c'est une orgie de bonheure! On dit comme ca, non ?! ... Connaitre la "profondeur de la vie", prendre les défis, se confirmer dans la vie...Merci Marie-Hélène pour cette belle amitié.

Ma belle Aude Porchet, mon inspiration sportive, ma compagnionne de randonnée. Les échanges avec toi sont des moments précieux. Parlons de la vie professionelle, de la vie de femme, et plein d'autres sujets. Tu es un ésprit critique avec un humour surprenand et une générosité touchante. Même si je ne pouvait pas participé à tes voyages sur d'autres continents, je $\mathrm{t}^{\prime}$ assure, que tes petits messages et les partages des ces paysages splendides, à coupé le souffle, m'ont motivé et inspiré dans ma vie quotitienne d'étudiante PhD. Merci Aude pour cette belle amité. 
My wonderful ladies Christu Wyss, Fabe Gerber, Vroni Waldboth, Myrta Kohler, Caro Dast, Naemi Pohl, Bahar Beskaya, Melie, Anja Schindler, Maike Bucket and Ghislène even if we saw us less in the last years, I still feel close to you. I very much appreciated those brief moments of exchange and I hope we can spend more time together now that my $\mathrm{PhD}$ is done.

Mes chères amies du comité du Club Chambord Sports. Quel bonheur de vous connaitre et de travailler, faire du sport et des randonnées avec vous. Merci Sandrine Beyeler, Giulia Fregni et Marie-Hélène Guilbert.

My lovely EANS friends, thank you for this great and amazing time in Germany, Sweden and Belgium. A special thank goes to Siobhàn from Ireland, Emma from the UK, Nienke from the Netherlands, Gemma from Spain, Mette from Denmark, Anne from Denmark, Emma from Iceland and Ina, Elisabeth and Kristin from Norway. You are wonderful nurses and excellent nursing researchers. 


\section{About the author}

"We all have dreams. But in order to make dreams a reality it takes an awful lot of determination, dedication, self-discipline and effort." (Jesse Owens)

Friederike J.S Thilo, was born in 1981 in Schwäbisch Gmünd, Germany. From early childhood she was not only exposed to intense human contact as the fourth child of five, but also to technologies. Nobody really knows what happened with this technology issue, but it was recognizable in daily life. As soon as a technology entered the parental home, at that time so-called devices like a stereo, a Walkman, an ice-making-machine, or a mobile phone, nobody else was "allowed" to discover the device before Friederike had checked its usability and functioning. Manuals were never of interest to her, because she already knew: a good technology, is a technology that can be used intuitively. Above all, the first computer in her parental home was her computer (not her brothers'), which was obtained by real endurance. This meant not only saving money, but also queueing up at five in the morning in front of a well-known supermarket. Her father was very keen on this device and she introduced him to this PC world and soon the world wide web. They were real "adventure tandem", hungry for technological discoveries.

It seems, looking back through today's lenses, that another astonishing characteristic developed: her early interest in older persons. Her grandparents had passed away before she was born, but during her childhood Friederike was eager to be in contact with an older lady from her neighbourhood (amongst other things, she often offered a nice variety of sweets and sugary drinks). As a teenager, Friederike was in weekly contact with a couple of older persons where she took her accordion lessons. It was the tradition that after the lessons given by the "older" man, she drank a glass with the "older" lady (sadly only apple or orange juice), and conversed a while, before going back home. Those moments were characterised by inspiring talks and time for exploration of the older persons' world. At the back of her mind, questions wandered around like: what topics they are interested in? How would it be to have grandparents? How does it feel to discuss with them? What they are doing? ...

In 2000, finishing secondary school (Abitur), she started her 3-years nurse's training at Stauferklinik Mutlangen, Germany. Completing in 2003, Friederike did not lose one second in going to la Suisse Romande, Switzerland, combining her passion, the language of Molière et Hugo, with her "freshly" acquired nursing diploma. She "caught" her first job as a nurse at Centre Hospitalier Universitaire Vaudois (CHUV), Lausanne, on the beautiful coast of the Lac Léman. A perfect life which felt like prolonged holidays: speaking French, being among friendly people in a bewitched landscape of water, 
mountain and sun combined with an urban feeling. As a nurse she worked in different specialities: dermatology, visceral surgery, intermediate care visceral surgery and intermediate care internal medicine.

A few years later, the "thirst for knowledge" re-emerged. In October 2009 Friederike received her Bachelor of Science in Nursing at Bern University of Applied Sciences BFH, Bern, Switzerland. The title of her bachelor's thesis was: "Health literacy - a concept analysis as a first step to integrate health literacy in nursing practice", supervised by Prof. Dr. Sabine Hahn. This thesis was awarded a prize at the BFH for the best thesis in 2009 of the Bachelor Programme Nursing Science.

Afterwards, in 2010, she started to work part time at the Institute of Nursing Science at the BFH, while keeping the work as a nurse in Lausanne. Rapidly Friederike realized that doing nursing research requires much more knowledge and skills. In 2012, she finished her Master of Science in Nursing at BFH, in a national Master's programme of three Universities of Applied Sciences. The title of her Master thesis was: "Health literacy defined from the patient perspective - a definition of persons with diabetes". Then, the moment was ripe: she left the nursing practice to shape nursing's future from a scientific approach.

In 2014 Friederike enrolled at Maastricht University, The Netherlands, and started her PhD trajectory under the supervision of Prof. Dr. Jos Schols (Maastricht University), Prof. Dr. Sabine Hahn (Bern University of Applied Sciences) and A/Prof. Dr. Ruud Halfens (Maastricht University). The PhD Programme Nursing Science was jointly organized by the Maastricht University, the Medical University of Graz (Austria) and Bern University of Applied Sciences (Switzerland).

Since 2010 Friederike has worked at the Institute of Nursing Sciences in the Health Department of $\mathrm{BFH}$. First, as a research assistant $(\mathrm{BSCN})$, then as a research associate (MSCN) and since August 2018 she is Head of the Innovation Field Technology and Health. Additionally, Friederike is involved in some teaching activities: from 2013 and 2016 in the Bachelor of Science in Nursing (thesis supervision and eHealth in nursing), since 2015 in the Bachelor of Science in Dietetics Programme (qualitative research) and since 2017 in the Master of Science in Nursing Programme (research proposal development, qualitative research, health literacy, complex intervention). To date, she has supervised a total of 17 theses: twelve Bachelor of Science in Nursing theses and seven Master of Sciences in Nursing.

Her academic work up until today includes over 40 oral and posters presentations at national and international conferences, and four poster awards. Friederike was the head organizer of the European Doctoral Conference in Nursing Science 2016 held in Bern, Switzerland. Since 2015 she is a member of the Cantonal Ethics Committee Bern, Switzerland and since 2016 she is a member of the Committee Nursing and eHealth 
of the Swiss Nurses Association (SBK-ASI) and since 2020 her president. Friederike completed the three-year programme of the European Academy of Nursing Science (EANS) summer school for doctoral studies, from 2016 to 2018. She participated at the "Effective Writing and Publishing Scientific Papers" Workshop from Maastricht University, May 15-16, 2014, provided by Daniel Kotz and Jochen W.L. Cals. Furthermore, Friederike was involved in the following Summer Schools: (1) Qualitative Research Methodologies: Participatory Action Research in Nursing and other Health Sciences, August 20 -24 2012; (2) Grounded Theory in Nursing and other Health Sciences wit Prof. Dr. Kathy Charmaz, August 26-30, 2013; (3) English for Academic Purpose, August 5-29, 2014, Dublin City University, Ireland; and (4) Designing a Mixed Methods Project: An Interactive-Participatory Workshop, August 21 - 25, 2017, University of Lausanne, provided by Dr. J. Forman and Prof. R.M. Pinto, University of Michigan. 



\section{List of publications}

\section{International refereed journals}

- O'Connor, S., Chu, C. H., Thilo, F., Lee, J. J., Mather, C. and Topaz, M. (2019), Professionalism in a digital and mobile world: A way forward for nursing. Journal of Advanced Nursing, 00:1-3. doi:10.1111/jan.14224.

- Thilo, F.J.S., Hahn, S., Halfens, R.J.G., and Schols, J.M.G.A. (2018). Usability of a wearable fall detection prototype from the perspective of older people - a real field testing approach. Journal of Clinical Nursing, 00:1-11. doi:10.1111/jocn.14599.

- Øvretveit, J., Wu, A., Street, R., Thimbleby, H., Thilo, F. and Hannawa, A. (2017). Using and choosing digital health technologies: A communication science perspective. Journal of Health Organization and Management, 31 (1) 28-37.

- Thilo, F.J.S., Bilger, S., Halfens, R.J.G., Schols, J.M.G.A., and Hahn, S. (2017). Involvement of the end user: exploration of older people's needs and preferences for a wearable fall detection device - a qualitative descriptive study. Journal of Patient Preference and Adherence, 11, 11-22.

- Bilger, S., Fuhrer, M., \& Thilo, F.J.S. (2016). A literature review of electronic nursing documentation: nurses' perspectives on its supporting and hindering aspects. Journal für qualitative Forschung in Pflege- und Gesundheitswissenschaften, 3(1), 46-53.

- Thilo, F.J.S., Hürlimann, B., Hahn, S., Bilger, S., Schols, J.M.G.A., \& Halfens, R.J.G. (2016). Involvement of older people in the development of fall detection systems: a scoping review. BMC Geriatrics, 16 (42).

- Thilo, F.J.S., Hahn, S., Sommerhalder, K. (2015). Eine qualitative Pilotstudie zur Konzeptualisierung von Gesundheitskompetenz aus der Perspektive von Patientinnen und Patienten mit Diabetes mellitus Typ II, QuPuG - Journal für Qualitative Forschung in Pflege- und Gesundheitswissenschaften, 2(1), 102-110.

- Kurmann, S., Thilo, F.J.S., Hürlimann, B., Hahn, S. (2014). Barrieren und Promotoren zur konsequenten Verwendung eines Mangelernährunsscreenings - Resultate einer PilotInterventionsstudie. Aktuelle Ernährungsmedizin, 10, 39, 325-332.

- Thilo, F., Sommerhalder, K. und Hahn, S. (2012). Gesundheitskompetenz - ein Konzept für die professionelle Pflege? Die Pflege, 25 (6), 427 - 438.

- Thilo, F., \& Hahn, S. (2011). Gesundheitskompetenz - Definition und Bedeutung für die professionelle Pflege. Pflegenetz, 2, 21-24.

\section{Non-refereed journals, books and book chapters}

- Thilo, F.J.S. (2019). Technologienutzung in der Gesundheitsversorgung - the "missing link". SocietyByte. Retrieved from https://www.societybyte.swiss/2019/08/09/technologienutzungin-der-gesundheitsversorgung-the-missing-link/

- Seifert, A., \& Thilo, F.J.S. (2019). Das Internet in Altersinstitutionen. SocietyByte. Retrieved from https://www.societybyte.swiss/2019/08/06/das-internet-in-altersinstitutionen/ 
- Hahn, S., Thilo, F.J.S., Gurtner, Caroline (2019): Mit- und voneinander lernen. Wie ältere Menschen mit ihren Krankheitserfahrungen zur Qualitätsentwicklung in Praxis, Lehre und Forschung beitragen können. NOVAcura, 50(6), 53-56.

- Thilo, F.J.S. and Hahn, S. (2018). Notrufsystem im häuslichen Setting - unerwartete Verknüpfungen und grosser Informationsbedarf. NOVAcura, 10, 33-34.

- Hahn, S. und Thilo, F.J.S. (2017) Mitsprache in der Digitalisierung: Systematischer und praxisnaher Einbezug der Nutzenden von gesundheitsrelevanten Technologien. In 'Digitale Transformation von Dienstleistungen im Gesundheitswesen III', Herausgeber Pfannstiel, M. Krammer, S., \& Swoboda, W. Springer Verlag.

- Thilo, F.J.S. (2017). Interview mit Prof. Elske Ammenwerth “Patienten können ihre Daten smart nutzen". SocietyByte https://www.societybyte.swiss/2017/11/29/patienten-koennen-ihredaten-smart-nutzen/

- Thilo, F.J.S., Hahn, S., Holm, J., \& Riedl, R. (2017). E-Health - Transformation des Gesundheitswesens. frequenz, Juni 2017, 8-10.

- Thilo, F.J.S. (2017). Interview mit Prof. Harold Thimbleby: "The quality of health IT has become very poor". SocietyByte https://www.societybyte.swiss/?s=thimbleby

- Thilo, F.J.S., \& Hahn, S. (2017). Innovation durch Einbezug der User. SocietyByte https://www. societybyte.swiss/?s=nnovation+durch+Einbezug+der+User

- Hahn, S., \& Thilo, F.J.S. (2017) Seniorinnen und Senioren entwickeln mit. NOVAcura, 48, 1, 45-47.

- Thilo, F.J.S., Heckemann, B., Peter, K.A., Fliedner, M., \& Hahn, S. (2017). Doktorierende im internationalen Austausch. Krankenpflege, 1, 18-9.

- Thilo, F.J.S., Heckemann, B., Fliedner, M., und Peter K.A. (Eds.) (2016). Nursing Science: shaping tomorrow's healthcare - 16th EDCNS. Bern: Berner Fachhochschule.

- Thilo, F.J.S., \& Hahn, S. (2016) EDCNS - the place to be für Doktorierende der Gesundheits- und Pflegewissenschaften. Frequenz, Dezember 16, 36-7.

- Thilo, F.J.S., \& Bilger, S. (2016) Die Wahrnehmung von gesunden älteren Paaren zum Einsatz assistiver Technologien. FIT-Nursing Care, 3, www.fit-care.ch/maerz-2016

- Thilo, F.J.S. (2015). Gesundheitskompetenz in der Gesundheitsversorgung - Handlungsfeld Pflege. In SAMW \& Allianz Gesundheitskompetenz (Eds.), Gesundheitskompetenz in der Schweiz - Stand und Perspektiven (1. Ed.) Bern.

- Thilo, F.J.S., Bossard, S., Sulser, Y. und Hahn, S. (2015), Zusammenarbeit von Praxis, Wissenschaft und Industrie. Krankenpflege, 108 (9), 13-15.

- Kucera, M. und Thilo, F.J.S. (2015) AIDE-MOI: aktiv, selbständig und sicher auch im Alter. Hitech, 2, 14-15.

- Thilo, F.J.S., \& Bilger, S. (2015), Anforderungen an tragbare und optische Geräte zur Sturzvorhersage und -erkennung in der häuslichen Anwendung. FIT-Nursing Care, 8(7), 1-3. www.fit-care.ch/august-2015

- Thilo, F.J.S. (2014) Destination Summer School: Academic English at Dublin City University. International Office Newsletter, 17, p. 10-11. Berner Fachhochschule.

- «Krankenpflege» im Gespräch mit Thilo, F.J.S. (2014), Qualität und Technologie - (k)ein Widerspruch? Krankenpflege, 107 (9), 22-24. 
- Thilo, F.J.S., Hürlimann, B., Kurmann, S., Boinay, F. und Hahn, S., (2014) Mangelernährung im klinischen Alltag erfassen. Krankenpflege, 107(8), 17-9.

- D’Anna-Huber im Gespräch mit Thilo, F.J.S. (2014) «Es darf nie darum gehen, Menschen durch Technik zu ersetzen». TA-SWISS Newsletter.

- Kohler, M., Gerber, F.S., Wyss, C., und Thilo, F., (2013) Forschungskompetenz für die Praxis erlernen. Krankenpflege, 106 (9), 24-7.

- Thilo, F., Klar definierte Berufsrollen. Der Bund, Nr. 220 (2011), S. 10.

\section{Conference contributions}

- Riedl, R., Laube, A., \& Thilo, F.J.S. (2019). Gläserne Patienten - wohin geht die Entwicklung? Treffpunkt BFH, 27 November, Bern, Switzerland. (oral presentation)

- Thilo, F.J.S., Müller, M., \& Roth, F. (2019). Ein Buch mit sieben Siegeln? Technologienutzung in der Pflege. Pflegekongress19, 2-3 October, Wien, Austria. (oral presentation)

- Thilo, F.J.S. (2019). "Next Big Thing” in der Digitalisierung. TRANSFORM - Digital Skills for the Transformation of Disciplines, Business and Government, 12 September, Bern, Switzerland. (invited participation at panel discussion)

- Thilo, F.J.S., (2019). Panorama professions de la santé 2030. Université de Lausanne, Journée de réflexion, 21 Mai, Lausanne, Switzerland. (invited oral presentation)

- Gianora, S., Soom Amman, E., \& Thilo, F.J.S. (2018). Robbe PARO in der Kinder- und Jugendpsychiatrie: Wie aus einem Roboter ein Gefährte wird. pflegekongress18, 29. - 30. November, Wien, Österreich. (oral presentation)

- Thilo, F.J.S., Halfens, R.J.G., Schols, J.M.G.A. \& Hahn, S. (2018). Use and non-use of alerting devices, when falls matter - the decision-making process of community-dwelling older people: a qualitative study. 17th EDCNS, 22-23 June, Maastricht, the Netherlands. (oral presentation)

- Thilo, F.J.S., Schols, J.M.G.A., Halfens, R.J.G., \& Hahn, S. (2018). A balancing act for relatives when falls matter in old age: taking care versus acknowledgement of selfdetermination. Nursing Research, 13-15 June, Oslo, Norway. (oral presentation)

- Thilo, F.J.S., Halfens, R.J.G., Schols, J.M.G.A., \& Hahn, S. (2018). Alerting devices for communitydwelling older people - implicit postponement of initial usage. The 1st International Conference of the German Society of Nursing Science, May 4th-5th, Berlin, Germany. (oral presentation)

- Hahn, S., Thilo, F.J.S., Gurtner, C. \& Soom, E. (2018). User Involvement - methodological consequences for Research. The 1st International Conference of the German Society of Nursing Science, May 4th-5th, Berlin, Germany. (Symposium)

- Koch, J., Reinhard, E., \& Thilo, F.J.S. (2017). Interprofesionelle Kommunikationsoptimierung für mehr Patientensicherheit: ein Literaturreview. pflegekongress17, 30.11.-1.12., Wien, Österreich. (2. Posterpreis)

- Berni, S., \& Thilo, F.J.S., (2017). Wohlbefinden und Kognition fördern nichtmedikamentöse Massnahmen bei "mild cognitive impairment" - ein Literaturreview. pflegekongress17, 30.11.1.12. Wien, Österreich. (3. Posterpreis) 
- Thilo, F.J.S., Golz, C., \& Hahn, S., (2017, September). User-Involvement - ältere Menschen designen und testen mit Forschenden einen Sturzsensor. Betrag präsentiert an der Konferenz European Nursing Informatics (ENI), Wie viel Technik braucht die Pflege?, Hall, Österreich. (oral presentation)

- Thilo, FJS, Schols, JMGA, Halfens, RJG, and Hahn, S, (2017). Development Trajectory of a Fall Detection Device Involving Community-Dwelling Older People. 28th International Nursing Research Congress, STTI, 21-31 July, Dublin, Ireland. (oral presentation)

- Hahn, S, Soom, E, Thilo, FJS, Rühle-Andersson, S, and Gurtner, C (2017). Changing the paradigm: Service user involvement in practice development, research and education. Florence Network Annual Meeting 2017 - Mental Health - Global Challenge - Local Actions, 18th - 22nd April 2017, Bern, Switzerland. (Workshop)

- Thilo, FJS, (2016). Intégrer les utilisateurs : technologie de détection des chutes parmi les personnes âgées à la maison. Conférence IUFRS, 13 October, Lausanne, Switzerland. (oral presentation)

- Thilo, FJS, Schwab, K, Bärtschi, M, Kucera, M, Hahn, S (2016), What we really want in caring for older people: user-involvement in fall technology development. 5th European Nursing Congress, Caring for Older People: How Can We Do the Right Things Right? 4-7 October, Rotterdam, The Netherlands, (poster). Cited in Journal of Advanced Nursing (JAN), 72;1, 65.

- Soom, E., Thilo, F.J.S., Gurtner, C., \& Hahn, S. (2016), Einbezug von Personen mit Krankheitsund Behinderungserfahrung in Forschung, Lehre und Weiterbildung. Swiss Congress for Health Professions, 1.-2. September, Lugano, Switzerland (oral presentation).

- Thilo, F.J.S., Schwab, K., Bärtschi, M., Kucera, M., \&Hahn, S. (2016). Interprofessionelle Forschung - Unterschiede als Chance. Kongress für Gesundheitsberufe - Interprofessionalität - Realität oder Mythos?, 4.-5. März, Bern (oral persentation).

- Ackaert Kössler, A., Lehmann, M., Hurni, D., Erhard, R., Thilo, F.J.S. (2016). Interprofessionelle praxis- und Forschungsprojekt: Partizipative Entwicklung einer eHealthplattform für die integrierte Gesundheitsversorgung rund um Schwangerschaft, Geburt und Wochenbett gemäss eHealth Suisse Emfpehlungen - eMatrix. Kongress für Gesundheitsberufe Interprofessionalität - Realität oder Mythos?, 4.-5. März, Bern (poster).

- Bilger, S., Fuhrer, M. und Thilo, F.J.S. (2015) Elektronische Pflegedokumentation: Eine Literaturreview zur Sicht von Pflegenden. Pflegekongress15. 5.-6. November 2015, Wien. (2. Posterpreis)

- Thilo, F.J.S., Halfens, R.J.G., Schols, J.M.G.A., and Hahn, S. (2015) A Scoping Review: Involvement of Older People in the Development of Fall Detection Technologies. European Doctoral Conference of Nursing Science (EDCNS). 18 \& 19 September 2015, Graz. (oral presentation)

- Thilo, F.J.S. (2015) AIDE-MOI: Implication des utilisateurs/-trices dans la recherche. Generalversammlung Verein für Pflegewissenschaft, Bern, 22. April 2015 (oral presentation).

- Thilo, F.J.S., Bilger, S. \& Hahn, S. (2015) Development of Fall Detection Technology: a Nurse-led User-centred Approach. 2015 Florence Annual Network Meeting, Copenhagen, April 13-17 (oral presentation).

- Thilo, F.J.S., \& Kurmann, S. (2015) Mangelernährungsscreening in die Praxis erfolgreich implementieren - Resultate einer Pilot-Interventionsstudie der BFH und des Universitätsspitals Bern Inselspital. Colloque Santé, Bern, 31. März (oral prsentation). 
- Thilo, F.J.S., Bossard Haas, S., Sulser, Y. (2014) Wenn die Zusammenarbeit zählt: Pflegepraxis, Pflegeforschung und Softwareanbieter entwickeln ein elektronisches Pflegeassessment nach Gordon. Pflegekongress14. Wien, 27.-28.11.2014 (oral presentation).

- Thilo, F.J.S. (2014) Gesundheitskompetenz - Experten und Patienten definieren einen komplexen Begriff. 23. Pflegesymposium, Schweizer Paraplegiker Zentrum, Nottwil, 6. November 2014 (oral presentation).

- Thilo, F.J.S., Kucera, M., Vetter, R., \& Hahn, S. (2014) Gesundheitsversorgung im Ambulanten Setting: Pflege, Technik und Betroffene entwickeln gemeinsam Sensortechnik. 3. Symposium zur Versorgungsforschung im Gesundheitswesen, Bern, 4. November 2014 (poster).

- Thilo, F.J.S., Hahn, S., \& Metzenthin, P. (2014) Gesundheitsversorgung im Jahr 2030 Auswirkungen auf die Rolle der Advanced Pracitce Nurse?! Zentralschweizer Pflegesymposium, Luzern, 21. Oktober 2014 (oral presentation).

- Thilo, F.J.S., Bilger, S., \& Hahn, S. (2014) Sensortechnik \& Ambient Assisted Living - Was heisst das für die Pflege? SBK-Kongress 2014, Basel, 4.-6. Juni 2014 (oral presentation).

- Beck, M., Hahn, S., Richter, D., \& Thilo, F.J.S. (2014) Ein Blick in die Zukunft - Kompetenzen der Pflege im Jahr 2030. SBK-Kongress 2014, Basel, 4.-6. Juni 2014 (oral presentation).

- Inniger, M., \& Thilo, F.J.S. (2014) Nachhaltige Förderung der Gesundheitskompetenz bei Diabetikerinnen und Diabetikern. SBK-Kongress 2014, Basel, 4.-6. Juni 2014 (poster).

- Bilger, S., Fuhrer, M. \& Thilo, F.J.S. (2014) Elektronische Pflegedokumentation - die Sicht von Pflegenden. Literaturreview und explorative Umfrage. SBK-Kongress 2014, Basel, 4.-6. Juni 2014 (poster).

- Hahn, S., Beck, M., Thilo, F., \& Richter, D. (2014) Panorama Gesundheitsberufe 2030: Zukünftige Kompetenzen der Gesundheitsberufe. Wirksame, kosteneffiziente Versorgung und Ethik - welche Wege versprechen nachhaltigen Erfolg? Inselspital, Universitätsspital Bern, 14.15.03.2014, Bern (oral presentation).

- Hahn, S., Beck, M., Thilo, F., \& Richter, D. (2013) Panorama Health Care Professionals 2030: Comptencies of the future health workforce. Symposium Versorgungsforschung in der Hausarztmedizin, SAMW, Bern, 6.11.2013 (poster).

- Thilo, F., Horlacher, K., Frei, C. \& Sommerhalder, K. (2013) Akut- und Übergangspflege wie erfolgreich ist das nurse led Trainingsprogramm für den Übergang vom Akutspital ins häusliche Setting?. ENDA, Zürich, 31. Oktober - 2. November 2013 (oral presentation).

- Thilo, F., Beck, M., Richter, D., \& Hahn, S. (2013) Pflege im Jahr 2030 - Aufgabenbereiche und Kompetenzen von Pflegenden. 3-Länderkonferenz Pflege und Pflegewissenschaft, Konstanz (D), 15.-17. September 2013 (oral presentation).

- Kurmann, S., Thilo, F., Hürlimann, B. \& Hahn, S. (2013) Barrieren und Promotoren zum Screening der Mangelernährung - Resultate einer Umfrage vor und nach Einführung eines Screenings. 12. Dreiländertagung, Nutrition 2013, Zürich, 6.-8. Juni 2013 (Poster)

- Kurmann, S., Thilo, F., Hürlimann, B. \& Hahn, S. (2013) Veränderung in Ernährungsdiagnostik und -therapie: Resultate einer retrospektiven Dokumentenanalyse vor und nach Einführung eines Screenings. 12. Dreiländertagung, Nutrition 2013, Zürich, 6.-8. Juni 2013 (Poster).

- Thilo, F., Hürlimann, B., Kurmann, S., \&Hahn, S. (2013) Kann das Screening der Mangelernährung verbessert werden? SBK-Kongress 2013, St. Gallen, 29.-31. Mai 2013 (oral presentation). 
- Thilo, F., Beck, M., Richter, D. und Hahn, S. (2013) Kompetenzen von Gesundheitsfachpersonen im Jahr 2030. (Poster) 6. Fachsymposium Gesundheit St. Gallen. Gesundheitsanspruch einer modernen Gesellschaft - kann, soll und muss unser Gesundheitswesen diesen Anspruch erfüllen? St. Gallen, 23. -24. Januar 2013.

- Thilo, F. und Sommerhalder, K. (2013) Informiert - was nun? (Poster) 6. Fachsymposium Gesundheit St. Gallen. Gesundheitsanspruch einer modernen Gesellschaft - kann, soll und muss unser Gesundheitswesen diesen Anspruch erfüllen? St. Gallen, 23. -24. Januar 2013.

- Thilo, F., Baltzer, M. und Stadler, M. (2012) Pflege: Von Daten zu Taten. 12. Schweizerischer eHealthcare Kongress. Nottwil, 19. bis 20. September 2012 (oral presentation).

- Thilo, F. und Sommerhalder, K. (2012) La compétence en santé (health literacy) - la perspective des patients. Swiss Public Health Conference. Lausanne, 30. bis 31. August 2012 (oral presentation).

- Hahn, S., Thilo, F., Sommerhalder, K. und Frey, S. (2012) Gesundheitskompetenz definieren, fördern, leben. Swiss Congress for Health Professions. Winterthur. 31. 5.-1. 6. 2012 (oral Presentation).

- Thilo, F., Sommerhalder, K. und Hahn, S. (2012) Gesundheitskompetenz: Was erwarten Patienten? SBK-Kongress 2012 PflegeWelten. Interlaken. 9. bis 11 . Mai 2012 (oral presentation).

- Thilo, F., Sommerhalder, K. und Hahn, S. (2010) Gesundheitskompetenz - ein neues Schlagwort oder Auftrag der Pflege. Pflegekongress10. Wien, 28.-29.10.2010 (oral presentation).

- Thilo, F. und Hahn S. (2009) Konzeptanalyse Gesundheitskompetenz. Pflegekongress09. Wien, 5. und 6. November 2009 (Poster, 1. Preis).

\section{Awards}

- Second poster award, Interprofessionelle Kommunikationsoptimierung für mehr Patientensicherheit: ein Literaturreview, Janina Koch, Eliane Reinhard und Friederike J.S. Thilo

- Third poster award, Wohlbefinden und Kognition fördern: nichtmedikamentöse Massnahmen bei "mild cognitive impairment" - ein Literaturreview; Seraina Berni und Friederike J.S. Thilo

- Second poster award, Elektronische Pflegedokumentation: Eine Literaturreview zur Sicht von Pflegenden; Selina Bilger, Miranda Fuhrer und Friederike J.S. Thilo

- Award for talented person in the field of medicine, distinction for Bachelor study performance and best price Bachelor thesis award, non-profit foundation, 2010

- Best poster award Gesundheitskompetenz - Konzeptanalyse als erster Schritt zur Integration von Gesundheitskompetenz in die Pflegepraxis; Friederike J.S. Thilo und Sabine Hahn

- Award best Bachelor thesis 2009 Gesundheitskompetenz - Konzeptanalyse als erster Schritt zur Integration von Gesundheitskompetenz in die Pflegepraxis; Friederike J.S. Thilo 